THE MECHANICAL STABILITY

OF GLAY SOILS AS INFLUENGED BY THE MOISTURE GONDITIONS AND SOME OTHER FACTORS

F. F. R. KOENIGS 


\title{
THE MEGHANIGAL STABILITY \\ OF GLAY SOILS AS INFLUENCED BY THE MOISTURE CONDITIONS AND SOME OTHER FACTORS
}

\author{
PROEFSCHRIFT \\ TER VERKRIJGING VAN DE GRAAD \\ VAN DOCTOR IN DE LANDBOUWKUNDE \\ OP GEZAG VAN DE REGTOR MAGNIFICUS, IR. W. F. EIJSVOOGEL, \\ HOOGLERAAR IN DE HYDRAULICA, DE BEVLOEIING, \\ DE WEG- EN WATERBOUWKUNDE EN DE \\ BOSBOUWARGHITECTUUR, \\ TE VERDEDIGEN TEGEN DE BEDENKINGEN \\ VAN EEN COMMISSIE UIT DE SENAAT \\ VAN DE LANDBOUWHOGESCHOOL TE WAGENINGEN \\ OP WOENSDAG 28 JUNI 1961 TE 16 UUR \\ DOOR
}

F. F. R. KOENIGS

GENTRUM VOOR

LANDBOUWPUBLIKATIES EN Pudoo LANDBOUWDOCUMENTATIE

WAGENINGEN 1961 


\section{STELLINGEN}

I

De korrelgrootte waarbij enkele fysische eigenschappen, toegeschreven aan „,klej”, naar voren treden, ligt bij $0,1 \mu$ equivalent diameter.

A.F. Thunn, Trans. Ist. Com. I.S.S.S. A 1, p. 111. (1933) Dit proefschrift.

\section{II}

Voor het meten van redox-potentialen in de grond is de koolstof elektrode meer geëigend dan de platina elektrode.

\section{III}

De methode van Emerson voor de bepaling van de stabiliteit van de bodemstructuur, kan geen uitsluitsel geven over de stabiliteit van de grond in situ.

W. W. Emerson, Journ. Soil Science 5, p. 233 (1954).

M. E. DettMann and W. W. Emerson, Fourn. Soil Science 10, p. 215 (1959).

IV

Bij de verklaringen over de invloed van kalk op de bodemstructuur wordt de invloed die de kalk als poeder kan hebbeh verwaarloosd.

\section{$\mathrm{V}$}

De bodemkundige omstandigheden in de gebieden van oorsprong, geven veelal aanwijzingen voor de eisen die de cultuurgewassen aan de grond stellen.

\section{VI}

Toepassing van de moifometrie, zonder rekening te houden met de geschiedenis van de grond, leidt veelal tot benamingen waaruit landbouwkundig verkeerde conclysies getrokken kunnen worden.

\section{VII}

Aangezien de biologische activiteit in de grond van veel belang kan zijn voor de wortelontwikkeling van de cultuurgewassen, is het gewenst dat men haar kan beheersen: hiervoor moeten de waarnemingen zo spoedig mogelijk door gerichte experimenten worden gevolgd.

\section{VIII}

Bij de verklaringen van de profiel differentiatie moet de geologische zienswijze steeds prevaleren boven de colloid-chemischie en chemische zienswijze.

\section{IX}

Het gebruik van groene bemesting bij de rijstbouw op lateritische gronden moet ontraden worden. 
X

Bij zwellende gronden kan het vochtgehalte van diepere lagen niet berekend worden door de meting van de vochtspanning ter plaatse en interpolatie in de pF curve.

\section{XI}

De luchtcirculatie is een groeifactor waaraan in de tuinbouw onder glas te weinig aandacht wordt besteed.

\section{XII}

Bij beschouwingen over het nut van gezelligheidsverenigingen wordt te weinig rekening gehouden met het optimum aantal leden.

\section{XIII}

In het praktische denken over lonen en arbeidsverhoudingen in onze huidige maatschappij, wordt het aspect dat arbeid op zich zelf genoegdoening verschaft verwaarloosd, waardoor de werker een deel van zijn levensvreugde mist.

\section{XIV}

Volgens de theorie van v. BöHM-BAWERK is de spaaractie op de lagere scholen tot mislukking gedoemd.

\section{XV}

Collectief afgedwongen loonsverhogingen hebben de ontwikkeling van het industriële kapitalisme bevorderd."

\section{XVI}

De steun aan de Nederlandse landbouw moet voor een groot deel beschouwd worden als een verzekeringspremie tegen oorlogsrisico.

\section{XVII}

Het veranderen van schuine wegkruisingen en splitsingen in haakse, is niet in overeenstemming met de eisen van het verkeer.

\section{XVIII}

De vergaande splitsing in studierichtingen aan de Landbouwhogeschool te Wageningen zou bij de propaedeuse moeten beginnen.

\section{Proefschrift Koenigs}

WAGENINGEN, juni 1961 


\section{WOORD VOORAF}

Gaarne betuig ik op deze plaats mijn dank aan u, Hoogleraren, Lectoren en Docenten aan de Landbouwhogeschool te Wageningen, die hebt bijgedragen tot mijn wetenschappelijke vorming. In het bijzonder ben ik u, hooggeleerde Edelman, dank verschuldigd voor het grote enthousiasme waarmee $\mathrm{u}$ mij in de bodemkunde hebt ingeleid.

Hooggeleerde Schuffelen, hooggeachte promotor, het vertrouwen dat $u$ in mij gesteld hebt door mij als gast op uw laboratorium een plaats in te ruimen, hoop ik niet beschaamd te hebben. Dat $\mathrm{u}$ mij toestond een onderwerp te onderzoeken dat allengs buiten de kring van uw engere belangstelling kwam te liggen waardeer ik ten zeerste, evenals uw bereidheid gerezen problemen te bespreken. Uw kritisch inzicht is bij het redigeren van het manuscript van groot nut gebleken.

Zeergeleerde Bolt, hoewel onze gesprekken over bodemfysische onderwerpen bemoeilijkt werden, doordat $u$ van een streng thermodynamische beschouwingswijze uitgaat waarvan ik destijds nog nooit gehoord had, waren zij, dank zij uw geduld, steeds vruchtbaar. Uw scherpe kritiek heeft ten zeerste tot het verdiepen van mijn inzicht bijgedragen.

Waarde collega Janse, voor je hulp bij het ontwerpen en uitvoeren van de benodigde apparatuur van deze plaats mijn dank.

Leden van de staf en van het personeel van het Laboratorium voor Landbouwscheikunde, ik dank $u$ allen voor uw medewerking; in het bijzonder $u$, heer Matser, voor de zorg waarmee $u$ de vele tekeningen drukklaar gemaakt hebt.

Ook de studenten, die in de loop der jaren aan het onderzoek medegewerkt hebben, de heren J. F. Dijkstra, H. A. Hietink, Ph. Jansen, A. Hidding, A. A. Franken, A. Kraai, L. K. Smedema en R. Reinders alsmede de analyste Mej. B. Pieters, wil ik bedanken voor het enthousiasme waarmee ze hun werk voor mij verricht hebben.

De heer E. Levy dank ik ten zeerste voor het corrigeren van het Engels van enkele hoofdstukken.

De heer Jahja, hoofd van het Bodemkundig Instituut te Bogor, ben ik dank verschuldigd voor het toezenden van enige grondmonsters.

Rest mij nog de taak mijn dank uit te spreken aan de belastingbetalers in de U.S.A., die mij via de Marshallhulp gedurende de eerste drie jaren van het onderzoek financieel gesteund hebben. 


\section{GONTENTS}

Preface ............................. 1

I THE INFLUENCE OF INITIAL WATERLOSS OF GLAY SUSPENSIONS ON THE SUBSEQUENT SWELLING IN EXCESS MOISTURE . . . . . . . . . . . . 3

$1 \quad$ Introduction ........................ 3

1.1 Definitions .................... 3

1.1.1 Suspensions .................... 3

1.1.2 Aggregates ..................... 3

1.1.2.1 Flock type .................... 3

1.1.2.2 Granules . . . . . . ............ 3

1.1.3 Crystals ...................... 3

1.1.4 Polyplates . . . . . . . . . . . . . . 4

1.1.5 Colloids . . . . . . . . . . . . . . . . 4

1.1.6 Elastic systems ..................... 4

1.1.7 Systems elastic over a certain range . . . . . . . . 4

1.1.8 Semi-elastic systems . . . . . . . . . . . . 4

1.1 .9 Inelastic systems . . . . . . . . . . . . . . 4

1.2 The colloid-chemical concept of soil structure . . . . . . . 5

1.3 Objections against the flocculation concept . . . . . . . . 8

1.3.1 Swelling of dried clay and of partly dehydrated suspensions . . . 8

1.3.2 The flock volume before and after drying and the permeability before and after freezing ............... 10

1.3.3 Permeability measurements .............. 11

1.3.4 The pretreatment for the determination of soil texture . . . . . . 11

1.3.5 Wet sieving method and dispersion ratio method of aggregate analysis ..................... 11

1.3.6 Conclusion .................. 12

2 Experimental. .................... 13

2.1 Outline .................... 13

2.2 Materials ..................... 14

2.2.1 Origin and characterization . . . . . . . . . 14

2.2.1.1 Montmorillonite .................. 14

2.2.1. Margalite . . . . . . . . . . . . . . 15

2.2.1.3 Illite . . . . . . . . . . . . . . . 15

2.2.1.4 Knip clay . . . . . . ............. 16

2.2.1.5 , River basin clay . . . ............... 16

2.2.1.6 Winsum clay ................. 16

2.2.1.7，Kaolinite ................... 17

2.2.1. Latosol . . . . . . . . . . . . . . . . 18

2.2.2 Methods of sample preparation and characterization . . . . 18 
Isolation of clay fraction . . . . . . . . . . . . 18

2.2.2.2

2.2.2.3

2.2.2.4

2.2.2.5

2.3

2.3.1

2.3.2

2.3 .3

2.4

2.4.1

2.4 .2

2.4.2.1

2.4.2.2

2.4.2.3

2.5

2.5.1

2.5.1.1.

2.5.1.3

2.5 .2

2.5.2.1

2.5.2.3

2.5.2.4

2.5.2.5

2.5.3

2.5.3.1

2.5.3.2

2.5.3.3

2.5.3.4

2.5.3.5

2.5.4

2.5.4.1

2.5.4.2

2.5.4.3

2.5 .5

2.5.5.1

2.5.5.2

2.5.5.3

2.5.5.4

2.5.5.5

2.5.6

2.5.6.1

Removal of organic matter ............... 18

Determination of surface area ............... . . 18

Preparation of homoionic clay suspensions ... . . . . . . 18

Preparation of slurries . . . . . . . . . . . . . 19

Experimental procedure ............... 19

The desorption curve . . . . . . . . . . . . . 19

The swelling after previous desorption (backswelling) . . . . 20

The influence of the salt concentration on the swelling . . . . 20

Treatment of data .................. 21

Representation of results . . ............. 21

Comparison with theoretical values .... . . . . . . . 21

Correction for the radius of the hydrated cations . .......... 21

Correction for the presence of lateral incompressible free pore space . . . 22

Corrections applied to the calculation of the pressure . . . . . . . 23

Experimental results .................. 26

Montmorillonite .................. 26

Sodium bentonite, in aqaeous solutions and in ethanol . . . . . . . 26

Potassium bentonite . . . . . . . . . . . . 30

Calcium bentonite ............... 31

Margalite colloid . . . . . . . . . . . 35

Sodium margalite colloid . . . . . . . . . . . . . 35

Potassium margalite colloid ... . . . . . . . . . . 36

Magnesium margalite colloid . . . . . . . . . . . . . 37

Calcium margalite colloid . .... . . . . . . . . . 37

Comparison of the margalite colloid with the bentonite . . . . . . . 38

Margalite soil . . . . . . . . . . . . . . 38

Sodium margalite . . . . . . . . . . . . . . . . . 38

Potassium margalite . . . . . . . . . . . . . . . . 39

Potassiumm argalite smaller than 2 micron............. . . . 39

Calcium margalite soil ... . . . . . . . . . . . 40 40

Conclusion ....................... . . . 41

Fithian illite ... . .................. . . . . 41

Sodium colloid, with and without the original organic matter. . . . . . . 41

Potassium illite... . . . . . . . . . . . . . 43

Calcium illite ..................... . . . . 43

Knip clay . ....................... 45

Sodium knip clay $\ldots \ldots \ldots \ldots \ldots \ldots$

Potassium knip clay ......................... . . . . . 45

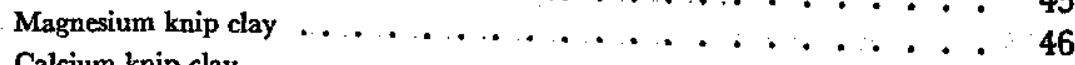

Calcium knip clay ... . . . . . . . . . . . . . . . . . . 47

Conclusion ......................... . . . . . 47

River basin clay . . . . . . . . . . . . . . . . . . . . . . 48

Sodium basin clay colloid ........................ 48 
Potassium basin clay colloid . . . . . . . . . . . . 49 49

Calcium basin clay colloid . . . . . . . . . . . . . . 50

II THE RESISTANCE OF GRANULES AgAinst DISPERSION IN WATER AS INFLUENGED BY THE SALT CONGENTRATION, AND THE INFLUENCE OF THE DEGREE OF DEHYDRATION ON THE RESISTANGE AGAINST DISPERSION . . . . . . 58

1 Introduction . . . . . . . . . . . . . . . 58

2 Preliminary investigations. . . . . . . . . . . . . . 59

2.1 Experimental method ................ 59

2.2 Experiments on margalite soil, $<50 \mu$. .......... . 59

2.3 Discussion of the method .. . . . . . . . . . . 60

3 Quantitative experiments . . . . . . . . . . . 61

3.1 Experimental method . . . . . . . . . . . . . 61

3.2 Treatment of the data . . . . . . . . . . 62

3.3 Comments . . . . . . . . . . . . . . . . 65

3.4 Limitations of the method . . . . . . . . . . . . 67

3.5 Other methods of mathematical treatment . . . . . . . 67

3.6 Conclusions . . . . . . . . . . . . . . . 67

3.7 Single value expression of the stability . . . . . . . . 67

3.8 Representation . . . . . . . . . . . . . . . 68

$4 . \quad$ Stability of clay and soil granules in dependence of salt concentration . . . . . 68

4.1 . Bentonite ........................... 68

4.1.1 , Sodium bentonite . . . . . . . . . . . . . 68

4.1.1.1 Sodium bentonite at various salt concentrations . . . . . . . . . 68

4.1.1.2 The influence of the dielectric constant . . . . . . . . . . 69

4.1.2 . Potassium bentonite. . . . . . . . . . . . . 70

4.1.3 Calcium bentonite . . . . . . . . . . . . 70

$4.2 ;$ Margalite colloid ................ 71 
5.

Illite .................. . . 72

Sodium illite. . . . . . . . . . . . . 72

Sodium illite, first and second batch, organic matter present . . . . . . 72

Sodium illite, colloid, second batch . . . . . . . . . . . 73

Potassium illite, colloid, second batch . . . . . . . 74

Calcium illite, colloid, second batch .... . . . . . 74

Basin clay and Winsum knip clay, . . . . . . . . . . 74

Sodium clays. . . . . . . . . . . . . . . 75

Potassium clays. . . . . . . . . . . . . . 75

Magnesium clays .................. 75

Calciurn clays . . . . . . . . . . . . . . 76

Basin soil and Winsum knip soil, natural aggregates 2-1 mm . . . 76

Sodium soils . . . . . . . . . . . . . 77

Potassium soils . . . . . . . . . . . . . 77

Magnesium soils ................ 77

Calcium soils. . . . . . . . . . . . 78

Untreated soils . . . . . . . . . . . . . 78

Conclusion. ................. 80

Kaolinite ..................... 80

Sodium kaolinite ... . . . . . . . . . . 80

Calcium kaolinite. . . . . . . . . . . . . 80

Latosol . . . . . . . . . . . . . . 81

Sodium latosol . . . . . . . . . . . . . . 81

Hydrogen latosol . . . . . . . . . . . . . 81

Calcium latosol. . . . . . . . . . . . . . 82

Conclusion. . . . . . . . . . . . . . . . 83

General discussion . . . . . . . . . . . . . . 83

Bentonite . . . . . . . . . . . . . . . 83

Salt concentration versus stability ............ . 83

Moisture content at $\mathrm{pF} 1$ versus stability . . . . . . . . 85

Conclusion. . . . . . . . . . . . . . . . . 86

Margalite colloid . . . . . . . . . . . . . . . . . 86

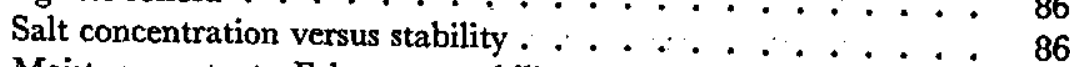

Moisture content pF 1 versus stability ............. 87

Conclusion. . . . . . . . . . . . . . . . . . 88

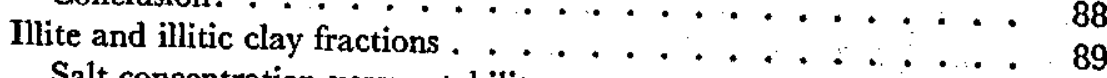

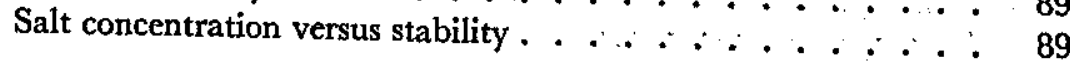


Fithian illites . . . . . . . . . . . . . . . 89

5.3.1.2 Granules of the colloids of basin clay and Winsum clay . . . . . . . 90

5.3.2 Moisture content pF 1 versus stability . . . . . . . . 9 91

5.3.2.1 Fithian illites. . . . . . . . . . . . . . . . 91

5.3.2.2 Basin clay and Winsum clay . . . . . . . . . . . 92

5.3.3 Conclusion .................... 92

5.4 Basin and Winsum soil, natural granules . . . . . . . . . 93

5.4.1 Salt concentration versus stability . . . . . . . . . . 93

5.4.2 Moisture content versus stability ............. 94

5.4.3 Conclusion ................... 94

$5.5 \quad$ Kaolinite and latosol ................. 95

5.5.1 Salt concentration versus stability . . . . . . . . . . 95

5.5.2 Moisture content pF l versus stability . . . . . . . . . 96

5.6 Conclusion . . . . . . . . . . . . . . 97

$6 \quad$ The influence of the degree of desorption on the resistance against dispersion . $\quad 97$

6.1 Semi-elastic system, e.g. slurry of margalite . . . . . . . 98

6.2 Inelastic system, e.g. slurry of magnesium latosol pH 7 . . . . . 99

7 Summary . . . . . . . . . . . . . . . 99

III The Influence of THE MOISTURE GONTENT AT TIllage ON The STABILITY OF THE SOIL IN THE SATURATED STAGE . . . . . . . . 103

1. General principles of tillage . . . . . . . . . . . . 103

1.1 Introduction . . . . . . . . . . . . . . . 103

1.1.1 Influence of moisture content on cohesion . . . . . . . 105

1.1.1.1 Intra-aggregate cohesion. . . . . . . . . . . . 105

1.1.1.2 Inter-aggregate cohesion and friction . . . . . . . . . 105

1.1.2 Transfer of energy into the aggregates . . . . . . . 106

1.2 Effectiveness of tillage operations . . . . . . . . . 106

1.2.1 Too low moisture content . . . . . . . . . . 106

1.2.2 Too high moisture content . . . . . . . . . . 106

1.2.3 Optimum moisture content . . . . . . . . . . 107

1.2.4 Cultivation of rice fields . . . . . . . . . . . 107

1.3 Discussion of some literature data and interpretations at variance with the above ................... . . 107

1.3.1 Compressibility. . . . . . . . . . . . . . 107

1.3.2 Drawbar pull through dry soil . . . . . . . . . . 108

1.3.3 Shear strength of moist soil .............. . . . 108

1.3.4 Objections against the application of data on remoulded soils to problems of soil tillage ... . . . . . . . . . 108

2 Stability of the soil structure after tillage operations . . . . . . . . . 109

3 Preliminary investigations. . . . . . . ....... 111 
3.1 Margalite ................. 111

3.2 Latosol . . . . . . . . . . . . . . 113

4. Quantitative experiments.............. 113

4.1 Influence of the application of large pressures . . . . . . . 114

4.1.1 Soils with slurries behaving like an elastic system over a wide range of suctions ....................... 114

4.1.2 Soils with slurries behaving like an elastic system over a restricted range of suctions ... . . . . . . . . 118

4.1.3 Soils with slurries behaving like a semi-elastic system . . . . 119

4.1.4 Soils with slurries behaving like an inelastic system . . . . . . 120

4.2 Influence of the application of small pressures . . . . . . . 121

4.2.1 Comparatively large influence ........... 121

4.2.2 Comparatively small influence of the treatment . . . . . 123

4.3 Influence of the salt concentration on the stability after working . . . 123

5. General remarks . . . . . . . . . . . . . . . . 124

5.1 Suction value at which the maximum destruction occurs . . . . 124

5.2 Stability of the part of the soil affected by tillage . . . . . . 125

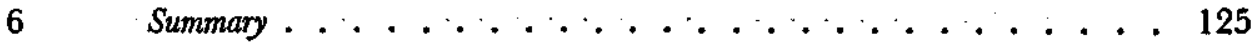

IV APPLICATIONS OF THE RESULTS TO AGRICULTURE . . . . . . . 127

1 Limitations of the results . . . . . . . . . . . . . . 127

1.1 Changes of the samples during drying . . . . . . . 127

1.2 Equilibrium with low suctions $\ldots \ldots \ldots \ldots \ldots \ldots \ldots$

1.3 Homoionic clays and soils . . . . . . . . . . . 127

1.4 State of aggregation of the soils . . . . . . . . . . . 128

1.5 The stability analysis ... . . . . . . . . . . . . 129

1.5.1 Influence of the cation concentration on the formation of soil structure. ..................... 129

1.5.2 Air explosion. . . . . . . . . . . 130

1.6 Deformability of granules . . . . . . . . . . . 130

1.7 Model tillage tests. . . . . . . . . . . . . 131

2 Normal agriculture . . . . . . . . . . . . 132

2.1 Necessity of aggregation . . . . . . . . . . . . 132

2.2 Application of backswelling characteristics . . . . . . . . . . . 132

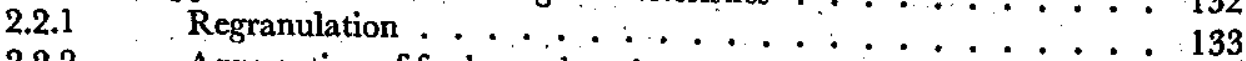

2.2.2 Aggregation of fresh sea deposits $\ldots \ldots \ldots \ldots$

2.2.3 Subsoils . . . . . . . . . . . . . 134

2.2.4 Filling in of drainage ditches. . . .

2.2.5 Frost action . . . . . . . . . . . . . . 135

$2.4 \quad$ Air explosion. . . . . . . . . . . . 136

2.4 . Stability tests. ............... 136 
$2.5 \quad$ Laboratory experiments on tillage . . . . . . . . . . . . 138

2.5.1 Suction at moisture content of maximum destruction . . . . . . . 138

2.5.2 . Influence of backswelling characteristic on results of tillage . . . . . 138

2.6 Non scouring of soils on implements . . . . . . . . . . . 139

3 Rice growing . . . . . . . . . . . . . 139

3.1 Desirability of a thin mud ............... 139

3.1.1 Granules versus mud ............... 140

3.1.2 Paste versus mud . . . . . . . . . . . 141

3.2 Technique of mud making . . . . . . . . . . . . . . . 144

3.2.1 Necessity of over-saturation . . . . . . . . . . . . 144

3.2.2 Influence of state of soil at irrigation . . . . . . . . . 144

$3.3 \quad$ Flocculation . . . . . . . . . . . . . . 146

3.4 Discussion of the investigated soils as to their suitability for rice growing . . . . . . . . . . . 146

V THEORETICAL CONSIDERATIONS . . . . . . . . . 147

1 Limitation of the swelling. . . . . . . . . . . . . . 147

1.1 Dispersion forces . . . . . . . . . . . . . . 147

1.1.1 Calculation of attractive potential due to LONDON-VAN DER WAALS 147

1.2 Galculation of the repulsive potential . . . . . . . . . 148

1.3 Comparison of attractive and repulsive potential . . . . . . . 149

1.4 Plate contraction caused by counter ions in the midway position . . . 149

1.4.1 Limitation of the Gouy-Ghapman theory . . . . . . . . . . 149

1.4.2 MacEwan's calculation of the Madelung potential . . . . . 150

1.4.3 Energy of activation of the swelling process . . . . . . . . 151

1.4.4 Qualitative discussion of the electrostatic attraction . . . . . . 151

1.4.5 Difference between sodium and potassium saturated systems . . . 152

2 Application of the concept of MADELUNG attraction . . . . . . . . 152

2.1 The cohesion of granules . . . . . . . . . . . 152

ح2.2 Observations supporting this concept . . . . . . . 153

3. Observations not explained completely by the concept of MADELUNo attraction 154

3.1 Flocculation phenomena . . . . . . . . . . . 154

3.1.1 'Flocculation' at low salt concentration . . . . . . . . . 154

3.1.2 Flocculation at high salt concentration . . . . . . . . . 155

3.2 Semi-elasticity . . . . . . . . . . . . 156

3.2.1 Semi-elasticity of suspensions . . . . . . . . . . . 156

3.2.2 Semi-elasticity of slurries. . . . . . . . . . . 157

$4 \quad$ Conclusion .................... 157

5 The exceptional behaviour of latosols .............. 158 
6 Summary ........................ 159

6.1 The swelling of bentonite polyplates . . . . . . . . 159

6.2 Implications for the swelling of granules . . . . . . . . . . 159

6.3 Semi-elasticity at low suctions . . . . . . . . . 160

6.4 Latosol .................... . 160

SuMMARY $\ldots \ldots \ldots \ldots \ldots 16 \ldots \ldots \ldots \ldots$

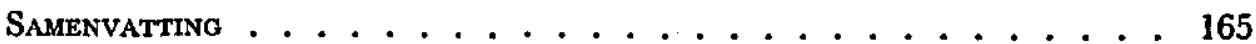

LTtrRature . . . . . . . . . . . . . . . . . 167 


\section{PREFACE}

As is well known clay occurs suspended in river water and as a 'solid' in soils. Only in the latter state can it be used for normal agricultural practices. In the 'solid' state clays and clay soils exhibit a certain swelling due to the adsorption of water at the clay surface, but this swelling is limited in soils of agricultural importance.

Though the properties of suspensions of clay in water and of clay as a 'solid' have been extensively investigated, the transition between these states has received relatively little attention. Therefore the change from suspension to 'solid state' (aggregate) was studied by the determination of the influence of initial water loss of homoionic clay suspensions on the subsequent swelling of the resultant paste in excess water. The lower this back-swelling would be, the more the clay will resemble a solid. According to the older theories, treated in chapter $I, 1$, the transition from suspension to aggregate is initiated by flocculation with electrolytes and the limitation of the swelling on saturation is also caused by the electrolyte concentration. As numerous objections can be raised against this theory, the experiments mentioned above were carried out at salt concentrations well below the flocculation value to ascertain whether flocculation is necessary for aggregate formation or not. The clays were made homoionic with respect to the saturating cation because it is known from agricultural practice that the degree of swelling depends on the kind of saturating cation.

For the ease of comparison with theory, overlays have been constructed on which the theoretical desorption curves are shown. The results of these investigations are reported in chapter $I, 2$.

Although one can determine in this way whether granules with a limited swelling are formed, no information is gained with regard to the stability of these granules. In order to obtain a quantitative insight into the magnitude of the resistance of clay, or clay-soil aggregates to mechanical dispersion forces, the latter was determined by a procedure discussed in chapter II, 3 .

The increase of this resistance with proceeding dehydration of a suspension was investigated in two cases (II, 6). The other experiments pertain to the influence of the salt concentration on the stability of dried clay and soil aggregates. These investigations are reported in chapter II, 4. In order to ascertain whether the stability is better related with the electrolyte content of the solution than with the moisture content at a low suction, the stability was plotted against moisture content and against salt concentration. The results are discussed in chapter II, 5.

The question as to how the stability in the saturated stage is changed by tillage, is reported in chapter III. A qualitative discussion on the influence of the moisture content at tillage on the result of these operations is found in chapter III, 1.

Qualitative and quantitative analyses of the stability after model tillage operations at different moisture contents are reported in chapter III, 2 and chapter III, 3. In two cases also the influence of the salt concentration on the stability after tillage at one moisture content was investigated. 
The application of the experimental results to agriculture are discussed in chapter IV, both form the point of view of 'dry' agriculture (IV. 2) and from that of 'wet' rice cultivation (IV, 3).

An explanation of the observed phenomena on a qualitative basis is given in chapter $V$. It shows that if most of the existing theories are combined a satisfactory picture is obtained. It follows that only a role of secondary importance may be assigned to 'flocculation'. 


\section{THE INFLUENGE OF INITIAL WATER LOSS OF GLAY SUSPENSIONS ON THE SUBSEQUENT SWELLING IN EXGESS MOISTURE}

\section{l . INTRODUCTION}

\subsection{Definitions}

\subsubsection{Suspensions}

A suspension is defined as a homogeneous dispersion in water or other liquids. In a stable suspension this situation does not change with time (days).

\subsubsection{Aggregates}

Aggregation may be defined as an association of clay particles into larger units. Two main types of âggregation are distinguished.

\subsubsection{Flock type}

The flock-type is a very loose building of clay particles, which is characterized by a low density, a corresponding low degree of orientation and a small resistance against mechanical forces.

If flocks have been made by raising the concentration of electrolyte, they disappear after lowering of the latter; therefore clay flocculation is a reversible process.

\subsubsection{Granules}

The second type of aggregation is characterized by a high apparent density and a high degree of orientation. It is caused by desiccation. Whether this orientation is lost after immersion in distilled water depends on the adsorbed cation. By addition of sufficient electrolyte, orientation may be preserved irrespective of the cation. This type of aggregation could have been called 'true aggregation' in this publication, had the notion 'aggregate' not been so differentiated by the pedologists. As it is difficult in this case, as well as immaterial, to discern between primary or secondary aggregates (not to speak of types and classes) the term 'granule' will be employed, with the meaning used by BRADFIELD (1950) at Amsterdam, to indicate something that has the aforementioned properties in contrast to flocks.

\subsubsection{Crystals}

The term crystal is used as a definition of the elementary unit of a clay mineral. Depending upon the type of clay mineral, a crystal may be composed by one (monoplate) or more (multiplate) unit layers.

The number of unit layers (composition) of the sodium saturated clay mineral at infinite dilution has been adopted as criterion for an elementary unit. 
So with montmorillonite the clay crystal is identical with a unit layer; with illite the crystal is composed of four or more unit layers. Some swelling $(\cong 10 \AA)$ between the unit layers of a muitiplate crystal is allowed, for the crystal does not lose its identity by this limited swelling.

(This distinction is arbitrary. If the elementary units had been defined by the number of unit layers of clays saturated with divalent ions, the montmorillonite would have been regarded as a multiplate crystal, since the unit layers do not separate completely. If the composition of lithium saturated clays is chosen, then vermiculite should be classified with the monoplate crystals since unit layers separate in that particular case. (WALKER, 1960).).

\subsubsection{Polyplates}

This term is introduced to define a dense parallel aggregate of crystals (usually plates) which is nearly identical with a multiplate crystal.

Polyplates have been made by replacing the sodium-ions of monolayer crystals in suspension by divalent ions, followed by dehydration.

They may differ from multiplate crystals by a lesser degree of orientation, but just as the crystals they do not lose their identity at infinite dilution. No definite value can be assigned to the dimensions of the polyplates, as much will depend on the mechanical forces employed to destroy their aggregates.

\subsubsection{Colloids}

By the term colloid is designated the clay fraction without organic matter.

\subsubsection{Elastic systems}

Those systems exhibiting complete reversibility of the moisture desorption-adsorption curve will be named elastic.

\subsubsection{Systems elastic over a certain range}

Those systems are named elastic over a certain range exhibiting complete reversibility over a certain range of suctions, but changing into semi-elastic systems if a certain suction is passed.

\subsubsection{Semi-elastic systems}

As semi-elastic systems will be designated those systems exhibiting partial reversibility of the adsorption-desorption curve, i.e. limited backswelling, on increase of the moisture potential after previous desorption.

\subsubsection{Inelastic systems}

Inelastic systems are those not exhibiting any backswelling upon increase of the moisture potential after previous desorption. 


\subsection{THE GOLLOID-GHEMICAL GONCEPT OF SOIL STRUGTURE}

This concept is based on the fact that the clay fraction of a soil has under certain conditions colloidal properties, and on the assumption, that the rules which govern the colloid-chemical behaviour of clay suspensions are applicable to the soil in situ.

This view will be elaborated upon later.

Clay is a colloid because the elementary units have colloidal dimensions and a predominantly negative charge. The negative charge of these particles is caused by a residual negative charge which is compensated by adsorbed cations (counter ions). In water, the adsorbed cations give origin to a diffuse layer which surrounds the particles. The properties of the diffuse layer have been considered by numerous authors, whose concepts will be discussed partly in the last chapter of this thesis.

The thickness of the double layer and the stability of a clay suspension is a function of the following factors:

A. The density of the negative charge on the clay mineral

a. The position of the negative charge in the clay mineral

b. The occurrence of positive charges on the edges. (Depending on $\mathrm{pH}$ )

B. The properties of the dispersion medium

a. The dielectric constant

b. The valency and radius of the cations

c. The electrolyte concentration of the equilibrium solution of the suspension

$\mathrm{d}$. The $\mathrm{pH}$ of the medium

As water is the only dispersion medium in systems of importance to agriculture, and as the other factors for a given clay are fixed, the thickness of the double layer can only be influenced by factors B.b, B.c and B.d.

Irrespective of the cation adsorbed, stable suspensions can in general be made from most clays if the salt concentration is low enough.

If salt is added to a stable suspension the clay particles concentrate into flocks. The salt concentration necessary to produce flocculation, the flocculation value, depends on the valency of the ion. The flocculation value decreases according to the rule of Schultze \& HARDY with the valency of the cation. According to VerweY \& OVERBEEK (1948) the ratio of the flocculation values of mono- to di- to tri-valent cations is $1:(1 / 2)^{6}:(1 / 3)^{6}$, but with decreasing surface potential this ratio may decrease to $1:(1 / 2)^{2}:(1 / 3)^{2}$.

This theory applies to colloids with a constant potential, where the quantity of adsorbed cations increases with increasing valency and salt concentration. The decrease of the repulsion energy with increasing valency of the counterions is therefore less steep than with colloids which have a constant charge. Consequently it may be expected that the ratio of the flocculation concentration between mono- to divalent ions should lie near $1:(1 / 2)^{8}$.

The rule of SGHulze \& HaRdy can be illustrated by figures calculated from data of JENNY \& REITEMEIER (1935) which are shown in table I. 
TABLE 1. Flocculation value of Putnam colloid (JENNY \& REITEMRTRR); concentration $1.085 \mathrm{~g} / \mathrm{l}$, C.E.C. 0.6 me./B

\begin{tabular}{lcccccccc}
\hline Cation & $\mathrm{Li}$ & $\mathrm{Na}$ & $\mathrm{K}$ & $\mathrm{NH}_{\mathbf{4}}$ & $\mathrm{Cs}$ & $\mathrm{H}$ & $\mathrm{Mg}$ & $\mathrm{Ca}$ \\
Flocculation value (me./l) & 16.95 & 9.64 & $\mathbf{5 . 0 9}$ & 3.20 & 2.74 & $\mathbf{0 . 2 3 4}$ & $\mathbf{0 . 4 5}$ & 0.36 \\
\hline
\end{tabular}

From this table the following ratios of the flocculation values are calculated:

$\mathrm{Mg} / \mathrm{Li}=0.026, \mathrm{Mg} / \mathrm{Na}=0.047, \mathrm{Mg} / \mathrm{K}=0.076 ; \mathrm{Ca} / \mathrm{Li}=0.021, \mathrm{Ca} / \mathrm{Na}=0.037$, $\mathrm{Ca} / \mathrm{K}=0.070$.

The calculated mean ratio of the flocculation value of divalent to monovalent cations is 0.046 (theoretically, after VERWEY \& OVERBEeK 0.016 to 0.25 ).

The influence of the $\mathrm{pH}$ on flocculation is demonstrated by the following experiment of DEMOLON \& BASTISE (1934). A clay isolated from a 'terre à briques' was used. Suspensions with a different $\mathrm{pH}$ were made by adding a certain amount of a base to a hydrogen clay. The maximum amount of salt which could be added without causing flocculation within an hour was determined in these suspensions. Table 2 was derived from their graph No.1.

TABLE 2. Influence of $\mathrm{pH}$ on flocculation value of different cations (DEMOLON \& Bastissz)

\begin{tabular}{lllllllllllll}
\multicolumn{10}{c}{$\mathrm{pH}$} \\
\hline 6.0 & 6.5 & 7.0 & 7.5 & 8.0 & 8.5 & 8.75 & 9.0 & 9.5 & 10.0 & 11.0
\end{tabular}

Flocculation value (me./l)

$\mathrm{NaCl}$

$\mathrm{KCl}$

$\mathrm{CaCl}_{2}$

$\begin{array}{rrrrrrrrrrr}11 & 14 & 23 & 50 & 87 & 127 & 149 & 143 & 127 & 113 & 86 \\ 5 & 8 & 20 & 53 & 71 & 70 & & 69 & & 68 & 66 \\ 1 & 1 & 1 & & 1 & & & 1 & & & \end{array}$

The influence of the $\mathrm{pH}$ of the suspension on the flocculation could be attributed to the following causes.

a. Preferential adsorption of the hydrogen ions.

From experiments of JENNY \& REITEMEIER (1935) it is apparent that the hydrogen ion is even stronger adsorbed than divalent ions.

This would infer that the charge of the clay mineral is neutralized over a short distance with as a consequence that the repulsive forces which interfere with the flocculation are smaller than with saturation by other ions, and that the flocculation value is lowest with hydrogen.

If a neutral salt is added the flocculation value will not be altered very much since the clay will remain largely hydrogen saturated due to the preferential adsorption of the hydrogen ion.

If however a base is added the hydrogen ions will form water with the hydroxyl ions and the exchange can proceed. As the flocculation value of the hydrogen ions is lower than that of the divalent and monovalent ions an increase of $\mathrm{pH}$ will automatically cause an increase in flocculation value. 
This explanation is however not quite correct since BoLt \& WARKENTIN (1956) have proved that freshly prepared hydrogen clay has the neutralisation curve of a strong acid, meaning that the hydrogen ion is not strongly adsorbed. The fact that a suspension made by exchange with hydrogen-resin acquired on aging the properties of a weak acid is explained by the adsorption of aluminium ions on the surface of the mineral. The alumina has been set free from the lattice of the clay mineral in the acid medium. As in the litterature cited above aged suspensions have always been used, the data refer to hydrogen-alumina clays which of course flocculate rather well, the better the lower the $\mathrm{pH}$. Clays, which have become acid by natural processes will also be partly saturated with aluminum-ions, but it is not yet known whether they are saturated to the same extent as the hydrogen clays used in the older investigations because the reaction will have never been as acid as during the preparation of the hydrogen clays.

$b$. Another cause involved is the one suggested by VAN OLPHEN (1951) and elaborated by SGhofield \& SAMson (1953).

According to their view flocculation is caused by the attraction between the positive edges and the negative plane surfaces of the clay mineral plates. The positive charge on the edges is caused by the broken bonds of the alumina ions present in the octahedral layer.

If the double layer is swollen, these positive charges are neutralized by the extended negative charge; this is not the case if the double layer is compressed (high salt content) and flocculation is consequently possible.

By raising the $\mathrm{pH}$ the positive charge is first neutralized and then reversed as the alumina groups have an amphoteric character. So at high $\mathrm{pH}$ (above $\mathrm{pH} 8$ ) the edgeto-plate mechanism of flocculation is inhibited and far larger quantities of salt are needed for flocculation. VAN OlpHEN's experiments corroborate this theory as he found that the flocculation value increased considerably after reversal of the edge charge by adsorption of organic molecules, Schofield \& SAMson found that the chloride adsorption decreased and the sodium adsorption increased with rising $\mathrm{pH}$.

In the colloid-chemical concept flocculation is thought to be the chief cause of aggregation. The flocks are then the smallest structual units. As flocculation is a reversible process much stress is laid on the concentration of the soil solution, since below a certain value (depending on the composition of this solution) deflocculation and consequently desaggregation must occur if excess moisture is present.

The colloid-chemical view. is expressed most strongly by WIEGNER (1931), who, commenting on his experiments relating the time of sedimentation with salt concentration, states 'Der Boden ist also eine reversibele Dispersion, die in ihrer Zerteilung auf Elektrolytzusatz nach Art eines mehr oder weniger leicht verschiebbaren Dispersitätsgleichgewichtes reagiert'.

This concept is shared e.g. by Mc Kenzie (1956), WikLander \& Hallgren (1944/1945), VAN SchuYlenborgh (1947, 1951) and Westerhof (1956). Though BRADFIELD (1936) distanciates himself from the pure flocculation concept, by his 
statement 'Aggregation is flocculation plus'. He still assigns to flocculation an important role in aggregate formation.

As a clay suspension is flocculated by a much lower concentration of divalent ions than of monovalent ions, the adsorption complex and the soil solution should contain preferably divalent ions, to ensure the stability of the aggregates.

This flocculation concept of the origin of soil structure is in accordance with many observations in agricultural practice.

In particular the reclamation of saline and alkaline soils has been based on this concept.

If salinity is caused by sodium salts the major difficulty in reclaiming these soils lies in the fact that they tend to disperse when the salts are leached. The permeability is lowered by dispersion to such a degree that leaching is no longer possible. By hydrolysis of the sodium clay the $\mathrm{pH}$ may rise so much that calcium carbonate becomes completely undissociated.

- The reclamation of these soils is based on the exchange of the adsorbed sodium ions. If sufficient calcium-carbonate is present, sulphur- or iron- or aluminiumsulphate may be applied in order to lower the $\mathrm{pH}$ and to change the calcium carbonate into the more soluble gypsum. If no calcium carbonate is present, gypsum is applied. If ferrous sulfide or pyrite are present in the soil, as is often the case with reclaimed sea beds, no additions of gypsum are necessary since the sulfides will be oxidized and form gypsum with the calcium carbonate present. The Russian litterature on this subject is summarized by JoFFE (1949), the Hungarian by DE Sigmond (1938), the American in the Agricultural Handbook No 60 (1954) and the Dutch by ZuUr e.a. (1953).

\subsection{OBJEGTIONS AGAINST THE FLOCGULATION GONGEPT}

The concept that the changes in soil structure can be explained by the behaviour of a clay suspension soon met with objections, since the concept was not compatible with the observations cited below and since some standard determinations or the preparations they required were at variance with it.

The swelling of clays, the change of the apparent density of flocks by drying and freezing and the change in permeability by freezing, must be depending on other factors than those taken into account by the flocculation theory. If the flocculation theory would be applicable, the preparation for the particle size measurement would be unnecessary, and the wet sieving method of aggregate stability determination, if done in distilled water, would give identical results with those of the texture analysis.

The observations and methods cited will now be discussed in some detail.

\subsubsection{Swelling of dried clay and of partly dehydrated suspensions}

Commenting on his swelling experiments MATTSON (1929) makes the following distinction between aggregation and flocculation.

'The process of breaking up of coherent aggregates, desaggregation, is independent of the phenomenon of defocculation. Desaggregation is opposed by the cohesive forces, whereas the forces holding 
the micelles together in the flocculated condition may be due to an interionic attraction. It is certain that cohesive forces do not here come into play. This can be demonstrated by the following simple experiment. If a piece of bentonite is placed in a $\mathrm{NaCl}$ solution of a concentration higher than that required for flocculation, e.g. $0.02 \mathrm{~N}$, it will swell considerably, and the individual micelles will not diffuse into the supernatant liquid but leave a sharp boundary between the gel and the liquid.

If the salt concentration is $0.005 \mathrm{~N}$ or even $0.01 \mathrm{~N}$, the micelles will diffuse into the liquid forming a suspension of decreasing density. In both cases there is desaggregation, but deflocculation only in the latter. In both cases the cohesive force is overcome by the electrical and osmotic forces of the dissociated ions and the particles are forced apart a distance equal two twice the thickness of the layer of osmotic hydration. At this distance the forces of flocculation come into play, linking the micelles together. In the weaker solution the micelles are not subject to any mutual attraction and are therefore carried farther apart by the Brownian movement'.

MAtTson also makes the very interesting observation that potassium saturated Sharkey clay swells considerably if dehydrated to a gel, but loses much of its swelling properties after complete drying.

BAVER \& WinterkoRn (1935) discuss the swelling of dried powdered clays with regard to the colloidal properties of the suspensions as zêta potential, hydration water (derived from the relative viscosity) and velocity of sedimentation. The differences between the clays saturated with different ions are rather small with regard to zêta potential and hydration. As to sedimentation velocity the differences are more pronounced, approximately a factor of 2 , but with regard to the swelling the differences are large. Whereas the lithium and sodium saturated clays adsorb nearly as much water as that which corresponds to the hydration in the suspended state, the potassium saturated clay adsorbs only $1 / 8$ th of this quantity, and the clays saturated with divalent ions $1 / 5$ th. The Wabash colloid, which they investigated, behaves similarly to the Putnam clay.

The conclusion to which BAVER \& WINTERKORN come discussing the behaviour of potassium Putnam clay is cited in full as it concerns the subject of this thesis:

'It appears that the potassium systems are unable to orient water around the surfaces of the primary colloidal particles whenever much energy is required for the dispersion of the secundary colloidal particles (granules). The lithium colloid attracts watermolecules very strongly even to the point of complete dispersion of aggregated systems. In colloidal suspension, where the individual particles have been brought into suspension by some external force, the potassium saturated surfaces do attract a rather large number of watermolecules as evidenced by viscosity measurements'.

The swelling of calcium, barium and hydrogen bentonite has also no relation with the hydration of the suspended clays. In this case the potassium saturated clay swells like the sodium saturated clay, but the calcium, barium and hydrogen clay swell to a much lower degree and take up only $1 / 10$ th of their hydration water.

Out of these experiments it appears that only the lithium and sodium clays take up an amount of water after drying which is proportional to the water of hydration. If the clays are saturated with magnesium, calcium, barium or hydrogen the amount of water is considerably less than the amount of hydration water, they exhibit a limited swelling at low salt concentrations which is one of the conditions stipulated in the 
general introduction. The behaviour of potassium saturated clays is not consistent but depends on the type of the clay mineral.

A further proof is given by the investigation of the compression curve of bentonite by Warkentin, Bolt \& Miller (1957). They showed that if a calcium bentonite suspension was dehydrated to a certain degree by compression, it did not swell back to the original moisturecontent, if the pressure was lowered again. The deviation between the moisture contents of the first compression curve and the swelling curve was more pronounced the more the suspension had been compressed. Sodium bentonite on the contrary, did swell back to its original water content. The swelling of calcium bentonite is limited even if the drying has proceeded to a small extent, in other words, the suspension behaves like an semi-elastic gel.

The sodium bentonite however swells back whatever its degree of drying, it behaves like an elastic gel.

Croney \& Coleman (1954) made the same observation on London clay when they desorbed a slurry (mechanically prepared suspension) of this soil. They also found a limitation of the swelling by small compressions. The swelling was least if the soil had been dried completely. As the curves for London clay and calcium bentonite have the same character the organic fraction does not seem to play a decisive part.

Further evidence is given by NoRRISH (1953), who determined the interlayer distance of bentonite crystals in relation to the saturating cation and salt concentration. In agreement with the above cited experiments, he found that the distance between the unit layers of sodium bentonite increased indefinitely with decreasing salt concentration, whereas the distance between the calcium bentonite layers did not increase beyond $10 \AA$ in excess pure water. This experiment proves very clearly that the calcium clay swells (adsorbing between the plates about $40 \%$ of water) but that
this swelling is limited.

1.3.2 The flock volume before and after drying and the permeability before and after freezing

That the mere flocculation of a clay suspension does not lead to granulation, but that compression by drying is also necessary, follows from the experiments of GARDNER
$(1945$ a).

After drying and replenishing the moisture, the volume of the soil suspensions whereas the sodium calcium, had decreased to one sixth of the original volume, obtained.

From this experiment GARDNER infers: 'Apparently the electrical forces causing flocculation are not able to bring the platey clay crystals into compact arrangement
unless supplemented by mechanical forces'.

The freezing of suspensions of bentonite and Ford Collins clay loam had similar results. GARDNER $(1945, \mathrm{~b})$ found that the calcium saturated suspensions showed a high apparent density after freezing, thawing and shaking, while that of the sodium saturated ones was not increased by this procedure. The apparent density of the 
calcium clay suspensions was after freezing and thawing the same as that of the original unpuddled material, which induces the conclusion that granulation had been restored by freezing.

In the same paper GARDNER publishes his investigations of the influence of freezing on the permeability for water.

He found that the permeability of the puddled soil, which was zero before freezing, became the same as that of the dry packed soil after the third freezing and thawing cycle. As the dry and puddled soil have the same electrolyte concentration, they should have the same permeability if the structure depended only on flocculation. The permeability of the puddled soil is however restored, not by flocculation but by the compressing effect of freezing.

\subsubsection{Permeability measurements}

Further indications on the limited swelling of clay, saturated with divalent cations are given by the permeability measurements of HaLLGREN (44/45), WikLANDER \& Hallgren (44/45) and Quirk \& Schofield (1955).

In every case it was found that if calcium or magnesium soils or clays were percolated with distilled water a certain permeability was maintained, whereas the latter decreased very much if the clays were saturated with sodium or potassium and the concentration of the salt solution was lowered. That the permeability for the salt solution is not caused by flocculation but by limited swelling was proved by HALLGREN.

A soil was first percolated with seawater and subsequently with distilled water, the filtrate became cloudy and the filtration rate was lowered considerably. When seawater was used again as percolation liquid, the filtrate became clear indicating that flocculation took place; but as the filtration rate did not increase again the soil was nog restored to its original structure by flocculation.

still

\subsubsection{The pretreatment for the determination of soil texture}

From the pretreatment of soils for the analysis of texture it follows that dilution with distilled water is insufficient to break down the aggregates into their primary particles. After removal of cementing substances like humus, calcium carbonate and partly iron, the procedure is to saturate the soil with a monovalent cation, usually sodium. This is not only done to overcome the flocculation by divalent ions, but also because the clays saturated with divalent ions have a limited swelling, as is demonstrated by PURI \& RAI (1944).

It appears from their experiments that only lithium- and sodium-saturated soils are completely dispersed.

It appears also that the degree of dispersion is not much changed by substitution of the lithium ion by other ions, provided that the suspension is not dried during the process.

1.3.5 Wet sieving method and dispersion ratio method of aggregate analysis

Dependent up on the size of the particles one is interested in, wet-sieving or 
dispersion ratio methods are used. With the wet-sieving method a set of sieves moving in water is used to determine the dimensions of the aggregates after slaking and swelling. With the dispersion ratio method use is made of the sedimentation velocity. In both cases the results are compared with the texture of the completely dispersed soil.

Microaggregate analyses were already done in 1911 by MOHR. An example of testing a red latosol from Tjitjerep near Bogor (Indonesia) is given in table 3 .

TABLE 3. Aggregate analysis of a red latosol (MoHR)

\begin{tabular}{|c|c|c|c|c|c|c|c|c|c|c|}
\hline & \multicolumn{10}{|c|}{ particle size } \\
\hline & \multicolumn{5}{|c|}{ in $\mathrm{mm}$} & \multicolumn{5}{|c|}{ in'micron } \\
\hline & $2-1$ & $1-0.5$ & $0.5-0.25$ & $0.25-0.10$ & $0.10-0.05$ & $50-20$ & $20-5$ & $5-2$ & $2-0.5$ & $0.5-0.00$ \\
\hline \multicolumn{11}{|l|}{ percentage } \\
\hline with $\mathrm{H}_{2} \mathrm{O}$ & 1 & 7 & 47 & 18 & 6 & 18 & 5 & 1 & 0.5 & 0.1 \\
\hline with $\mathrm{NH}_{4} \mathrm{OH}$ & 0 & 0.5 & 1 & 1 & 2 & 7.5 & 7 & 11 & 19 & 54 \\
\hline
\end{tabular}

Later on this type of analysis was used by VAgeler \& Alten (1931) and MiddleTON (1930).

Obviously the wet sieving method derives its existence from the fact that all soils, except the sodium- and sometimes the potassium-saturated ones exhibit only a limited swelling.

In both types of determination the soil is shaken with an excess of water low in electrolytes (this is certainly a condition for the dispersion-ratio method, since flocculation would make the determination unreliable). If the soil would behave like a reversible flocculated system desaggregation would occur spontaneously and the methods would be unusable.

As Trul.in (1933) stated: ,A complete irreversibility in water is possible for gels saturated with calcium, a complete reversibility takes place for gels saturated with sodium. An aggregate analysis is on principle oriented on the test of the reversibility or irreversibility of gels'.

As the aggregate analysis has been done with soils, the stability in excess water might be attributed to the humus fraction.

Numerous authors have, however, noted that a positive correlation also exists between the aggregate stability and clay content of soils, e.g. HeINONEN (1955) finds that the stability was related both to the clay and to the organic matter content of the soil and that $80 \%$ of the correlation was due to the clay. It is therefore probable that the limited swelling of the soil is not merely caused by humus fraction but that it is a property of the clay.

\subsubsection{Conclusion}

The following conclusion can be drawn from the experiments discussed above:

1. A close contact between the clay crystals is necessary to change a suspension 
into particles with a limited swelling; mere flocculation is not sufficient to concentrate the particles to the desired degree.

2. Only granules of clays saturated with lithium and sodium have an unlimited swelling in dilute solutions, which leads to complete dispersion. Clays saturated with divalent ions and hydrogen display a limited swelling in pure water and spontaneous dispersion does not occur. Whether saturation with potassium will cause a limitation of the swelling depends on the type of clay mineral and the degree of dehydration.

Apparently both the liquid and the solid states of clay have been extensively investigated, but the knowledge of the transition region between these forms is limited. Therefore the degree of moisture desorption necessary to change a suspension into a granule with limited swelling has been studied extensively. Results of this investigation are given in $I, 2$.

\section{EXPERIMENTAL}

\subsection{OutLine}

From the evidence given in chapter 1, one may infer that dehydration of a clay suspension is necessary to form aggregates of the density encountered in the field. Furthermore it appeared that most clays; saturated with monovalent ions did swell back after dehydration to such a degree that they could not have any stability in water, but would go into suspension spontaneously. Granules of clays saturated with divalent ions however showed only a limited swelling, and the suspensions of these clays showed a gradual decrease in swelling if increasing suctions were applied changing the suspensions into gels and pastes.

In order to investigate this reversibility of the swelling phenomena, experiments were set up to answer the following questions.

1. Whether dehydration of a given suspension leads to the formation of waterstable granules.

2. To which degree the dehydration has to proceed to obtain waterstable granules. (To measure the dehydration, the suction which had to be applied and not the percentage of moisture, was used).

3. The influence of the salt concentration on the swelling of granules; of particular interest for those clays which disperse spontaneously at low concentrations.

Although one can see quite easily whether a dry granule is waterstable, simply by dropping it into the liquid and observing the changes, this method is not satisfactory if a gradual change from suspension to waterstable granules is to be investigated. A method therefore was developed, based on the empirical results described in the previous chapter.

As the water retention of a swollen clay granule is always lower than that of a suspension, a change from a suspension into a granule will be reflected by a decrease of the moisture content at low suctions. 
Consequently the water content after swelling of the material, which had already been subjected to increasing degrees of dehydration was chosen as a measure for the formation of waterstable granules. The swelling was allowed to take place in the presence of excess free liquid in order to avoid hysteresis (cf. 2.5.1.3.) and also because under natural conditions the soil is often wetted by free liquid.

As it is impossible to determine the moisture content of a submerged sample, the moisture percentage at $\mathrm{pF} \mathrm{l}$ was taken as a measure for that of the submerged sample. The range of moisture contents at $\mathrm{pF} 1$ of the partly dehydrated material after backswelling, lies obviously between that of the original suspension and that of the ovendried granules at $\mathrm{pF} 1$ after backswelling.

In the following discussion the relationship between the decrease in moisture content at $\mathrm{pF} 1$ after backswelling and the suction applied to the original suspension or slurry prior to backswelling will be indicated by the term 'backswelling characteristic' of the clay or soil.

\subsection{Materials}

\subsubsection{Origin and characterization}

The backswelling characteristics of three clay minerals, viz. montmorillonite, illite and kaolinite were investigated. In most experiments the clays and soils studied were made homoionic with respect to the adsorbing cations.

In order to investigate whether the clay mineral governs the behaviour of soils containing it, five soils were also investigated, containing mainly the clay minerals mentioned above. A 'margalite' from Java was used as a representative of a montmorillonite containing soil. Two clay soils from Friesland and Groningen recently deposited by the sea and a clay deposited by the Rhine branch Waal, were used as representatives of illite containing soils. Finally a latosol from Java was taken as typical for the kaolinite containing soils. The soils were in some cases investigated in their natural composition. In other experiments the isolated clay fraction was studied, in most cases after removal of organic matter. A more detailed description of the material used in this or the next part follows below.

\subsubsection{Montmorillonite}

A sample of unground Wyoming bentonite, supplied by Ward's Establishment left to swell in 10 liters of distilled water. After 24 hing way. About 100 grams were and left in order to allow the coarse particles to hours the bottle was shaken by hand layer formed on the bottom and then a white layer settled out gravity. First a black a yellowish tinge. After 48 hours the fraction layer settled out, the suspension having of using unground rock over that of impurities are so finely divided finely ground materials is, that in the latter the especially if the suspension is as that they fail to settle within reasonable time,

The base exchange capas concentrated as $1 \%$.

zero, the surface area was about $900 \mathrm{~m}^{2} / \mathrm{g}$. 


\subsubsection{Margalite}

The name margalite is used in accordance with MoHR \& van BAREN (1954) for the black clays low in organic matter and high in smectite content found over extensive areas of the dry tropics and subtropics.

The name margalite is a latinization of the older more common name of 'marl' soils, but it comprises also the black clay soils formed on vulcanic ash. The name margalite was first used by Dames in 1948. For reason of the seniority of the Dutch work it is used in preference to grumosol, introduced by OAKes \& THORP (1950).

The clay fraction of the margalites has been investigated by HARDON \& FAVEjEE (1939) and by HaRDON (1939) and proved to consist chiefly of smectite. It is present in a well crystallized form as is demonstrated by photograph no. 1 .

The sample in stock at the laboratory consisted of blocky aggregates $0.2-2 \mathrm{~cm}$ in diameter, neutral dark grey in colour. It contained some lime nodules, therefore the parent material was probably a marl.

As these lime nodules would be a handicap if small representative samples were needed, the fraction smaller than 50 micron was separated by ovendrying the soil, stirring it in excess of water, passing it through a 50 micron sieve and drying it again. The texture of the fraction smaller than 50 micron is shown in table 4.

TABLe 4. Mechanical composition of margalite, fraction smaller than $\mathbf{5 0}$ micron

\begin{tabular}{lcccccc}
\hline fraction in $\mu$ & $50-20$ & $20-10$ & $10-5$ & $5-2$ & $2-0.5$ & $0.5-0.00$ \\
percentage & 2.0 & 6.0 & 3.3 & 5.5 & 9.8 & 73.4 \\
\hline
\end{tabular}

The carbon content was $1.04 \%$. The base exchange at neutrality $0.48 \mathrm{me} . / \mathrm{g}$. The $\mathrm{pH}$ in water was 7.71 , in $1 \mathrm{~N} \mathrm{KCl} 6.95$.

The adsorbed cations are reported in table 5.

TABl.E 5. Adsorbed cations of margalite

$\begin{array}{lcccc}\text { cation } & \mathrm{Ca} & \mathrm{Mg} & \mathrm{K} & \mathrm{Na} \\ \% \text { of total } & 81.0 & 18.0 & 0.85 & 1.57\end{array}$

This soil, may, therefore, be regarded as a calcium clay. The salt content as calculated from the resistance of a $1: 5$ extract, was equivalent to 0.23 me. calcium chloride per $100 \mathrm{~g}$.

Part of the experiments were done with the soil fraction described, others were conducted on samples made homoionic with respect to sodium or potassium. In addition the clay fraction, both with and without organic matter was investigated.

The colour changed after removal of the organic matter from dark grey to pale yellow (5Y 7/3 Munsells notation). The base exchange capacity of the clay fraction was $0.625 \mathrm{me} . / \mathrm{g}$, the surface area $530 \mathrm{~m}^{2} / \mathrm{g}$. Approximately $80 \%$ of the clay fraction was smaller than $0.13 \mu$.

\subsubsection{Illite}

The clay was isolated from illite bearing shale from Fithian, Ill., as supplied by 
Ward's. The clay fraction was brought into suspension by puddling and stirring, and separated off by sedimentation. As later on it became apparent that the organic matter fraction had a very decisive influence on the behaviour of the clay, the clay from another piece of shale was isolated and oxidized. As a result the two batches used in the experiments are not necessarily indentical. The data are represented in table 6.

TABLE 6. Data of Fithian illite clay fraction

\begin{tabular}{lcc}
\hline & 1st batch & $\begin{array}{c}\text { 2nd batch } \\
\text { (oxidized) }\end{array}$ \\
\hline carbon (\%) & 0.83 & \\
C.E.G. (me. $/ \mathrm{g})$ & 0.265 & 0.25 \\
surface area (m²) & 155 & 130 \\
\hline
\end{tabular}

\subsubsection{Knip clay}

'Knip' clay is a subrecent sea deposit (400-800 A.D.) from brackish sea water (VEENENBOS e.a., 1951). The sodium percentage is often still high enough to get a high degree of dispersion without addition of a peptizing agent. Since only the clay fraction of this soil was to be studied, the latter feature was advantageous and a sample of this clay was therefore chosen for comparison with the pure illite.

The clay fraction consisted of $10 \%$ montmorillonite, $10 \%$ quartz, $7 \%$ kaolinite and $73 \%$ illite. (Analysis by VAN DE PLAs, Lab. of Regional Pedology, Mineralogy and Geology, Wageningen). The illite was badly crystallized. A suspension of the sodium clay separated on standing into two fractions, a greyish opaque mass settled out in 48 hours leaving a blackish nearly transparent liquid in suspension. The two fractions were separated by centrifugation, some properties are given in table 7 .

TABle 7. Some data of 'Knip' clay, clay fraction

\begin{tabular}{lcccc} 
& whole clay & coarse fr. & fine fr. & $\begin{array}{c}\text { fine fr. } \\
\text { (carbon free) }\end{array}$ \\
\hline C.E.C. (pH 8.2; me./g) & 0.55 & 0.35 & 0.75 & 0.73 \\
carbon (\%) & 1.75 & 0.89 & 3.06 & \\
$\%$ of total & & 50.7 & 49.3 & \\
surface area $\left(\mathrm{m}^{2} / \mathrm{g}\right)$ & & 132 & & 452 \\
\hline
\end{tabular}

\subsubsection{River basin clay}

The basin clays are recent heavy deposits of the Rhine and Meuse rivers and their branches, (Edelman, 1950). As they are surrounded by higher levee soils, they are Bommelerwaard (hey are used chiefly as haylands. The sample was taken in the the basin clay are given in table 8 . Meuse) at a depth of 5 to $30 \mathrm{~cm}$. Some data on

The colour varied wint the 8.

being $10 \mathrm{YR} 3 / 1$ vhen with the organic matter from $10 \mathrm{YR} 5 / 1$ to $4 / 1$ in the dry state,

The fraction smaller than $0.2 \mu$ was a dark transparent material and consisted of
( $\left.\mathrm{H}_{2} \mathrm{O}\right)$ is 5.5 , the $\mathrm{pH}(\mathrm{KCl}) 4.9$. 
TABLE 8. Data on basin clay soil

\begin{tabular}{|c|c|c|c|c|c|c|c|c|}
\hline $\begin{array}{l}\text { fraction in } \mu \\
\text { percentage }\end{array}$ & $\begin{array}{l}>250 \\
1.3\end{array}$ & $\begin{array}{c}250-50 \\
2.6\end{array}$ & $\begin{array}{c}50-20 \\
2.4\end{array}$ & $\begin{array}{c}20-10 \\
10.0\end{array}$ & $\begin{array}{l}10-5 \\
11.0\end{array}$ & $\begin{array}{c}5-2 \\
19.4\end{array}$ & $\begin{array}{c}2-0.128 \\
23.6\end{array}$ & $\begin{array}{c}0.128-0 \\
28.8\end{array}$ \\
\hline carbon total $4.06 \%$ & fraction & $>50 \mu$ & $0.97 \%$ & & & & & \\
\hline $\begin{array}{l}\text { fraction in } \mu \\
\text { C.E.C. (me. } / \mathrm{g}) \\
\text { surface area }\left(\mathrm{m}^{2} / \mathrm{g}\right) \\
\% \text { of clay fraction }\end{array}$ & & $\begin{array}{r}<2 \\
0.4 \\
315\end{array}$ & & & $\begin{array}{c}2-0.2 \\
0.25 \\
180 \\
40\end{array}$ & & $\begin{array}{r}<0 \\
480 \\
46\end{array}$ & 13 \\
\hline
\end{tabular}

very fine and badly cristallized illite (X-ray analysis by courtesy of Ferro-Enamels, Rotterdam). The coarser clay fraction, a light gray opaque material, consisted of well-cristallized illite with small admixtures of quartz and kaolinite.

\subsubsection{Winsum clay}

This soil is comparable to the Knip clay from Friesland. The sample had been taken near Winsum (Groningen) from a field under permanent pasture at a depth of 20 to $60 \mathrm{~cm}$. The clay content was about $46 \%$ and the carbon content $0.68 \%$. The colour changes on moistening from $5 \mathrm{Y} 7 / 1$ to $5 \mathrm{Y} \mathrm{5.5/1}$. The $\mathrm{pH}$ in $\mathrm{H}_{2} \mathrm{O}$ was 7.0 , the $\mathrm{pH}$ in KCl 5.8.

The properties of the clay fraction are summarized in table 9.

TABLE 9. Data on Winsum clay, clay fractions

\begin{tabular}{lccc}
\hline & \multicolumn{4}{c}{ particle size in $\mu$} \\
\cline { 2 - 4 } & $<2$ & $2-0.2$ & $<0.13$ \\
\hline C.E.C. (me./g) & 0.40 & 0.33 & 0.59 \\
surface (m $2 / g$ ) & 250 & n.d & 460 \\
$\%$ of clay fraction & & 46 & 43 \\
\hline
\end{tabular}

The coarse fraction consisted of $35 \%$ illite and muscovite, $10 \%$ kaolinite and $55 \%$ of quartz. The finest fraction consisted of some kind of expanding illite. (Analysis by courtesy of FAVEjEe, Lab. of Regional Pedology, Mineralogy and Geology, Wageningen.)

\subsubsection{Kaolinite}

The kaolinite (Dry Branch Georgia) was dispersed by puddling; shaking and raising the $\mathrm{pH}$ to 8 by addition of sodium carbonate, whereafter the clay fraction was isolated. The adsorption capacity of this fraction was $0.068 \mathrm{me} . / \mathrm{g}$ and the surface $50 \mathrm{~m}^{2} / \mathrm{g}$.

\subsubsection{Latosol}

The latosol investigated came from Pasar Minggu, a few miles south of Djakarta (Indonesia). According to the old Dutch nomenclature it is a deep old red lateritic clay soil, derived from andesitic tuf. Colour, 2.5 YR - 5 YR 4/6 dry and 2.5 YR $3 / 6$ wet. The texture of the soil is given in table 10 . 
TABLE 10. Texture of Latosol

\begin{tabular}{llcccc}
\hline fraction in $\psi$ & $>50$ & $50-20$ & $20-5$ & $5-2$ & $2-0$ \\
percentage & 1.5 & 0.8 & 5.5 & 4.3 & 88.0 \\
\hline
\end{tabular}

The carbon content was $0.53 \%$, the reducable iron content $7.8 \%$ calculated as $\mathrm{Fe}$, probable occurring as haematite (WEENIG, 1951), the base exchange capacity was $0.12 \mathrm{me} . / \mathrm{g}$ at $\mathrm{pH} 6.5$ and $0.15 \mathrm{me} . / \mathrm{g}$ at $\mathrm{pH} 8.0$. The $\mathrm{pH}\left(\mathrm{H}_{2} \mathrm{O}\right)$ was 4.8 and $\mathrm{pH}(\mathrm{KCl})$ was 4.25 . The surface was $125 \mathrm{~m}^{2} / \mathrm{g}$. The clay minerals present (Photograph no. 2) were fine and badly crystallized kaolinite, and crystoballite, the latter was probably present in the parent material (RACHMAT, 1956).

\subsubsection{Methods of sample preparation and characterization}

\subsubsection{Isolation of the clay fraction}

If the material was not largely sodium saturated like the bentonite, the saturation with sodium was achieved by washing with $1 \mathrm{M}$ sodium chloride, until all calcium was removed. The soil was then peptized by dilution with distilled water and shaken up. The clay fraction was syphoned off at the depth indicated by Stokes's law. The remnant was shaken up again with distilled water and the fractionation repeated until the clay fraction had been removed completely.

\subsubsection{Removal of organic matter}

In those cases where the clay colloid was to be investigated, the organic matter was removed prior to the saturation with sodium. The removal was effected by treatment with $30 \%$ hydrogen peroxide reagent grade. As the peroxide decomposes spontaneously in neutral and alcaline soil, these soils (e.g. margalite) were acidified with acetic acid prior to oxidation.

\subsubsection{Determination of the surface area}

The surface was measured by the ethylene-glycol retention method of BOWER \& GOERTZEN (1959). It proved that the weight of the glycol saturated sodium montmorillonite continued to decrease after 30 hours of equilibration, whereas the calcium clay showed a constant level. The sodium margalite and ' $\mathrm{Knip}$ ' clay reached a constant level, significantly lower than that of the calcium clays. The surface determination was therefore only done on calcium saturated oxidized clay samples.

\subsubsection{Preparation of homoionic clay suspensions}

In order to obtain suspensions with the maximum degree of dispersion it was necessary to prepare the suspensions saturated with divalent cations from dispersed sion was washed repeatedly without drying. For this purpose the sodium clay suspenand the supernatant liquid was decanted solions of calcium or magnesium chloride suspension was then washed with decanted after sedimentation. The flocculated 
traces of salt were removed by dialysis until the outside solution became free of chloride ions.

The sodium clay was prepared by washing the clay or soil with normal chloride solutions, until no calcium could be detected in the supernatant liquid. As none of the materials used contained calcium carbonate, acid treatment was not necessary. Washing with distilled water followed until the material started to peptize.

This suspension was then dialyzed with an outside solution of $10^{-4} \mathrm{~N}$ sodium hydroxide to repress hydrolysis. Potassium clays were made either like the suspensions saturated with divalent ions or like the sodium clays depending on the characteristics of the clay mineral.

Instead of dialysis against $10^{-4} \mathrm{~N}$ sodium hydroxide the suspension was in some cases washed with ethanol to remove the salt. In this case it proved necessary to dry the soil since with continued washing the suspension deflocculated even in ethanol, while the dried clay did not peptize. To remove traces of alcohol still present after drying, the clay was boiled with distilled water for half an hour, the clay concentration being about $1 \%$. No appreciable difference due to the way of preparation of the sodium clays was found, though the $\mathrm{pH}$ of the ethanol prepared clay was usually slightly higher.

Though the purpose had been to obtain suspensions with very low salt concentrations by removing the last traces of chloride ions, this aim was not achieved. All suspensions remained near $10^{-4} \mathrm{~N}$, probably due to the hydrolysis of the clay itself.

\subsubsection{Preparation of slurries}

Slurries or mechanical suspensions were prepared by adding moisture gradually to the dry clay or soil, while working the material continuously. When the consistency of a stiff paste had been reached, the working was continued till the paste was quite homogeneous. Then some more water was added and worked through the soil to facilitate the subsequent dispersion by stirring.

If more than a few grams had to be converted into a slurry, then enough water was added at once to bring the moisture content to that of the paste and the working was started after equilibration of the moisture.

\subsection{EXPERMENTAL PROCEDURE}

\subsubsection{The desorption curve}

The desorption curve was established by applying the required suction (expressed as $\mathrm{pF}$, the logarithm of the suction in $\mathrm{cm}$ of water) on the sample and determining the moisture content after equilibrium had been established. If necessary a correction for the salts in the solution was made. An amount of suspension containing approximately $100 \mathrm{mg}$ of dry matter was used for each determination, as the moisture content could be determined accurately enough with this quantity, using an analytical balance. 
For the range from $\mathrm{pF} 1$ to $\mathrm{pF} 2$ a Szigmondy funnel was used with a membrane from the Membranfilter Gesellschaft Göttingen (medium type) supported by filterpaper. The distance from the membrane to the outlet was regulated by the height of the narrow outlet of a rubber U-tube. Funnel and U-tube were filled with water or the equilibrium solution used. Evaporation from the sample was prevented by a rubber stopper with a capillary tube.

For the range from pF 2 to 3 sintered glass funnels were used, SchotT \& GEN, type 4 or 5 . Since above $100 \mathrm{~cm}$ of water, this medium became too cumbersome, the suctions were applied with the aid of mercury using Russell's apparatus (1941). The suspensions sealed the larger pores of the sintered glass perfectly and suctions up to $65 \mathrm{~cm}$ of mercury could be applied. If granules were investigated, $46 \mathrm{~cm}$ of mercury was the maximum suction obtainable. Later a special pressure membrane apparatus was designed for the range between $\mathrm{pF} 2.5$ and 3.5, pressure was applied with a bicycle pump, air tight fittings were provided with rubber $O$ rings and thin cellophane or Göttingen membrane was used as membrane. For the range from $\mathrm{pF} 3.5$ to 4.2 a pressure membrane apparatus designed by JANSE (1954) with a cellophane membrane $\left(100 \mathrm{~g} / \mathrm{m}^{2}\right)$ underlain by two layers of nylon gauze was used. The pressure was applied by compressed air and regulated by a reducer. For $\mathrm{pF}$ values between 4.2 and $5.13 \mathrm{a}$ remake of BolT's apparatus, Bolr \& Miller (1955), was used. Though with the latter the whole range between $\mathrm{pF} 1$ and 5 might have been investigated, the advantage of the use of several instruments is that the results are obtained in a shorter time. To prevent drying through the prolonged contact with the compressed air in the cylinders the samples were covered with a plastic film. Since suspensions could not be handled without difficulty in BoLTs apparatus, pastes were used instead ( $\mathrm{pF} 2$ ).

For the range between $\mathrm{pF} 5$ and 6.2 the vapour pressure equilibrium method with sulfuric acid of known concentration was used in some cases. The results were rather unsatisfactory as only an air thermostat was available. Later a saturated sodium chloride solution was used to determine the moisture content at pF 5.6.

\subsubsection{The swelling after previous desorption (backswelling)}

Part of a sample which had been equilibrated with a certain suction was completely immersed in the equilibrium solution used and allowed to swell for 24 hours. Care was taken not to change the structure of the paste.

As the moisture content of the completely saturated sample could not be determined, the backswelling was estimated by comparison of the moisture content of the swollen paste at $\mathbf{p F ~ 1 , ~ w i t h ~ t h a t ~ o f ~ t h e ~ o r i g i n a l ~ s u s p e n s i o n ~ o r ~ s l u r r y . ~}$

\subsubsection{The influence of the salt concentration on the swelling}

In order to establish this relation ovendried granules were submerged in the salt solution and left to swell for a period of 24 hours or longer. After the completion of the swelling, the moisture content at $\mathrm{pF} 1$ was determined. Usually the swelling and the equilibration with $\mathrm{pF} 1$ took place in the same vessel, the outlet being closed or raised during the swelling period. The moisture contents were corrected by sub- 
stracting the weight of the imbibed salt from the dry weight. The weight of the salt was found by multiplying the waterloss by the salt content of the solution determined as g solid: $\mathrm{g}$ water.

\subsection{TrEatMenT OF DATA}

\subsubsection{Representation of the results}

The results are shown in graphs. The $\mathrm{pF}$ is represented on the abscissa and the logarithm of the moisture content in equilibrium with the applied suction on the ordinate. By the term $\mathrm{pF}$ is meant the decimal logarithm of the height in centimetres of a column of water, corresponding to the free energy difference between free water and that held by soil, excluding the effects of salts, expressed on a gravitational scale. The moisture content is expressed as percentage of the dry weight. The logarithm of the moisture content has been adopted, because the lower moisture contents, which are of most interest in these investigations are then relatively enlarged.

In order to get the clearest representation, the scales should be adapted in such a way that the curve or line has a $1: 1$ slope.

From theoretical considerations, first published by ScHofield (1946) it follows, that for salt free systems the relation between $\mathrm{pF}$ and the log of the moisture content should be $2: 1$. Therefore the scale of the $\log$ of the moisture content was chosen twice as large as the $\mathrm{pF}$ scale.

The moisture content of the samples at pF 1, which had been subjected to a certain suction and were then allowed to swell under positive water pressure is indicated by an arrow at that suction.

The influence of the salt concentration on the swelling is shown in separate figures. As the swelling is primarily influenced by the concentration of the cations in the solution, the $\log$ of the osmotic pressure of the cations $\left(\log \mathrm{RTc}_{\mathrm{o}}^{+}\right)$is plotted on the abscissa. On the same axis the molarity of the solution is represented on a logarithmic scale. On the ordinate the log of the moisture precentage is plotted.

\subsubsection{Comparison with theoretical values}

As a complete theory has been developed for the swelling pressure of clays by Sahofield (1946) and Bolt e.a. (1952, 1953, 1954, 1955, 1956, 1958) it is desirable to compare the experimental data with the theoretical ones. In 1956 BoLT published a table from which the relation between interplate distance and suction at various salt concentrations can easily be derived. In order to facilitate this comparison four overlays have been constructed with the aid of Bour's data, to which the following minor corrections have been applied.

\subsubsection{Correction for the radius of the hydrated cations}

A double layer can no longer be regarded as diffuse if the ions are situated in one plane. This situation must occur, when the moisture content is decreased to the point 
where the half-distance is equal to the radius of the hydrated ion. At this point the ions will be forced into the midway position because the energy required for dehydration exceeds by far the kinetic energy of the ions. At smaller separations the repulsive energy will be increased with an amount equal to the energy of hydration. Since this energy increase is very large in comparison to the osmotic effects taken into account by the standard double layer theory, all calculations have been terminated at the point where the half-distance equals the hydrated radius of the ions. Since this radius is not known with accuracy a standard half distance was adopted, roughly equal to the ionic radius plus the diameter of one molecule of water, i.e. $4 \AA$.

As a result the half-distance calculated from the moisture content according to BolT (cf. 2.3.8.2.) must be increased by $4 \AA$. This tends to flatten the slopes of the $\mathrm{pF}$ curves at high suction values.

\subsubsection{Correction for the presence of lateral incompressible free pore space}

In the second place the calculation of the half-distance from the moisture content according to the relation:

$$
\mathrm{d}=\frac{\mathrm{M}}{\mathrm{S.10^{-4 }}} \quad \begin{aligned}
& \mathrm{S} \text { where d is given in } \mathrm{A} \\
& \mathrm{M} \text { (specific surface area) in } \mathrm{m}^{2} / \mathrm{g}
\end{aligned}
$$

does not seem satisfactory upon close consideration. Thus the irregularity in shape of the clay crystals in the direction of the $a$ and $b$ axis will prevent close fitting of the plates in that plane. In contrast to the suggestion made by BoLT (1956) to introduce a constant 'dead volume' it seems that at least the extra pore space due to mis-match at the contour should increase with increasing moisture content (cf. fig. 1). In fact' one could even imagine that upon increase in moisture content the plates would separate in all directions. Since, however, the respulsion at the edges is presumably much less than between the plane surfaces it would seem reasonable to assume that upon increase in moisture content only the transversal distances would increase, while the lateral spacing remains roughly constant. This is also evidenced by the observation that a disc of oriented clay swells practically only in the direction perpendicular to the plates. Departing from the above assumption the moisture content corresponding to a given spacing $2 \mathrm{~d}$ will be equal to:

$$
\begin{aligned}
& M=10^{-\ell} \text { S.d. }(1+e)+\frac{e}{p}=10^{-4} \text { S.d' } \\
& =\frac{2}{\rho A} \cdot d \cdot(1+e)+\frac{e}{p}
\end{aligned}
$$

in which $\rho=$ density of the solid phase in $\mathrm{g} / \mathrm{cm}^{\mathrm{a}}$
$\mathrm{A}=$ plate-thickness in $\mathrm{A}$

$\mathrm{e}=$ volume of incompressible voids, due to mis-match: volume of solids.

Taking e equal to $\frac{1}{2}(=1 / 3$ incompressible pore space) and $p$ as 2.75 , (cf. Low and ANDERson, 1958) one thus finds for montmorillonite: 


$$
M=\frac{2}{2.75 \times 10} \cdot d \cdot 1 \frac{1}{2}+\frac{1}{5.5}=0.109 \mathrm{~d}+0.182
$$

\subsubsection{Corrections applied to the calculation of the pressure}

Obviously not only the moisture content but also the swelling pressure is affected by the introduction of a variable 'dead volume' as mentioned above. As the pressure in the larger interstices, $M$ (Fig. 1) is less than in the smaller voids, $O$, the constancy of the moisture potential throughout the entire system requires that a difference between the gauge pressures at $M$ and $O$ must exist (Bolt \& Miller, 1957).

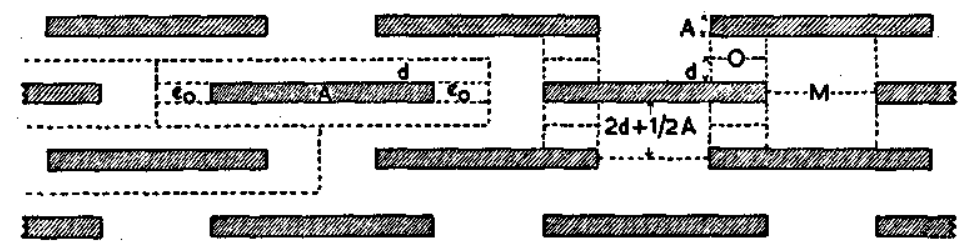

Fig. 1. Model of swollen clay. Incompressible lateral pore space $=1 / 3$ ie. void ratio $e_{0}=\frac{1}{2}$.

$\mathrm{d}=$ halfdistance; $\mathrm{A}=$ thickness of plates; $\mathrm{e}_{0}=$ incompressible part of pore space; $\mathrm{O}=$ region at large distance; $=$ region at large distance.

Neglecting the edge effects on the electric fields and on the corresponding ionic concentrations one can show that at equilibrium the gauge pressure at $O$ is positive, while being negative at $M$. Thus the moisture potential, and accordingly the swelling pressure, must be decreased in absolute value in comparison to the value found from the uncorrected theory using $\left(d+x_{0}-4\right)$ as half distance, to be indicated hereafter as $\mathrm{P}_{\text {od }}$ (cf. Bolt, 1956) table 1). Evidently the reduction of the swelling pressure, as compared to $P_{\text {od }}$ is now dependent upon the assumed magnitude of the 'dead volume' and upon the type of arrangement of the particles. It can be shown that the actual swelling pressure may vary roughly between the approximation mentioned above divided by $\left(1+\mathrm{e}_{0}\right)$ as a maximum, and the value $\mathrm{P}_{\text {od }}$, obtained from the same theory substituting $d^{\prime}=d .\left(1+e_{0}\right)$ as a minimum.

$$
\text { Or: } \mathrm{P}_{\text {od }}{ }^{\prime}<\mathrm{P}<\mathrm{P}_{\mathrm{od}} / 1+\mathrm{e}_{0}
$$

The effects of the corrections applied to the distance and to the pressure are illustrated in figure 2 . In this figure the relation between $P$ and $d$ according to the uncorrected theory is plotted for a salt free system. A second axis is also given on which the moisture content is indicated according to eq. (1) which is the basis of the calculation neglecting dead volume. The corrections for the introduction of different types of dead volume, according to eq. (2) then lead to a moisture content as indicated with MC. As was stated above the actual pressure corresponding with this moisture content, lies now between $P_{o d} / 1+e_{o}$ and $P_{o d}$. Although in principle the actual pressure should strive toward its minimum value, i.e. $P_{\text {od', }}$, the arrangement to obtain this value is fairly improbable. Therefore an intermediary value of $P$, corresponding to a 


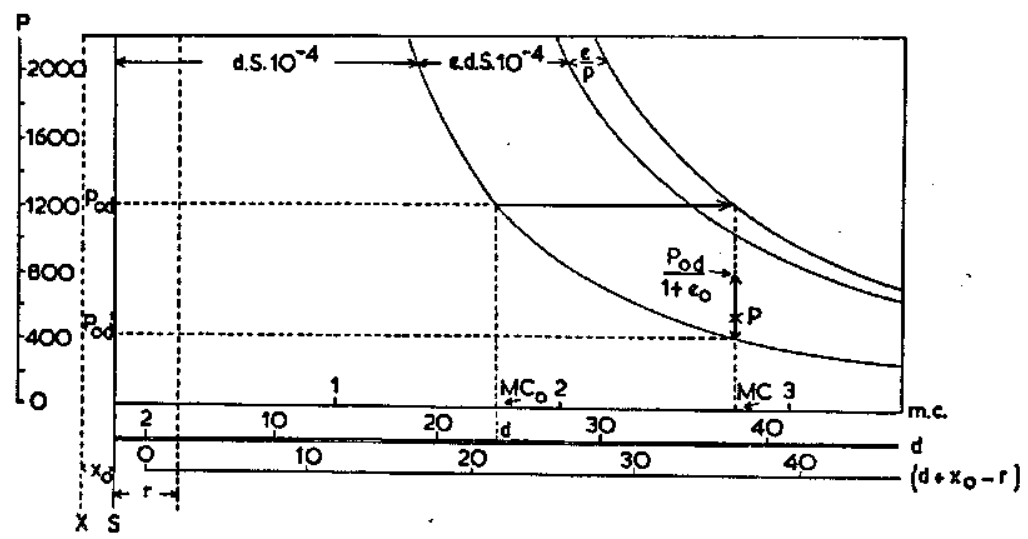

Fic. 2. Pressure-moisture relation for calcium montmorillonite, and changes caused by the introduction of pore space.

$\mathrm{P}$ (ordinate) = pressure in $\mathrm{cm}$ water; $\mathrm{S}=$ surface of clay plate; $\mathrm{X}=$ plane of infinite potential; $\mathbf{x}_{0}=$ distance between $S$ and $X ; \mathbf{r}=$ radius of hydrated ion; $d=$ halfdistance between the plates in $\AA ; m . c .=$ moisture content in $\mathrm{cm}^{8} / \mathrm{g} ; \mathrm{P}_{\text {od }}=$ pressure corresponding to $\mathrm{d}$ in the absence of incompressible pore space; $\mathrm{P}_{\mathrm{od}} \mathrm{d}^{\prime}=$ pressure corresponding to

$d^{\prime}=d\left(1+e_{0}\right)+\frac{e}{p S} ; P=$ pressure corresponding to $d$ in the presence of incompressible pore space for plate-hole matching.

more probable type of arrangement, was selected as the basis of calculations. This value corresponds with:

$$
P=\frac{1-e_{0}}{1+e_{0}} \cdot f \cdot\left(d+x_{0}-4\right)+\frac{2 e_{0}}{1+e_{0}} \cdot f \cdot\left(2 d+\frac{1}{2} A+x_{0}-4\right)
$$

in which $\mathrm{f} .\left(\mathrm{d}+\mathrm{x}_{0}-4\right)$ signifies the functional relationship between $\mathrm{P}$ and $\left(\mathrm{d}+\mathrm{x}_{0}\right.$ -4) according to Bolt's ideal case.

As at values of $d$, large compared with $\left(\frac{1}{2} A+x_{0}-4\right)$ and at $c_{0}=0$ $f\left(2 d+\frac{1}{2} A+x_{0}-4\right)=\frac{1}{4} f\left(d+x_{0}-4\right)$, one obtains in that case using $e_{0}=\frac{1}{2}, P=9 / 8$. $P_{o d}=\frac{1}{2} . P_{\text {od }}$. For systems containing salt its value must be evaluated numerically for

The curves shown in the four overlays (no's $3 a, 4 a, 5 a, 6 a$ ) were calculated according to the chosen arrangement employing a value of $e_{0}$ equal to $\frac{1}{2}$, corresponding with an incompressible pore space of $1 / 3$. A comparison with figures $3,4,5$ pore space. The difference $4 \AA$ correction had been applied, shows the influence of the the saturating cation and high salt pronounced at low specific surface, high valency of pressible pore space is felt the strongentration. Obviously the influence of incom- 
Fro. 3. Theoretical desorption curves of montmorillonite $\mathrm{v}=1$; surface area $=730 \mathrm{~m}^{2} / \mathrm{g}$

I, $c_{0}=10^{-\infty}$;

II, $c_{0}=10^{-4}$;

III, $c_{0}=10^{-\mathrm{s}}$;

IV, $c_{0}=5.10^{-3}$;

$\mathrm{V}, \mathrm{c}_{0}=5.10^{-2}$;

VI, $c_{0}=5.10^{-1} \mathrm{M}$.

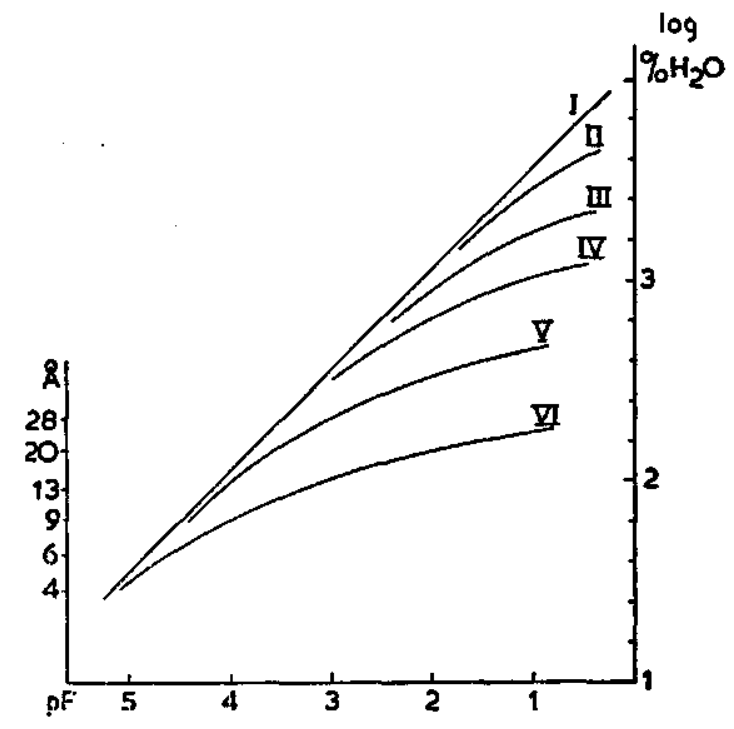

Frc. 4. Theoretical desorption curves for montmorillonite $\mathrm{v}=2$; surface area $=730 \mathrm{~m}^{2} / \mathrm{g}$

I, $c_{0}=10^{-\infty}$;

II, $c_{0}=10^{-4}$;

III, $c_{0}=10^{-8}$;

IV, $c_{0}=5.10^{-3}$

$\mathrm{V}, \mathrm{c}_{0}=5.10^{-2}$

VI, $c_{0}=5 \cdot 10^{-1} \mathrm{M}$.

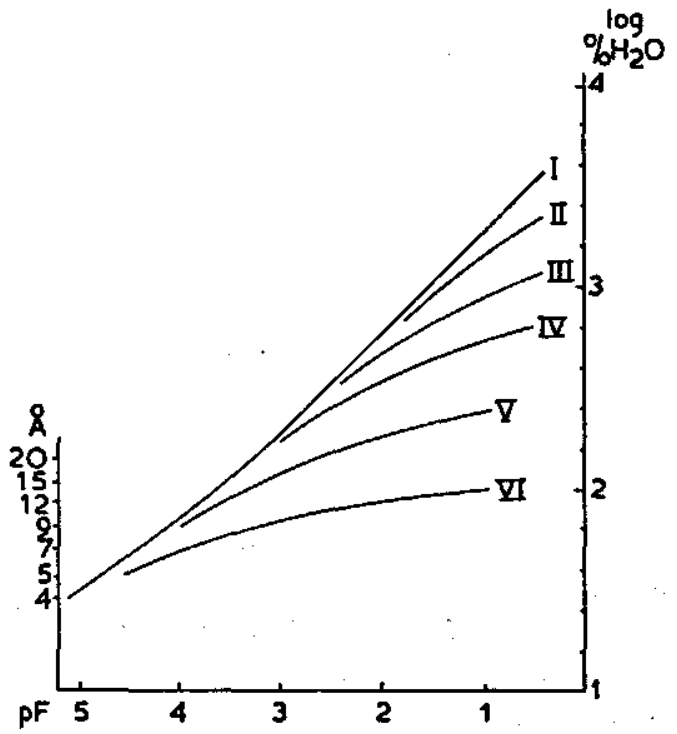




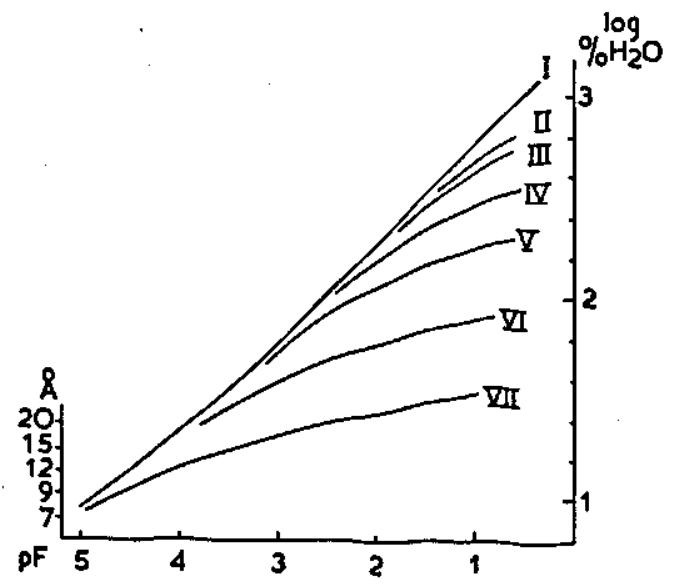

Fic. 5. Theoretical desorption curves for illite $v=1$; surfacearea $=120 \mathrm{~m}^{2} / \mathrm{g}$

$$
\begin{aligned}
\text { I, } c_{0} & =10^{-\infty} ; \\
\text { II, } c_{0} & =10^{-4} ; \\
\text { III, } c_{0} & =2.10^{-4} ; \\
\text { IV, } c_{0} & =10^{-8} ; \\
\text { V, } c_{0} & =5.10^{-3} ; \\
\text { VI, } c_{0} & =5.10^{-2} ; \\
\text { VII, } c_{0} & =5.10^{-1} \mathrm{M} .
\end{aligned}
$$

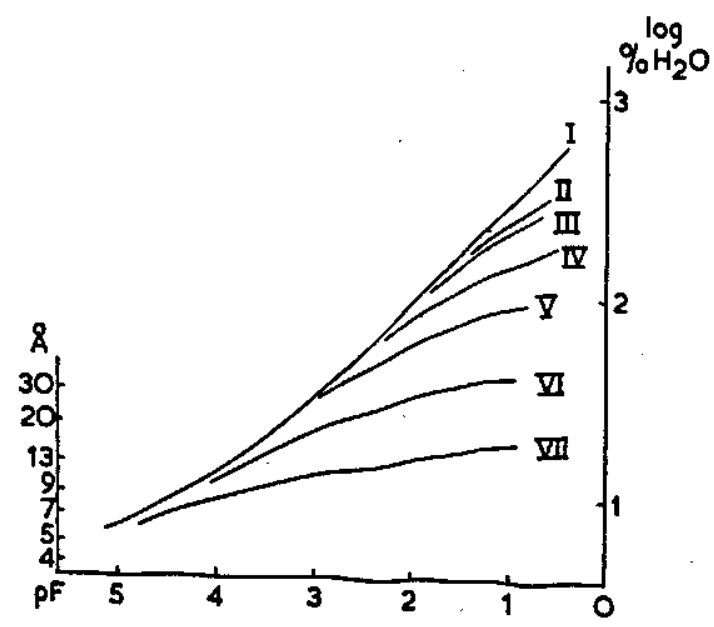

Fic. 6. Theoretical desorption curves for illite $\mathrm{v}=2$; surface area $=120 \mathrm{~m}^{2} / \mathrm{g}$

$$
\begin{aligned}
\text { I, } c_{0} & =10^{-\infty} ; \\
\text { II, } c_{0} & =10^{-4} ; \\
\text { III, } c_{0} & =2.10^{-4} ; \\
\text { IV, } c_{0} & =10^{-3} ; \\
\text { V, } c_{0} & =5.10^{-3} ; \\
\text { VI, } c_{0} & =5.10^{-2} ; \\
\text { VII, } c_{0} & =5.10^{-1} \mathrm{M} .
\end{aligned}
$$

\subsection{EXPERIMENTAL RESULTS}

\subsubsection{Montmorillonite}

2.5.1.1 Sodium bentonite in aquaeous solutions and in ethanol Comparing the desorption curve of the dialyzed suspension (cf. fig. 7) with the theoret-

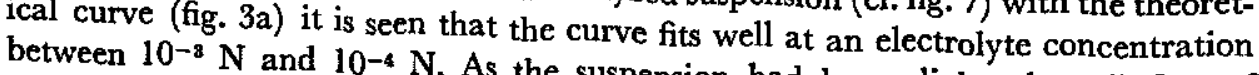
chloride it was expected that the desorptionsion had been dialyzed until free of below $\mathrm{pF} 1$. 
Fic. 7. Desorption curves for Nabentonite

(1) in $5.10^{-4} \mathrm{M}$;

(2) in $5.10^{-8} \mathrm{M}$;

(3) in $5.10^{-2} \mathrm{M}$;

(4) in $2.10^{-1} \mathrm{M}$;

(5) in $5.10^{-1} \mathrm{M}$;

(6) in $77 \%$ ethanol;

(7) data of MOONEY e.a.

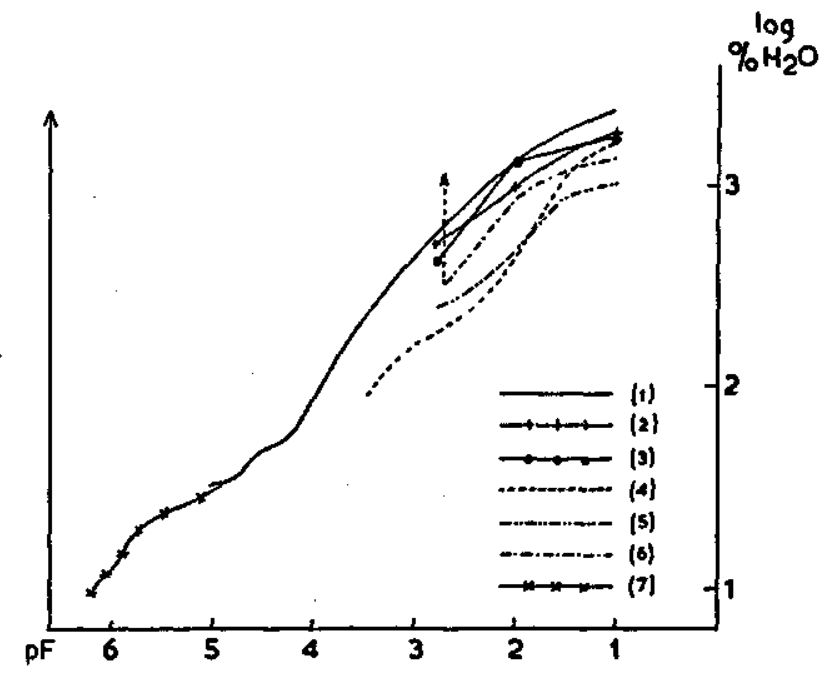

That the outside concentration was higher than expected may be caused by the part-solution of the clay mineral. Between $\mathrm{pF} 1.5$ and 3.5 the slope of the curve is in accordance with the theoretical one but it lies slightly above the latter (factor 1.32). This has been also found by WARKENTIN, Bolt and Miller. At suctions higher than pF 4.2 the deviation from the theoretical curve becomes pronounced, the theoretical moisture being higher. Near pF 5 the curve merges into that of MOONEY, KEENAN and WOOD (1953a). The steps in the last part of the desorption curve may have been caused by the stepwise desorption of successive waterlayers. The large step in the region of $\mathrm{pF} 4$ would represent a decrease in interplanar distance (2d) from 56 to $12 \AA$ if no allowance is made for pore space, and from 32 to less than $8 \AA$, if the pore space is $1 / 3$. The exact distance can not be ascertained if the pore volume is not exactly known. The above jump lies, however, in the region where Norrish (1954) found a sudden increase of interplate distance when the salt concentration was lowered below a critical value.

Thus it might indicate that other forces than those considered by the double layer theory become active in this region.

The swelling of sodium bentonite proved to be unlimited as was to be anticipated. Discs of dried sodium montmorillonite after three weeks of swelling at a suction of $10 \mathrm{~cm}$ of water, reached the same moisture content as the original suspension at that suction.

The influence of the salt concentration was also investigated. The shape of the curve of the $0.05 \mathrm{~N}$ suspension checks with theory except that the curve lies higher than might be expected. This last feature is also observed with the $0.05,0.2$ and $0.5 \mathrm{~N}$ suspensions.

Furthermore the form of the curves is more or less sigmoidal which may have been caused by the presence of a flock structure. The frame of the flocks would have to be compressed by the suction force when moisture is withdrawn. So in addition to the 
osmotic forces of the double layer the strength of the flock structure must be overcome if water is desorbed from flocculated suspensions. This explanation is confirmed by the fact that the reproducibility of the determinations decreased with increasing salt concentration.

In order to investigate whether the interplanar swelling of bentonite in dependance of the salt concentration as analysed by NORRISH, had also a macroscopic and readily measurable effect, the following experiment was carried out. Flakes of dialysed sodium montmorillonite, dried at $105^{\circ} \mathrm{C}$, were put into a series of beakers with decreasing concentrations of sodium chloride.

As is shown in photographs 3 and 4 the flakes retain their shape at electrolyte concentrations above $0.5 \mathrm{~N}$.

In the range from 0.4 to 0.2 . $N$ the sharp edges of the flakes seemed to fold open and the whole flake became an ill defined mass with blurred contours; the colour changing from yellow to whitish.

Further lowering of the concentration does not result in an observable alteration, until at concentrations below $0.01 \mathrm{~N}$ the clay did spontaneously go into suspension. The swelling of sodium bentonite in distilled water looks in the beginning very much like the swelling in about $0.2 \mathrm{~N} \mathrm{NaCl}$, but while the swelling in $0.2 \mathrm{~N}$ stops at a definite point, it continues in water, till the unit layers finally float away. This change has also been noted by MatTson, whose observations on the subject have been cited in the introduction. The change of the flakes into the blurred mass looking like a dense flock is well illustrated by the increase in moisture held at $\mathrm{pF} \mathrm{1.} \mathrm{(see}$ Fig. 8). In this figure the relation between the salt concentration and the moisture content at pF 1 is given.

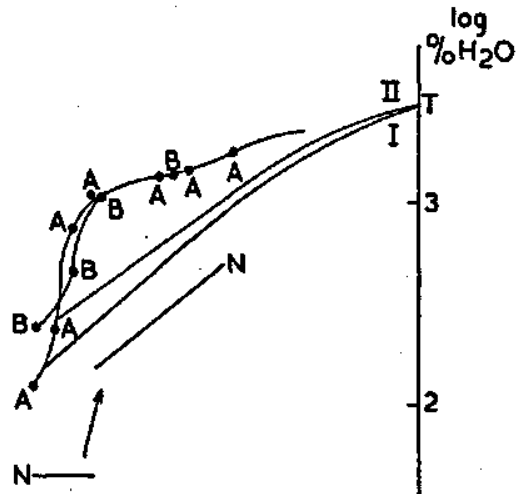

Fra. 8. Swelling of Na-bentonite in dependance of salt concentration

$A=$ flakes from dialyzed clay B = aggregates dried from $1 \mathrm{~N}$ solution

T-I $=$ theoretical curve, incompressible pore space absent T-II = theoretical curve, incompressible pore space present

$\mathrm{N}=$ derived from measurements of spacings (Norrish)

The salt concentration is represented on the abscissa on a logarithmic scale and is plotted against the $\log$ of the moisture content. The theoretical relationship, taken from fig. 3a, is also shown. The agreement between the two curves is poor, especially 
near $0.4 \mathrm{~N}$ the clay contains more moisture than predicted. In the same graph the moisture contents at different concentrations of sodium chloride as found by NORRISH are shown. The data were obtained from this authors fig. 5 by transforming the interlayer distance into moisture content.

A difficulty is that NORRIsH determined the interlayer distance in excess liquid, whereas the other graphs give the moisture content at $10 \mathrm{~cm}$ suction. Nevertheless the agreement with BoLTs curve is not bad though the moisture content is about 0.55 of the theoretical value. The only agreement between the authors and NorRIsH's curve is the sudden change, taking place here between 0.8 and $0.6 \mathrm{M}$, and in NorRISH's experiment at $0.4 \mathrm{M}$. The much higher moisture contents found by the author are most probably due to the effect of the change in structure from granule to flock, in addition to the rise in interplanar distance.

The moisture content at which this change of structure begins to manifest itself visually is too low, $(200 \%$ giving a mean distance of $50 \AA)$, to allow for a change in stacking of all the unit layers in the granule. It is more probable that within the package of unit layers, the polyplates, orientation is maintained while the orientation between the polyplates is changed. The orientation in the polyplates will be broken up gradually with proceeding dilution, the best oriented ones at the lowest concentration.

As the swelling pressure of a clay is proportional to the square root of the dielectric constant of the medium, the lowering of this constant may have a similar effect on the swelling of a clay as a rise of the salt concentration.

This was investigated by increasing the ethanol content of the distilled water in which flakes of dried sodium bentonite were immersed.

The suppressing action of ethanol was demonstrated by a preliminary experiment (photograph 5). Flakes of about $1 \mathrm{~cm}^{2}$ were put into a series of Petri dishes with ethanol water mixtures of increasing ethanol content.

The dimensions of the flakes were noted at different intervals. It proved that up to $57 \%$ ethanol the initial swelling was not much suppressed. In this concentration the flakes had changed after about 5 hours into lumps of gel. After 24 hours the clay in 0 and $19 \%$ ethanol had dispersed completely. With a concentration of 38 and $57 \%$ ethanol the gel like lumps were still in existence. With $67 \%$ the swelling resulted in some fragmentation after one day, with higher percentages no visible swelling occurred.

The swelling was also evaluated by determining the moisture content at $\mathrm{pF} 1$. The results were expressed as $\mathrm{cm}^{3} / \mathrm{g}$ and are reproduced by table 11 .

The theoretical values are only put in to show that the decrease of the moisture retention with decreasing dielectric constant is a gradual one. They do not necessarily apply to this case as the salt concentration will have been about $10^{-4} \mathrm{M}$.

It is seen again that there is a sharp transition in moisture content correlated with a change in aggregation from granule to lump of gel. This transition takes place near $70 \%$ ethanol. As the commanding factor changes only gradually, whereas an abrupt change is observed, it is probable that a barrier of some kind is present which must be surmounted by the swelling pressure before the latter can manifest itself. 
TABLE 11. Influence of ethanol on swelling of sodium bentonite

\begin{tabular}{clcc}
\hline $\begin{array}{c}\text { \% ethanol } \\
\text { (vol) }\end{array}$ & $\begin{array}{l}\text { diel. } \\
\text { const. }\end{array}$ & $\begin{array}{c}\text { liquid content at } \mathrm{pF} \mathrm{1} \\
\text { after rewetting }\left(\mathrm{cm}^{8} / \mathrm{g}\right)\end{array}$ & $\begin{array}{c}\text { theoretical value } \\
\text { (zero salt concentration) }\end{array}$ \\
\hline 0 & 81 & 19.40 & 37.90 \\
19.2 & 72.5 & 20.50 & 36.00 \\
38.4 & 62.7 & 19.70 & 33.60 \\
57.6 & 50.6 & 16.90 & 30.00 \\
76.8 & 39.1 & $0.609(13.42) *$ & 26.40 \\
86.4 & 33.6 & 0.702 & 24.60 \\
96 & 28.1 & 0.482 & 22.40 \\
\hline
\end{tabular}

* This sample was not dried, but was brought from water directly into the ethanol medium.

To demonstrate, that the formation of a diffuse layer by the cations is not prohibited once the crystals are separated, the following experiment was carried out. A suspension of sodium bentonite in $77 \%$ of ethanol was prepared by stirring a $3 \%$ clay suspension with enough ethanol to obtain the ethanol content desired. Part of the $\mathrm{pF}$ curve was obtained which is shown in fig. 7. The liquid content of the suspension at $\mathrm{pF} 1$ (table 11) is of the same order as that of gels obtained by letting the flakes swell at lower ethanol contents.

The desorption curve is very similar to that of the sodium bentonite in 0.05 $\mathrm{M} \mathrm{NaCl}$. The backswelling from $\mathrm{pF} 2.7$. is strong (neariy the original value at $\mathrm{pF} 1$ ), in consequence it may be anticipated that sodium bentonite in $77 \%$ ethanol is an elastic colloid up to high suctions, above which its elasiticity will be limited.

\subsubsection{Potassium bentonite}

A homoionic suspension of this clay was prepared by the dialysis procedure.

The desorption curve (not reproduced) coincides best with the theoretical curve without free pore space, concentration $10^{-3} \mathrm{M}$.

The part between $\mathrm{pF} 1$ and 2.5 lies slightly higher than the theoretical one (factor 1.2); between $\mathrm{pF} 2.5$ and 4.5 the theoretical curve is crossed and at higher suctions it coincides with the curve of MOONEY, KEENAN and WOOD (1953a). A stepwise dehydration is not observed, except near $\mathrm{pF} 6.4$.

As dried potassium bentonite attained its initial moisture content when allowed to absorb moisture against a suction of $100 \mathrm{~cm}$, the conclusion was drawn that it behaved like an elastic gel.

Also the potassium bentonite was left to swell in a series of potassium chloride solutions of decreasing concentrations. A previous observation that granules of potassium bentonite lose their shape only at low concentrations was confirmed. This took place between 0.025 and $0.01 \mathrm{~N}$. The data are represented by fig. 9 .

The curve lies below the theoretical curve. It does not agree at all with NorRIsH's data for potassium bentonite which would yield a line parallel to the abscissa. In comparison with the curve of sodium bentonite a shift of nearly 1.5 logarithmic units has occurred to the right. The change of sodium bentonite from a granule into a flock takes place at $0.5 \mathrm{~N}$, whereas that of potassium bentonite occurs at $0.017 \mathrm{~N}$. The 


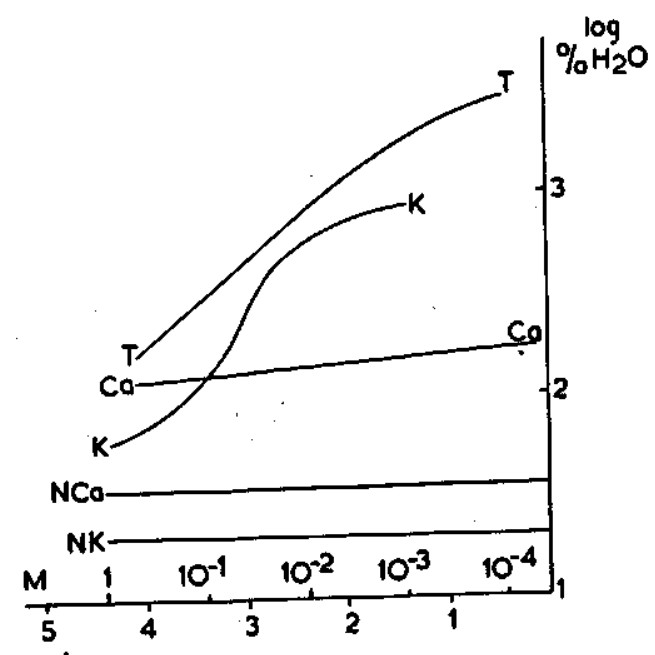

$\log$ RTCO $^{+}$

Fig. 9. Swelling of K- and Ca-bentonite in dependence of salt concentration

$\mathrm{K}=$ flakes of $\mathrm{K}$-bentonite $\mathrm{Ca}=$ flakes of Ca-bentonite $\mathrm{T}=$ theoretical curve $\mathrm{v}=1$, incompressible pore space absent $\mathrm{NCa}$ and $\mathrm{NK}$, derived from measurements of spacings (NORRISH), for $\mathrm{Ca}$ - and $\mathrm{K}$ bentonite respectively

moisture content in the steepest part of the curve is the same: about $400 \%$ giving a distance of about $100 \AA$, but with sodium bentonite the change starts at a lower moisture content.

From these experiments the conclusion can be drawn that the saturation of the clay by potassium decreases its susceptibility to dispersion compared with sodium.

\subsubsection{Calcium bentonite}

The agreement of the desorption curve of the calcium bentonite (Fig. 10) with the theoretical one $\left(10^{-3}-10^{-4} \mathrm{M}\right.$, no pore space) must be fortuitous. This is seen by the arrows indicating the amount of backswelling after previous equilibration at increasing suctions, (cf 2.3.2). It is seen that this back-swelling is limited by some unknown force or forces, which should also influence the desorption curve. As the desorption proceeds the lesser becomes the amount of back-swelling, the difference in swelling between a paste with a moisture-content of $30 \%$ and an ovendry sample being negligible. This swelling in distilled water gave a visible increase in volume but no marked change in the shape of the particles. From these experiments, which are quite in accordance with those of WARKENTIN, BoLT \& MILLER (1957), it follows that calcium montmorillonite behaves like a semi-elastic gel.

The last part of the desorption curve nearly coincides with that of MooNEY KeENan \& Wood, (1953 a).

Raising the calcium chloride concentration resulted in an increased moisture content at low suctions, the higher the salinity the higher this moisture content became. The reproducibility of the determinations decreased thereupon as was the case with sodium bentonite. With sodium bentonite the deviation from the theoretical value increased also with increasing salt content, but compared with the dialyzed suspension the moisture content was lowered, whereas in the case of calcium bentonite the mois- 
ture content was increased upon salt additions. The calcium ion seems to give rise to a more open or stable type of flocculation.

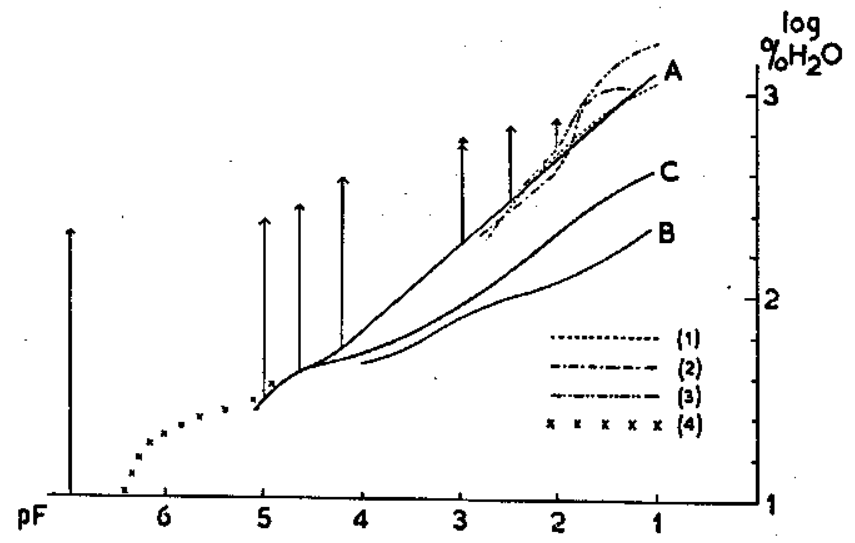

Fic. 10. Desorption and backswelling characteristic of Ca-bentonite $\mathrm{A}=$ dialyzed suspension; (1) in $0.0025 \mathrm{M}$; (2) in $0.025 \mathrm{M}$; (3) in $0.25 \mathrm{M}$; (4) data of MOoney e.a.

$\mathrm{B}=$ granules; $\mathrm{C}=$ slurry

Curve B (Fig. 10) is the desorption curve of ovendried granules which had swollen during 24 hours in distilled water. The granules were the remnants of the moisture-determinations at various suctions. Though the granules increased in volume and became rather weak, they did not lose their form or disperse spontaneously. The slope of this desorption curve is much weaker than that of the suspension. The moisture content at low suctions is much lower but it must be the same or nearly so at high suctions, as there the hydration of the cations begins to determine the moisture content which is then equal for the suspension and the granules. 2.3.2.

From the dried bentonite a slurry was prepared by the procedure outlined in

There was little difference in settling between the original suspension and the

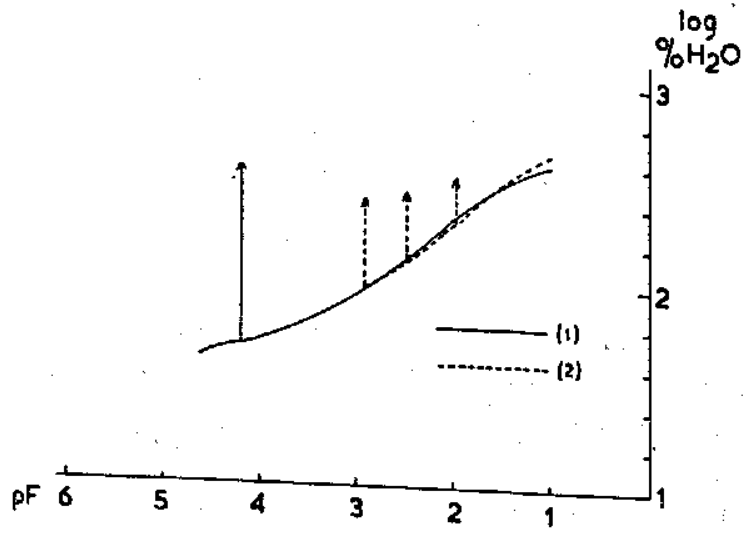

Fre. 11. Desorption and backswelling characteristic of $\mathrm{Ca}$ bentonite slurries

(1) slurry in $0.0001 \mathrm{M}$

(2) slurry in $0.001 \mathrm{M}$ 
slurry. Both had a whitish colour and from both some material settled out after prolonged standing. The desorption curve of the slurry is shown in fig. 10 curve $\mathrm{C}$ and in fig. 11. Though it is doubtful whether comparison with the theoretical curve is permitted, the low suction part of the desorption curve coincides with the $0.001 \mathrm{M}$ line after lowering the abscissa by 0.34 logarithmic moisture units, which might mean that the surface has been diminished with regard to swelling by a factor 2.2 from 800 to $366 \mathrm{~m}^{2}$. The back-swelling of the slurry deviates from that of the dialyzed suspension as it swells back to its original water content as determined at $\mathrm{pF} 1$, going into suspension during the swelling. Only at suctions above $\mathrm{pF} 4.2$ does the slurry lose its elasticity.

If the salt concentration was raised to $0.001 \mathrm{M}$ the suspension became semi-elastic as is seen by the dotted arrows in fig. 11.

From these experiments it follows that a slurry of calcium bentonite which represents the highest degree of dispersion in agricultural practice, has the character of a system which is elastic over a certain range of suctions but which loses its elasticity if higher suctions are employed and then becomes semi-elastic.

This experiment was repeated with another Wyoming bentonite, this time a finely ground sample. It had been calcium saturated by passing it as a $0.5 \%$ suspension through a calcium resin column. The conductivity was lowered by rotating the suspension with hydroxyl resin until the $\mathrm{pH}$ rose to 9 , and then with hydrogen resin till the $\mathrm{pH}$ fell to 6 , and so on until further treatment gave no lowering of the conductivity. The ultimate conductivity of the suspension was equivalent to $0.5 \times$ $10^{-4} \mathrm{M}$ calcium chloride and the $\mathrm{pH}$ 8.3. The desorption and swelling are shown in fig. 12, which does not differ appreciably from fig. 10 , only the difference between the

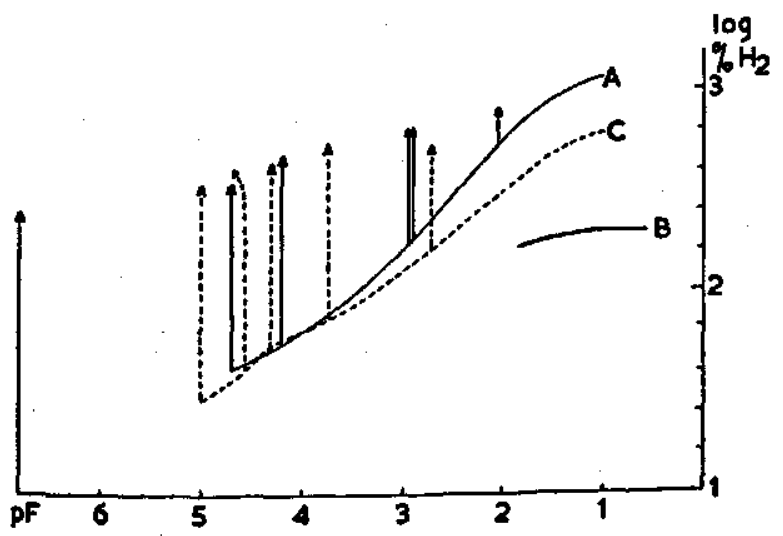

Frg. 12. Desorption and backswelling characteristic of resin prepared Ca-bentonite

$\mathrm{A}=$ suspension in $0.5 \times$

$10^{-4} \mathrm{M}, \mathrm{pH} 8.3$

$\mathrm{B}=$ oriẹnted granules

$\mathrm{C}=$ slurry in $0.87 \times 10^{-4}$ $\mathrm{M}, \mathrm{pH} 8.5$

swelling from $\mathrm{pF} 5$ and ovendry is a bit larger. (This observation is of some importance as it shows that the way of preparation is not very influential provided that high acidity is avoided).

The $0.5 \%$ slurry was prepared by vigorous stirring of a paste of the same clay which had been desorbed by a pressure of 4 atmospheres ( $\mathrm{pF} 3.6$ ). 
The conductivity was lowered in the same way as that of the suspension, the concentration being $0.87 \times 10^{-4} \mathrm{M}$, the $\mathrm{pH}$ 8.5. The desorption and swelling are shown in fig. 12. Though the stirring had been vigorous the moisture content at low suctions was only about half the moisture content of the suspension, which might indicate that the active surface had been reduced during the previous desorption by a factor 2. The reduced surface can not be increased to its original value by mechanical manipulations, though the compressive force had been low compared with complete drying. Up to suctions of $\mathrm{pF} 4.2$ the pastes went into suspension and the swelling was consequently not lowered. After desorption at $\mathrm{pF} 4.2$ the paste remained intact in excess of liquid. It is interesting to observe that at pF 4.5 the back-swelling of the slurry exceeds the back-swelling of the suspension.

As AyLmore \& Quirk (1959), studying the uptake of water by dry calcium bentonite, found only a moisture content of $91 \%$, whereas here $200 \%$ was found on desorption, some investigations were made into the matter. Because a difference in degree of orientation within the granules may play a role, oriented granules were made by partial dehydration of the resin prepared suspension on a Göttingen membrane (suction $0.5 \mathrm{~atm}$.) and ovendrying. The granules were left to swell at $\mathrm{pF} 1$ on the membrane for different periods; after 3 days the clay contained $106.5 \%$ of moisture, after 18 days $167 \%$ and after 60 days $163 \%$. After 60 days swelling at pF 1 the other half of this sample was inundated for 2 days and then equilibrated at $\mathrm{pF} 1$ for another 2 days; the moisture content was $210 \%$.

Another batch of these granules was allowed to swell at pF 1, inundated for 24 hours and then equilibrated with various suctions for another 24 hours. The results are represented as curve B in fig. 12. It nearly coincides with curve B, fig. 10, where unoriented samples had been used.

As the moisture content of the inundated samples at $\mathrm{pF} \mathrm{1,} \mathrm{was} \mathrm{nearly} 200 \%$, while the not inundated samples obtained only a moisture content of $165 \%$, there exists a substantial hysteresis, which will be due to internal friction hampering expansion and shrinking.

Accordingly with calcium bentonite at least three main types of aggregation are distinguished (exempting the flocks), which may be simultaneously present at the same low electrolyte concentration. The first is represented by the original suspension, made by changing the sodium clay into a calcium clay without drying; it behaves ike a semi-elastic gel. The second is the dried bentonite which shows a limited swelling, like a normal soil. The third type is the slurry, made from dried clay, which may be regarded as the maximum of dispersion to be encountered in agricultural practice; it behaves like an elastic gel up to suctions between pF 4 and 5 .

Tentatively the differences in moisture characteristic may be explained as follows. In the original suspension the clay crystals are united into relatively thin polyplates consisting of stacks of 3-4 clay crystals (cf. BLACKMORE \& MILLER, 1961). These polyplates increase in thickness with increasing suction, after ovendrying and
rewetting they form a coherent mass.

The swelling between the crystal is limited to $10 \AA$. That the swollen clay con- 
tains more water than corresponds with the $10 \AA$ spacing, pore space of $1 / 3$ included, may be caused by the air entrapped and compressed in the voids, which may increase the swelling pressure. During the preparation of the slurry the aggregates are broken up into polyplates, which will be thicker than those of the original suspension; the outer surface, on which the osmotic swelling takes place, will be relatively smaller, hence the water retention at low pressures will be lower. Further explanation will be given in part $\mathrm{V}$.

The salt concentration has little effect on the swelling of the dried clay, as was to be expected. The data are represented in fig. 9, together with those deduced from NORRISH's measurements.

\subsubsection{Margalite colloid}

\subsubsection{Sodium margalite colloid}

The slope on the curve is in good accordance with the theoretical curve for bentonite, but it lies a factor $1.38 \mathrm{low}$, which would represent a reduction of $31 \%$ of the surface. This is in good accordance with the surface of $530 \mathrm{~m}^{2} / \mathrm{g}$. The swelling of this clay is not limited. Ovendry clay left to swell in excess of moisture holds the same amount of water at $\mathrm{pF} \mathrm{l}$ as the original suspension.

The influence of the salt concentration on the swelling is shown in fig. 13. The curve fits the theoretical one very closely. The agreement with NORRISH's determinations corrected for the smaller surface, is partly rather good though the values are 1.7 too high except near one molar concentration, where the moisture content is $\mathbf{4 . 6}$ times the amount derived from NoRRISH's measurements.

Fic. 13. Swelling of margalite colloids in dependence of salt concentration

$\mathrm{Na}$, granules of Na-margalite colloid

$\mathrm{K}$, granules of K-margalite colloid

$\mathrm{Ca}$, granules of Ca-margalite colloid

$X$ theoretical value for $v=1$.

$\mathrm{NNa}, \mathrm{NCa}$ and $\mathrm{NK}$ derived from measurements of spacings (NoRRish) for $\mathrm{Na}, \mathrm{K}$ and Ca-bentonite respectively

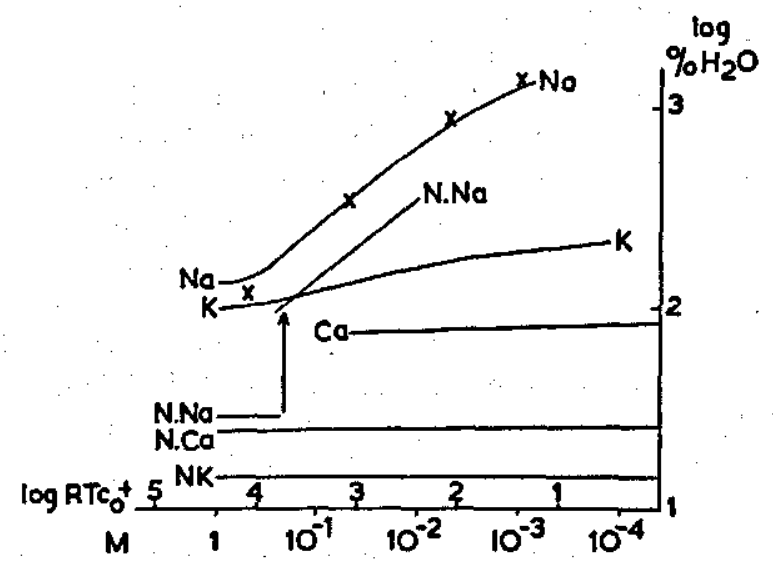

In contrast to the sodium bentonite the margalite did not show appreciable changes in structure, which explains the more regular proceeding of the swelling, and the better fitting with the theoretical curve. 


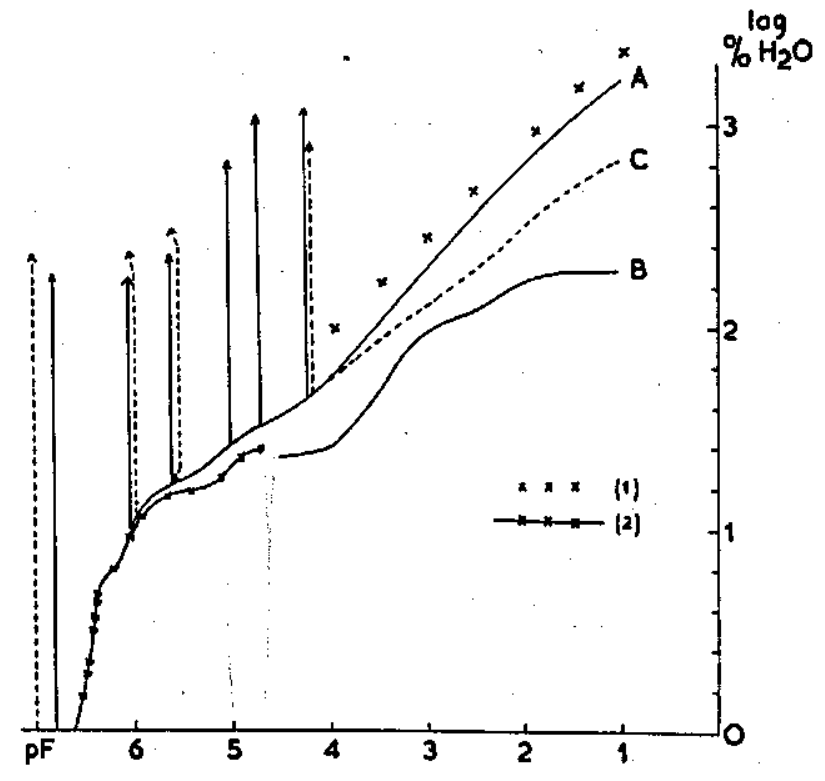

Fig. 14. Desorption and backswelling characteristic of K-margalite colloid
A. suspension
(1) theoretical values $(\mathrm{e}=1 / 3)$
(2) values obtained by equilibration with sulphuric acid
B. granules
C. slurry

\subsubsection{Potassium margalite colloid}

The desorption curve of the potassium margalite, shown in Fig. 14, lies a factor 0.79 lower than the theoretical curve for a surface of $530 \mathrm{~m}^{2}$. Some points of the theoretical curve have been indicated by crosses in this graph. The agreement of the desorption curve, using sulphuric acid, with the points determined with the aid of a saturated salt solution ( $\mathrm{pF} 5.6$ and 6.01) is rather good. This part of the curve has the shape of that of sodium bentonite.

The swelling of the clay is not decreased by suctions up to $\mathrm{pF} 4.7$, by equilibration with $\mathrm{pF} 5$ a small reduction occurred while most of it was completed after equilibration with $\mathrm{pF} 5.6$, equivalent to a decrease in moisture from 27 to $17.5 \%$.

The surface area being $530 \mathrm{~m}^{2} / \mathrm{g}$ this moisture loss is equivalent to a decrease in interparticle distance from 10.1 to $6.6 \AA$, if no allowance is made for incompressible porespace.

So potassium margalite suspension behaves like a completely elastic system, till a certain moisture content is reached. If dehydration is continued the elastic system changes within the range of a few percent of moisture into a semi elastic system.

The desorption curve of the clay granules is shown by curve $B$.

An interesting feature is that the moisture content of the granules depends on temperature. This is shown by fig. 15. Granules of the colloid were allowed to swell in distilled water of different temperasharp rise in the moisture 5 days, the experiment was repeated with a swelling period of 14 days. The ling. Even at $90^{\circ} \mathrm{C}$ the granules between 5 and $30^{\circ} \mathrm{C}$ is in accordance with the visible increase in swelnearly the same as that of the slury. not go into suspension though the moisture content at pF I was or granules of calcium bentonite, but there was of temperature could be detected on sodium bentonite 
Fig. 15. Swelling of K-margalite granules in dependance of temperature

- 5 days swelling

+14 days swelling

$x$ clay containing organic matter

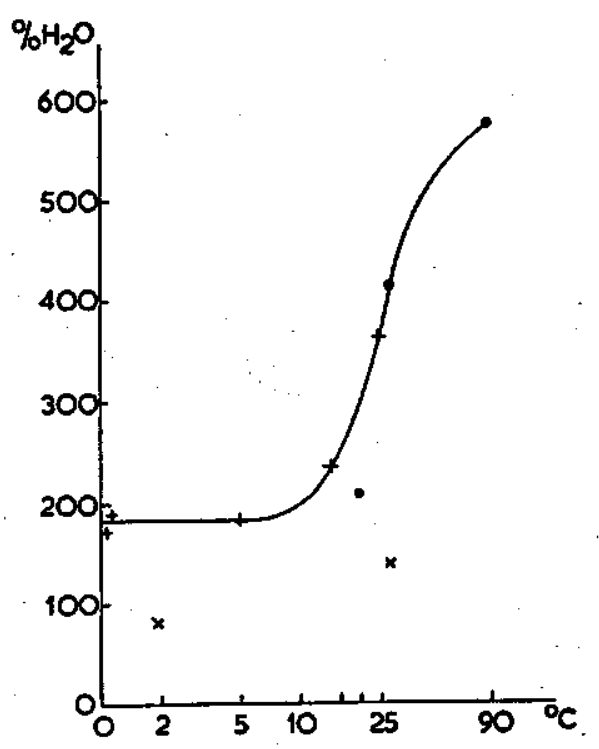

The slurry (fig. 14, curve $\mathrm{C}$ ) contains at low pressures about half as much water as the original suspension, but at higher suctions the differences decrease, and the same moisture content is reached near $\mathrm{pF} 4$. The number of determinations was too small to determine whether the backswelling of the slurry differs from that of the suspension.

As the swelling of the dry potassium margalite is limited the influence of the salt concentration is slight, as is shown in fig. 13. There is no relation with the theoretical curve, but some conformity with the swelling of NoRRISH's potassium bentonite.

\subsubsection{Magnesium margalite colloid}

The properties of this colloid were not studied extensively, just enough to make sure that there exist no major differences in the behaviour of the magnesium saturated colloid with the calcium saturated one. The desorption curve lies considerably lower than expected from the desorption curve of sodium margalite and the slope is not quite steep enough. The decrease in swelling is very marked, the minimum swelling is already obtained at a pF below 4.3, whereas the minimum for calcium bentonite lies beyond pF 5 . So the magnesium margalite is a less elastic system than the calcium bentonite.

\subsubsection{Calcium margalite colloid}

The desorption curve of this colloid is shown in fig. 16, curve A. The decrease of swelling by progressing dehydration is marked, and the maximum reduction of swelling is reached near pF 5. The clay adsorbs in this state less moisture than from the dry state probably because in the latter case some mild form of air explosion takes place and some water is held between the resulting small particles. The desorption curve of the granules is shown by curve $B$. 


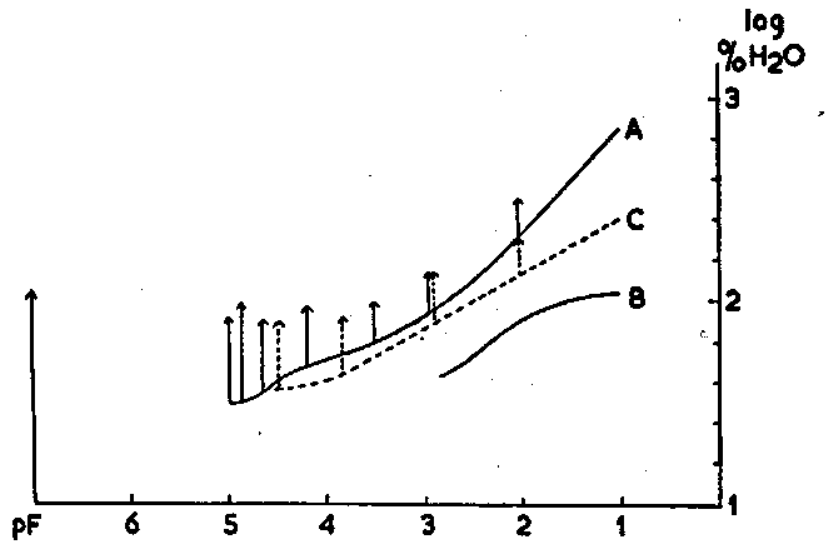

Frc. 16. Desorption and backswelling characteristic of Ca-margalite colloid

A. dialyzed suspension

B. granules

C. slurry

The slope of the desorption curve of the slurry (curve $\mathrm{C}$ ) is less steep. The swelling of the desorbed slurry has some resemblance with that of the calcium bentonite in so far as, in order to limit the swelling of the slurry, higher suctions have to be applied than with the original suspension. With calcium margalite this limitation begins already at $\mathrm{pF} 3$, but with calcium bentonite only at $\mathrm{pF}$ 4.2. So calcium margalite behaves like a semielastic system and also the slurry has largely this character.

The swelling of calcium margalite granules in solutions of calcium chloride was also investigated. This influence was small as might be anticipated. The line is shown in fig. 13. Except for the higher moisture content it resembles the curve derived from NORRISH's measurments of calcium bentonite.

\subsubsection{Comparison of the margalite colloid with the bentonite}

Though the desorption curve of the sodium margalite makes it probable that the clay belongs also to the smectites, the following important differences are apparent.

The potassium margalite behaves like a gel with a limited elasticity, this limitation occurring at suctions higher than pF 5. The swelling of the dry potassium clay is limited, while the swelling of the potassium bentonite is unlimited. The calcium margalite behaves like the montmorillonite but the elasticity is lower especially that
of the slurry.

\subsubsection{Sodium margalite}

\subsubsection{Margalite soil}

Since the sodium humus dissolves partly in water if the salt concentration is lowered and not in ethanol, the only way to prepare salt free sodium soils is by leaching the excess salt with ethanol. Even so some organic matter is lost by diffusion through the sintered glass during equilibration at $\mathrm{pF} 2$.

As the desorption curves of margalite soil were established at the beginning of the of limited accuracy.

The desorption curve of the sodium margalite soil is shown in fig. 17, curve $I$. The 
Frg. 17. Desorption and backswelling characteristic of Naand $\mathrm{K}$-margalite

I. Na-margalite soil

IIB. K-margalite soil granules

IIC. K-margalite soil slurry

IIIA. suspension of $\mathrm{K}$ margalite $<2 \mu$

IIIB. granules of $\mathrm{K}$ margalite $<2 \mu$

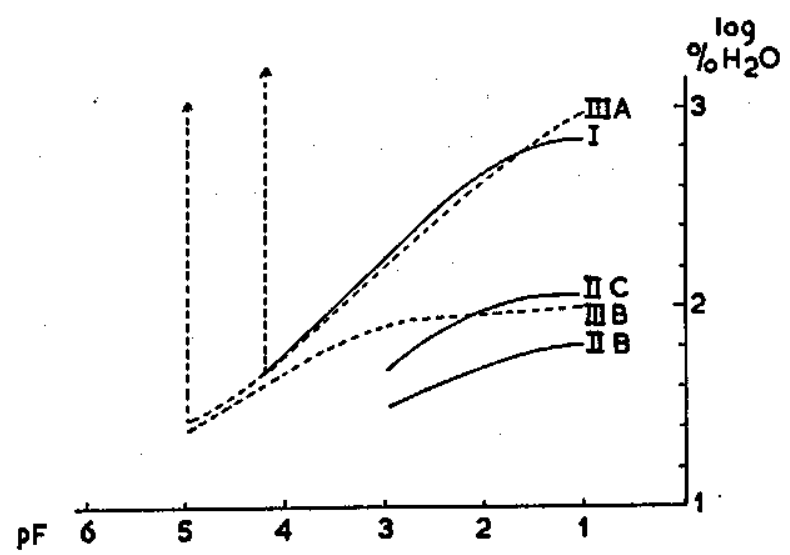

water content at different suctions is about 50 to $70 \%$ of that of the colloid, which does not quite fit with the reduction in clay content. If the ovendry sodium soil was left to swell in distilled water the moisture content at $\mathrm{pF} 1$ was the same as that of the suspension, prepared by boiling the alcohol washed sodium soil in excess of water. So the sodium margalite soil behaves like an elastic system and there is no marked difference in behaviour between the isolated clay fraction and the soil.

\subsubsection{Potassium margalite}

During the preparation of salt free granules of the potassium soil by washing with distilled water it became apparent that potassium humates diffused out of the granules while the latter remained intact. In fig. 17 parts of the desorption curve of the slurry (II C) and the granules are shown (II B).

The difference in moisture content between the potassium soil and the potassium colloid is much larger than the difference, between the sodium soil and the sodium clay.

The potassium soil granules contain at $\mathrm{pF} 1$ only 0.33 times the amount of water the colloid granules can hold. The slurry of the soils holds only $19 \%$ of the water the colloid-slurry holds.

These differences are very large. They may either be attributed to the organic matter, or to the better orientation of the clay plates within the polyplates of the soil granules, compared with that in the clay granules. In the soil granules the original stacking will have been preserved during the preparation of the potassium soil, but it will have been lost during the preparation of the potassium colloid suspension.

In order to investigate which of these causes is preponderant, a dialyzed suspension of potassium clay fraction with the organic matter was prepared.

\subsubsection{Potassium margalite smaller than 2 micron}

The suspension was prepared from the clay fraction of sodium margalite soil, which had been freed of the coarser particles by sedimentation. This suspension was washed with normal potassium chloride and then dialyzed. Though part of the organic matter was lost during the preparation, the difference in watercontent at low suctions 
between the clay granules containing organic matter (fig. 17, curve III B) and the granules without, is still large, the organic matter reducing the moisture content by $50 \%$. At $\mathrm{pF} 1$ the soil granules contain about $70 \%$ of the moisture the clay contains, which may be explained by the difference in clay content.

So it is probable that the small organic fraction has a large influence on the swelling of the granules. It also reduces the influence of temperature (fig. 15). The organic matter has a rather small influence on the desorption curve of the dialyzed clay suspension (curve IIIA) and does not change the range over which limitation of the swelling occurs.

\subsubsection{Calcium margalite soil}

As the original soil is chiefly saturated with calcium (table 4) it was not considered necessary to change it further.

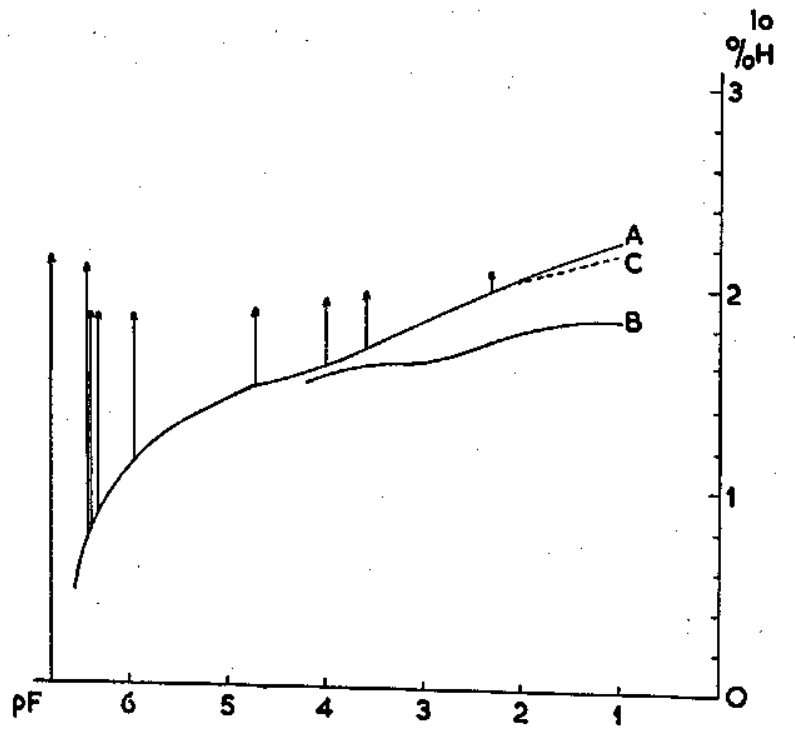

Fic. 18. Desorption and backswelling characteristic of $\mathrm{Ca}$ margalite soil
A. slurry
B. dried and slowly moistened granules C. ovendry granules im- mersed

The desorption curve of the slurry is shown in fig. 18, curve A.The slope has no relation with the theoretical value. The decrease in swelling in relation to the water desorption is marked, the swelling varies little in the region between pF 5 and 6.3 but it increases again after equilibration with higher suctions. This increase of moisture adsorption coincides with a change in colour of the soil from black to gray (from

The entry of air into the small pores is thought to be the main cause of this effect, which is accompanied by a rapid and enormous swelling leading to near total des-
integration of the granule.

This phenomenon observed first by Cernuda, Smith \& Chandler (1954), is thought to be caused, by the replacement of air, adsorbed to the internal surface of the granule, by water. Together with the gas present it is compressed by the same 
force by which the water is adsorbed unless some large pores exist through which air can escape. The entrapped and compressed air will try to expand, by moving the walls further apart. The bonds between the polyplates or units of them may consequently be broken and these particles separated completely. More moisture may be adsorbed and retained due to the expanding force of the air bubbles which try to accept the spherical form. Photograph 6 and 7 illustrate this phenomenon in its extreme form which is called 'air explosion'. It is observed as slaking with some other clays, but usually the resulting particles are too big (or the increase in unlimited absorbing surface is too small) to give a marked increase in moisture content at $\mathrm{pF} 1$.

The desorption curve of the air dry margalite soil after sudden immersion is shown by curve $\mathrm{G}$, fig. 18 . It closely resembles that of the slurry.

The air explosion is only observed if the soil is saturated with divalent cations.

Comparing the moisture contents at $\mathrm{pF} 1$ of the slurry and granules of the calcium soil with those of the calcium clay, one finds that the soil contains about $65 \%$ of the amount of water the clay holds, which agrees with the amount of silt and sand.

\subsubsection{Conclusion}

The behaviour of the soil is essentially in accordance with the behaviour of the colloid isolated from it, though the swelling of the potassium soil is more repressed than that of the clay, probably due to organic matter. If air is allowed to enter the granules of calcium soil it suffers extreme swelling after immersion (air explosion) which is not observed with the clay.

\subsubsection{Fithian illite}

\subsubsection{Sodium colloid, with and without the original organic matter}

The $\mathrm{pH}$ of the carbon containing suspension was 9.6 and the salt concentration as sodium carbonate $0.0026 \mathrm{~N}$, while these values were for the carbon free suspension 8.13 and 0.0014 respectively. The desorption curves are shown in fig. 19. The agreement between the two curves is bad. The carbon containing suspension shows some resemblance with the theoretical curve, cf. overlay $5 \mathrm{a}$, in the concentration region

FIG. 19. Desorption and swelling of Na-illite (Fithian)

(1) colloid

(2) clay fraction with organic matter

(3) data of Bolt $<0.1 \mu$ in $0.0002 \mathrm{M}$

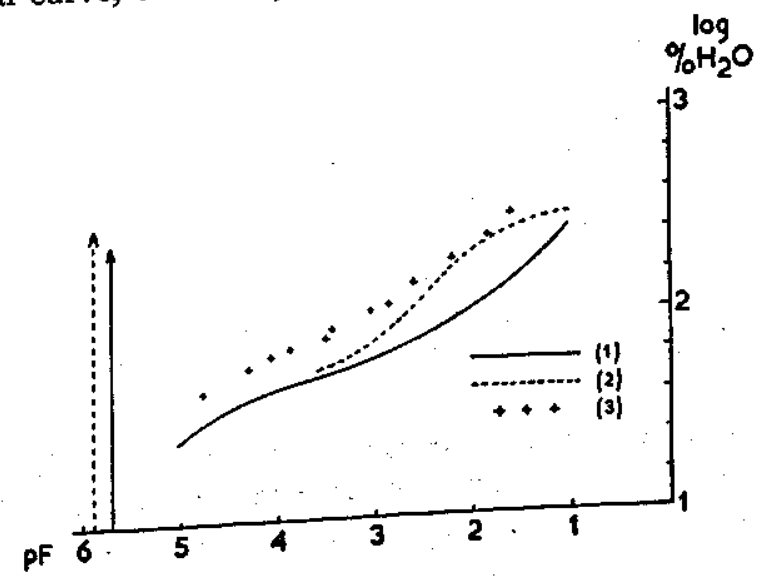


between 0.001 and $0.005 \mathrm{M}$. It lies slightly higher which agrees with the slightly higher surface.

The curve of the carbonfree suspension does not fit the theoretical line. As the pastes were highly thixotropic at $\mathrm{pF} \mathrm{I}$ and 1.5 , the interpretation of this part of the $\mathrm{pF}$ curve is questionable.

The theoretical and empirical curves flatten out at the same moisture level, indicating that the correction for free space is in the right order of magnitude.

BoLT's curve (1954) lies a factor 2 higher, which may be caused by the different technique he used.

The dried sodium clay did disperse spontaneously after immersion and contained the same amount of water at $\mathrm{pF} 1$ as the original suspension, so the sodium illite behaved like an elastic system.

The swelling of the ovendry carbon containing illite is abnormal. At first it behaves like a clay with a limited swelling. After submersion in distilled water, the larger granules break apart into smaller ones and adsorbed air escapes but the shapes remain distinct and the edges sharp. After half an hour or longer some of the granules start to desintegrate, light grey clay suspension diffusing from them, while other granules remain unchanged. It may take more than twelve hours before all the granules desintegrate in distilled water.

The influence of the salt concentration on the swelling of illite is illustrated by fig. 20. The faint slope of the curves may be explained by the relatively large free

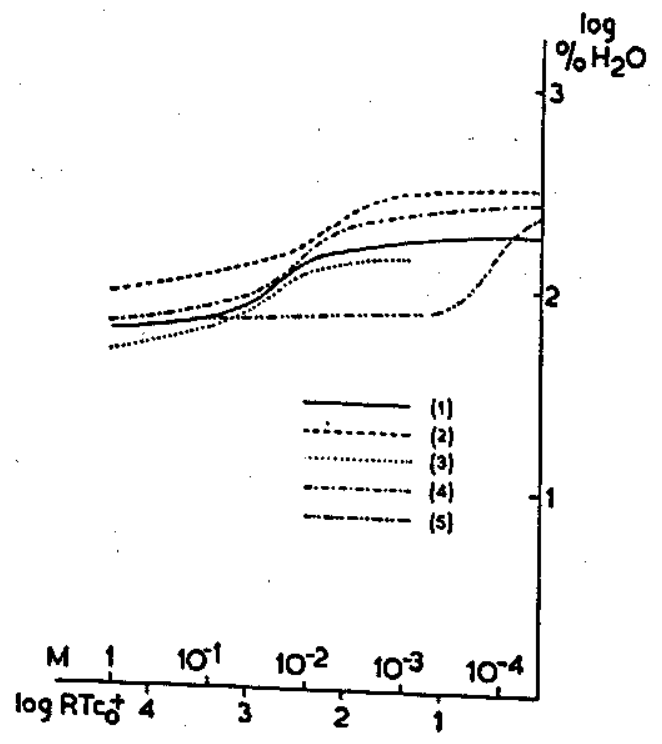

Fro. 20. Swelling of illite (Fithian) colloid in dependence of salt concentration

(1) Na colloid 2nd batch

(2) and (3) $\mathrm{Na}$ clay fraction organic matter present, 1 st batch and 2nd batch resp.

(4) K colloid 2nd batch

(5) Ca colloid 2nd batch

space. The stepwise swelling is in accordance with the visible desintegration the gra-
nules suffer on low nules suffer on lowering of the concentration; with the colloid free of organic matter this desintegration occurs at a salt concentration slightly lower than $0.01 \mathrm{M}$, with 
the organic matter containing colloid this occurs between 0.01 and $0.001 \mathrm{M}$. One may therefore conclude that the organic matter, in this particular case, decreases the susceptibility to peptisation.

\subsubsection{Potassium illite}

The desorption curves of the clay colloid were determined (fig. 21) Curve A represents the desorption of the fraction smaller than 2 micron, the salt concentration

Fic. 21. Desorption and swelling of K-illite (Fithian)

$\mathrm{A}=<2 \mu$;

$\mathrm{B}=<0.13 \mu$

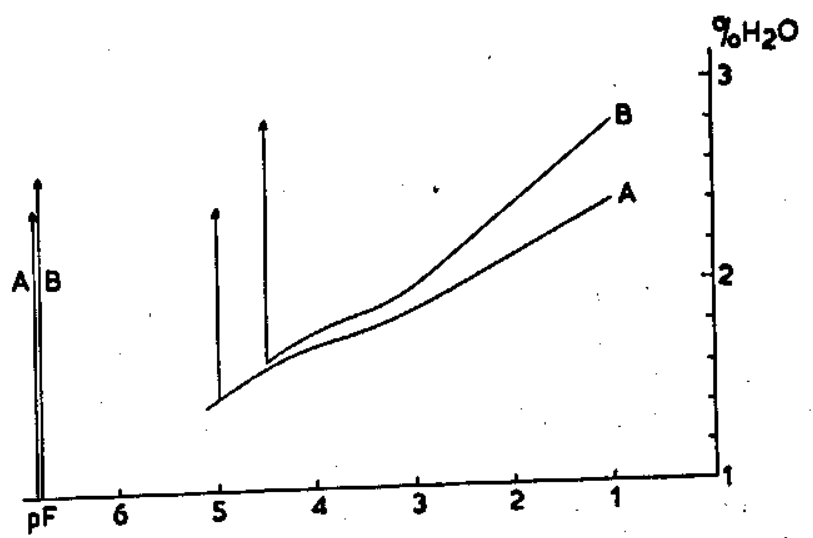

being $0.001 \mathrm{M}$ the $\mathrm{pH} 7.3$. The fraction smaller than 0.13 micron was separated by centrifugation (curve B), the concentration will have been slightly lower, the pH 7.7. As the pastes at low suctions were strongly thixotropic, the moisture content near pF 1 will be too high. The two curves resemble one another, but the slope of the curve of the finest clay is steeper. This may be explained by the higher surface of this fraction.

Though ovendry granules of both clays disperse completely after immersion, the suspension of the finest clay became coarser as can be seen from the increased scattering of light and from the decrease in moisture the clay holds at $\mathrm{pF} 1$. Before drying the finest clay holds $595 \%$ moisture at $\mathrm{pF} \mathrm{1,} \mathrm{after} \mathrm{drying} 400 \%$, the fraction $0.126-0.77$ micron holds before drying $283 \%$ and after drying $245 \%$, while these values are for the fraction, $0.77-2$ micron, 97.7 and $94.0 \%$.

Probably the coarse particles are too irregular in shape to come in close contact over a large enough percentage of the surface for the attractive forces to act. The contact area will be somewhat larger with the smallest particles, but the irregularity is still too big to allow for any but microscopic water stable aggregation.

The potassium illite without organic matter behaves like an elastic system. The influence of the salt concentration on the swelling of potassium illite is shown in fig. 20. The desintegration accompanied by a sudden increase in moisture takes place near $0.01 \mathrm{M}$.

\subsubsection{Calcium illite}

Part of the desorption curve of the dialyzed organic matter containing suspension is shown in fig. 22, II A. Some irregularities near $\mathrm{pF} 2$ are difficult to explain; they 


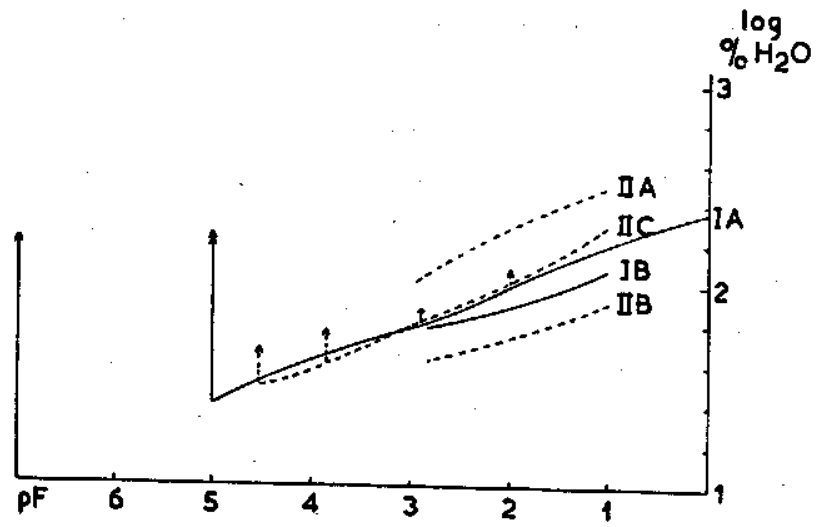

FIG. 22. Desorption and backswelling of Ca-illite (Fithian)

I. colloid

IA. suspension

IB. granules slowly moistened II. clay fraction organic matter present IIA. suspension IIB. granules IIC. slurry

may be attributed to some structural effect like collapsing of free space at this suction. It is curious that the moisture contents of the calcium and sodium illites with organic matter are nearly the same, so that the chief difference lies not in the desorption characteristic, but in the swelling of the dried clay. The desorption curve of the granules, which suffer a rather vigorous slaking if immersed in the dry state, is shown by curve IIB. Curve IIC represents the desorption of the slurry, which had a concentration of about $0.00024 \mathrm{M}$. The moisture content of the slury is only $60 \%$ of that of the original suspension, thus the dispersion by puddling has not been complete. The slurry is rather inelastic as indicated by the arrows; that the paste desorbed at pF 4.5 contains less moisture after swelling than the ovendry granules is explained by the absence of slaking. The curve of the carbon free illite, containing $0.0002 \mathrm{M} / 1$, (I A) nearly coincides with curve II C, but in contrast to the organic matter containing slurry, this clay disperses spontaneously even after ovendrying, though, as is shown in fig. 20 , only at concentrations lower than $0.001 \mathrm{M}$.

If the granules are slowly wetted, however, they retain their form after submersion, although their stability is extremely small.

If this clay is desorbed, the range where the desorption is reversible merges into the range where the air explosion causes destruction of the internal bonds, without a transitional stable zone as with calcium margalite soil. Only if the air explosion effect is avoided by slow moistening a small stability can manifest itself. The desorption curve of the granules without organic matter is shown by curve I B. The moisture content is a bit lower at low suctions than that of the suspension but at suctions above containing granules, curve II B.

The organic matter containing calcium illite behaves like a semi-elastic system, whereas the clay without organic matter behaves like an elastic system, at least at low electrolyte concentrations. Further one might conclude that the organic matter raises in this case the moisture content of the suspension, but lowers the moisture content of
the granules. 


\subsubsection{Knip clay}

\subsubsection{Sodium knip clay}

The determination of the desorption characteristic met with difficulties. The coarse illite fraction settled on the membrane and the permeability decreased consequently, so it was doubtful whether true equilibrium was reached at low suctions. Therefore the desorption curves of the oxidized fine and the coarse fraction were determined separately.

Fig. 23. Desorption and swelling of Na-knipclay

A. colloid $<0.13 \mu$

B. coarse clay fraction

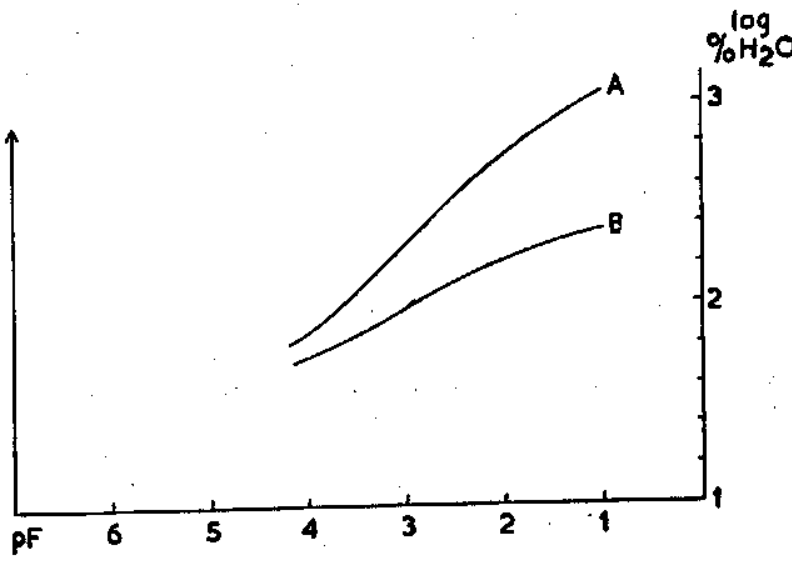

The results are shown in fig 23. Compared with sodium montmorillonite the moisture content of the fine fraction of the knipclay has been reduced by $50 \%$, which is slightly more than the reduction of the surface. The desorption curve of the coarse fraction shows some resemblance with the theoretical curve at $0.5 \times 10^{-3} \mathrm{M}$. As after drying the fine fraction held nearly as much moisture at $\mathrm{pF} 1$ as the original suspension, the sodium knip clay belongs to the elastic systems.

\subsubsection{Potassium knip clay}

The potassium clay was prepared by washing the slurry of the original soil with normal potassium chloride solution and dialysis. Consequently the suspension had not the finest degree of dispersion possible. The potassium clay did not separate markedly into the two fractions. The desorption and swelling curve is shown by fig. 24. There is no resemblance with the theoretical curve. Above pF 5.1 the equilibration technique with sulfuric acid was used to obtain the suction; as temperature control was insufficient the curves are fitting badly.

The swelling of the desorbed suspension proved to be unlimited up to very high compressions. The first marked decrease in swelling occurred in the range between pF 5.3 and pF 5.47 by a reduction of the moisture content from 14.0 to $10.8 \%$, resulting in a reduction of moisture content at $\mathrm{pF} 1$ from 182 to $74 \%$.

Further decrease in moisture content did result in a small additional decrease in swelling. If on the other hand the paste was left to swell at $80^{\circ} \mathrm{C}$ reduction of backswelling took place between pF 5.7 and 6 . As the time of swelling of the sample at room temperature was a week and the sample was not larger than $0.1 \mathrm{~g}$, equilibrium 


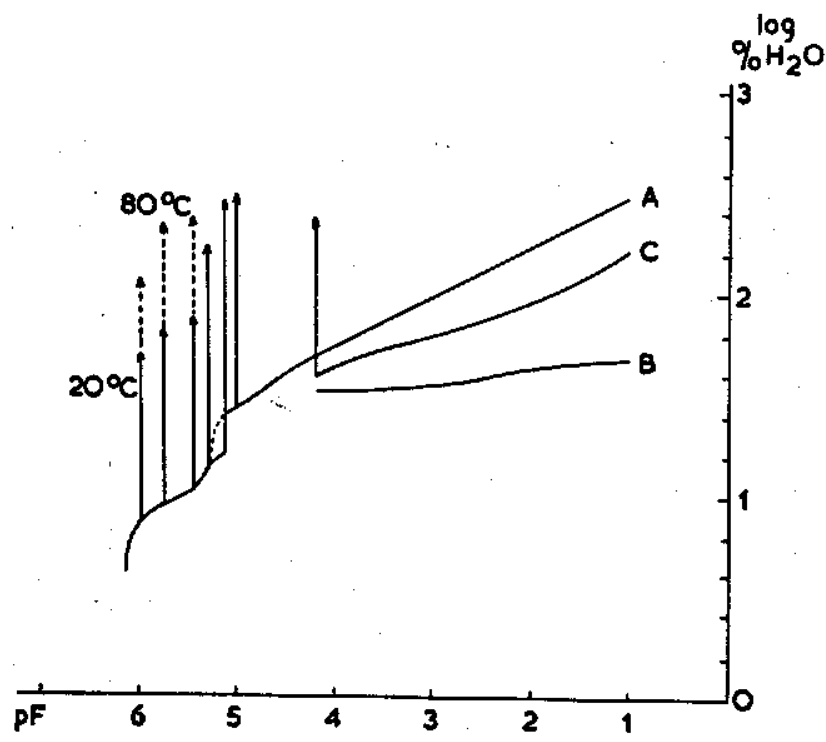

Fio. 24. Desorption and swelling of $\mathrm{K}$-knipclay $<2 \mu$
A. suspension
B. granules
C. slurry

should have been reached and the influence of the temperature on the swelling will have been real.

The slope of the $\mathrm{pF}$ curve of the granules, curve $\mathrm{B}$, is very weak, only $10 \%$ of moisture is available between $\mathrm{pF} 2$ and 4.2 , which is extraordinary low for a clay. The slurry, curve $\mathrm{C}$, has only half the moisture content at low suctions of that of the suspensions, though the suspension did not represent the finest dispersion.

The process of water desorption of the suspension of potassium knipclay is reversible up to a high degree of dehydration. The range of suction where the reversibility is changed into a semi-reversibility lies near $\mathrm{pF} 5.4$.

\subsubsection{Magnesium knip clay}

The suspension was prepared in the same way as that of the potassium clay. The desorption and swelling curves are not shown, because they largely resemble those of the calcium clay. The swelling of the slurry is only limited by a rather high degree of desorption. A small decrease in swelling is shown by desorption at $\mathrm{pF} 4.78$, the paste did not disperse spontaneously. A marked decrease in swelling occurred between $\mathrm{pF}$ 4.8 and 5 . The reduction in moisture content at $\mathrm{pF} 1$ after swelling in excess of water, from 160 to $86 \%$ is caused by a lowering of the original moisture content from 31.5 to $27 \%$. This is about the same reduction as obtained by ovendrying.

Compared with the potassium clay the reduction occurs at a moisture content which is more than twice as high. The granules formed by desorption of the slurry at pF 5 kept their form after immersion water in contrast with the granules formed by
desorption at $\mathrm{pF} 4.8$.

So the magnesium knip clay behaves like a system which is elastic over a large range of suctions, the system being converted into a semi-elastic one near pF5. 


\subsubsection{Calcium knip clay}

The way of preparation of the suspension has been the same as with the potassium clay. The desorption curve is shown in fig. 25 , curve A. It nearly coincides with that of the potassium and the magnesium clay. Also the desorption curve of the granules (B) looks very much the same, $23 \%$ water is available between $\mathrm{pF} 2$ and 4.2 . The

Fro. 25. Desorption and backswelling characteristic of Ca-knipclay $<2 \mu$
A. suspension
B. granules
C. slurry
D. slurry of coarse clay fraction

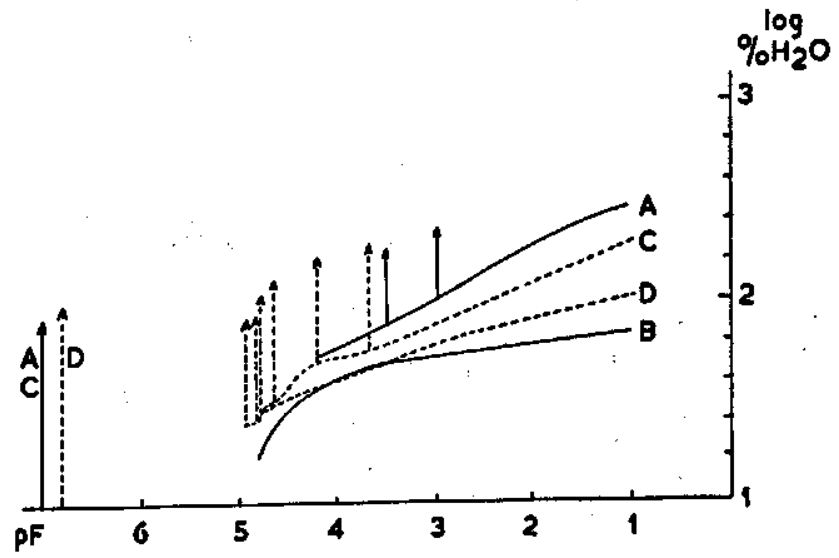

limitation of the swelling of the slurry occurs at a lower suction than with the magnesium clay. An increase in suction from $\mathrm{pF} 4.77$ to 4.81 , resulting in a reduction in water content from 29.5 to $25.5 \%$, lowers the swelling, as measured by the watercontent at $\mathrm{pF} 1$, from 113 to $89 \%$. The paste formed by equilibration at $\mathrm{pF} 4.81 \mathrm{did}$ not disperse spontaneously.

The desorption curve (D) of the coarse fraction made by converting the coarse fraction of the sodium clay into a calcium clay, was also determined. The curve is less steep than that of the slurry of the whole clay, but the main difference is that the granules desintegrate spontaneously if immersed, even if they have been slowly moistened on a $10 \mathrm{~cm}$ suction plate.

One may conclude that the calcium knip clay behaves like an elastic system up to a suction of $\mathrm{pF} 4.8$; by equilibration with higher suctions it is converted into a semielastic one.

\subsubsection{Conclusion}

The knip clay deviates from the pure illite, in so far as the potassium, magnesium and calcium clay form waterstable granules. The conversion of the elastic into the semielastic system takes place at rather high suctions, even though the organic matter is not removed. (The organic matter seems to be less active than that of the Fithian illite.) The difference is probably also due to large fraction of ultra clay, as the coarse fraction with organic matter behaved like the pure illite. 


\subsubsection{River basin clay}

\subsubsection{Sodium basin clay colloid}

The clay was prepared by the alcohol method. The salt concentration of the suspension, measured by the conductivity of the dialyzate, was $0.75 \times 10^{-3} \mathrm{M}, \mathrm{pH} 7.56$. The desorption curve fig. 26, No. I A, does not show any special features. Comparison with the theoretical curve for illite shows that the surface should be $1.32 \times 120 \mathrm{~m}^{2}=$ $158 \mathrm{~m}^{2}$, whereas $315 \mathrm{~m}^{2}$ have been measured by the ethylene glycol method.

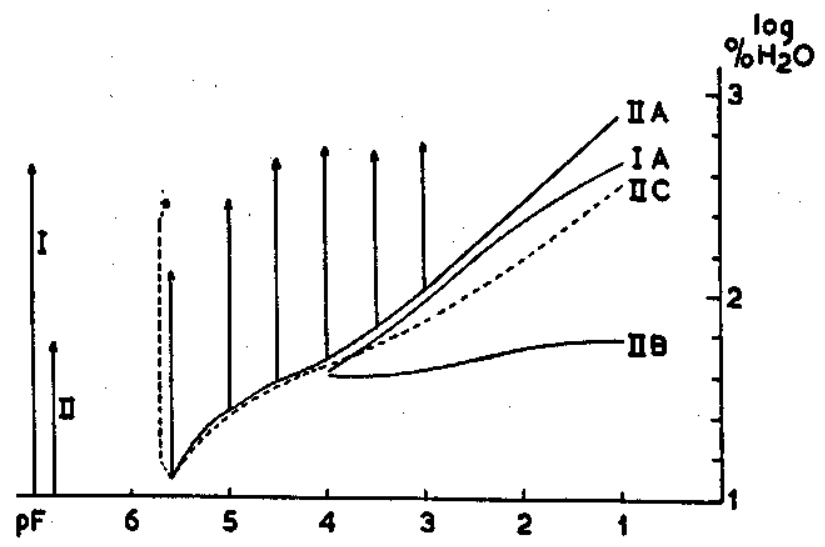

Frc. 26. Desorption and backswelling characteristic of basin clay colloid

IA. Na basin clay suspension IIA. $\mathrm{K}$ basin clay suspension IIB. $\mathrm{K}$ basin clay granules IIC. $\mathrm{K}$ basin clay slurry

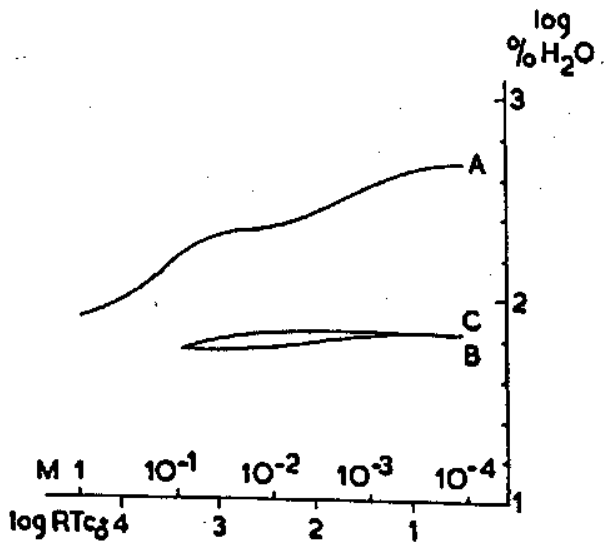

Fre. 27. Swelling of basin clay colloid in dependance of salt concentration
A. $\mathrm{Na}$ colloid
B. $\mathbf{K}$ colloid
C. Ca colloid

The influence of the salt concentration on the swelling of sodium basin clay granules is shown by fig. 27, curve A. The swelling starts at a lower salt concentration compared with that of the illite; at $0.032 \mathrm{M}$ the structure of the granules disappears but only at $0.01 \mathrm{M}$ does the clay separate into its fine and coarse fraction. 


\subsubsection{Potassium basin clay}

2.5.6.2.1 Potassium basin clay colloid. The clay was prepared by rotation of a suspension of sodium clay with potassium resin. The saltconcentration amounted finally to $0.87 \times 10^{-4} \mathrm{M}$, the $\mathrm{pH}$ to 7.55 .

The desorption curve of this suspension is shown by fig. 26 , No. II A.

As the salt concentration was 0.1 of that of the sodium clay, the curve lies somewhat higher and is straighter between $\mathrm{pF} 1$ and 2 . Reduction in swelling starts only at $\mathrm{pF} 5$ where the paste disperses only partly. At $\mathrm{pF} 5.6$ the swelling is largely reduced, but the moisture content after swelling is till considerably larger than of the granules.

With the granules, curve II B, only a $15 \%$ of moisture is available between $\mathrm{pF} 2$ and 4.

The slope of the desorption curve of the slurry (II C) is less steep than that of the suspension, it is seen that the swelling of the slurry is not limited by desorption up to pF 5.6.

The influence of the salt concentration on the swelling of the potassium granules is nearly absent, as shown in fig. 27, curve B.

2.5.6.2.2 Potassium basin clay, colloid smaller than 0.12 micron. The desorption and swelling of the fine fraction is shown by fig. 28 (I A). The suspension desorbed at

Fig. 28. Desorption and backswelling characteristic of $\mathrm{K}$ basin clay colloid
I. $<0.12 \mu$
IA. suspension
IB. granules
IC. slurry
IIA, suspension of coarse clay fraction

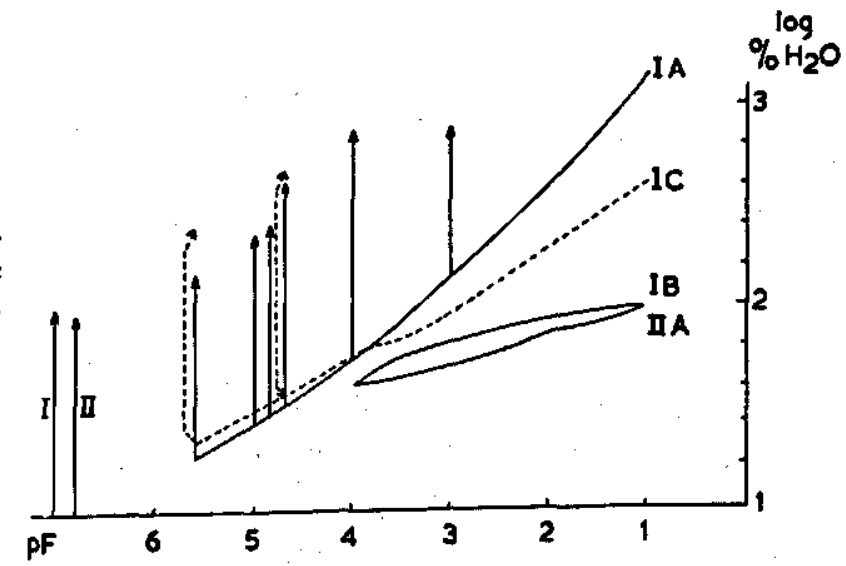

$\mathrm{pF} 1$ was completely liquid. The curve lies higher and is steeper than that of the whole clay fraction but it lies still considerably lower than might be expected from the surface measurements. Although the concentration was unchanged by the centrifugation procedure, the limitation of the swelling begins at $\mathrm{pF} 4.7$ where the paste does not disperse completely. The increase of suction from $\mathrm{pF} 4.7$ to 4.85 , giving a decrease in moisture content from 36.9 to 32.7 results in a decrease in moisture content at $\mathrm{pF}$ 1 after swelling from 433 to $270 \%$. The suspension desorbed at pF 5.6 has a swelling which is only slightly higher than that of the granules. (curve I B).

The granules, adsorb slightly more moisture than the granules of the whole clay and also the moisture available between $\mathrm{pF} 2$ and 4.20 is higher $(45 \%)$. 
The swelling of the slurry, curve $\mathbf{I} \mathrm{C}$, is not limited enough by equilibration at pF 5.6 to give water stable granules.

2.5.6.2.3 Potassium basin clay, coarse fraction. This curve (II A) has as most pronounced characteristic its extreme flatness and the fact that the swelling is not limited by ovendrying. The granules disperse slowly if immersed in $10^{-4} \mathrm{M}$ potassium hydroxyde.

2.5.6.2.4 Conclusion. The potassium basin clay suspension behaves like a partly elastic system; the smaller the particles and the higher the degree of dispersion the lower is the suction at which complete elasticity is lost. The suspension of ultra clay loses it at $\mathrm{pF}$ 4.7. The suspension of the whole clay loses it at $\mathrm{pF}$ 5. The slurries lose it at a $\mathrm{pF}$ higher than 5.6. The coarse fraction behaves like an elastic system.

\subsubsection{Calcium basin clay colloid}

The suspension was made by washing the sodium clay suspension with normal calcium chloride, washing with distilled water and dialysis. The final concentration (by conductivity) proved to be $0.65 \times 10^{-4} \mathrm{M}$. The desorption curve of the suspension is represented in fig. 29, curve A. The curve fits the theoretical one for $120 \mathrm{~m}^{2} / \mathrm{g}$ rather good but lies only 1.6 times higher, which is not in accordance with the surface $\left(350 \mathrm{~m}^{2}\right)$.

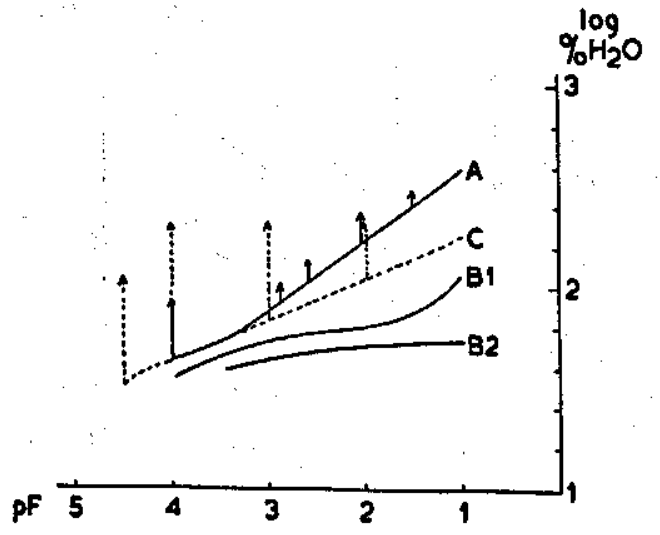

Fic. 29. Desorption and backswelling characteristic of $\mathrm{Ca}$ basin clay colloid
A. suspension
B1. granules suddenly immersed
B2. granules slowly wetted
C. slurry

In contrast with the knip clay the back-swelling of the Ca basin clay colloid is lowered at very low suctions. The moisture content of the granules formed by equilibration at $\mathrm{pF} 4$ is after swelling even lower at $\mathrm{pF} 1$ than that of the dried granules. This is due to the rather strong desintegration the ovendry granules suffer by sudden immersion.

This effect of the desintegration by sudden immersion is demonstrated by curves $B 1$ and B 2. Curve B 1 represents the desportion curve of the ovendry granules immersed at once, curve B 2, represents the desorption curve of the same granules saturated by capillarity $(10 \mathrm{~cm}$ suction) and then immersed. The difference is most 
striking at $\mathrm{pF} 1$ as might be expected, as the air explosion causes desintegration into macroscopic particles and water will be held in the interstices only at low suctions. Curve $C$ represents the desorption curve of the slurry. The lower slope and lower moisture content at low $\mathrm{pF}$ seems to indicate, that the material of the slurry is coarser than that of the original suspension. The surface where unlimited wateradsorption is possible, is lowered by the coarsening, but on the other hand the shrinkage is hampered as difficultly compressible interstices will be formed between the larger and rougher particles. Clearly is demonstrated again that the swelling of a slurry is not lowered by the desorption at low suctions. Whereas the pastes of the original suspension made by desorption at low suctions remained stable after immersion, the pastes of the slurry did disperse completely up to $\mathrm{pF} 4.5$. After equilibration at this suction the paste did show only partial desintegration.

The influence of the salt concentration on the swelling is small, as shown by curve G, fig. 27.

The calcium basin clay suspension behaves like a system with small elasticity, while the slurry is elastic up to $\mathrm{pF}$ 4.5. The influence of the rate of moistening of the granules is reflected in the desorption curve.

\subsubsection{Conclusion}

Whereas the granules from the pure Fithian illite were not waterstable at low salt concentrations, the granules of a colloid isolated from a basin clay were waterstable except the sodium saturated ones.

As the coarse clay fractions of calcium knipclay and potassium basin clay behaved like the pure illite, this difference is probably caused by the difference in amount of ultra clay, which is reflected by the total surface. The small fraction of organic matter present in the unoxidized illite has a large influence on its behaviour, the slurry of the calcium clay showing the characteristics of a semi-elastic system and the granules being waterstable. The organic matter present in the knipclay had not the same influence, as the coarse suspensions of the clay, saturated with divalent cations, behaved like elastic systems up to high suctions.

It may therefore be concluded that the fineness of the illitic clays has a decisive influence on their waterstability and that the role of organic matter is important.

The behaviour of the pure illite differs so much from the behaviour of illitic clay minerals isolated from soils, that one may not expect that conclusions drawn from the former are applicable to soils.

\subsubsection{Kaolinite}

\subsubsection{Sodium kaolinite colloid}

The homoionic clay was prepared by the washing method. Excess salt was removed by desorption in a pressure membrane; this was repeated after suspending the paste again. After the second desorption and stirring the $\mathrm{pH}$ was adjusted to 8 . The salt content by conductivity was $2.65 \times 10^{-4} \mathrm{M}$ as sodium carbonate. The desorption curve is represented in fig. 30 , curve $I$. Though there were small particles present, 


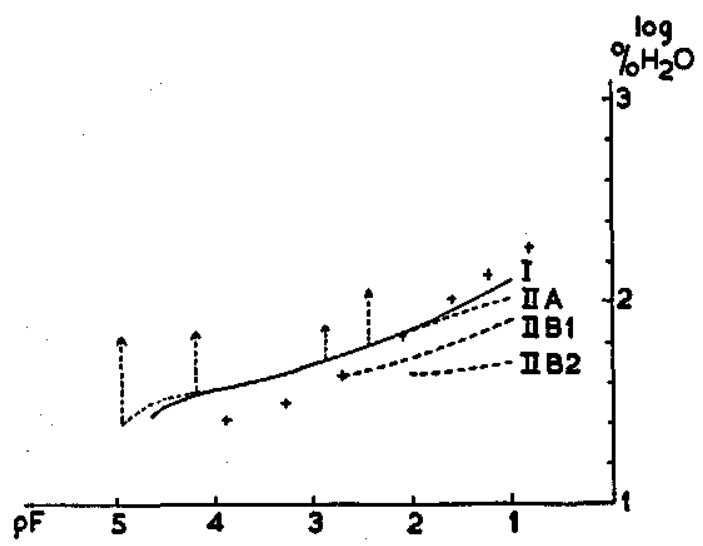

Fic. 30. Desorption and backswelling characteristic of kaolinite I. Na colloid, + theoretical value for $\mathrm{v}=1$

II. Ca colloid

IIA. suspension

IIB1. granules suddenly immersed

IIB2. granules wetted slowly

passing Schott \& Gen sintered glass funnels No. 4, the shallow slope indicates a very small surface. It is still flatter than the theoretical curve for a clay of the same composition. The clay did swell back to the same moisture content the original suspension had, irrespective of the degree of desorption. The swelling was not affected by raising the $\mathrm{pH}$ of the liquid from 8 to 10 .

The influence of the salt concentration on the swelling is demonstrated by curve $I$, fig. 31. In the $1 \mathrm{M}$ solution some disruption of the granules occurred, causing a slightly higher moisture content than at $0.1 \mathrm{M}$. At $0.01 \mathrm{M}$ and lower concentrations the granules dispersed completely causing a higher moisture content.

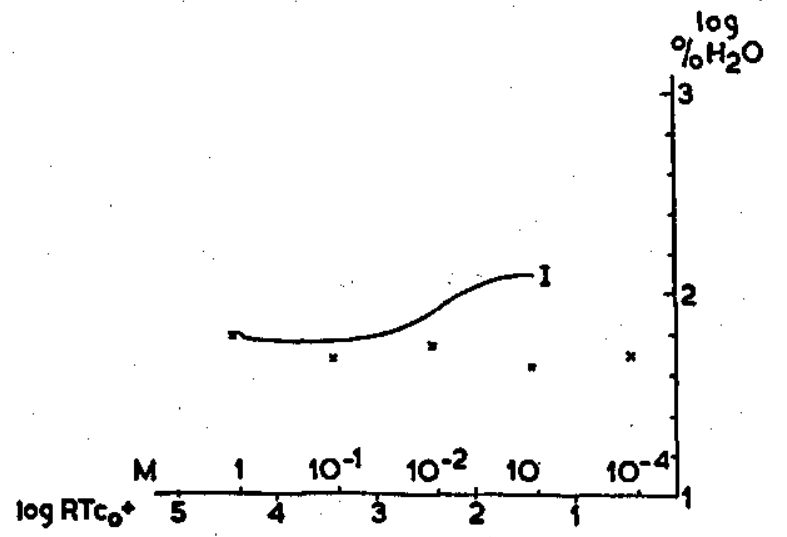
FIG. 31. Swelling of kaolinite in dependance of salt con- centration

I. Na kaolinite $\times$ Ca kaolinite

\subsubsection{Calcium kaolinite colloid}

The homoionic clay was prepared by percolating a $0.5 \%$ suspension through a column of calcium resin. After repetition all sodium had been removed. The $\mathrm{pH}$ was brought up to 7 , and the salt concentration, measured by the conductivity of the suspension, was $10^{-4} \mathrm{M}$. 
The desorption curve is shown by fig. 30, II A. It nearly coincides with that of the sodium clay, but whereas the sodium clay did disperse spontaneously after immersion, the calcium clay did not, in fact the swelling was lowered by suctions of $\mathrm{pF} 2.9$ and higher.

The desorption of the granules is shown by curve II B 1 . The rather small difference between the moisture content of the original suspension and the granules is caused by the desintegration caused by air explosion. If the granules are allowed to imbibe water on a moisture table (10 cm suction) and are then left to swell in free water, a very flat desorption curve is the result as shown by curve II B 2 .

It was impossible to detect any influence of the salt concentration on the swelling as is shown by the points in fig. 31. The differences in moisture content are not systematic but probably due to some irregularities of the granules and the air explosion.

\subsubsection{Conclusion}

The only difference between the sodium and the calcium kaolinite is that the sodium clay behaves like an elastic system and the calcium clay suspension as an elastic system only up to $\mathrm{pF} 2.9$, by this and higher suctions it is converted into a semi-elastic system.

\subsubsection{Latosol}

For the investigations the whole soil was used except in case the rotation with resins technique was emploied to prepare homoionic clays. In the latter case the use of a 50 micron sieve was necessary to separate the resin from the clay. As the fraction larger than 50 micron amounts only to $1.5 \%$, its influence will be negligible.

\subsubsection{Sodium latosol}

During preliminary investigations it was found that the soil washed with normal sodium chloride did not disperse spontaneously when washed subsequently with water, in fact only the sodium ions were partly replaced by hydrogen ions during this procedure without any physical change occurring. As it was thought that the $\mathrm{pH}$ would have a dominant influence on the swelling of latosol, the desorption curves of slurries with different $\mathrm{pH}$ were run. The $\mathrm{pH}$ was corrected by addition of sodium carbonate. The slurries tended to flocculate up to $\mathrm{pH} 9$ but were stable at $\mathrm{pH} 10$. At this $\mathrm{pH}$ also the granules dispersed spontaneously, which they did not at lower values.

Curve I A, fig. 32, represents the desorption curve of the slurry at $\mathrm{pH} 8.25$ (prepared by percolation, salt removed by titration with hydroxyde and hydrogen resin, $\mathrm{pH}$ adjusted, concentration $0.21 \times 10^{-3} \mathrm{~N} \mathrm{Na}_{2} \mathrm{CO}_{3}$ ). The slope is rather flat as was the case with sodium kaolinite. The moisture content at $\mathrm{pF} 2$ is 1.7 larger than that of the kaolinite.

The paste formed by desorption of the slurry does not swell back to its original moisture content, small pressures resulting in a reduction of the swelling. After de- 


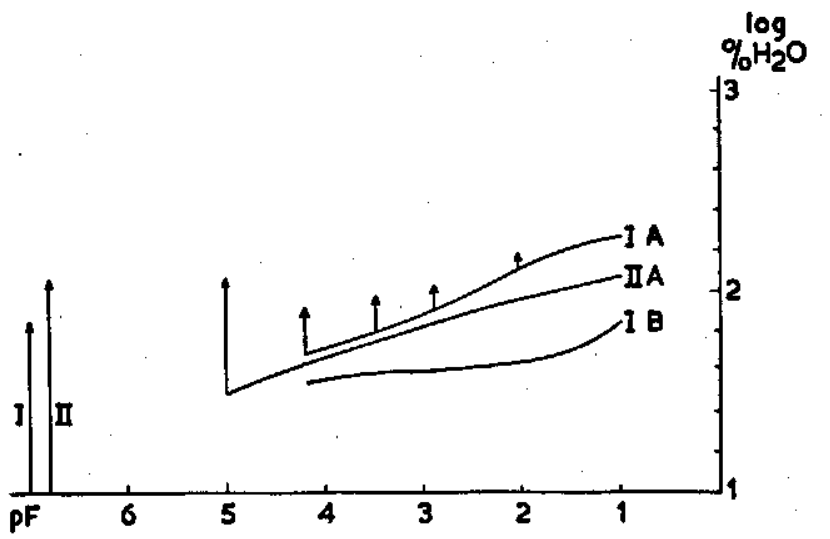

Fig. 32. Desorption and backswelling characteristic of Na-latosol

IA. slurry, $\mathrm{pH} 8.25$

IB. granules Hp. 2,58

IIA. slurry, $\mathrm{pH} 10$

sorption at $\mathrm{pF} 4.2$ the moisture content is after swelling only slightly higher at $\mathrm{pF} 1$ than that of the ovendry granules.

The desorption curve of the granules (I B) is very flat in the region between $\mathrm{pF} 2$ and 4.2 , which suggests that there is an incompressible free space present of about $40 \%$ moisture or $100 \%$ by volume.

The desorption curve of the slurry at $\mathrm{pH} 10$ (II A) is still flatter than that at $\mathrm{pH} 8.25$, and the moisture content at $\mathrm{pF} 1$ is only 0.625 of that of the latter. This difference may be due to the higher concentration of the solution, about $10^{-3} \mathrm{~N}$ at pH 10, against $2 \times 10^{-4} \mathrm{~N}$ at $\mathrm{pH} 8.25$. An other cause may be that the flocks at pH 8.25 give an extra resistance to compression, which is not the case with the suspension of $\mathrm{pH} 10$.

However, the most important change caused by the rise in $\mathrm{pH}$ is that the soil granules disperse spontaneously at $\mathrm{pH} \mathrm{10,} \mathrm{and} \mathrm{accordingly} \mathrm{the} \mathrm{swelling} \mathrm{of} \mathrm{the} \mathrm{sus-}$ pension is not limited by desorption.

The conclusion is that a slurry of sodium latosol with a pH below 9 behaves like a semi-elastic system, above $\mathrm{pH} 9$ it behaves like an elastic system.

\subsubsection{Hydrogen latosol}

As the reaction of the latosols is usually rather acid, it was thought usefull to investigate the behaviour of the hydrogen soil also. The soil was prepared by the washing method, the electrolyte concentration of the slurry will have been $1.5 \times 10^{-4}$ $\mathrm{M}$ as $\mathrm{HCl}$, the $\mathrm{pH}$ in water 4.35 and in $\mathrm{KCl} 3.86$.

The desorption curve of the slurry is nearly identical with that of magnesium latosol. The slurry flocculated quickly. The most interesting feature is the practical absence of swelling after desorption. The curve lies a bit higher than that of the sodium slurry $\mathrm{pH} 8.25$, this suggests that the flocculation is in this case the chief agent in moisture retention, as it hampers the compression as well as the swelling.

As the soil suffers a mild form of air explosion if immersed in water, the moisture content of the granules at pF 1. is higher than that of the paste desorbed at pF 4.2 swollen and desorbed again at $\mathrm{pF} 1$. The flatness of the desorption curve between $\mathrm{pF} 2$ and 2.9 suggests a pore volume equivalent to $43 \%$ moisture. 
Conclusion: The slurry of the hydrogen latosol behaved like an inelastic system.

\subsubsection{Potassium and ammonium latosol}

Preliminary investigations on the latosol partly neutralized with potassium indicated that it behaved just as the sodium latosol. The $\mathrm{pH}$ at which spontaneous dispersion occurred was determined by adding every day small increments of potassium resp. ammonium hydroxyde $(0.01 \mathrm{me}$.) to two grams of granules of hydrogen latosol in $100 \mathrm{ml}$ of water, and measuring the $\mathrm{pH}$ next day. It was found that above pH 9 spontaneously dispersion took place and that the resultant suspension did not flocculate.

\subsubsection{Magnesium latosol}

The homoionic clay was prepared by the washing procedure. The slurry has a concentration of $0.77 \times 10^{-4} \mathrm{M}$ as $\mathrm{Mg}\left(\mathrm{HCO}_{3}\right)_{2}$, the $\mathrm{pH}$ was 5.6. The desorption is shown in fig. 33 curve I. It is almost identical with that of the hydrogen latosol and the hydrogen-sodium latosol. Swelling after desorption is practically absent.

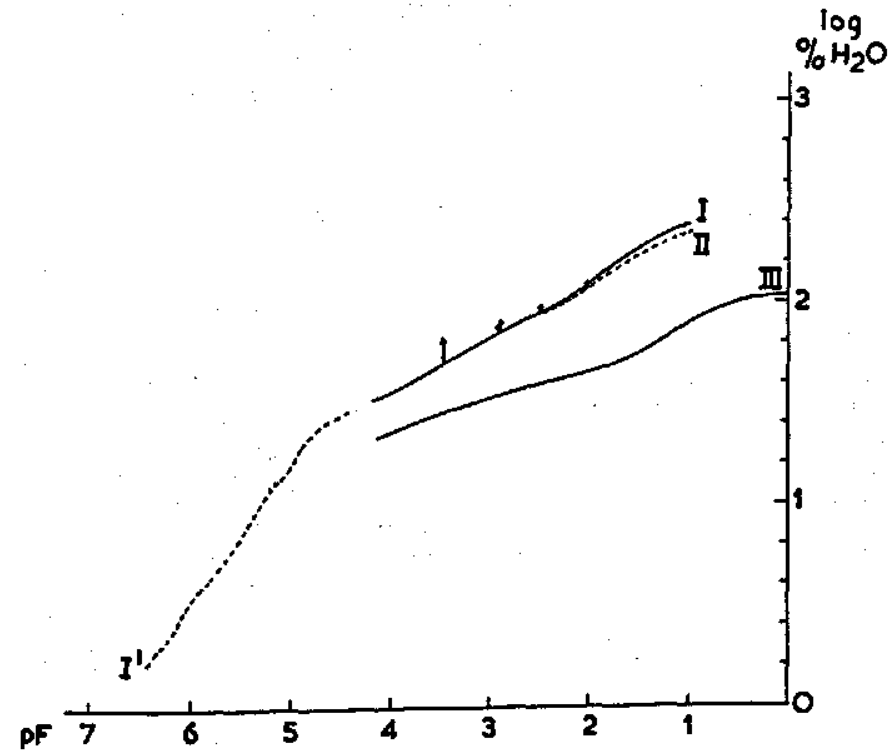

Frg. 33. Desorption and backsweiling characteristic of $\mathrm{Mg}$ latosol

I. slurry, $\mathrm{pH} 5.6$, I' equilibration with sulphuric acid.

II. slurry, $\mathrm{pH} 8.8$

III. Ca-latosol granules

The same suspension was brought on higher $\mathrm{pH}$ levels by shaking with a saturated magnesium hydroxyde solution and decanting. Though the suspensions at all $\mathrm{pH}$ 's investigated flocculated eventually, the flocculation was slowest at $\mathrm{pH} 8.8$ (concentration $1.22 \times 10^{-4} \mathrm{M}$ ). Probably the concentration was high enough at higher $\mathrm{pH}$ and 
the acidity high enough at lower $\mathrm{pH}$ to cause flocculation. The desorption characteristic of the slurry with $\mathrm{pH} 8.8$ is reproduced as curve II, the difference is negligible. So the slurry of the magnesium latosol behaves like an inelastic system.

\subsubsection{Calcium latosol}

Preliminary investigations indicated that its behaviour is identical with that of the magnesium latosol.

\subsubsection{Conclusion}

The desorption curve of kaolinite and latosol do not differ materially, the influence of the saturating cation is absent. The elasticity of the latosol slurries is negligible, except with systems saturated by monovalent cations above $\mathrm{pH} 9$. The slurry of calcium kaolinite is more elastic and the sodium kaolinite is completely elastic. So there is a marked difference in behaviour between the clay mineral and the latosol.

\subsection{Summary}

The results of the experiments treated in this part, may be summarized by table 12 in which the clays and soils are grouped according to their backswelling characteristic.

The salt concentration at which the degranulation of some of the elastic systems occurs is given underneath.

Critical salt concentration (M/1) of elastic systems

\begin{tabular}{|c|c|c|c|}
\hline $\begin{array}{l}0.6 \\
0.04^{\prime} \\
0.032^{\prime} \\
0.016^{\prime} \\
0.01^{\prime} \\
0.004^{\prime} \\
0.00015\end{array}$ & $\begin{array}{l}\mathrm{Na} \text { bentonite } \\
\mathrm{Na} \text { margalite col. } \\
\mathrm{Na} \text { basin } \mathrm{c} . \\
\mathrm{Na} \text { illite col. } \\
\mathrm{K} \text { illite col. } \\
\mathrm{Na} \text { illite } \mathrm{c} . \\
\mathrm{Ca} \text { illite col. }\end{array}$ & $\begin{array}{l}\text { c } \\
\text { susp. } \\
\text { slur. } \\
\text { fr. }\end{array}$ & $\begin{array}{l}=\text { organic matter present } \\
=\text { suspension } \\
=\text { slurry } \\
=\text { rough estimation } \\
=\text { fraction }\end{array}$ \\
\hline
\end{tabular}


TABLE 12. Behaviour of suspensions and slurries at low salt concentration

\begin{tabular}{|c|c|c|c|c|}
\hline elastic & $\begin{array}{l}\text { elastic over a } \\
\text { certain range }\end{array}$ & $\begin{array}{l}\text { limiting } \\
\text { pressure } \\
\text { range }\end{array}$ & semi-elastic & inelastic \\
\hline
\end{tabular}

Na bentonite

$\mathrm{K}$ bentonite

Na margalite, col.

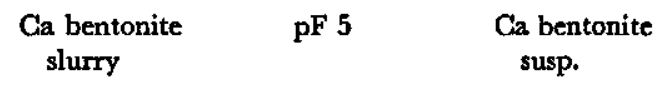

$\mathrm{Na}$ margalite soil
$\mathrm{K}$ margalite, col. $\quad$ pF 5-5.6
suspension
K margalite col.- $\quad \mathrm{pF} 6.0$ and clay-slurry
Ca margalite, col. slurry
pF 2-2.9
$\mathrm{Mg}$ margalite
col. susp.
Ca margalite
col. susp.
Ca margalite
soil slurry

Na illite, Fith., col.

$\mathrm{K}$ illite, Fith., col.

Ca illite, Fith., col.

$\mathrm{Na}$ knip clay

Ca knip clay

coarse fr.

$\mathrm{Na}$ basin clay

col.

$\mathrm{Na}$ basin clay

soil

$\mathrm{K}$ basin clay, col. coarse fr.

$\mathrm{Na}$ kaolinite, col.

K knip clay $\quad$ pF 5.3-5.45

Mg knip clay, slur. $\quad$ pF 4.8

Ca knip clay, slur. $\quad \mathrm{pF} 4.8$
Ca illite, Fith., c slurry

$\mathrm{K}$ basin clay, col. $\quad$ pF 5.6

$\mathrm{K}$ basin clay, col. $\quad \mathrm{pF} 4.8$

fine fr.

Ca basin clay, col. pF $4.5 \quad$ Ca basin clay slurry

col. susp.

Ca kaolinite, col. pF 2.2-2.9 susp.

Na latosol, $\mathrm{pH}>9$

$\mathrm{Na}$ latosol $\mathrm{pH} 8.25$

H latosol

$\mathrm{Mg}$ latosol

$\mathrm{Ca}$ latosol 


\section{THE RESISTANGE OF GRANULES AGAINST DISPERSION IN WATER AS INFLUENCED BY THE SALT CONGENTRATION, AND THE INFLUENGE OF THE DEGREE OF DEHYDRATION ON THE RESISTANGE AGAINST DISPERSION}

\section{INTRODUCTION}

In the previous chapter it was established whether cohesion still existed in clay and soil granules in the presence of free water. Also qualitative investigations on the influence of the electrolyte concentration on the stability were reported. In this chapter the resistance to mechanical action in the saturated stage will be treated in a qualitative way.

As will be explained in chapter IV, soil aggregates should have a certain resistance to mechanical forces, even if saturated with water. As the contact with excess of water occurs as long as rainwater percolates through the soil and since the cohesion of the aggregates is minimum in this condition the stability of soil aggregates is often measured in the saturated state.

There are three methods to evaluate the stability in the saturated state:

a. The VILENSKy method (1934)

The number of waterdrops necessary to cause desintegration is measured. As the saturation of the aggregates is usually achieved with a few drops, mainly the stability in the saturated state is determined. If dry aggregates are used the air explosion may also influence the results. If unsaturated granules are used and the swelling takes a long time, as is the case with sodium bentonite, the swelling time is measured and not the stability in the saturated state. This is shown by VAN SchuYLENBORGH's experiments (1951) using artificial aggregates made by mixing $60 \%$ of sodium or calcium bentonite with sand. In the case of sodium bentonite more than 100 drops of water were necessary to destroy the aggregates and in the case of calcium bentonite only $10.4 \mathrm{ca} .0 .7$.

Though these difficulties may be overcome by using saturated granules, the criterion, i.e. the falling apart of the granules, is difficult to interpretate as this may be either a good or a bad property of the soil depending on the dimensions of the resulting particles.

\section{b. The wet sieving method of analysis}

This method was first employed by TruLrv (1933), who used single sieves. In order to get more information on the size distribution of the aggregates after slaking and sieving, YoDER (1936) used a set of sieves of decreasing mesh. As the quantity of data obtained in this way made comparison difficult, they were represented by a single value, i.e. the 'mean weight diameter', VAN BAVEL (1950). 
De Boodt uses the difference in mean weight diameter, between dry and wet sieving; the wet sieving is in this case done after wetting the dried soil to field capacity by artificial raindrops, (De LeENheER \& De Boodt, 1958).

The method meets with the objection that the mechanical forces acting on the aggregates depend on the quantity of aggregates on the sieve. The interpretation of the mean weight diameter encounters the same difficulty as ViLENSKY's test. Even if a single sieve is used, the amount of material necessary to establish the influence of the mechanical action on the destruction, is in this case prohibitive.

\section{c. The end over end shaking method}

This method employed by Purr \& Keen (1925), MaGeorge (1937) and QuirK (1950) has the advantage that small quantities are sufficient to establish the relation between destruction of the aggregates and the amount of energy applied. The destruction is measured by determination of the clay concentration in the liquid after a certain settling time (PURI \& KEEN) of the silt and clay concentration (QUIRK), or by measuring the total volume after sedimentation (Ma GeORGE). A handicap of the method is, that the absolute amount of energy applied is not known, in contrast to VILENSKY's method. Therefore the method has to be standardized and calibrated with the aid of soils with known properties. Because of the limited amounts of material available this method was adopted in this investigation.

\section{PRELIMINARY INVESTIGATIONS}

\subsection{EXPERIMENTAL METHOD}

As is demonstrated by Ma George (1937) the sedimentation volume of a clay soil depends on the degree of dispersion. Thus if aggregates are destroyed by shaking, the increase of the volume of the sediment is a measure for the destruction. As the claysoils become in most cases dispersed to such a degree that they flocculate (orthokinetic flocculation) a distinct boundary is observed between the sediment and the supernatant liquid and a second boundary can be observed in the sediment between the original granules and the mass of flocks. If calibrated vessels are used, the flock volume, after standard settling time ( 20 hours), can be read directly and used as such or as a percentage of the ultimate volume i.e. the volume of the flock sediment when no increase on further rotation is apparent.

With the preliminary experiments usually $10 \mathrm{~g}$ of soil were shaken in a volumetric graduated vessel of $60 \mathrm{ml}$ and a height of $15 \mathrm{~cm}$. An airbubble of $1 \mathrm{ml}$ and 5 glassbeads ( $\varnothing 4 \mathrm{~mm}$ ) were included to increase the abrasive forces.

\subsection{EXPERIMENTS ON MARGaLITE SOIL, $<50 \mu$}

Portions of $10 \mathrm{~g}$ of ovendry granules were slurried by submersion and stirring. The excess of moisture was allowed to evaporate at room temperature and the dishes 
weighed regularly. To obtain moisture contents below $5 \%$, drying at 40 or $50^{\circ} \mathrm{C}$ was necessary. When the desired moisture content was obtained, the paste was cut into pieces of about $3 \mathrm{~mm}$ and transferred to the measuring cylinders.

The effect of a certain number of revolutions on the volume of flocculated sediment is represented by fig. 34. It is represented not as absolute volume but as percentage of the ultimate volume of each object (after 20000 revolutions). It is seen that the initial moisture content has a large influence on the resistence of the aggregates, which is not surprising as we know from fig. 18 that the margalite soil slurry is a semi-elastic system.

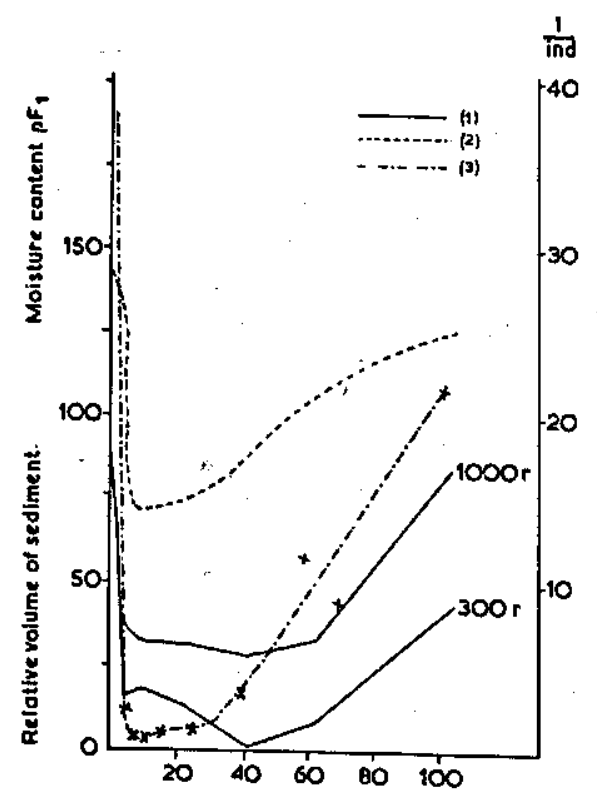

Fro. 34. Drying slurry of Ca-margalite; stability versus initial moisture content

(1) Volume of sediment in $\%$ of ultimate volume after 300 and 1000 revolutions

(2) Moisture content at $\mathrm{pF} 1$ after backswelling $(100 \%=100 \%$ moisture by weight)

(3) Reciprocal value of stability index (right hand side axis)

As with swelling soils the distance between the particles which compose a granule (polyplates) will be proportional to the moisture content and as the forces, which hold a granule together, must be inversely related to the distance, it is obvious that the desorption of the slurry must increase the resistance of the resulting granules even after complete swelling, provided the slurry behaves like a semi-elastic system. In this particular case a sharp limit is put to the increase of the resistance by the air explosion effect, to which this soil is very susceptible.

The moisture content at $\mathrm{pF} 1$ after complete swelling has been plotted as perthe curves is good.

\subsection{Discussion ôf THE METHOD}

Though this method gives good qualitative results and is very easy, it was abandoned because the results could not be expressed quantitatively. The most serious objection 
is that the density of the flocculated sediment is not constant but increases with increasing quantity.

This is demonstrated by the following experiment. Increments of latosol and margalite soil were puddled, transferred to the graduated cylinders and shaken till no increase in sedimentation volume was observed. The final sedimentation volume after 5 days standing is represented in table 13 .

TABLE 13. Influence of the quantity of sediment on its volume

\begin{tabular}{lcllll}
\hline weight of material (in g) & 0.5 & 1 & 2 & 5 & 10 \\
latosol (ml/g) & 10.4 & 8.4 & 6.7 & 5.1 & 4.06 \\
margalite $(\mathrm{ml} / \mathrm{g})$ & & 7.5 & 6.4 & 5.7 & 4.6 \\
\hline
\end{tabular}

Though these data are quite interesting as they permit the calculation of the moisture content at very low $\mathrm{pF}$ values, they show clearly that the volume of flocculated sediment is not a suitable measure for the weight of the aggregates destroyed. Neither is the volume of the undestroyed aggregates because the packing may vary considerably during the experiment.

\section{QUANTITATIVE EXPERIMENTS}

\subsection{EXPERIMENTAL METHOD}

The following modification of the method used with the preliminary investigations was adopted.

In order to obtain a better approximation of the quantity of granules destroyed by a certain number of revolutions, all material which did not settle after a standard settling time was syphoned of, dried and weighed. As the influence of salt concentration on the resistance was to be investigated also, a settling time of two minutes was chosen because flocculation has usually no disturbing effect during so short a time. In the few cases where the flocculation had such an effect, the upper half of the volume was sucked off after one minute the flocculated sediment suspended again and the other half was syphoned off after another minute of standing.

Applying STOKEs's law as an approximation, one may estimate the maximum size of the particles removed as 40 micron, the maximum height of fall being $15.5 \mathrm{~cm}$. This estimate is not accurate at all, as the undestroyed granules caused considerable turbulence by which the finer particles were moved in an upward direction. Probably the majority of the particles peeled off from the clay granules had much smaller dimensions, since they flocculated.

As the quantity of material was limited, two grams of granules were used. If not stated otherwise they were submerged in the liquid at once and left to swell overnight before the shaking began.

In order to keep the destructive energy per revolution constant, 5 glassbeads and 
one $\mathrm{ml}$ of air were introduced and when working with soil also two grams of quartz sand $(175-250 \mu)$. The latter was done in order to overcompensate the effect of sand grains liberated during the shaking process, which might contribute to the destructive action of the glass beads.

In order to evaluate the abrasive action of sand grains, a series of stability determinations was done on granules of margalite clay dried from a slurry to $14 \%$ moisture. The results, treatmed by the method described in the next paragraph, are represented in table 14 .

TABLE 14. Influence of the addition of sand on the stability of calcium margalite

(constants $\times 10^{8}$, quantities in $\%$ )

\begin{tabular}{lcccc}
\hline object & quant. & const. & quant. & const. \\
\hline 2 g gran., 5 beads, $1 \mathrm{ml}$ air & 21 & -2.8 & 79 & -0.16 \\
2 g gran., 5 beads, $1 \mathrm{ml}$ air, 1 g sand & 24 & -3.0 & 76 & -0.36 \\
2 g gran., 5 beads, $1 \mathrm{ml}$ air, 2 g sand & 30 & -3.1 & 70 & -0.31 \\
\hline
\end{tabular}

It is seen, that the addition of sand resulted in a decreased stability of the granules, especially the more stable part was influenced. As the increase from 1 gram to two grams of sand had no systematic influence, it was thought that the influence of any sand liberated during the analysis would be overcompensated by the addition of two grams. As the stability constants of the most stable part were lowered by a factor two, half of the stability constant determined in the presence of sand would be equal to the stability constant without sand.

\subsection{Treatment of the Data}

If soil granules have been submerged long enough so that destruction due to air compression and swelling, has stopped, any further destruction is caused by the mechanical action of the procedure.

Trying to describe the process of desaggregation it is reasonable to assume that: The quantity of aggregates destroyed per unit of mechanical action is proportional to the quantity of undestroyed aggregates present.

Let $\mathrm{A}$ be the quantity of aggregates present at the beginning of the agitation, $\mathrm{X}$ the quantity of material destroyed per unit of mechanical action $R$, and $K$ the constant of proportionality, then the following differential equation may be written:

$$
\frac{\mathrm{dX}}{\mathrm{dR}}=\mathrm{K} \cdot(\mathrm{A}-\mathrm{X})
$$

after integration between $X=O$ and $X=A$ we get $\ln (A-X)=-K \cdot R+\ln A$. This implicates that, if the soil is homogeneous, a straight line is found if $\log (A-X)$, is plotted against $R$. This line intersects the $\log (A-X)$ axis at $\log A$. So $A$ can be evaluated. Usually $X$ is expressed as percentage of $A$, so $A$ becomes constant for all soils. If the soil is not slaking $A$ is equal to $A^{\prime}$ the quantity introduced into the bottle. $A^{\prime}$ is found by the sum of $X$ after infinite shaking time. 
The constant $\mathrm{K}$, the parameter for the stability, is equal to $2,303\left[\left(\log \left(A^{\prime}-X_{R}\right)-\log A^{\prime}\right)\right] \cdot R^{-1}$.

The best fitting line is taken for calculation. The value of $\mathrm{K}$ varies from minus infinite, for spontaneously dispersing soils, to zero, for absolutely stable soils. If 1000 revolutions are taken as unit for $R$, it varies in practice from -100 to -0.01 .

As an example for homogeneous not slaking aggregates, the desintegration of granules of calcium bentonite in decreasing concentrations of calcium chloride may serve.

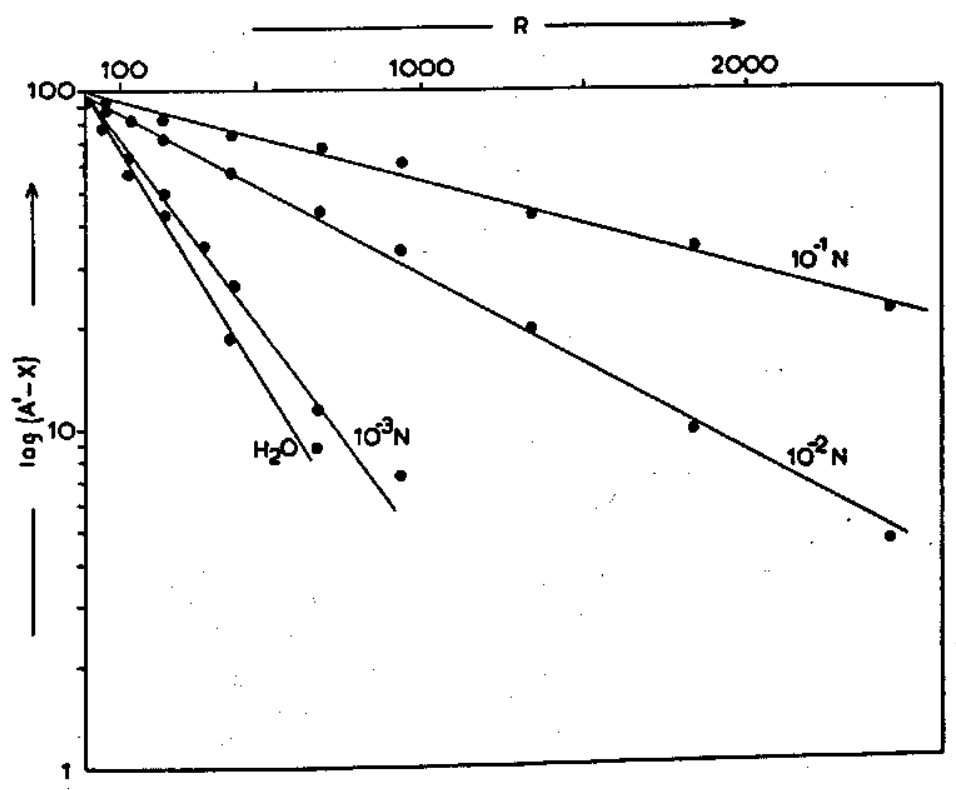

Fro. 35. Desintegration of Ca-bentonite

Quantity of undestroyed material present $\left(A^{\prime}-X\right)$ in dependence of number of revolutions

(R)

$\mathrm{N}=$ normality of the $\mathrm{CaCl}_{2}$ solution

If we find, that a line drawn through the data intersects the $\log \left(\mathrm{A}^{\prime}-\mathrm{X}\right)$ axis below $\log \mathrm{A}^{\prime}$, than obviously a certain quantity has been dispersed before the mechanical action started. (Another possibility is, that the dimensions of some of the aggregates were smaller than the critical ones to begin with). This quantity, $A^{\prime}-A$, can be read from the graph at once if semilogarithmical paper is used. Though the data are figured as percentage of $A^{\prime}$ instead of $A$, the points will lie also on a straight line and the slope will not be changed, as $\mathrm{A}^{\prime}-\mathrm{X}$ has been put on a log. scale. (Dividing by a larger constant results in a parallel displacement of the line). The constant is found by application of the same equation, only $A$ has to be used instead of $\mathrm{A}^{\prime}$.

Instead of a straight line relation one often finds, that the points representing the observations, lie on a curve. These curves are usually steep near the $\log \left(\mathrm{A}^{\prime}-\mathrm{X}\right)$ axis, concave towards the $\mathrm{R}$ axis, and flatten out with increasing time of rotation. 
The analysis of this type of curves is based on the assumption, that aggregates of different stability, occurring in different quantities, are present and that they are attacked simultaneously by the mechanical action.

As the separate desintegration of each class of aggregates would result in straight line, each having its own slope and constant, the simultaneous desintegration is represented by the sum of these lines and will be a curve.

As the least stable classes will be quickly destroyed, they cause the steep part of the curve and will have little influence on the flatter part, which therefore represents the desintegration of the most stable part only. So extrapolation of the straight part to the $\log (\mathrm{A}-\mathrm{X})$ axis gives the amount of this fraction, and its slope the stability constant. Plotting now the log of the numerical differences between the line and the original curve against $R$, one often obtains a straight line as is shown in figure 36 .

This line then furnishes amount and stability of the less stable part.

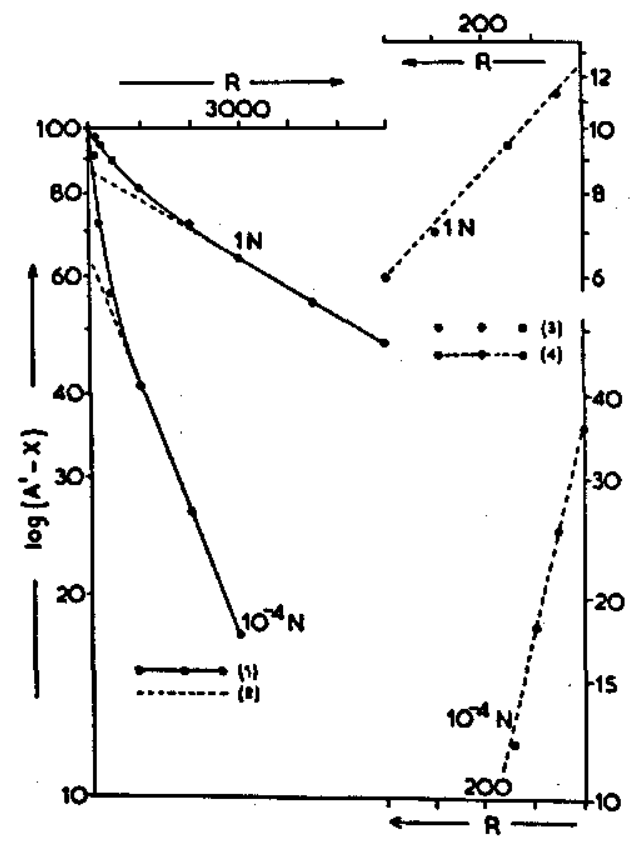

Fro. 36. Desintegration of K-Winsum clay soil

Quantity of undestroyed material present $\left(A^{\prime}-X\right)$ in dependance of number of revolutions

$\mathrm{N}=$ normality of $\mathrm{KCl}$ solution

(1) left hand side, curve through original data

(2) left hand side, stability characteristic of most stable part

(3) right hand side, difference between

(1) and (2) left hand side

(4) right hand side, stability characteristic of less stable part

If this line is still curved near the $\log (\mathrm{A}-\mathrm{X})$ axis, the procedure has to be repeated by extrapolation of the straight part of the second curve to the $\log (A-X)$ axis and plotting the log of the numerical differences between the second line and the second curve against $R$, which provides the data for the least stable class of aggregates.

An example of this is given by the stability analysis of Fort Knox silt loam (RusselL \& FENG, 1947).

The method of analysis has been applied to data of QUIRK (1950) and of RusseLL \& FENG (1947), to see whether this method was applicable to the results of other authors, who used different techniques. 
Fig. 37. Desintegration of Fort Knox silt loam

(1) Curve through original data

(2) stability characteristic of most stable part

(3) difference between (1) and (2)

(4) stability characteristic of less stable part

(5) difference between (3) and (4)

(6) stability characteristic of least stable part

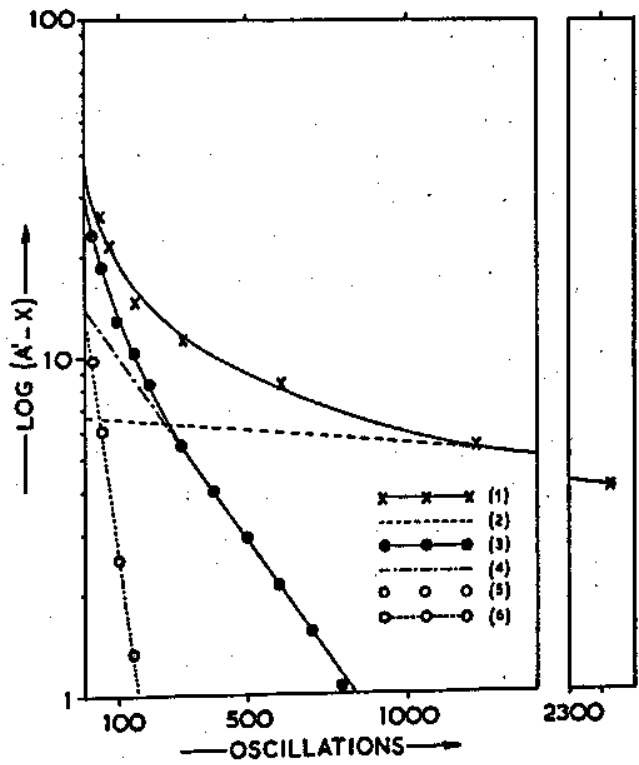

The results are given in table 15 , as mechanical unit 1000 rotations or oscillations were chosen.

TABLE 15. Analysis of data of QurRK and Russele \& FENG (constants $\times 10^{3}$, quantities in \%)

\begin{tabular}{lccccccccc}
\hline Soil & quant. & const. & quant. & const. & quant. & const. & \multicolumn{2}{c}{ quant. const. } \\
\hline Urrbrae 16 years & 81 & - inf. & & & 10 & -8.0 & 9 & -0.55 \\
Urrbrae virgin & 48 & - inf. & 10 & -30 & 21 & -5.0 & 21 & -0.36 \\
Wunnamura & 31 & - inf. & 13 & -60 & 25 & -3.2 & 31 & -0.29 \\
Moira loam 1 & 20 & - inf. & 13 & -36 & 34 & -2.7 & 33 & -0.23 \\
Knox 30' & 65 & - inf. & 14 & -15 & 14 & -2.6 & 7 & -0.20 \\
Marshall 300' & 44 & - inf. & 23 & -35 & & & 43 & -0.37 \\
Clinton $300^{\prime}$ & 10 & - inf. & 67 & -10 & & & 23 & -0.20 \\
Muscatine $300^{\prime}$ & 18 & - inf. & & & & & & -0.17 \\
\hline
\end{tabular}

\subsection{Comments}

With this kind of tests the state of desaggregation is assumed to have been reached if the aggregates have been reduced to particles with a diameter, smaller than the critical one, corresponding with a certain sieve opening or a standard settling time. As the texture of a soil may be such, that a fraction can not be reduced to these dimensions, not the whole of the destroyed aggregates is determined, but only that textural fraction which has a diameter smaller than the critical one. Thefore the quantities determined are not $X$ and $A^{\prime}$, but a fraction of these, viz. f.X and f. $A^{\prime}$.

The coarser particles remain on the bottom of the cylinder or on the sieve. If the measured fraction is set free in strict proportionality to the weight of the aggregates 
destroyed there is no objection against measuring $X$ by means of $f . X$ and $A^{\prime}$ by means of f. $A^{\prime}$. As f.X is expressed as percentage of $f . A^{\prime}, \log f . A^{\prime}$ is the same as $\log A^{\prime}(=2)$, and the treatment can be applied without alteration.

f. $A^{\prime}$ is determined as the sum of f.X after infinite shaking time. The objection against the use of the conventional textural analysis for determination of f. $\mathrm{A}^{\prime}$ is, that the dispersion with the aid of chemicals may not give results identical with the mechanical dispersion used in this method.

The smaller the dimensions are of the fraction which is chosen as criterion for desintegration, the more energy will have to be applied to reduce the aggregates and the larger the constant will become therefore.

Though one is able to analyse the desaggregation with the aid of the proposed method, the actual mechanism of the desaggregation is not known. As KIRKHAM pointed out to the author at the VIIth congress of I.S.S.S. (Madison, 1960), it is probable that the abrasion of the granules is not a function of the weight but of the surface area exposed. The measurement of the surface of the aggregates is, however, unfeasible during the determination. So the best that can be hoped in case KIRKHAM's hypothesis is valid, is that the surface is related to the weight and that this relation remains constant during the analysis. As the weight is $\mathrm{f} . \mathrm{r}^{3}$ and the surface f. $r^{2}$, the slope of the curves should be lowered by $2 / 3$, which is no problem.

If, however, large and small aggregates of the same hardness are present, then the smaller ones will be quicker abraded, due to their larger surface and this will show up in the analysis as a fraction with small stability.

Furthermore any stability constant will be a function of the degree of slaking, which commands the surface after wetting and of the hardness of the granules.

This would not be serious if some natural agent causing desintegration would also be related with the surface. The surface exposed to rainfall, (the most common destroying agent), does not increase linearly with the decrease of the dimensions of the aggregates, however; so if aggregates of different dimensions with the same stability are present, there will be no correlation between the desaggregation during the stability analysis and desaggregation by rainfall.

The concept that desaggregation is only dependent on surface and stability may be incomplete. The quantity which is scraped off a granule during a collision may be also the result of the energy liberated during that collision. The collisions may take place with the wall or the glassbeads, during the passing of the airbubble through the cylinder. It is conceivable that the granules will obtain the same velocity as the swirling water and the energy of collision will then be proportional to the mass of the particle.

The quantity picked of the surface will in this case depend on the weight of the particle. The velocity of fall of the larger aggregates is according to STOKEs's law related with the square of the diameter, therefore destruction upon collision with the bottom will be larger in the case of large aggregates.

So if the second hypothesis is also true, it will tend to outbalance the first.

The consequence of KIRKHAM's hypothesis is, that it is uncertain whether the classes identified as stability classes, differ only with regard to their stability. As it is how- 
ever impossible to make a correction for the external surface area, the weight of the aggregates was used without correction.

\subsection{Limitations OF THE METHOD}

The method will give erroneous results if the content of fine material of the different stability classes is not the same. The condition that the fraction f. $\mathrm{A}^{\prime}$ which is collected, should be set free in strict proportionality to the weight of the aggregates destroyed, is then no longer met with.

The second premise is that the aggregates of different stability should be attacked simultaneously.

This will not be the case if coatings are present, which have a resistance differing from that of the enveloped part of the aggregate.

If the stability of the coating is smaller, the presence will not be detected by the analysis, but will be treated as a class with low stability and its constant will be evaluated too low. If the coating is more resistant than the rest, then this will be shown by the analysis as the curve will turn away from the $\mathrm{R}$-axis.

\subsection{Other METHODS OF MATHEMATIGAL TREATMENT}

Quirk (l.c.) tested the following equation which, in the same notation as used here, reads $\mathrm{A}-\mathrm{X}=\mathrm{C}-\mathrm{K} \cdot \log \mathrm{R}$. If one tries to evaluate the quantity present at zero revolutions one finds + infinite. Consequently QuIRK could not assign a definite value to his constants and returned to the fraction destroyed after standerd shaking time as parameter for the stability.

Russel \& Feng $\cdot(1 . c$.$) used \log (A-X)=a-b . \log R$. At zero shaking time $\log (A-X)=a+b . \infty$, so also with this equation the exact amount of the quantity dispersed by wetting alone could not be evaluated.

As $\log (\mathrm{A}-\mathrm{X})$ is in this case plotted against $\log \mathrm{R}$, the curvature of the line through the observations is only visible with the most stable soil, the Muscatine.

\subsection{Conglusions}

1. The proposed method gives satisfactory results if applied to data found in literature. It is however not quite certain whether other differences than the stability do play a role.

2. It furnishes more detail and the measurement of the waterstable part is more accurate than with other treatments.

3. If the conditions, that the content of fine material of the stability classes should be equal, and that the classes should be attacked simultaneously, are not fulfilled, the treatment will give erroneous results.

\subsection{SiNGLE VALUE EXPRESSION OF THE, STABILITY}

The quantity of data obtained by the analysis makes the comparison of more than a few samples impossible. It is therefore necessary to find one figure as parameter for 
the stability. This can not be done by taking the weighed mean of the constants, as often minus infinite is one of them.

As indicator for the stability the surface is chosen, which is included by a plot of $(A-X)$ against $R$ and the $25 \%$ line of $(A-X)$.

In these graphs 1000 revolutions and $100 \%$ are chosen as unity. If sand has been introduced then $500 \times$ revolutions is unity as the abrasive power has been doubled by the introduction of the sand. The low value of $25 \%$ had to be taken as with higher values quite a number of sodium systems low in salt would get an index of zero. Details are invariably lost in this way, especially the difference between very unstable and spontaneously slaking soils.

If necessary the values of the corrected logarithmic graphs have been used for the determination of the index.

\subsection{REPRESENTATION}

In order to get easily readible values for the constants, they have been multiplied by $10^{3}$ if no sand had been introduced, and by $\frac{1}{2} \times 10^{3}$ if this had been the case. As the multiplication coefficient is mentioned in the caption of the tables, there is no need to mention the addition of sand in the text.

\section{STABILITY. OF GLAY AND SOIL GRANULES IN DEPENDENGE OF SALT CONCENTRATION}

In the following paragraphs only the results of the experiments and a short comment are given. The data are discussed more extensively with the aid of graphical representations in II, 5 .

\subsection{Bentonite}

\subsubsection{Sodium bentonite}

\subsubsection{Sodium bentonite at various salt concentrations}

About two gram of flakes, prepared by drying of a nearly deflocculated suspension followed by washing with ethanol and drying again, were brought into the cylinder which had been partially filled with the salt solution. The cylinder was kept in a nearly horizontal position for fear that the swelling flakes might clog together. After 24 hours of swelling five glassbeads were introduced, the bottle was filled and $1 \mathrm{ml}$ of air left. The results are represented in table 16. In order to investigate the influence of flocculation prior to drying on the stability, a $1 \%$ sodium bentonite suspension in $1 \mathrm{~N}$ sodium chloride was dried. The very porous and fluffy aggregates contained about $4.5 \mathrm{~g}$ of salt per gram of clay. About $3 \mathrm{~g}$ of the salt-clay mixture was introduced into the cylinders and the salt content was brought to the desired concentration by repeated washing. In the case of $0.025 \mathrm{~N}$ the washing had to be stopped at a concen- 
TABLE 16. Stability classes $(\%)$, constants $\left(\times 10^{3}\right)$ and indices of sodium bentonite

\begin{tabular}{|c|c|c|c|c|c|c|c|c|c|c|c|}
\hline \multirow[b]{2}{*}{$\begin{array}{l}M \\
1\end{array}$} & \multirow[b]{2}{*}{ quant. } & \multirow{2}{*}{ const. } & \multicolumn{3}{|c|}{ dialyzed } & \multicolumn{3}{|c|}{ partly floc. } & \multicolumn{3}{|c|}{ flocculated } \\
\hline & & & $\begin{array}{l}\text { quant. } \\
82\end{array}$ & $\begin{array}{l}\text { const. } \\
-0.033\end{array}$ & $\begin{array}{l}\text { ind. } \\
15.3\end{array}$ & $\begin{array}{c}\text { quant. } \\
83\end{array}$ & $\begin{array}{c}\text { const. } \\
-\quad 0.178\end{array}$ & $\begin{array}{l}\text { ind. } \\
3.01\end{array}$ & $\begin{array}{c}\text { quant. } \\
90\end{array}$ & $\begin{array}{c}\text { const. } \\
-\quad 0.11\end{array}$ & ind. \\
\hline 0.6 & 15 & -14.6 & 78 & -0.552 & 0.609 & & & & & & \\
\hline 0.4 & 24 & -84 & 76 & -2.58 & 0.112 & 83 & -1.96 & 0.288 & 100 & -8.75 & 0.0533 \\
\hline 0.2 & & & & & & 96 & -5.6 & 0.103 & 84 & -71 & 0.0105 \\
\hline 0.05 & & & & & & & & & 100 & -131 & 0.0044 \\
\hline 0.025 & & & & & & 92 & -11.7 & 0.052 & & & \\
\hline 0.005 & & & & & & 100 & -27.2 & 0.0233 & & & \\
\hline
\end{tabular}

tration of $0.05 \mathrm{~N}$ as further washing was impossible due to the volume of sediment. The constants are given in table 16.

The experiment was partly repeated with granules of dialyzed clay, from another batch of bentonite. The swelling time was 14 days. (See photographs 3 and 4).

It is seen, that the aggregates made by drying of a dialyzed suspension are more stable than those formed by flocculation and drying.

From $0.2 \mathrm{~N}$ downwards the destruction constants do not represent the effort to destroy distinct aggregates, but to make a homogeneous suspension of the liquid mass of the concentrated suspension, of which in reality the bentonite consists at these concentrations, and the supernatant liquid.

\subsubsection{The influence of the dielectric constant}

The influence of the ethanol content of the liquid on the stability was also investigated. It had been proved by the swelling experiments $(I, 2.5 .1 .1)$ that the critical range was between 57 and $77 \%$ of ethanol, therefore the stability within this range was determined.

One gram of granules of sodium bentonite was shaken after swelling.

Before the determination started it was observed, that the granules did only swell in the 57 and $62 \%$ solutions. The results of the analysis are shown by table 17.

TABLE 17. Influence of ethanol on the stability constants $\left(\times 1 / 2.10^{3}\right)$ of sodium bentonite

\begin{tabular}{cccc}
\hline$\%$ ethanol (vol.) & diel. const. & quant. \% & const. \\
57.6 & 50.6 & 100 & -13.2 \\
62.3 & 47.5 & 100 & -9.6 \\
67.2 & 44.4 & 86 & -0.25 \\
76.8 & 39.1 & 96 & -0.0125 \\
\hline
\end{tabular}

The largest change takes place between 67.2 and $62.3 \%$ ethanol. If the increase in dielectric constant is the only change caused by dilution of the ethanol, than the increase by a few units (from 44.4 to 47.5 ) is sufficient to change the character of the sodium bentonite of a clay with a high stability to one with a low stability. 


\subsubsection{Potassium bentonite}

Flakes of potassium bentonite, prepared by drying of a nearly deflocculated suspension and washing with ethanol, were treated in the same way as the sodium bentonite. Ranges and constants are given in table 18.

TABLE 18. Stability classes $(\%)$, constants $\left(\times 10^{3}\right)$ and indices of potassium bentonite

\begin{tabular}{lrrll}
\hline M & quant. & const. & ind. \\
\hline 1 & 92 & -0.0301 & 19.6 \\
0.4 & 82 & -0.0296 & 19.6 \\
0.1 & 78 & -1.26 & 4.62 \\
0.025 & 100 & -2.66 & 0.195 \\
0.01 & 100 & -8.13 & 0.0694 \\
\hline
\end{tabular}

\subsubsection{Galcium bentonite}

Dried dialyzed clay was used. In the first series of experiments the reaction will have been slightly acid, in the second the $\mathrm{pH}$ was adjusted to 8.5 . The results are presented by table 19 .

TABLE 19. Stability classes (\%), constants and indices of calcium bentonite

\begin{tabular}{|c|c|c|c|c|c|c|}
\hline \multirow[b]{2}{*}{$\mathbf{M}$} & \multicolumn{3}{|c|}{ slightly acid } & \multicolumn{3}{|c|}{ pH 8.5} \\
\hline & quant. & const. $\left(\times 10^{3}\right)$ & ind. & quant. & const. $\left(\times \frac{1}{2} .10^{9}\right)$ & ind. \\
\hline 0.3 & 86 & -0.18 & 2.84 & & & \\
\hline 0.05 & & & & 100 & -0.30 & 1.76 \\
\hline 0.03 & 82 & -0.252 & 2.18 & & & \\
\hline 0.005 & & & & 100 & -0.625 & 0.834 \\
\hline 0.003 & 86 & -0.461 & 1.18 & & & \\
\hline 0.0006 & & & & 100 & -1.50 & 0.370 \\
\hline 0.0001 & & & & 100 & -1.65 & 0.344 \\
\hline $\mathrm{H}_{2} \mathrm{O}$ & 60 & -0.715 & 0.76 & & & \\
\hline
\end{tabular}

The most noteworthy feature is the stability of the clay in distilled water, which decreases by a factor two if the $\mathrm{pH}$ is raised to 8.5 .

If the soil is worked at $100 \%$ moisture content using salt solutions of decreasing concentration, the results are the following; they are represented in table 20.

TABLE 20. Stability classes $(\%)$, constants $\left(\times 10^{3}\right)$ and indices of puddled calcium bentonite

\begin{tabular}{lcccccc}
\hline $\mathbf{M}$ & quant. & const. & quant. & const. & ind. & ind. gran./ind. puddled \\
\hline 0.3 & & & 84 & -1.08 & 0.468 & 6.06 \\
0.03 & & & 81 & -1.09 & 0.468 & 4.66 \\
0.003 & 58 & -3.47 & 42 & -1.05 & 0.236 & 5.0 \\
$\mathrm{H}_{2} \mathrm{O}$ & 85 & -3.63 & 10 & -0.39 & 0.174 & 4.37 \\
\hline
\end{tabular}


Thus with the calcium bentonite the stability of the granules is lowered by puddling with the same coefficient regardless of the salt concentration.

\subsection{Margalte colloid}

\subsubsection{Sodium margalite colloid}

The flakes were prepared by drying of a dialyzed suspension of the colloid. The data are represented in table 21.

TABLE 21. Stability classes $(\%)$, constants $\left(\times 10^{3}\right)$ and indices of sodium margalite

\begin{tabular}{lccc}
\hline M & quant. & const. & ind. \\
\hline 1 & 83 & -0.027 & 20.5 \\
0.2 & 80 & -0.055 & 7.15 \\
0.025 & 80 & -0.43 & 1.22 \\
0.005 & 70 & -3.06 & 0.177 \\
\hline
\end{tabular}

\subsubsection{Potassium margalite colloid}

Flakes of dried dialyzed suspension of the colloid were used. The material is probably not homogeneous as at salt concentrations of $0.01 \mathrm{M}$ and lower a fraction of considerable stability is present. The material has some stability even in distilled water.

The results are presented in table 22.

TABLE 22. Stability classes $(\%)$, constants $\left(\times 10^{3}\right)$ and indices of potassium margalite

\begin{tabular}{lccccccc}
\hline $\mathrm{M}$ & quant. & const. & quant. & const. & quant. & const. & ind. \\
\hline 1 & & & 23 & -4.75 & 69 & -0.055 & 6.44 \\
0.1 & & & 11 & -8.15 & 83 & -0.069 & 6.89 \\
0.01 & & & 52 & -4.3 & 32 & -0.22 & 0.76 \\
0.001 & 63 & -23 & 21 & -5.5 & 15 & -0.59 & 0.042 \\
$\mathrm{H}_{2} \mathrm{O}$ & 38 & -36 & 46 & -9.8 & 16 & -1.06 & 0.0507 \\
\hline
\end{tabular}

This clay was also worked at a critical moisture content (i.e. $60 \%$ ) using salt solutions of decreasing strength. The results, extensively discussed in chapter III, show, that at low concentration a large fraction has zero stability, as might be expected with a system elastic over a large range.

\subsubsection{Calcium margalite colloid}

The stability of the colloid was determined, using oriented granules. The results are given in table 23.

The influence of the salt concentration is quite small. As in the case of potassium margalite the material proved to be unhomogeneous. 
TABLE 23. Stability classes $(\%)$, constants $\left(\times \frac{1}{2} \cdot 10^{3}\right)$ and indices of calcium margalite ( $\mathrm{pH} 8.2$ )

\begin{tabular}{lccccc}
\hline $\mathrm{M}$ & quant. & const. & quant. & const. & ind. \\
\hline 0.05 & 14 & -1.33 & 86 & -0.155 & 2.79 \\
0.005 & 25 & -0.75 & 75 & -0.125 & 2.89 \\
0.0006 & 17 & -1.46 & 83 & -0.178 & 2.27 \\
0.0001 & 21 & -2.25 & 79 & -0.22 & 1.66 \\
$\mathrm{H}_{2} \mathrm{O}$ & 27 & -1.84 & 73 & -0.235 & 1.44 \\
\hline
\end{tabular}

\subsection{Calcium Margalite soIl smaller than 50 micron}

\subsubsection{Moistened granules}

As this soil suffers a pronounced degree of air explosion if wetted suddenly, the granules had to be moistened to $30 \%$, before the influence of the salt concentration on the stability could be established. The characteristics are reproduced by table 24 .

TABLE 24. Stability classes $(\%)$, constants $\left(\times \frac{1}{2} \cdot 10^{a}\right)$ and indices of moistened and dry margalite soil

\begin{tabular}{|c|c|c|c|c|c|c|c|c|c|}
\hline \multirow[b]{2}{*}{$\mathbf{M}$} & \multicolumn{7}{|c|}{ moistened } & \multicolumn{2}{|c|}{ dry } \\
\hline & quant. & const. & quant. & const. & quant. & const. & ind. & quant. & const. \\
\hline 0.05 & 10 & -19.5 & & & 90 & -0.145 & 2.69 & 80 & 一 inf. \\
\hline 0.005 & & & 18 & -1.72 & 82 & -0.170 & 2.23 & 82 & 一 inf. \\
\hline 0.0005 & 12 & -38.3 & 10 & -2.69 & 78 & -0.199 & 1.64 & 78 & 一inf. \\
\hline $\mathrm{H}_{2} \mathrm{O}$ & 12 & -47.5 & 7 & -4.87 & 81 & -0.534 & 1.38 & 73 & -inf. \\
\hline
\end{tabular}

During the determination it was observed that the suspension with 0.005 molar and higher concentrations of calcium chloride did flocculate, while the suspensions with lower concentration did not. The increase of the destruction constant is however quite gradual and shows no sharp transition. The data are nearly identical with those of calcium margalite colloid.

\subsubsection{Ovendry granules}

If however ovendry granules of margalite soil are used, the stability is so low that it is difficult to collect enough data for a correct determination. The best guess from the data is represented in table 24. Although the data are not reliable enough to permit the conclusion that the air explosion effect is enhanced by the higher salt concentration, it is certain that the raising of the salt concentration does not suppress this effect.

\subsection{ILLITE}

\subsubsection{Sodium illite}

4.4.1.1 Sodium illite, first and second batch, organic matter present The desintegration characteristic of the granules of the first batch was difficult to 
analyse, as the plots of $\log (\mathrm{A}-\mathrm{X})$ against rotations gave undulating curves. The constants in table 25 are derived from the best fitting straight lines. The indices were derived from original data. With the aggregates of the second batch these difficulties were not encountered (constants $\times \frac{1}{2} \cdot 10^{2}$ ).

TABLE 25. Stability, classes (\%), constants $\left(\times 10^{3}\right)$ and indices of sodium illite

\begin{tabular}{|c|c|c|c|c|c|c|c|c|}
\hline \multirow[b]{2}{*}{$\mathbf{M}$} & \multicolumn{3}{|c|}{ Ist batch $+\mathbf{C}$} & \multicolumn{5}{|c|}{ 2nd batch $+\mathbf{C}$} \\
\hline & quant. & const. & ind. & quant. & const. & quant. & const. & ind. \\
\hline 1 & 75 & -0.24 & 2.88 & & & & & \\
\hline 0.88 & & & & 80 & 1.43 & 20 & -0.38 & 0.518 \\
\hline 0.4 & 68 & -0.35 & 2.48 & & & & & \\
\hline 0.088 & & & & 61 & $-\quad 2.71$ & 39 & -0.815 & 0.330 \\
\hline 0.0278 & & & & 100 & -10.2 & & & 0.0543 \\
\hline 0.0139 & & & & 42 & -564 & 58 & -73.1 & 0.00468 \\
\hline 0.01 & 83 & -1.87 & 0.447 & & & & & \\
\hline 0.001 & 70 & -1.57 & 0.143 & & & & & \\
\hline
\end{tabular}

It is seen that the granules of the first batch are considerably more stable than those of the second.

The difference may be caused by the way of preparation of the granules. Those of the first batch were made by ovendrying the alcaline suspension, those of the second one by drying after drainage of most of the moisture at $\mathrm{pF}$ 2.6. Thus the granules of the first batch may have been cemented by the hydrolysis products in the suspension, this cementation being the cause of the higher stability. In case the granules of the second batch were made by drying the suspension then also their desaggregation characteristic showed a wavy character, in some cases it resembled that of sodium latosol $\mathrm{pH} 10$, see 4.8.1.

\subsubsection{Sodium illite, colloid, second batch}

Granules were used prepared by desorption at $\mathrm{pF} 2.6$ of the oxidized clay fraction. The curves were quite normal, the constants are presented in table 26 . The material is not homogeneous for even at very low concentrations a small fraction had a certain stability.

TABLE 26. Stability classes $(\%)$, constants $\left(\times \frac{1}{2} \cdot 10^{3}\right)$ and indices of sodium illite, second batch, organic matter removed

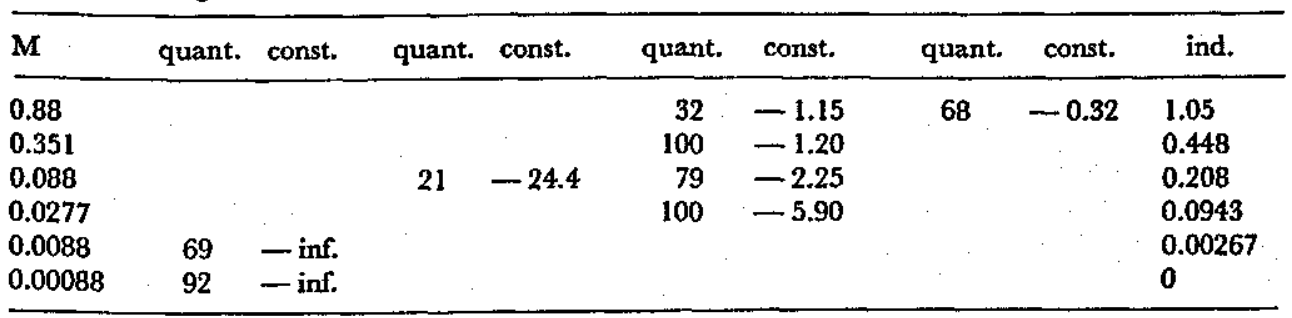


Comparing the indices of the illite with and without organic matter one can not detect any benificial influence of the organic matter on the stability.

\subsubsection{Potassium illite, colloid, second batch}

The investigated material consisted of oriented granules, wetted by capillarity. The results are given in table 27.

TABLE 27. Stability classes $(\%)$, constants $\left(\times \frac{1}{2} .10^{3}\right)$ of potassium illite

\begin{tabular}{lrrrrrrr}
\hline M & quant. & const. & quant. & const. & quant. & const. & ind. \\
\hline 1 & & & 7 & -2.82 & 93 & -0.26 & 2.00 \\
0.1 & & 11 & -5.25 & 89 & -0.73 & 0.633 \\
0.01 & & 100 & -9.70 & & & 0.0587 \\
0.001 & 95 & $-i n f$. & & & & & 0 \\
\hline
\end{tabular}

The potassium illite is more stable than the sodium illite, the difference being most pronounced at 0.1 and $0.01 \mathrm{M}$ salt concentration.

\subsubsection{Calcium illite, colloid, second batch}

The investigated material consisted of oriented granules, which were slowly moistened. The data are reproduced in table 28.

Table 28. Stability classes $(\%)$, constants $\left(\times \frac{1}{2}, 10^{3}\right)$ and indices of calcium illite

\begin{tabular}{|c|c|c|c|c|c|c|c|c|c|}
\hline $\mathbf{M}$ & quant. & const. & quant. & const. & quant. & const. & quant. & const. & ind. \\
\hline 0.115 & & & & & 70 & -1.34 & 30 & -0.135 & 0.674 \\
\hline 0.0116 & & & & & 75 & -1.25 & 25 & -0.30 & 0.472 \\
\hline 0.00125 & & & 11 & -14.35 & 52 & -1.44 & 37 & -0.42 & 0.472 \\
\hline 0.0001 & 95 & 一inf. & $\mathbf{5}$ & -19.3 & & & & & \\
\hline
\end{tabular}

The stability is considerably larger than that of the potassium illite. The material is not homogeneous.

\subsection{BASIN GLAY AND WINSUM KNIP CLAY, COLLOID}

In order to avoid the influence of the cation on the packing in the granules, the following procedure was followed. Oriented granules were prepared by desorption of the sodium clay suspension in the pressure membrane at 1 atmosphere suction, followed by cutting and drying. The saturating cation was changed by percolation with normal solution, after slow wetting on a Büchner funnel. If a certain $\mathrm{pH}$ was needed the $\mathrm{pH}$ of the percolating liquid was adjusted with the hydroxide. The percolation was continued until the $\mathrm{pH}$ of the percolate was the same as that of the percolating liquid. To remove the excess salts the percolation was continued with $70 \%$ ethanol, adjusted to the desired $\mathrm{pH}$. After removal of all chloride the granules 
were dried by sucking air through the Büchner funnel followed by ovendrying. No macroscopic changes of the granules were observed.

\subsubsection{Sodium clays}

The data for both clays are reported in table 29 .

TAele 29. Stability classes $(\%)$, constants $\left(\times \frac{1}{2}, 10^{s}\right)$ and indices of sodium basin clay and sodium Winsum clay (pH 8)

\begin{tabular}{|c|c|c|c|c|c|c|c|c|c|c|}
\hline \multirow{2}{*}{$\mathbf{M}$} & \multicolumn{5}{|c|}{ sodium basin clay } & \multicolumn{5}{|c|}{ sodium Winsum clay } \\
\hline & quant. & const. & quant. & const. & ind. & quant. & const. & quant. & const. & ind. \\
\hline 1 & & & 100 & -0.131 & 4.12 & & & 100 & -0.115 & 7.46 \\
\hline 0.1 & 50 & -4.20 & 50 & -0.57 & 0.336 & & & 100 & -0.86 & 0.322 \\
\hline 0.01 & 100 & - inf. & & & & 24 & - inf. & 76 & -82.0 & 0.00367 \\
\hline
\end{tabular}
clay.

The stability of the Winsum clay seems to be slightly larger than that of the basin

\subsubsection{Potassium clays}

The data are summarized in the table 30 .

TABLE 30. Stability classes $(\%)$, constants $\left(\times \frac{1}{2} \cdot 10^{3}\right)$ and indices of potassium basin clay and potassium Winsum clay ( $\mathrm{pH} 8$ )

\begin{tabular}{|c|c|c|c|c|c|c|c|c|}
\hline \multirow[b]{2}{*}{$\mathbf{M}$} & \multicolumn{5}{|c|}{ potassium basin clay } & \multicolumn{3}{|c|}{ Winsum clay } \\
\hline & quant. & const. & quant. & const. & ind. & quant. & const. & ind. \\
\hline 0.1 & & & 99 & -0.026 & 19.0 & 100 & -0.041 & 13.0 \\
\hline 0.01 & & & 96 & -0.054 & 10.2 & 100 & -0.131 & 4.13 \\
\hline 0.001 & & & 96 & -0.081 & 6.45 & 94 & -0.191 & 2.46 \\
\hline 0.0001 & 6 & -2.41 & 94 & -0.096 & 5.16 & 100 & -0.270 & 1.68 \\
\hline
\end{tabular}

The potassium clays are very stable in contrast with the Fithian illite, even at low salt concentrations. The basin clay is about twice as stable as the Winsum clay.

\subsubsection{Magnesium clays}

The data for magnesium clay are presented in table 31 .

Table 31. Stability classes $(\%)$, constants $\left(\times \frac{1}{2} \cdot 10^{3}\right)$ and indices of magnesium basin clay and magnesium Winsum clay, (pH 8 )

\begin{tabular}{|c|c|c|c|c|c|c|c|c|c|c|}
\hline \multirow[b]{2}{*}{$\mathbf{M}$} & \multicolumn{5}{|c|}{ magnesium basin clay } & \multicolumn{5}{|c|}{ magnesium Winsum clay } \\
\hline & quant. & const. & quant. & const. & ind. & quant. & - const. & quant. & const. & ind. \\
\hline 0.1 & & & 100 & -0.062 & 8.9 & & & 100 & -0.057 & 9.28 \\
\hline 0.01 & & & 100 & -0.066 & 7.56 & & & 100 & -0.103 & 5.36 \\
\hline 0.001 & 6 & -2.15 & 94 & -0.117 & 4.24 & 10 & -1.01 & 90 & -0.142 & 3.22 \\
\hline 0.0001 & 11 & -1.61 & 89 & -0.150 & 3.04 & 30 & -0.82 & 70 & -0.170 & 1.88 \\
\hline
\end{tabular}


The differences between the two clays are small, the basin clay being slightly more stable at the lowest salt concentrations. The magnesium basin clay is throughout less stable than the potassium clay. The magnesium Winsum is at low concentrations slightly more stable than the potassium clay.

\subsubsection{Calcium clays}

The data are represented in table 32 .

Table 32. Stability classes $(\%)$, constants $\left(\times \frac{1}{2} \cdot 10^{3}\right)$ and indices of calcium basin clay and calcium Winsum clay, (pH 8)

\begin{tabular}{|c|c|c|c|c|c|c|c|c|c|c|}
\hline \multirow[b]{2}{*}{$\mathbf{M}$} & \multicolumn{5}{|c|}{ calcium basin clay } & \multicolumn{5}{|c|}{ calcium Winsum clay } \\
\hline & quant. & const. & quant. & const. & ind. & quant. & const. & quant. & const. & ind. \\
\hline 0.1 & & & 94 & -0.056 & 8.50 & & & 100 & -0.073 & 7.10 \\
\hline 0.01 & 11 & -0.442 & 89 & -0.069 & 6.41 & & & 100 & -0.093 & 5.95 \\
\hline 0.001 & 20 & -0.447 & 80 & -0.088 & 4.39 & 22 & -0.41 & 78 & -0.121 & 3.38 \\
\hline 0.0001 & 43 & -0.33 & 57 & -0.11 & 2.93 & 81 & -0.46 & 29 & -0.134 & 1.70 \\
\hline
\end{tabular}

The basin clay is again more stable at low salt concentration than the Winsum clay, the differences with the magnesium clay are very small.

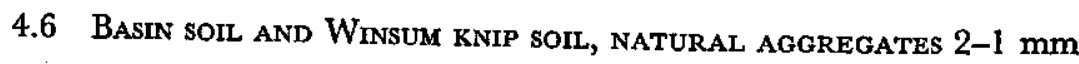

In order to exclude the influence of the saturating cation on the structure of the aggregates the following procedure was followed.

The aggregates obtained by crushing and sieving were saturated with the different bases in the same way as the clay granules. As the first percolate of the basin soil was rather acid, the first portion of the percolating salt solution of the Winsum soil was acidified to the same $\mathrm{pH}$ by acetic acid.

TABLE 33. Stability classes $(\%)$, constants $\left(\times \frac{1}{2}, 10^{3}\right)$ and indices of sodium basin soil

\begin{tabular}{|c|c|c|c|c|c|c|c|c|c|}
\hline $\mathbf{M}$ & quant. & const. & quant. & const. & quant. & const. & quant. & const. & ind. \\
\hline $\begin{array}{l}1 \\
0.1 \\
0.01 \\
0.0055 \\
0.00223\end{array}$ & $\begin{array}{l}17 \\
22 \\
40 \\
37\end{array}$ & $\begin{array}{l}\text { - inf. } \\
\text { - inf. } \\
\text { - inf. } \\
\text { - inf. }\end{array}$ & $\begin{array}{l}12 \\
17 \\
40 \\
60 \\
63\end{array}$ & $\begin{array}{r}3.8 \\
-\quad 4.8 \\
-28.1 \\
-26.0 \\
-30.0\end{array}$ & $\begin{array}{l}15 \\
20\end{array}$ & $\begin{array}{l}-0.44 \\
-5.0\end{array}$ & $\begin{array}{l}83 \\
51 \\
27\end{array}$ & $\begin{array}{l}-0.040 \\
-0.075 \\
-0.22\end{array}$ & $\begin{array}{l}11.9 \\
1.82 \\
0.0667 \\
0.0163 \\
0.0179\end{array}$ \\
\hline \multicolumn{9}{|c|}{ sodium Winsum soil } & \\
\hline $\begin{array}{l}1 \\
0.1 \\
0.01 \\
0.001\end{array}$ & 40 & 一inf. & $\begin{array}{l}24 \\
37\end{array}$ & $\begin{array}{l}-42.1 \\
-40.1\end{array}$ & $\begin{array}{l}17 \\
50 \\
17\end{array}$ & $\begin{array}{l}-2.75 \\
-3.85 \\
-4.6\end{array}$ & $\begin{array}{r}80 \\
26 \\
6\end{array}$ & $\begin{array}{l}-0.27 \\
-0.275 \\
-0.326\end{array}$ & $\begin{array}{l}1.535 \\
0.184 \\
0.00946\end{array}$ \\
\hline 0.0001 & 55 & 一 inf. & 30 & -54.5 & 14 & -4.2 & 5 & -0.238 & 0.00267 \\
\hline
\end{tabular}




\subsubsection{Sodium soils}

The sodium basin clay had been dried without removal of the excess salt. After introduction into the test cylinders the salt content had been lowered by repeated washing with salt solutions of the desired concentration. The data are reproduced in table 33.

At $1 \mathrm{M}$ electrolyte concentration the stability of the basin soil is much higher than that of the Winsum soil. By reduction of the salt concentration to $0.1 \mathrm{M}$ the stability has been impaired with both soils. It is apparent that the sodium soils are very unhomogeneous at low concentrations as a part disperses spontaneously, another part has very little stability and a very small part keeps a normal resistance.

\subsubsection{Potassium soils}

The data on the influence of the salt concentration on the stability are listed in table 34 .

TABLE 34. Stability classes $(\%)$, constants $\left(\times \frac{1}{2} \cdot 10^{3}\right)$ and indices of potassium basin soil and potassium Winsum soil ( $\mathrm{pH} 8.2$ )

\begin{tabular}{|c|c|c|c|c|c|c|c|c|c|c|}
\hline \multirow[b]{2}{*}{$\mathbf{M}$} & \multicolumn{5}{|c|}{ potassium basin soil } & \multicolumn{5}{|c|}{ potassium Winsum soil } \\
\hline & quant. & const. & quant. & const. & ind. & quant. & const. & quant. & const. & ind, \\
\hline 1 & 4 & -0.99 & 96 & -0.00675 & 69.8 & 8 & -1.67 & 92 & -0.059 & 7.84 \\
\hline 0.1 & 4 & -2.27 & 96 & -0.0217 & 23.0 & 9 & -2.61 & 89 & -0.100 & 4.56 \\
\hline 0.01 & 6 & -3.83 & 94 & -0.0481 & 10.2 & 22 & -2.12 & 75 & -0.152 & 2.08 \\
\hline 0.001 & 9 & -4.02 & 91 & -0.065 & 7.25 & 33 & -2.79 & 67 & -0.175 & 1.48 \\
\hline 0.0001 & 11 & -4.4 & 89 & -0.0725 & 6.04 & 37 & -3.40 & 63 & -0.212 & 1.05 \\
\hline
\end{tabular}

The soils behave like the isolated clay fraction as the stability at very low salt concentration, $10^{-4} \mathrm{M}$, is pronounced. This stability is, however, considerably decreased with respect to that in $1 \mathrm{M}$ solution, since the indices amount to only one tenth. The differences in stability indices between the two soils are larger than those between the clays, the coefficient varies here between 5 and 10 , with the clays between 1.5 and 3 .

\subsubsection{Magnesium soils}

The influence of the salt concentration was investigated at two $\mathrm{pH}$ levels, 7 and 8.2. The data are represented in tables 35 and 36 .

With the magnesium basin soil the influence of the $\mathrm{pH}$ on the stability is difficult to assess as much depends on the stability of the least stable fraction, which is given no special weight at the determination of the index. The stabilities at low concentration are the same as with the potassium soil. With the Winsum soil an increase of the least stable fraction by the raise of the $\mathrm{pH}$ can be noted, and the decrease of the stability with decreasing concentration is stronger at high $\mathrm{pH}$. The differences with the potassium Winsum are small at low salt concentration. 
TABLE 35. Stability classes $(\%)$, constants $\left(\times \frac{1}{2} \cdot 10^{3}\right)$ and indices at $\mathrm{pH} 7$ of magnesium basin soil and magnesium Winsum soil

\begin{tabular}{|c|c|c|c|c|c|c|c|c|c|c|}
\hline \multirow[b]{2}{*}{$\mathbf{M}$} & \multicolumn{5}{|c|}{ magnesium basin soil } & \multicolumn{5}{|c|}{ magnesium Winsum soil } \\
\hline & quant. & t. const. & quant. & const. & ind. & quant. & const. & quant. & const. & ind. \\
\hline 0.1 & 6.5 & -0.675 & 92 & -0.0319 & 14.7 & 25 & -1.52 & 72 & -0.153 & 2.10 \\
\hline 0.01 & 15.5 & -0.80 & 85 & -0.0605 & 7.68 & 33 & -1.15 & 61 & -0.153 & 1.67 \\
\hline 0.001 & 9 & -0.65 & 86 & -0.059 & 7.13 & 28 & -1.80 & 67 & -0.194 & 1.35 \\
\hline 0.0001 & 14 & -0.88 & 82 & -0.062 & 6.10 & 35 & -1.25 & 57 & -0.185 & 1.20 \\
\hline
\end{tabular}

TABLE 36. Stability classes $(\%)$, constants $\left(\times \frac{1}{2} \cdot 10^{s}\right)$ and indices at $\mathrm{pH} 8.2$ of magnesium basin soil and magnesium Winsum soil

\begin{tabular}{|c|c|c|c|c|c|c|c|}
\hline \multicolumn{8}{|c|}{ magnesium basin soil } \\
\hline $\mathbf{M}$ & quant. & const. & quant. & const. & quant. & const. & ind. \\
\hline $\begin{array}{l}0.1 \\
0.01 \\
0.001 \\
0.0001\end{array}$ & $\begin{array}{l}4 \\
5 \\
4 \\
4\end{array}$ & $\begin{array}{l}-45.5 \\
-28.5 \\
-30.2 \\
-38.5\end{array}$ & $\begin{array}{r}8 \\
11 \\
13 \\
14\end{array}$ & $\begin{array}{l}-1.17 \\
-0.605 \\
-0.705 \\
-0.815\end{array}$ & $\begin{array}{l}88 \\
84 \\
83 \\
82\end{array}$ & $\begin{array}{r}-0.0347 \\
-0.0425 \\
-0.0502 \\
-0.0510\end{array}$ & $\begin{array}{r}12.25 \\
8.96 \\
7.32 \\
7.32\end{array}$ \\
\hline \multicolumn{8}{|c|}{ magnesium Winsum soil } \\
\hline $\begin{array}{l}0.1 \\
0.01 \\
0.001 \\
0.0001\end{array}$ & $\begin{array}{r}6 \\
7 \\
13 \\
14\end{array}$ & $\begin{array}{r}8.2 \\
-16.8 \\
-\quad 9.8 \\
-14.2\end{array}$ & $\begin{array}{l}33 \\
44 \\
49 \\
43\end{array}$ & $\begin{array}{l}-1.31 \\
-1.0 \\
-0.88 \\
-0.885\end{array}$ & $\begin{array}{l}59 \\
49 \\
38 \\
33\end{array}$ & $\begin{array}{r}-0.116 \\
-0.117 \\
-0.112 \\
-0.123\end{array}$ & $\begin{array}{l}1.82 \\
1.44 \\
1.03 \\
0.835\end{array}$ \\
\hline
\end{tabular}

\subsubsection{Calcium soils}

The data for calcium basin soil at $\mathrm{pH} 8.2$ quickly and slowly wetted, and those for calcium Winsum soil (slowly wetted, $\mathrm{pH} 8.2$ ) are given in table 37 .

Comparing the slowly wetted calcium basin soil with the magnesium soil it is seen that the indices of the calcium soil are only a little higher. With the Winsum soil the difference is more marked, the stability indices of the calcium soil amounting to 1.8 times that of the magnesium soil. With both a steady increase of the classes with low stability is observed with decreasing salt concentration, with the basin clay soil a decrease of the stability constants is also observed.

The sudden immersion has as effect that the stability of the least stable part is decreased and that the quantity of the most stable class decreases.

\subsubsection{Untreated soils}

In order to investigate whether the percolation with salts and ethanol had altered the resistance of the aggregates, the following experiments were carried out: the untreated aggregate fraction of basin clay soil was shaken with slightly acid solutions of calcium chloride as this soil is chiefly calcium saturated and acid, the Winsum soil was shaken with magnesium chloride solutions of $\mathrm{pH} 8.2$ as it is chiefly magnesium saturated and alkaline. The data are listed in tables 38 and 39. 
TABLE 37. Stability classes $(\%)$, constants $\left(\times \frac{1}{2}, 10^{3}\right)$ and indices of calcium basin soil, wetted by capillarity and by immersion, and of calcium Winsum soil, wetted by capillarity

calcium basin soil, wetted by capillarity

\begin{tabular}{lccccccc}
\hline M & quant. & const. & quant. & const. & quant. & const. & ind. \\
\hline 0.1 & 4 & -11.5 & 9.5 & -1.07 & 84 & -0.0255 & 15.8 \\
0.01 & 8 & -15.3 & 15 & -0.462 & 78 & -0.0399 & 10.3 \\
0.001 & 5 & -9.4 & 6 & -0.895 & 86 & -0.0477 & 8.6 \\
0.0001 & 5 & -15.7 & 7 & -0.670 & 86 & -0.0477 & 8.6 \\
\hline \multicolumn{7}{c}{ calcium basin soil, wetted by immersion } \\
\hline 0.1 & 7 & -55.5 & 15 & -1.62 & 78 & -0.0339 & 10.2 \\
0.01 & 7 & -72.5 & 18 & -1.37 & 75 & -0.0381 & 8.2 \\
0.001 & 9 & -71.5 & 14 & -2.36 & 77 & -0.0515 & 6.45 \\
0.0001 & 6 & -80.5 & 17 & -1.95 & 77 & -0.0515 & 6.45 \\
\hline \multicolumn{7}{c}{} & \multicolumn{7}{c}{ calcium Winsum soil, wetted by capillarity } & & \\
\hline 0.1 & 10 & -3.36 & 26 & -0.404 & 64 & -0.0842 & 3.26 \\
0.01 & 7 & -4.46 & 45 & -0.489 & 49 & -0.0707 & 2.46 \\
0.001 & 13 & -4.90 & 52 & -0.395 & 35 & -0.072 & 1.85 \\
0.0001 & 21 & -3.95 & 37 & -0.450 & 42 & -0.099 & 1.55 \\
\hline
\end{tabular}

TABLE 38. Stability classes $(\%)$, constants $\left(\times \frac{1}{2} \cdot 10^{3}\right)$ and indices of natural basin soil $\left(\mathrm{CaCl}_{2}\right)$

\begin{tabular}{|c|c|c|c|c|c|c|}
\hline \multicolumn{2}{|r|}{$0.05 \mathrm{M}$} & \multicolumn{2}{|l|}{$0.005 \mathrm{M}$} & $0.0005 \mathrm{M}$ & \multicolumn{2}{|l|}{$\mathrm{H}_{8} \mathrm{O}$} \\
\hline quant. & const. & quant. const. & ind. & quant. const. ind. & quant. const. & ind. \\
\hline 97 & -0.0245 & 86. -0.0271 & 16.3 & $\begin{array}{lll}89 & -0.0317 & 13.3\end{array}$ & -0.0322 & 13.3 \\
\hline
\end{tabular}

TABLE 39. Stability classes $(\%)$, constants $\left(\times \frac{1}{2} \cdot 10^{3}\right)$ and indices of natural Winsum soil with $\mathrm{MgCl}_{2}$ (pH 8.2)

\begin{tabular}{|c|c|c|c|c|c|c|c|}
\hline $\mathbf{M}$ & quant. & const. & \multicolumn{2}{|c|}{$\begin{array}{l}\text { wetted by capillarity } \\
\text { quant. }\end{array}$} & const. & \multicolumn{2}{|c|}{ ind. } \\
\hline 0.1 & 50 & -1.63 & & 47 & -0.132 & \multicolumn{2}{|c|}{1.06} \\
\hline 0.01 & 44 & -1.98 & & 54 & -0.150 & \multicolumn{2}{|c|}{1.25} \\
\hline 0.001 & .45 & -3.10 & & 53 & -0.182 & \multicolumn{2}{|c|}{0.905} \\
\hline 0.0001 & 51 & -3.22 & & 47 & -0.184 & \multicolumn{2}{|c|}{0.695} \\
\hline & & & \multicolumn{2}{|c|}{ wetted by immersion } & & & \\
\hline $\mathbf{M}$ & quant. & const. & quant. & const. & quant. & const. & ind. \\
\hline 0.1 & & & 45 & -2.27 & 52 & -0.142 & 1.08 \\
\hline 0.01 & 10 & -28.6 & 32 & -2.05 & 58 & -0.140 & 1.35 \\
\hline 0.001 & 18 & -20.0 & 32 & -2.16 & 50 & -0.142 & 0.966 \\
\hline 0.0001 & 13 & -17.2 & 40 & -2.15 & 47 & -0.167 & 0.736 \\
\hline
\end{tabular}


It is seen that the untreated soil is more stable (coefficient of indices 1.5), but as the $\mathrm{pH}$ was lower too this might have had a favourable influence on the stability.

It is seen that the sudden wetting of the Winsum soil resulted in a class with very low stability. This is however not reflected in the indices, which give no special weight to the less stable classes. Comparison with table 36 shows that the stability of the aggregates was slightly increased by the preparation of the homoionic soil.

\subsubsection{Conclusion}

Comparing the data of the colloid clay granules with those of the whole soil it is seen that potassium basin clay and soil have nearly the same stability. The magnesium soil is more stable at low concentrations than the clay, which is also the case with the calcium soil and clay. The presence of humus seems to overcompensate the dilution of the clay fraction with silt. The potassium Winsum clay is more stable than the Winsum soil, the same holds for the magnesium and the calcium clays and soils; the humus content is most probably insufficient to compensate for the loss of stability by admixture of silt.

\subsection{KaOLINITE}

\subsubsection{Sodium kaolinite}

One gram portions of the granules of sodium kaolinite were shaken with solutions of sodium chloride of $0.1 \mathrm{M}$ and lower concentrations at $\mathrm{pH}$. The granules shaken with $0.01 \mathrm{M}$ solution had some stability, at lower concentrations spontaneous dispersion occurred. Only with a salt concentration of $0.1 \mathrm{M}$ any measurable stability was observed. The constant $\left(\times \frac{1}{2} \cdot 10^{3}\right)$ was -38 , the index 0.0143 , for $0.01 \mathrm{M}$ the index was 0.003 aproximately.

\subsubsection{Calcium kaolinite}

One gram portions of calcium kaolinite were shaken with alkaline solutions ( $\mathrm{pH} 8.5$ ) of calcium chloride.

The results are listed in table 40.

For the determination of the indices the original data have been used. The stabilities are very low, though not abnormal.

TABLE 40. Stability classes $(\%)$, constants $\left(\times \frac{1}{2}, 10^{3}\right)$ and indices of calcium kaolonite $(\mathrm{pH} 8.5)$

\begin{tabular}{|c|c|c|c|c|c|c|c|c|c|c|c|}
\hline \multicolumn{3}{|c|}{$0.05 \mathrm{M}$} & \multicolumn{3}{|c|}{$0.005 \mathrm{M}$} & \multicolumn{3}{|c|}{$0.0006 \mathrm{M}$} & \multicolumn{3}{|c|}{$0.0001 \mathrm{M}$} \\
\hline quant. & const. & ind. & quant. & const. & ind. & quant. & const. & ind. & quant. & const. & ind. \\
\hline 71 & -3.42 & 0.066 & 76 & -6.25 & 0.0582 & 76 & -8.80 & 0.043 & 94 & -21.6 & 0.0236 \\
\hline
\end{tabular}




\subsection{LAtosol}

\subsubsection{Sodium latosol}

Remnants of the latosol used for the $\mathrm{pF}$ determination were crushed and sieved, the 2-1 $\mathrm{mm}$ fraction was used.

One series was run with solutions of $\mathrm{pH} 8.8$ the other with a $\mathrm{pH}$ of 10 . The data are represented in table 41 .

TABLE 41. Stability classes $(\%)$, constants $\left(\times \frac{1}{2} \cdot 10^{8}\right)$ and indices of sodium latosol ( $\mathrm{pH} 8.8$ and $\left.\mathrm{pH} 10\right)$

\begin{tabular}{|c|c|c|c|c|c|c|c|c|c|c|}
\hline \multirow[b]{2}{*}{$\mathbf{M}$} & \multicolumn{5}{|c|}{ pH 8.8} & \multicolumn{5}{|c|}{$\mathrm{pH} 10$} \\
\hline & quant. & const. & quant. & - const. & ind. & quant. & const. & quant. & const. & ind. \\
\hline 0.1 & & & 96 & -0.086 & 6.66 & & & 90 & -0.40 & 1.45 \\
\hline 0.01 & & & 95 & -0.065 & 9.17 & 30 & -1.08 & 45 & -2.75 & 0.421 \\
\hline 0.0011 & 8 & -0.95 & 90 & -0.041 & 10.8 & & & 75 & -8.75 & 0.0621 \\
\hline 0.0001 & 8 & -0.725 & 88 & -0.0385 & 11.3 & & & 80 & -5.50 & 0.113 \\
\hline
\end{tabular}

The stability of the latosol at $\mathrm{pH} 8.8$ is high and increases with decreasing salt concentration, which is most unexpected. Only 8 percent of the soil follows the usual trend as its stability decreases with decreasing concentration.

At $\mathrm{pH} 10$ the stability increases with increasing concentration. At $0.1 \mathrm{M}$ salt concentration the index is only $1 / 4$ th of that at $\mathrm{pH} 8.8$ the differences increase with decreasing concentration. An exception to the rule that the least stable parts are dispersed first is found at $0.01 \mathrm{M}$ and lower salt concentrations.

The curves become gradually steeper and the straight part is steeper than the first part of the curve. A plausible explanation seems to be that some coating material has been deposited on or near the surface during the drying for moisture determination after equilibration with a certain $\mathrm{pF}$. Indeed only the granules derived from the deflocculated suspensions had a shiny surface. This coating might also explain the stability of the granules in sodiumcarbonate solution of $\mathrm{pH} 10$, which is not quite in accordance with the $\mathrm{pF}$ determinations where the granules dispersed spontaneously to a large degree. As usually the reaction of a latosol is acid, one can expect an abnormal behaviour if the $\mathrm{pH}$ is raised to 10 .

\subsubsection{Hydrogen latosol}

The hydrogen form of this soil had been prepared by leaching with $0.1 \mathrm{M}$ hydrochloric acid till free of calcium, and removing the excess acid by leaching with distilled water. Granules of the 2-1 $\mathrm{mm}$ fraction were prepared by puddling, drying and sieving. The influence of the acid concentration on the stability was investigated. As the acid might react with the soil during the drying of the desintegrated quantities it had to be neutralized first by titration with $0.1 \mathrm{M}$ sodium hydroxyde using methylorange as indicator. During the shaking with hydrochloric acid some alumina but no iron was liberated. 
The interpretation of the data met with some difficulties as some graphs showed two straight lines without a transitional zone. The second line had a much smaller slope than the first. If granules are present with a harder core, then such crossing lines are expected. The less resistent shell would be destroyed first and the more stable core would be attacked subsequently. The curve of the latosol shaken with distilled water could be interpreted in the usual way by assuming that granules with a high and low resistence were present at the beginning of the experiment.

The result is figured in both ways and given in table 42 .

TABLE 42. Stability classes $(\%)$, constants $\left(\times \frac{1}{2} \cdot 10^{3}\right)$ and indices of hydrogen latosol

\begin{tabular}{|c|c|c|c|c|c|c|c|c|c|}
\hline \multirow[b]{2}{*}{$\mathbf{M}$} & \multicolumn{4}{|c|}{ 'hard core' } & \multicolumn{5}{|c|}{ 'no core' } \\
\hline & quant. & const. & quant. & const. & quant. & const. & quant. & const. & ind. \\
\hline 0.16 & & & 100 & -0.182 & & & 100 & -0.182 & 2.83 \\
\hline 0.08 & & & 100 & -0.152 & & & 100 & -0.152 & 3.59 \\
\hline 0.04 & 79 & -0.108 & 30 & -0.050 & 48 & -0.21 & 52 & -0.050 & 5.25 \\
\hline 0.02 & 69 & -0.102 & 31 & -0.036 & 56 & -0.176 & 44 & -0.023 & 5.84 \\
\hline 0.01 & 38 & -0.047 & 57 & -0.023 & 45 & -0.124 & 55 & -0.016 & 15.1 \\
\hline 0.001 & 70 & -0.050 & 30 & -0.028 & 60 & -0.071 & 40 & -0.024 & 11.12 \\
\hline $\mathrm{H}_{2} \mathrm{O}$ & 55 & -0.055 & 45 & -0.022 & 40 & -0.123 & 60 & -0.021 & 12.4 \\
\hline
\end{tabular}

Whether the more stable class is considered as cores, appearing during the test or as separate particles present from the start it is apparent that the stability diminishes with increasing acid concentrations. With the first concept this decrease starts between 0.01 and $0.02 \mathrm{M}$, lower acid concentrations giving the same stability.

\subsubsection{Calcium latosol}

This soil was prepared by washing natural aggregates with normal solution of calcium chloride, removing the excess salts with distilled water.

By this method the absorbed calcium ions are replaced to a large extent by hydrogen ions, so that the $\mathrm{pH}$ of the $1: 2.5$ extract may vary between 5 and 6 . The $\mathrm{pH}$ of the suspensions syphoned off after the seventh shaking varied between 4.6 and 5.2.

Natural aggregates of $1-0.15 \mathrm{~mm}$ were sieved out and portions of two gram were used for the determination.

Another series was shaken with calcium chloride solutions alkalinized to $\mathrm{pH} 8.8$. The results of both experiments are given in table 43 .

It is seen that the stability of the acid clay does decrease with increasing salt concentration. The stability is higher than with the hydrogen clay, most probably because in this case natural granules have been used instead of artificial ones, prepared by puddling and drying.

At $0.05 \mathrm{M}$ the difference between the acid and the alkaline series is negligible, but at $\mathrm{pH} 9$ the stability remains constant with decreasing salt concentration: 
TABLE 43. Classes $(\%)$, constants $\left(\times \frac{1}{2} \cdot 10^{2}\right)$ and indices of calcium latosol ( $\mathrm{pH} 4.6-5.2$ and $\left.\mathrm{pH} 8.8\right)$

\begin{tabular}{|c|c|c|c|c|c|c|c|}
\hline \multirow[b]{2}{*}{$\mathbf{M}$} & \multicolumn{3}{|c|}{$\mathrm{pH} 4.6-5.2$} & \multirow[b]{2}{*}{$\mathbf{M}$} & \multicolumn{3}{|c|}{ pH 8.8} \\
\hline & quant. & const. & ind. & & quant. & const. & ind. \\
\hline 0.05 & 100 & -0.0590 & 9.0 & 0.05 & 96 & -0.0482 & 10.5 \\
\hline 0.005 & 96 & -0.0350 & 15.7 & 0.005 & 96 & -0.0410 & 12.3 \\
\hline 0.0005 & 96 & -0.0167 & 34.0 & 0.0007 & 100 & -0.038 & 13.6 \\
\hline $\mathrm{H}_{2} \mathrm{O}$ & 96 & -0.0126 & 48.7 & 0.0002 & 100 & -0.049 & 10.7 \\
\hline
\end{tabular}

\subsubsection{Conclusion}

There is no similarity in the behaviour of kaolinite and latdsol. In the first place the stability of the latosol is a 100 times higher; in the second place the stability of the latosol decreases with increasing salt concentration, whereas that of the kaolinite increases.

\section{GENERAL DISCUSSION}

For the ease of comparison plots have been made of the osmotic pressure of the cation concentration against the stability index. A double logarithmic scale has been chosen as the variation of the indices is so large that the data of the different clays could not have been represented with a linear scale without obscuring the variations of the indices in the less stable region. On the ordinate the log of the index is plotted, on the abscissa the log of the osmotic pressure of the cations in $\mathrm{cm}$ of water. Also the molarity of the solutions has been plotted on a logarithmic scale.

In order to investigate the relation between stability and swelling graphs have been prepared on which the log of the stability index is plotted against the log of the corresponding moisture content at $\mathrm{pF} 1$.

One should bear in mind, that the stability will be a function of the moisture content at zero suction and not of that at $\mathrm{pF} 1$. This is of importance as the relative decrease of moisture by applying $10 \mathrm{~cm}$ suction will be larger with swollen or dispersed systems, than with granules.

\subsection{Bentonite}

\subsubsection{Salt concentration versus stability; Fig. 38}

The curves $a$, A and $\alpha$ represent the relation between concentration and stability of the various sodium bentonites. In curves $a$ and $\alpha$, for the aggregates prepared by drying of a partly flocculated and a strongly flocculated suspension respectively, the most vertical part, indicating the largest decrease of stability per decrease of concentration, lies between 1 and $0.4 \mathrm{M}$, the region where the flakes change into flocks.

The more curved parts illustrate the deflocculation. Curves $a$ and $\alpha$ are prolonged 


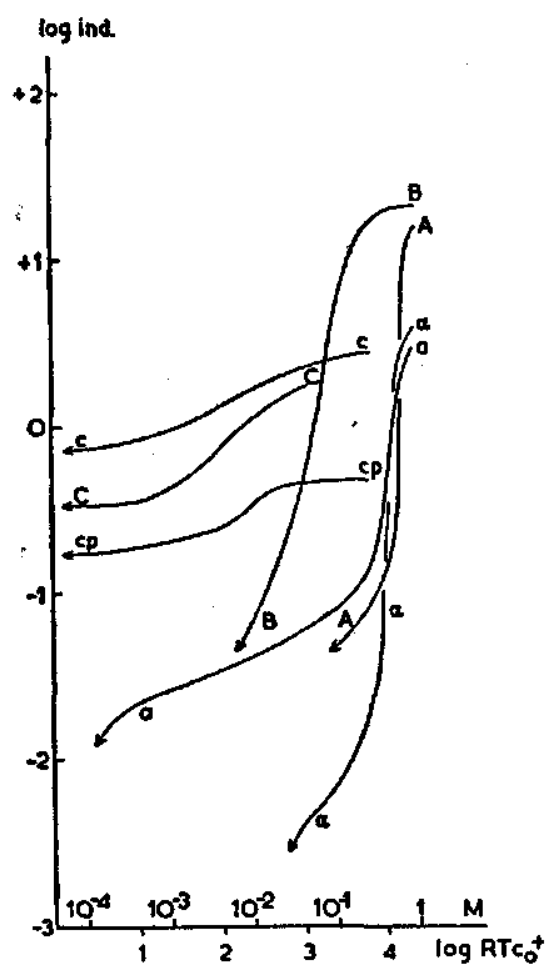

Fig. 38. Stability of bentonite in dependance of salt concentration
a. Na-bentonic flakes
A. Na-bentonite granules
$\alpha$. Na-bentonite dried from $1 \mathrm{~N}$ salt solution
B. K-bentonite flakes
c. Ca-bentonite flakes
C. Ca-bentonite flakes pH 8.5
cp. Ca-bentonite puddled

by an arrow pointing downwards, indicating that by further lowering of the concentration the stability constant will decrease to minus infinite. With curve A (dialyzed clay) the steepest part lies at a slightly higher concentration, which is probably caused by the higher stability of the granules at $1 \mathrm{M}$ salt concentration.

The potassium bentonite is represented by curve B. There is no difference in stability between 1 and $0.4 \mathrm{M}$, so the maximum stability is reached. The stability decreases sharply between 0.1 and $0.025 \mathrm{M}$, the same range where a visible change in structure occurs.

Curves $c, \mathrm{G}$ and $\mathrm{cp}$ represent the influence of the salt concentration on calcium montmorillonite, $c$ for a slightly acid system, $\mathrm{C}$ for a slightly alkaline one $(\mathrm{pH} 8.5)$ and $\mathrm{cp}$ for a slightly acid puddled system. It is seen that the influence of the concentration is small compared with that of the monovalent ions, while at $\mathrm{pH} 8.5$ this influence is somewhat more pronounced.

By puddling the stability has been decreased substantially, but even at very low concentrations some stability remains, this is not expected as the slurry of calcium bentonite is elastic over a wide range. The curves are prolonged by arrows pointing in the direction of zero concentration, indicating that the granules are expected to have some stability in pure water. At high concentrations the stability of the calcium bentonite is distinctly lower than that of the potassium clay. Here two factors which might function simultaneously, may be active. 
The first factor is the relatively stronger swelling of calcium bentonite at high concentrations, which will impair the resistance to abrasive forces. The second factor is that the structural arrangement of the calcium bentonite might differ from that of the potassium bentonite. The granules had been prepared by drying concentrated suspensions and pastes so that the kind of cation may have influenced the formation of structure, the calcium saturated granules being less dense than the potassium or sodium saturated ones.

\subsubsection{Moisture content $\mathrm{pF} 1$ versus stability, (fig. 39)}

Gurve $a$ represents the relation between moisture content at $\mathrm{pF} 1$ and stability for flakes of sodium bentonite. Starting at low moisture content, the slope of the curve increases contineously to give a rather straight line at higher moisture contents. This

FIo. 39. Stability of bentonite in dependance of moisture content at pF1
a. Na-bentonite flakes
๙. Na-bentonite dried from $1 \mathrm{~N}$ solution
B. K-bentonite flakes
c. Ca-bentonite flakes
C. Ca-bentonite flakes $\mathrm{pH} \mathbf{8 . 5}$

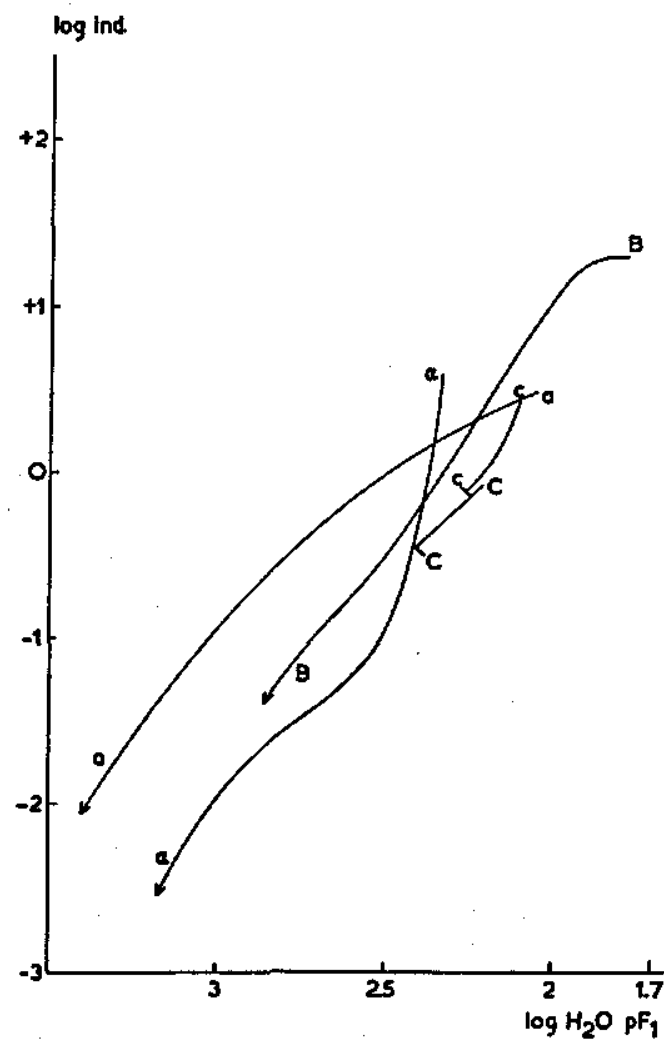

means that in the region where the change in structure occurs, the raise in moisture content has smaller influence on the stability than at lower concentrations. This may be explained by assuming that excess liquid is absorbed in voids caused by the change in structural arrangement from flake to concentrated flock, which structure also 
shows a marked but lower stability. That the moisture content of the flakes made by drying sodium bentonite from a suspension 1 molar in salt, curve $\alpha$ is higher, at high stability, than that of the granules (curve $a$ ), is explained by the numerous voids, which are made by dissolving the sodium chloride crystals during equilibration with the sodium chloride solution. That at higher moisture contents curve $\alpha$ shows less stability than the granules, may be caused by the longer time of swelling during equilibration.

Curve $B$ representing the relation between moisture content and stability for the potassium clay, shows a small horizontal part at high stability. This indicates a small increase in moisture content without influence on the stability. The following increase in moisture content has however a very marked influence on the stability. Compared with the sodium bentonite (curve $a$ ) the stability at the same moisture content is much lower, which again may be due to the intrinsic properties caused by the potassium saturation or the adventitious properties acquired during the formation of the granules.

The curves for calcium bentonite $c$ and $\mathrm{C}$ have a decreasing slope, curve $\mathrm{C}$ being nearly a prolongation of curve $c$, indicating that the first increase in moisture content has a larger influence on the stability than the latter. The high stability part nearly coincides with that of curve $a$. The curve is stopped by a line perpendicular to its direction, indicating that on further dilution no increase in moisture content or diminution of the stability is to be expected.

\subsubsection{Gonclusion}

The curves in fig. 39 show more or less the same trend, if one takes changes in structure into account. This is not the case with the curves in fig. 38. It is therefore probable that the stability is primarily connected with the moisture content and that the salt concentration influences the stability via the regulation of the swelling.

\subsection{Margalite. Colloid}

\subsubsection{Salt concentration versus stability; (fig. 40)}

These relations are demonstrated for the sodium clay by curve A. From the increase in curvature at high concentration it can be derived that the maximum stability will have been nearly reached at $1 \mathrm{M}$. Compared with sodium bentonite the curve is more regular and flatter, indicating a lesser influence of salt concentration on stability, especially in the region between 1 and $0.4 \mathrm{M}$.

Curve $B$ shows the relation between salt concentration and stability for potassium margalite. The stability decreases sharply in the region between 0.1 and $0.001 \mathrm{M}$, while the largest change in stability with potassium bentonite occurred between 0.1 and $0.025 \mathrm{M}$. Further lowering of the concentration has little influence on the stability 
FrG. 40. Stability of margalite granules in dependance of salt concentration
A. $\mathrm{Na}$ colloid flakes
B. $\mathrm{K}$ colloid flakes
b. $\mathbf{K}$ colloid puddled
G. Ca-colloid granules
D. Ca-margalite soil slowiy moistened

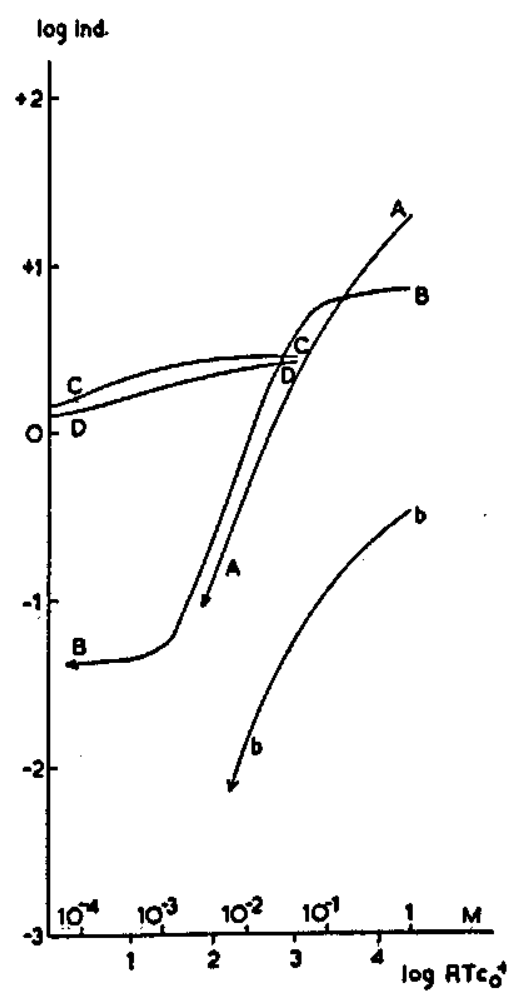

which even persists in distilled water. If the clay is puddled at the appropriate moisture content the stability is impaired to a large extent as shown by curve $b$. In contrast with the calcium bentonite most of the clay puddled at low salt concentrations disperses spontaneously. This is in accordance with the desorption characteristic of the suspension as it is elastic over a large range of moisture contents. Curve $b$ has some resemblance with that of the sodium clay.

Curve $G$ shows that there exists practically no influence of the concentration on the stability of calcium margalite clay mineral granules. Curve D for the moistened soil granules resembles closely curve $\mathrm{C}$ for the clay mineral. As this soil is specially susceptible to air explosion it had to be moistened to about $30 \%$ in order to avoid this phenomenon.

\subsubsection{Moisture content $\mathrm{pF} 1$ versus stability; (fig. 41)}

For sodium margalite this relation is presented by curve $A$. The smooth curve shows, that the initial rise in moisture has slightly more influence on the stability than at higher moisture contents. An influence of the transition of the granule to the condensed flock was not observed. Comparison with the curve for sodium bentonite shows that at high moisture contents, near $1000 \%$, the stability is not much higher, but at lower moisture contents a strong deviation occurs, the margalite being more stable at the same moisture content than the bentonite. 


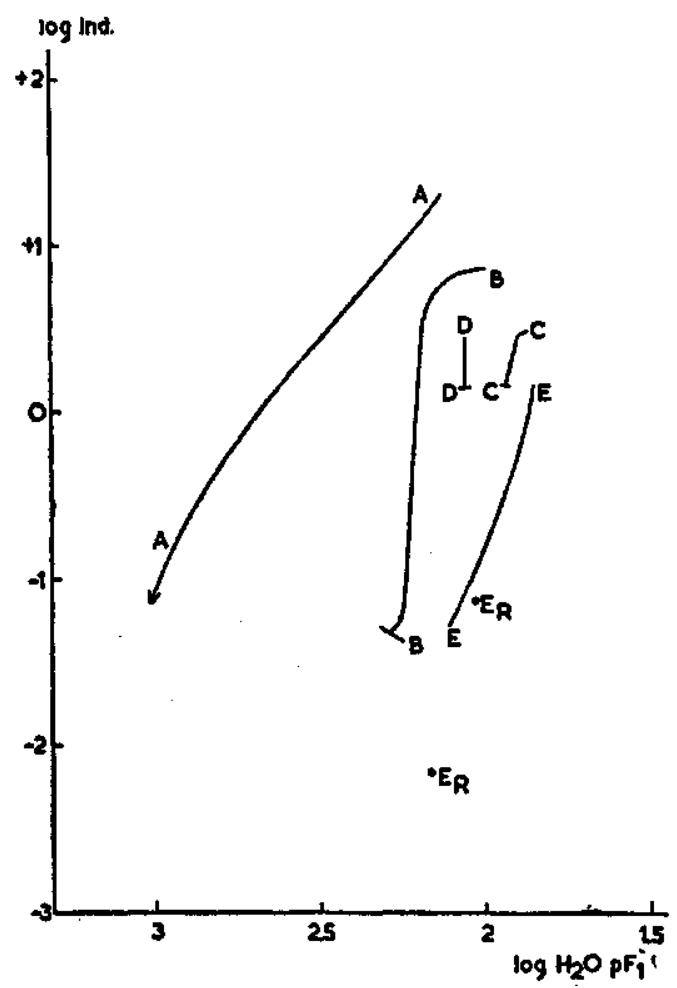

Fic. 41. Stability of margalite in dependance of moisture content at $\mathrm{pF}$ l
A. Na-colloid flakes
B. K-colloid flakes
C. Ca-colloid granules
D. Ca-margalite soil slowly moistured
E. Ca-margalite soil slurry de- sorbed

The influence of the moisture content on the stability of potassium margalite is shown by curve B. The small increase from 120 to $160 \%$ moisture has an enormous influence on the stability. This influence of the swelling is much larger than with the sodium margalite. It may be explained by assuming that there is a very limited swelling possible within the clay polyplate and that most of the swelling takes place between the polyplates. Thus the strength of the granules may be impaired by a relatively small water uptake compared with the sodium clay where the swelling takes also place between the single clay plates so that the distances remain more uniform. As the swelling is limited, a certain stability persists in distilled water.

Curve $G$ represents the influence of the swelling on stability for calcium margalite clay mineral. The slope of the curve is steep. For moistened margalite soil, curve $D$, no influence of the salt concentration on the swelling could be determined notwithstanding an influence of the salt concentration on stability exists. By the moistening of the ovendry material cracks developed (HAINEs, 1923) which hold moisture at $\mathrm{pF} 1$ thereby obscuring the effect of the swelling.

\subsubsection{Conclusion}

Comparison of the margalite with the bentonite shows that the sodium margalite has a higher stability except at very low concentrations, where the stabilities coincide. 
Potassium margalite has in contrast with potassium bentonite a stability at low concentrations. That the decrease of the stability of the potassium margalite is out of proportion with the increase in swelling is explained by the assumption of a swelling chiefly limited to the surfaces between the polyplates.

Both calcium margalite and bentonite show a limited swelling and a stability in distilled water which is higher for the margalite.

The stabilities of moistened margalite soil is about the same as that of the clay mineral.

\subsection{ILLITE AND ILLITIG GLAY FRAGTIONS}

\subsubsection{Salt concentration versus stability}

\subsubsection{Fithian illites; fig. 42}

The curves marked $a, A$ and $\alpha$ represent the relation between salt concentration and stability for sodium illite. Curve $a$, of the organic matter containing first batch is nearly a straight line except for the stronger curvature near $1 \mathrm{M}$, indicating that the maximum stability is nearly reached. The stability of the clay without organic matter is lower, curve A. The organic matter of the clay of the second batch, curve $\alpha$, is probably the cause why little stability is lost during the first swelling. The stability is however hardly increased by the organic matter.

Frg. 42. Stability of illite (FrrHan) in dependance of salt concentration

a. Na-clay fraction organic matter present 1st batch

A. Na-colloid 2nd batch

$\alpha$ Na-clay fraction organic matter present

B. K-illite colloid 2 nd batch

C. Ca-illite colloid 2 nd batch

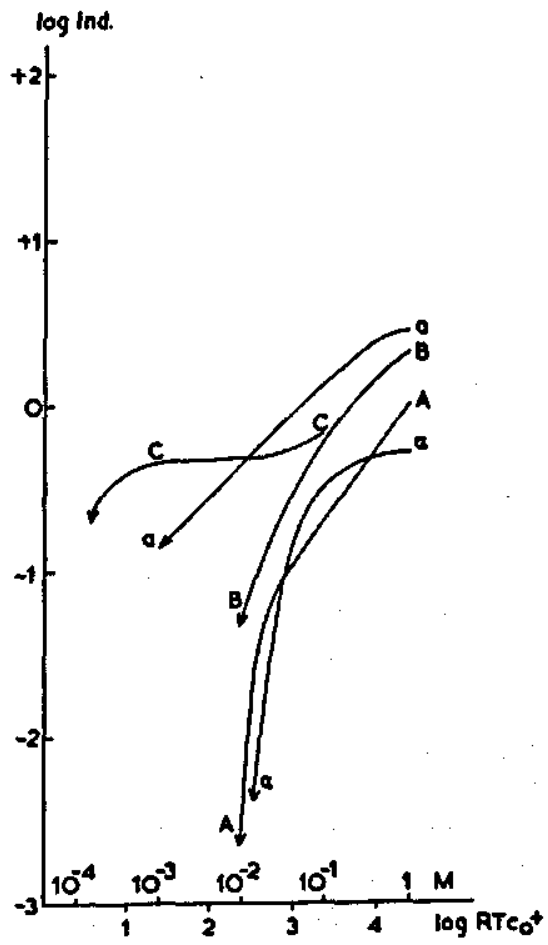


Curve B, of the potassium clay shows that this clay is more stable at high concentrations than the sodium clay, at low concentrations, however, all stability is lost.

Curve $\mathrm{C}$ represents the relations between concentration and stability for the calcium clay. The stability at high concentrations is probably lower than that of the potassium clay, but it remains the same up to $0.001 \mathrm{M}$. At $0.0001 \mathrm{M}$ however no stability is left; this in contrast with the margalite and bentonite. From the desorption curve of the organic matter containing illite (first batch), (fig. 22, curve II B) it may be inferred that this clay will have stability in distilled water.

\subsubsection{Granules of the colloids of basin clay and Winsum clay; fig. 43}

Curves $\mathrm{A}$ and $a$, for the sodium clays show that the stability at $1 \mathrm{M}$ is considerably higher than that of the Fithian illites but it decreases faster with decreasing concentration, with slight difference between the two clays.

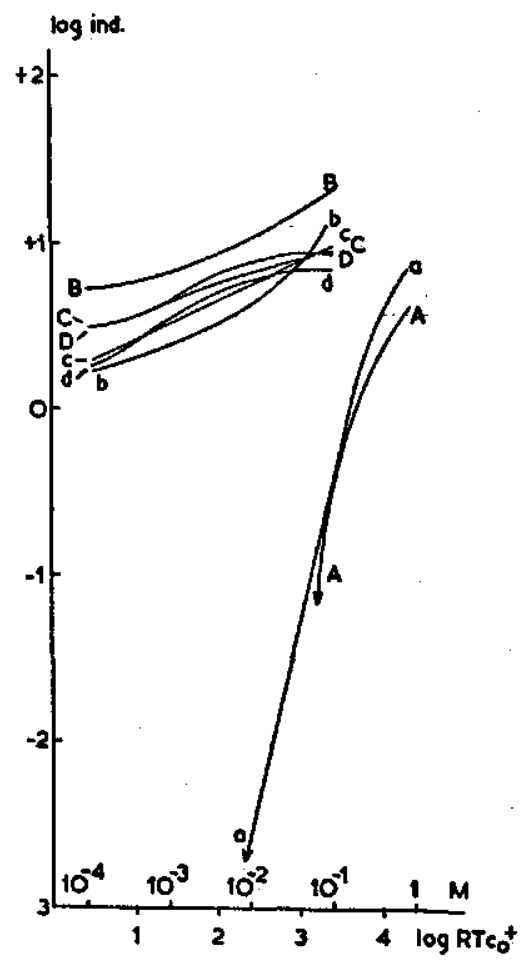

Fro. 43. Stability of basin- and Winsum clay colloid granules in dependance of salt concentration
A. Na-basin colloid
B. K-basin colloid
a. Na-Winsum colloid
C. Mg-basin colloid
b. K-Winsum colloid
D. Ca-basin colloid
c. Mg-Winsum colloid
d. Ca-Winsum colloid

Curves B and $b$ represent the relation for the potassium soil clays. The difference is this time pronounced, the basin clay being considerably more stable than the Winsum clay. The potassium basin clay remains the most stable at low concentrations. the stability of the potassium Winsum clay decreases sharply; it becomes less stable than the magnesium clay.

The magnesium basin clay, curve $\mathrm{C}$, is less stable than the potassium clay. The influence of the decrease in salt concentration from 0.1 to $0.01 \mathrm{M}$ has less influence 
on the stability than with the potassium clay. The magnesium Winsum clay, curve $c$, is slightly more stable than the corresponding potassium clay. There is little difference with the calcium clays, curves $\mathrm{D}$ and $d$. Though at the lowest concentration the Winsum calcium clay seems to be less stable than the magnesium clay.

All basin and Winsum clays except the sodium ones, will have a fair stability with infinite dilution.

\subsubsection{Moisture content $\mathrm{pF} 1$ versus stability}

\subsubsection{Fithian illites; fig. 44}

The relation between moisture content and stability is represented by curve $a$ for organic matter containing illite first batch. It is seen that the first swelling has comparative little influence, but that further swelling impairs the stability to a high degree. The same features are shown by the other carbon containing illite of the second batch, curve $\alpha$. The stability of the clay without organic matter, curve A, is however diminished by the first swelling. It seems that the organic bonds can be stretched over some distance, without loss of stability.

Fro. 44. Stability of illite (Fithian) in dependance of moisture content at $\mathrm{pF} 1$

a. Na-clay fraction organic matter present lst batch

$\alpha$. Na-clay fraction organic matter present 2 nd batch

A. Na-colloid 2nd batch

B. K-illite colloid 2nd batch

C. Ca-colloid 2nd batch

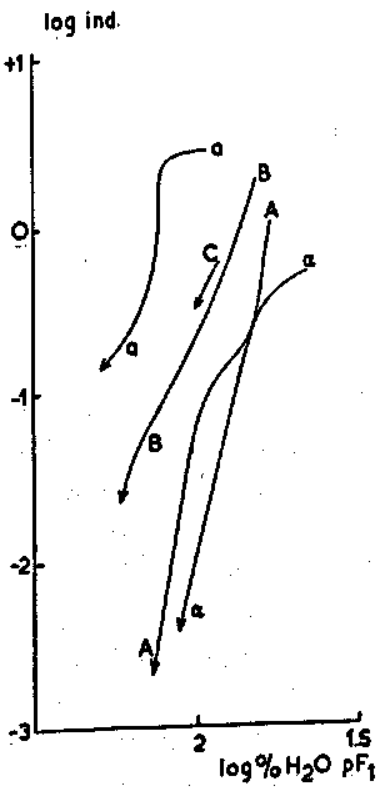

The curve of the potassium clay, curve B, resembles slightly that of the sodium clay without organic matter, but the stability is considerably higher at the same moisture content.

Curve $\mathrm{C}$ of the calcium clay, indicates that the stability varies little while the moisture content varies little also, but a further increase of the moisture content reduces the stability abruptly to zero. The stability of the calcium clay is higher than that of the potassium clay at the same moisture content. 


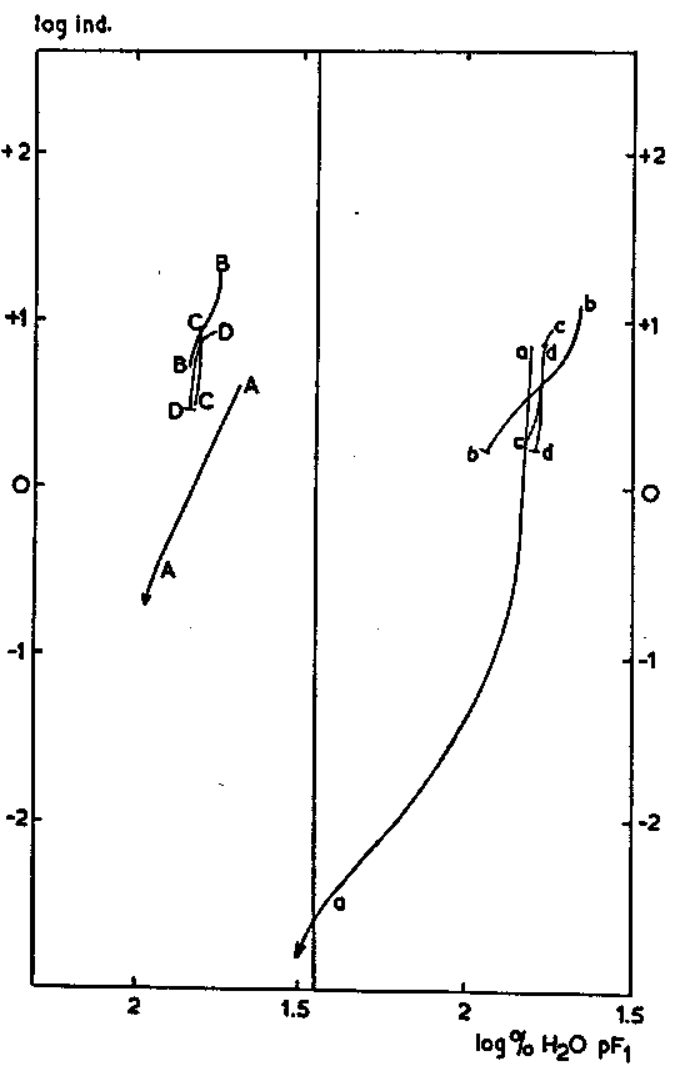

Frg. 45. Stability of basin and Winsum clay colloid granules in dependence of moisture content at $\mathrm{pF} 1$
A. Na-basin colloid
B. K-basin colloid
C. Mg-basin colloid
D. Ca-basin colloid
a. Na-Winsum colloid
b. K-Winsum colloid
c. Mg-Winsum colloid
d. Ca-Winsum colloid

\subsubsection{Basin clay and Winsum clay; fig. 45}

Through the two determinations for the sodium basin clay only a straight line could be drawn, curve A. The curve for the sodium Winsum clay, curve $a$, shows that the first small increase in moisture content has a large influence on the stability.

The curves for the potassium clays, $B$ and $b$, show that the initial swelling has a large influence, that there is a region where this influence is smaller, to increase again with further swelling. This character is most pronounced with the Winsum clay.

The curves of the magnesium clays, $\mathrm{C}$ and $c$, are nearly vertical, but here the initial swelling has less influence than the subsequent. The curves for the calcium clays, $\mathrm{D}$ and $d$, nearly coincide with those of the magnesium clays, and in the case of the basin clay also with the potassium clay.

\subsubsection{Conclusion}

Compared with bentonite and margalite, the Fithian illite differs in so far that no form is stable in water, while the calcium forms of bentonite and margalite are stable and the potassium clay of the latter also. Even at high concentrations the stability of the calcium illite is lower than that of the bentonite and margalite.

The soil clays are all waterstable except the sodium saturated ones. The potassium 
saturated basin clay is the most stable. There is no appreciable difference between the magnesium and the calcium clays. The basin clay is slightly more stable than the Winsum clay. In the case of potassium saturation this difference is appreciable.

The slopes of the graphs relating stability with moisture content are much steeper than those of the bentonite and the moisture contents are lower. This will have been caused by the smaller surface area by which the relative importance of the free space is enhanced and the moisture content decreased at the same interparticle distance, which will determine the stability.

It is seen again, especially with the soil clays, that the relation between moisture and stability is narrower than that of salt-concentration and stability.

\subsection{Basin ANd Winsum SOIL, NATURAL GRANULES}

\subsubsection{Salt concentration versus stability; fig. 46}

FI0. 46. Stability of basin and Winsum clay soil granules in dependence of salt concentration

A. $\mathrm{Na}$ basin soil $\mathrm{pH} 8.2$

B. $\mathrm{K}$ basin soil $\mathrm{pH} 8.2$

C. $\mathrm{Mg}$ basin soil $\mathrm{pH} 7.0$

D. $\mathrm{Mg}$ basin soil $\mathrm{pH} 8.2$

E. Ca basin soil $\mathrm{pH} 8.2$

a. $\mathrm{Na}$ Winsum soil $\mathrm{pH} 8.2$

b. K Winsum soil pH 8.2

c. $\mathrm{Mg}$ Winsum soil $\mathrm{pH} 7.0$

d. $\mathrm{Mg}$ Winsum soil $\mathrm{pH} 8.2$

e. Ca Winsum soil pH 8.2

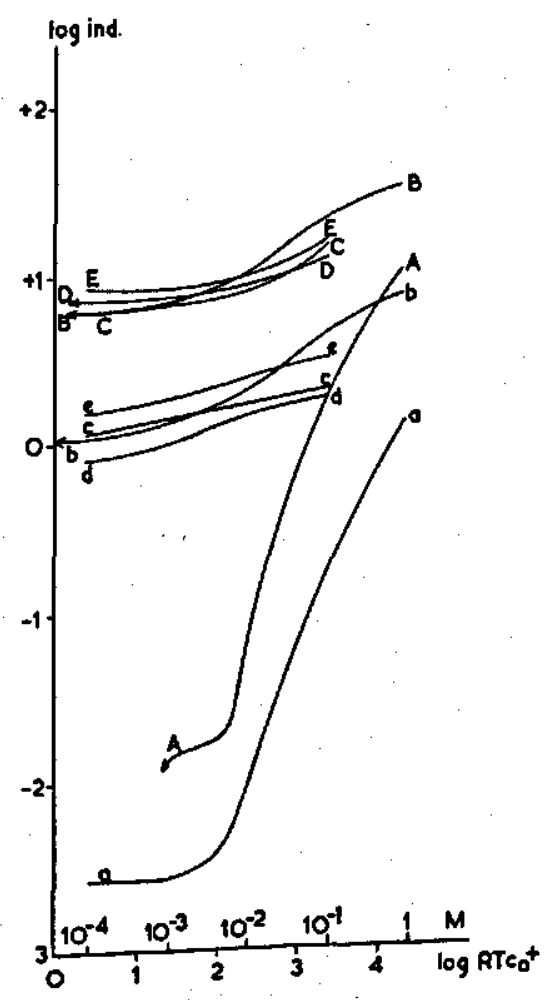

Curves $\mathrm{A}$ and $a$, for the sodium basin and Winsum soil respectively, show a regular decrease of stability with decreasing concentration. The basin soil is more stable than Winsum. At $0.01 \mathrm{M}$ and lower a considerable part is dispersing spontaneously, 
but a certain part remains stable at very low concentrations, hence the deviation of the curve in the horizontal direction.

The potassium soils, curves B (basin) and $b$ (Winsum), are at 0:1 M more stable than the other soils but at low concentration this difference disappears.

With the basin clay soil the stabilities at low concentration of the potassium; magnesium and calcium soils are very much the same. With the Winsum soil a difference between the stabilities can be observed existing throughout the range of concentrations. The calcium soil, $e$, is more stable than the magnesium soil $\mathrm{pH} 7, \varepsilon$, this is more stable than the magnesium soil, $d, \mathrm{pH} 8.2$. The potassium soil has the same stability as the magnesium soil $\mathrm{pH} 7$ at low concentrations: The high content of organic matter of the basin clay soil may have masked the influence of the cations. This may be more pronounced if the organic matter content is lower, as is the case with the Winsum soil.

\subsubsection{Moisture content versus stability; fig. 47}

Curve A of the sodium basin soil and $a$ of the sodium Winsum soil have the same smooth character. Both are nearly prolongations of the curves for the potassium soils, $B$ and $b$.

The curves for the magnesium and calcium basin soil, $\mathrm{C}$ and $\mathrm{D}$, have a sigmoidal character, the slopes are steep and the moisture content is slightly higher than that of the potassium soil. The curves $c$ and $d$ for the magnesium and calcium Winsum soil partly overlay that of the potassium soil, but the moisture content rises less with decreasing stability. The moisture content of the calcium soil is lower than that of the magnesium soil.

\subsubsection{Conclusion}

Compared with the pure clays the basin soils are more stable, while an influence of the cation except that of sodium is not observed at low concentrations. The stability of the Winsum soils is lower than that of the clay granules. Probably the high content of organic matter of the basin clay soil, causes the higher stability. The high stability of the basin clay soil, compared with that of the Winsum soil is in accordance with agricultural practice. While with the Winsum clay the order of decreasing stability was magnesium, calcium, potassium, with the soil the sequence was, calcium, magnesium $\mathrm{pH} 7=$ potassium, magnesium $\mathrm{pH}$ 8.2. It is possible that the organic fraction plays a role.

The influence of concentration on stability was less with the soils than with the clays, sodium and potassium excepted.

The relation between moisture content at $\mathrm{pF} \mathrm{l}$ and stability is narrow with both soils and especially so with the Winsum. With Winsum soil, the sodium soil contains the same amount of water as the potassium soil at the same stability, magnesium nearly coincides with the potassium soil, the deviation between calcium and potassium being small, though the curves are slightly divergent. The difference in stability of 
Frg. 47. Stability of basin and Winsum clay soil granules in dependance of moisture content at $\mathrm{pF} 1$
A. Na basin soil $\mathrm{pH} 8.2$
B. $\mathrm{K}$ basin soil $\mathrm{pH} 8.2$
C. $\mathrm{Mg}$ basin soil $\mathrm{pH} 8.2$
D. Ca basin soil pH 8.2
a. Na Winsum soil pH 8.2
b. $\mathrm{K}$ Winsum soil $\mathrm{pH} 8.2$
c. Mg Winsum soil pH 8:2
d. Ca Winsum soil pH 8.2

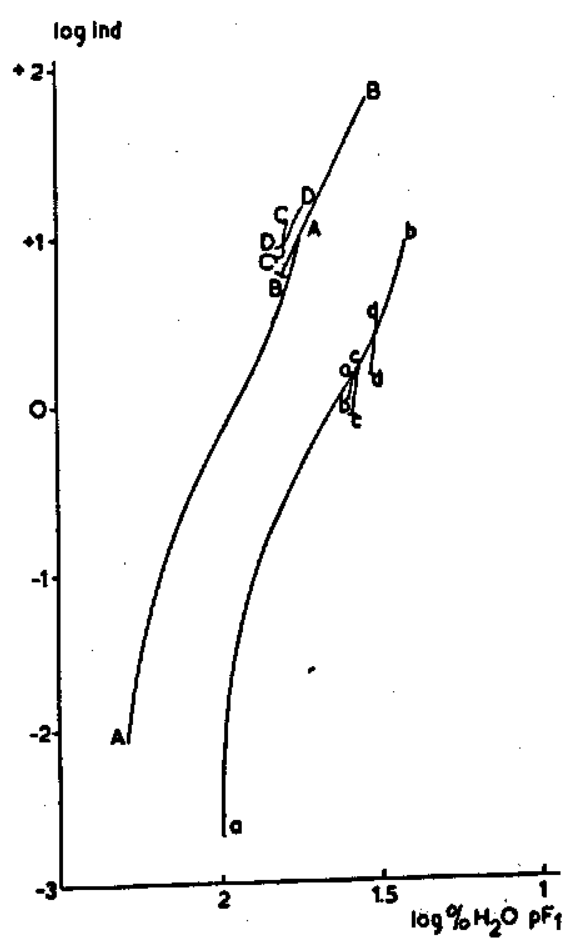

calcium and magnesium soil can be explained by the difference in swelling.

Generally speaking: there is no principal difference in the behaviour of the pure soil clay granules and that of the natural soil granules, both have no connection with the pure clay mineral.

\subsection{KAOLINITE AND LATOSOL}

5.5.1 Salt concentration versus stability; fig. $\mathbf{4 8}$

Of the sodium kaolinite only two points could be determined with some accuracy. The line through these points, curve $A^{\prime}$, indicates that the stability at $0.1 \mathrm{M}$ is extremely low.

Curve $\mathrm{B}^{\prime}$, giving the relation for calcium kaolinite $\mathrm{pH} 8.5$ shows that the stability is very low but decreases not much with decreasing concentration, in distilled water some stability is left.

Curve A for sodium latosol, $\mathrm{pH} 8.8$, shows that the stability of this soil is very high and that it increases by a coefficient 2 with decreasing concentration. If the $\mathrm{pH}$ is raised to 10 , the stability is lowered substantially, even at $0.1 \mathrm{M}$, and it decreases sharp at further dilution as shown by curve $\alpha$. It is not quite certain at which concentration the stability constant becomes minus infinite, for reasons mentioned in chapter II, 4.8.1. 


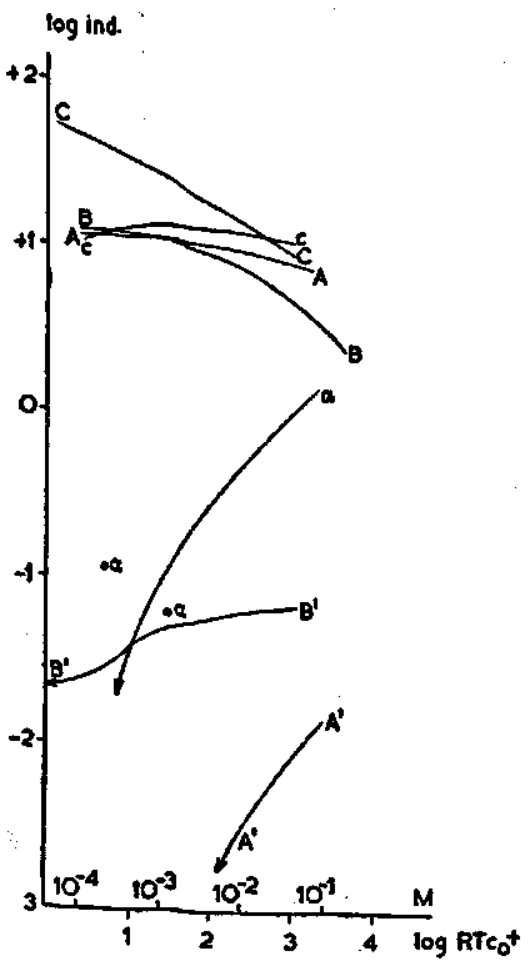

FIG. 48. Stability of kaolinite and latosol in dependence of salt concentration

$\mathrm{A}^{\prime}$. Na-kaolinite colloid

$\mathrm{B}^{\prime}$. Ca-kaolinite colloid

A. Na-latosol pH 8.2

$\alpha$. Na-latosol pH 10

B. H-latosol

C. Ca-latosol $\mathrm{pH} 5$

c. Ca-latosol pH 8.8

Curve $B$ represents the relation for hydrogen latosol. Neglecting one point one gets a regular increase of stability with decreasing concentration down to $0.001 \mathrm{M}$.

Curves $\mathrm{C}$ and $c$ both give the relation between concentration and stability for calcium latosol, curve $G$ for a slightly acid medium, curve $c$ for $\mathrm{pH}$ 8.8. The pronounced increase in stability with decreasing concentration, which is observed in curve $\mathrm{C}$, is not observed if the $\mathrm{pH}$ is raised to 8.8 .

\subsubsection{Stability versus moisture content $\mathrm{pF} 1$; fig. 49}

As the concentration does not influence the swelling to a measurable extent, perhaps because the procedure was not quite adapted (the granules were wetted by immersion and not by capillarity); no relation was found between the moisture content at pF 1 and the stability. The sodium latosol pH 10, curve $\alpha$, forms an exception. The curve shows a strong decrease of the stability with increasing moisture
content.

Near the other curves an arrow has been drawn, indicating in which direction the concentration decreases. So it is demonstrated that with calcium kaolinite, the stability decreases with decreasing concentration whereas with most latosols the stability increases with decreasing concentration. 
Frg. 49. Stability of kaolinite and latosol in dependance of moisture content at $\mathrm{pF} 1$

$A^{\prime}$. Na-kaolinite colloid

B'$^{\prime}$. Ca-kaolinite colloid

A. Na-latosol pH 8.2

a. Na-latosol pH 10

B. H-latosol

C. Ca-latosol pH 5

D. Mg-latosol drying slurry

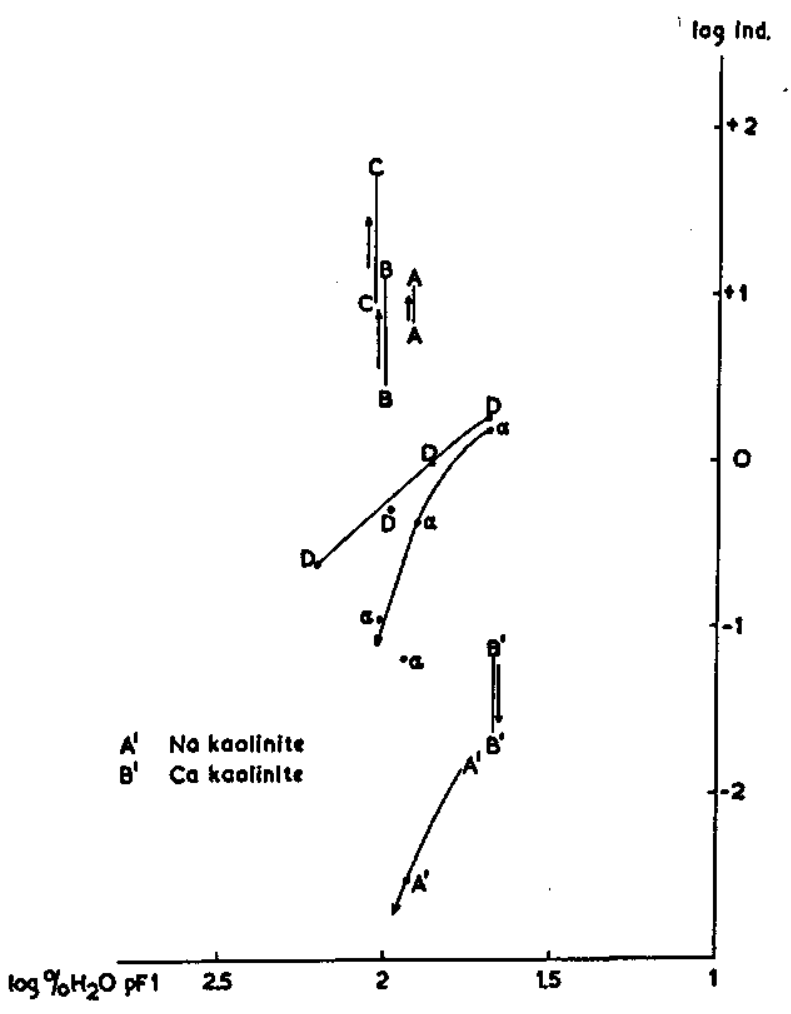

\subsection{Conchusion}

The latosols at a $\mathrm{pH}$ below 9 have an abnormal behaviour as their stability is lowered by increasing salt concentration of the solution. Above $\mathrm{pH} 10$ the stability of sodium latosol is increased by increasing concentration. There is no correlation between the latosol and kaolinite as the latter has a much lower stability (factor 100), which is reduced by lowering the salt concentration.

\section{THE INFLUENGE OF THE DEGREE OF DESORPTION ON THE RESISTANGE AGAINST DISPERSION}

At low salt concentrations this relation can only exist if the systems belong to the semi-elastic and inelastic types. This follows from the results of the experiments cited in I, 2. Systems which become only semi-elastic after equilibration at high suctions are rather unsuitable for these investigations, as technical difficulties interfere with the preparation of a series of samples equilibrated over a range of high suctions. 
Thus the experiments were conducted with a slurry of margalite as example of an semi-elastic system and with a slurry of magnesium latosol as example of an inelastic system.

\subsection{SEMI-ELASTIC SYSTEM, E.G. SLURRY OF MARGALITE}

In order to obtain samples in equilibrium over a wide range of suctions, the following procedure was adopted. $2 \mathrm{~g}$ portions of ovendry margalite soil were weighed on flat bottomed metal dishes, and slurried by addition of $10 \mathrm{ml}$ of water and stirring. The excess water was allowed to evaporate at room temperature (with the lowest moisture contents drying at 40 - and $50^{\circ} \mathrm{C}$ was employed) and the dishes were weighed regularly until a moisture content near the desired one had been obtained. When this was reached the soil was cut into pieces and transferred into the shaking vessels filled with water. After 24 hours of swelling the stability was tested. The suction at the moisture content obtained was found by interpolation in the $\mathrm{pF}$ curve. The results are represented in table 44.

The results are represented graphically by fig. 34 and fig. 41 , curve E. In fig. 34 the reciprocal value of the indices is plotted against the initial moisture content. The accordance with the moisture content at $\mathrm{pF} 1$ after swelling and with the results of the qualitative stability tests is good.

Curve $\mathrm{E}$ represents the relation between moisture content at $\mathrm{pF} 1$ and the stability.

TABLE 44. Stability classes $(\%)$, constants $\left(\times \frac{1}{2} \cdot 10^{3}\right)$ and indices of aggregates prepared by drying a slurry of margalite soil

\begin{tabular}{cccccccccc}
\hline $\begin{array}{l}\% \mathrm{H}_{2} \mathrm{O} \\
\text { initial }\end{array}$ & $\mathrm{pF}$ & $\begin{array}{c}\% \mathrm{H}_{2} \mathrm{O} \\
\text { swollen }\end{array}$ & quant. & const. & quant. & const. & quant. & const. & ind. \\
\hline 100 & 2.31 & 126 & 39 & - inf. & 37 & -9.65 & 24 & -0.351 & 0.0463 \\
70 & 3.01 & 108 & & & 80 & -6.1 & 20 & -0.563 & 0.113 \\
$60^{\prime}$ & 3.24 & 107 & & & 63 & -12.1 & 31 & -0.587 & 0.0867 \\
$50^{\prime}$ & 3.59 & 95.5 & & & 50 & -8.44 & 48 & -0.97 & 0.159 \\
$40^{\prime}$ & 4.05 & 87 & & & 38 & -6.58 & 58 & -0.89 & 0.263 \\
40 & 4.06 & 87 & & & 58 & -1.4 & 42 & -0.42 & 0.287 \\
24 & 5.24 & 74 & & & 26 & -7.9 & 74 & -0.325 & 0.781 \\
15 & 5.94 & 72 & & & 26 & -3.5 & 74 & -0.36 & 0.875 \\
10 & 6.20 & 71 & & & 19 & -4.4 & 81 & -0.25 & 1.44 \\
7.5 & 6.33 & 71 & & & 20 & -4.2 & 80 & -0.25 & 1.46 \\
5 & 6.44 & 106 & 24 & - inf. & 25 & -6.35 & 51 & -0.16 & 0.747 \\
0 & 7 & 143 & 52 & - inf. & 48 & -15.5 & & & 0.00694 \\
$\left(60^{\prime}, 50^{\prime}\right.$ and $40^{\prime}$ other series $)$ & & & & & & & \\
\hline
\end{tabular}

With decreasing moisture content the stability increases continuously, the curve being steepest in the region where the soil becomes air dry. If the drying continues to the point where air enters into the small pores the granules are disrupted by air explosion which causes a higher moisture content and decreased stability. These points marked by $R$ have a lower stability than the others. The most stable granules 
formed by drying are a bit more stable than the ones moistened to $30 \%$ before immersion, curve $\mathrm{E}$, and shaken in distilled water. The moisture content is considerably lower, which is explained by the reasons mentioned in 5.2.2.

\subsection{INELASTIG SYSTEM, E.G. SLURRY OF MAGNESIUM LATOSOL PH 7}

A concentrated slurry was prepared in the usual way and amounts containing about $2 \mathrm{~g}$ were equilibrated with increasing suctions. A small fraction of the samples was used for the determination of the moisture content, the remnant was cut up to the appropriate size and introduced into the shaking bottles. After swelling overnight the stability was determined. The results are given in table 45 .

TABLE 45. Influence of dehydration on the stability of a slurry of magnesium latosol, pH7

\begin{tabular}{|c|c|c|c|c|c|c|}
\hline $\mathrm{pF}$ & moist. (\%) & quant. & const. & quant. & const. & ind. \\
\hline 1.94 & 132 & 100 & -2.30 & & & 0.24 \\
\hline 2.5 & 95.5 & 100 & -1.04 & & & 0.51 \\
\hline 3.0 & 72 & 68 & -0.68 & 32 & -0.237 & 0.99 \\
\hline 3.48 & 58.3 & 51 & -0.591 & 49 & -0.240 & 1.40 \\
\hline 4.0 & 48.4 & 39 & -0.57 & 61 & -0.188 & 1.81 \\
\hline air dry & & & & 100 & -0.110 & 4.50 \\
\hline
\end{tabular}

It is seen that even at high moisture contents the stability is rather high; at $\mathrm{pF} 4$ the stability is near that of a normal soil, though it is still lower than that of the air dry latosol. (The last value has been taken from the tillage experiments, chapter III, 4.5).

The results are presented graphically by curve $\mathrm{D}$, fig. 49 . The slope of the curve is less than that for the drying margalite. This will probably be caused by the different type of aggregation of the latosols as discussed in part $\mathrm{V}$.

\section{SUMMARY}

The data of II, 4 are summarized by grouping the clays and soils with waterstable granules in order of decreasing resistance, in table 46 . The log of the stability index at $10^{-4} \mathrm{M}$ salt concentration is adopted as parameter. The stability of clays and soils dispersing spontaneously in water is indicated by two parameters. The first one is the salt concentration necessary to convey to the granules a stability index equal to 1 , the second is the salt concentration where the stability of the granules equals that of the corresponding calcium saturated ones. The first value indicates the salt concentration that has to be maintained for a medium stability. The second one is used in particular for clays and soils that do not even possess a medium stability in the calcium form, 
Table 46. Waterstable clays and soils. Log stability indices at $0.0001 \mathrm{M}$ salt concentration or lower

$1.69 \mathrm{Ca}$. latosol pH 5

1.09 H-latosol

$+1-0.93$ Ca-basin soil pH 8.2

$1.05 \mathrm{Na}-1$ atosol $\mathrm{pH} 8.8$

1.03 Ca-latosol pH 9

$0.87 \mathrm{Mg}$-basin soil pH 8.2

$0.78 \mathrm{Mg}$-basin soil $\mathrm{pH} 7=\mathrm{K}$-basin soil $\mathrm{pH} 8.2 \quad 0.71 \mathrm{~K}$-basin col.

$+0.5-0.48 \mathrm{Mg}$ basin col.

0.47 Ca-basin col.

$0.27 \mathrm{Mg}$-basin col.

$0.19 \mathrm{Ca}-W i n s u m$ soil $\mathrm{pH} 8.2$

0.23 Ca-Winsum col.

$0.22 \mathrm{~K}-$ Winsum col.

0.16 Ca-margalite col.

$0.14 \mathrm{Ca}$-margalite soil

$0.079 \mathrm{Mg}-$ Winsum soil $\mathrm{pH} 7$

+0.021 K-Winsum soil pH 8.2

$-0.078 \mathrm{Mg}$-Winsum soil pH 8.2

- 0.12 Ca-bentonite pH 5

0.32 Ca-illite col. $\left(10^{-s} \mathrm{M}\right)$

$-0.5-0.46$ Ca-bentonite pH 8.5

$-1$

$1.30 \mathrm{~K}$-margalite col.

1.63 Ca-kaolinite 
it is a relative value. Both concentrations are obtained by interpolation of the curves relating stability to salt concentration.

From a scrutiny of the data represented in table 46 it is apparent that a salt concentration above the flocculation value is not a condition for the stability. The calcium and magnesium soils (latosols excepted) flocculate at concentrations above $10^{-3}$ molar but their stability does not show any abrupt change near the flocculation value. From the figures showing the relation between stability and salt concentration (cf. II, 5) it is seen that the stability of the calcium and magnesium systems depends only slightly on the salt concentration. The stability of the potassium saturated granules is more dependent on the salt concentration in particular the stability of the potassium margalite colloid. Furthermore it is seen, especially with the illitic clays and soils, that the influence of the cations on the stability of the granules is rather small although the desorption characteristics varied considerably. We will see in the next chapter whether this holds true under all conditions.

The stability sequence of the soils is in agreement with practice. This is in favour of the usefulness of the determination. The stability of the margalite compares perhaps too favourable, but it must be remembered that the stability had been determined on the soil in the most resistant condition.

Whereas the stability of most soils increases with increasing concentration, that of the latosol decreases. A hypothesis to explain this abnormal behaviour is advanced in chapter $\mathrm{V}$.

TABLE 47. Clays and soils dispersing spontaneously in water

I. Salt concentration (M/1) necessary to obtain a medium stability

II. Salt concentration (M/1) necessary to obtain the same stability as the corresponding calcium clay at $10^{-4} \mathrm{M}$

\begin{tabular}{lcc}
\hline Clay or soil & I & II \\
Na-bentonite granules & 0.57 & 0.57 \\
Na-bentonite flakes & 0.52 & 0.40 \\
Na-bentonite dried from flocculated suspension & 0.48 & 0.44 \\
K-bentonite flakes & 0.063 & 0.036 \\
Na-margalite colloid & 0.020 & 0.028 \\
Illite (Fithian), (compared with Ca-illite in 10-8 M solution) & & \\
Na-illite + C Ist batch & 0.048 & 0.010 \\
Na-illite colloid 2nd batch & 1 & 0.33 \\
Na-illite + C 2nd batch & 1 & 0.33 \\
K-illite colloid 2nd batch & 0.21 & 0.069 \\
Ca-illite colloid 2nd batch & 0.1 & \\
Na-basin clay colloid & 0.20 & 0.52 \\
Na-basin clay soil & 0.054 & 0.62 \\
Na-Winsum colloid & 0.17 & 0.23 \\
Na-Winsum clay soil & 0.64 & 1.0 \\
Na-kaolinite colloid & & $>0.1$ \\
Na-latosol pH 10 & & $>0.1$ \\
\hline
\end{tabular}


The stabilities of the soil clays and the pure clay minerals differ considerably in the cases of kaolinite and illite. The knowledge of the physical behaviour of these pure clay minerals is therefore of little value to predict the behaviour of the corresponding soils.

The values I of table 47 may be compared with the values at which spontaneous degranulation occurs. The concentrations necessary to maintain a medium stability are, especially for the illites, considerably higher than those necessary to prevent degranulation. The latter value may be regarded as a minimum, in most cases insufficient to give the resistance necessary in practice.

As the relation between stability and moisture content at $\mathrm{pF} l$ is narrower than the relation between stability and salt concentration (cf. II, 5) it is probable that the stability is primarily related to the moisture content (a function of the interplate distance) and that the salt concentration influences the stability via the regulation of the swelling. The relation between moisture content and stability is, however, far too wide to predict the stability by the moisture content at $\mathrm{pF} 1$.

The influence of the degree of desorption on the resistance against dispersion is illustrated by two experiments, one with a slurry of margalite soil (a semi-elastic system), the other with a slurry of magnesium latosol (an inelastic system). The curve relating the moisture content at $\mathrm{pF} 1$ after swelling with the stability is steeper with the semi-elastic system than with the inelastic one. 


\title{
THE INFLUENGE OF THE MOISTURE CONTENT AT TILLAGE ON THE STABILITY OF THE SOIL IN THE SATURATED STAGE
}

\author{
1 GENERAL PRINCIPLES OF TILLAGE
}

\subsection{INTRODUCTION}

In the previous chapter the cohesion of clay granules in the saturated stage was determined. One might expect that these data will be correlated to the resistance of the granules to the dispersing action of rain. However, in agricultural practice rain is not the only factor which tends to disperse the aggregates; the mechanical action of tillage and other implements may under certain circumstances play a major role. At a critical moisture content the internal arrangement of the granules may be altered by the shearing and compressive forces exerted by the implements. As shown by McGEORGE (1937) this working of the soil at a critical moisture content prior to shaking in excess water results in a higher degree of dispersion than obtained by shaking in water alone. This implies that by the working the composing particles have been loosened from one another and consequently a worked mass of soil will show the same properties on saturation as a desorbed slurry, the more so the farther the alteration proceeded. Thus the working of a soil at the wrong moisture content may have as consequence that, apart from the apparent harmful results, also the resistance to rain may be very much reduced, or even that the waterstable granules are converted into a mass that peptizes spontaneously. This change is not apparent at once, nesessary since the strongest effect of the working takes place at moisture contents where the puddled soilstill shows a marked cohesion. It will manifest itself only in case that the soil gets saturated after working, before regranulation by drying can occur.

The relation with the previous chapters being established, the mechanism of the tillage will be considered now.

All tillage operations have in common that soil units either large or small (e.g. clods, crumds, dust) are dislocated, while during dislocation both compressive and shearing forces are exerted on the soil units.

Whether and to which degree these forces will break up the structural arrangement within the soil units, depends on the magnitude, direction and duration of the applied force, and on the cohesion of the soil units. The latter varies considerably with the moisture content. In turn the cohesion and thus also the moisture content have a strong influence on the magnitude of the force necessary for the cultivation.

Depending on the moisture content, continued working of a soil will result in a more or less complete homogenization of the soil mass. In clays it should eventually lead to equal distances between all particles. At this stage the worked soil will strongly resemble a desorbed paste of the same moisture content. It would be inter- 
esting to know whether the resistance against dispersion in the saturated stage is the same irrespective of the method of preparation.

From a study of the existing literature it is difficult to obtain a comprehensive notion of the way moisture affects tillage operations and their results. Different methods and materials have been used, and the authors often fail to analyse the results of their treatments. Therefore it is perhaps justified to give at this place a qualitative sketch of the subject.

The object of tillage on clay soils is to break up large soil units and to rearrange them in a rather loose packing. (The ploughing operations carried out in the autumn to obtain the largest profit from frost action, are not considered.) Both the breaking of the cohesive bonds and the rearrangement require the application of a certain amount of mechanical energy. Thus a successful tillage operation requires the application of a sufficient amount of energy to the soil and its transfer into the soil units which are to be broken up. Especially if smaller units are to be fractured this transfer may well prove to be the limiting factor. With ploughing the transfer of energy into the soil units is mainly determined by the friction and cohesion between the soil units themselves, and between the soil units and the implements employed.

As will be shown this friction and cohesion depends heavily on the moisture content of the soil. As the transfer determines also the amount of energy employed during the tillage operation, it may be concluded, that the latter amount varies

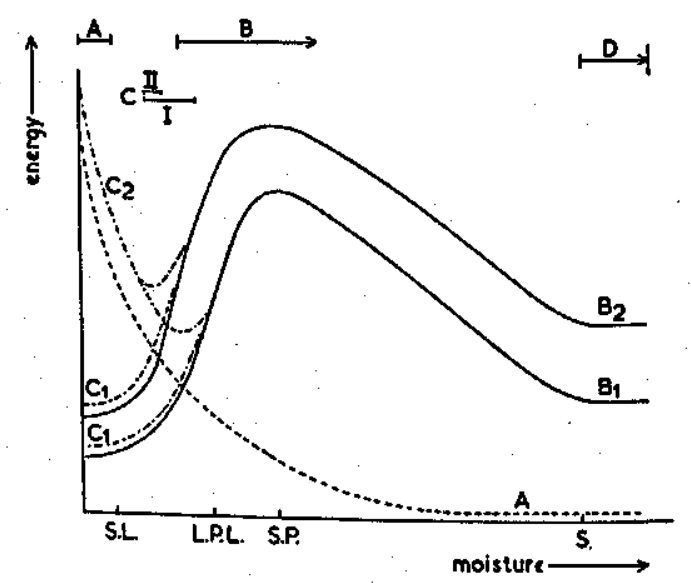

Fio. 50. Energies in soil in dependance of moisture content

$$
\begin{array}{ll}
\text { S.L. } & =\text { Shrinkage limit } \\
\text { L.P.L. } & =\text { lower plastic limit } \\
\text { S.P. } \quad \text { = sticky point } \\
\text { S. } \quad \text { = saturation } \\
\text { Range A. too dry for effective tillage } \\
\text { Range B. too wet for effective tillage } \\
\text { C I. effective range small forces } \\
\text { C II. effective range large forces } \\
\text { D. } \quad \text { range for wet tillage (paddy) }
\end{array}
$$

curve $A$. intra-aggregate cohesion curve $B_{1}$. inter-aggregate cohesion small force curve $B_{2}$. inter-aggregate cohesion large force curve $\mathrm{C}_{\mathbf{1}}$. transfer of energy (draw bar pull) small units present for small and large forces resp.

curve $C_{2}$. transfer of energy very large units present. 
considerably with the moisture content of the soil. The factors stated above will now be treated separately, with the aid of fig. 50 . This figure has been taken with some changes from the third edition of BAver's Soil Physics.

\subsubsection{Influence of moisture content on cohesion}

\subsubsection{Intra-aggregate cohesion; curve A, fig. 50}

The intra-aggregate cohesion will have a maximum value at very low moisture content. At this stage the attractive forces between the primary particles composing the unit are fully developed, whereas the osmotic swelling pressure is absent (cf. chapter V). When moisture becomes available for the aggregate the difference in energy level of the intra- and extra-aggregate moisture will result in a tendency of the aggregate to swell. At a certain critical energy level of the exterior moisture a net swelling pressure will develop, resulting in the uptake of moisture by the aggregate. The ensuing increase in distance between the elementary particles will cause a rapid decrease of the cohesion forces. This swelling will also be accompanied by shear stresses, as the expansion will differ for different directions in the aggregate. Fracture planes will arise, which again lead to a strong decrease of the cohesion of the aggregates. Thus when considering the cohesion in the unit as a function of its moisture content one may conclude that it has its maximum value in the dry state unit; with increasing moisture content it falls off rather sharply and obtains its minimum value at saturation.

\subsubsection{Inter-aggregate cohesion and friction; curve $B$, fig. 50}

The inter-aggregate cohesion follows a different pattern when considered in dependance of the moisture content. At very low moisture level the cohesion between aggregates is at a minimum (distances between adjacent external surfaces are generally very large); only at a few points of contact the distance is small enough to come within reach of cohesive forces. With increasing moisture content the points of contact will be surrounded by water rings. The surface tension will now contribute to the binding between the aggregates, which roughly will increase near to the point where the separate water rings will coalesce. There after the inter-aggregate cohesion will diminish again and reach a minimum value at saturation. It is obvious that the inter-aggregate cohesion, per unit of crossection through the soil, will increase with decreasing dimensions of the aggregates as the number of point of contacts per unit area is inversely related to the magnitude of the aggregates.

In addition to cohesive forces between aggregates the friction must be considered. In dry soil it will be proportional to the inter-aggregate cohesive forces and never obtain high values, if the action of the plough is considered, as the aggregates can evade the compressive forces by slyding over each other. If, however, the moisture content increases, the aggregates will become more and more deformable under the influence of the pressure exerted by the implement. This deformation will result in the change of points of contact into planes of contact and consequently increase the friction, which will inhibit the evasive movements of the aggregates. 


\subsubsection{Transfer of energy into the aggregates; curves $\mathrm{C}$, fig. 50}

Obviously the maximum energy transfer is limited by the inter-aggregate bonding and friction. Thus this transfer becomes very ineffective at low moisture contents of the soil, and will increase with increasing moisture content, roughly proportional to the inter-aggregate cohesion and friction.

\subsection{EFFECTIVENESS OF TILLAGE OPERATIONS}

\subsubsection{Too low moisture content; range $A$, fig. 50}

Whereas the transfer of energy into the aggregates is difficult at very low moisture content, the amount of energy needed to break up the aggregates at this stage is at a maximum. This implies that tillage of a soil at too low a moisture content is very ineffective. Although very large units may be broken up (e.g. surface crust) or cut through, it is virtually impossible to attack non-coherent units. In this stage the drawbar pull of the implement is usually low unless massive crusts are to be broken up, or large clods are to be cut through.

\subsubsection{Too high moisture content; range $\mathrm{B}$, fig. 50}

Obviously the effect of tillage on the structure of the aggregates themselves is maximum when the intra-aggregate cohesion is low, while the inter-aggregate bonding is high. This moisture content is near the Moisture Equivalent; it is the point where drawbar pull reaches its maximum value, and where the risk of converting the granular soil into a plastic mass, puddling, is largest.

Under the influence of the shearing and compressive forces the aggregates are easily deformed at this moisture content. This deformation causes intimate contact between the aggregates and therefore enlarged inter-aggregate friction. Also, the area of contact with the implement is enlarged and therefore the friction with the metal surface. The thus increased friction increases the applied energy which in turn causes an increase in deformation and so on. The cumulative effect of friction and applied force may become so large that the more or less rigid internal arrangement of the soil units is broken up and that the individual aggregates are united into a plastic mass. This mass will have a moisture content near the sticky point of Atterberg where the worked soil begins to adhere to metal surfaces. Another factor is that the increased spacing between the primary particles causes a lowering of the energy of the soil moisture. This in term causes also an increase of soil metal (cf. chapter IV, 2,6) friction and interaggregate friction and thus of the drawbar pull.

Thus tillage of the soil at too high a moisture content may have as result that instead of breaking up large clods even bigger and denser units will be formed with all the unfavourable characteristics of puddled soils, as loss of air filled pores, decreased permeability and a loss of moisture availability for plants. 


\subsubsection{Optimum moisture content; range $\mathrm{C}$, fig. 50}

Normal tillage operations are thus only practicable at moisture contents in between the two extremes just discussed. In effect one needs a point at which a sufficient amount of energy transfer into the aggregates is possible, in order to enable one to break them up to a sufficient extent, without going so far as to smear the entire soil by the operation. The smaller the energy employed with the operation (low velocity) the higher the moisture content can be for successful tillage.

\subsubsection{Cultivation of rice (paddy) fields}

With respect to the preparation of rice fields the situation is different. In this case the aim of the tillage operation is to prepare a thin mud with a minimum amount of drawbar pull. This can obviously be effected best at a moisture content slightly above the saturation. At this point the inter-aggregate cohesion is small but also the intraaggregate cohesion has now obtained its minimum value. Thus with only a slight effort a thin mud may be prepared.

\subsection{Discussion OF SOME LITERATURe DATA AND INTERPRETATIONS AT VARIANCE WITH THE ABOVE}

\subsubsection{Compressibility}

There exists a marked discrepancy between the results of compressibility experiments of Christensen (1929) and Bodman \& Rubin (1948). Christensen found that dry soil blocks had a definite yield value, that the deformation before the crushing was small, and that the compressive force fell of abruptly once the yield value had been surpassed. If moister soil was used the deformation before the yield value was reached became larger, the yield value decreased and the pressure did fall off less abruptly as the moisture films were able to bridge the arising fissures to some extent. BODMAN \& RUBIN using loosely packed aggregates did not find a definite yield value with their compression tests even if when the aggregates were dry. This is explained by the investigations of DAY \& HOLMGREN (1952). If stress is applied on a mass of aggregates it is localized in the contact points between the aggregates. In these areas the stress is a multiple of the applied stress, so that the shearing stress or yield value of the aggregates may be overcome in these areas. Either by plastic flow or by crumbling of the points, the contact area between the aggregates will be enlarged, with as result that the maximum stress per unit of contact area diminishes. This process of flattening continues until the local stress is met by the shearing resistance of the aggregates and will be resumed if the load is increased. This flattening of the contact points will be measured as a compression. Moreover, a loose pack of dry aggregates with a strong internal cohesion may rotate and slide over each other if a load is applied large enough to overcome the inter aggregate-friction, just as with dry sand.

As the aim of the tillage operation is to break up individual clods, the measure- 
ments of the yield values of single units will contribute most to a better understanding of the way tillage affects the soil.

\subsubsection{Drawbar pull through dry soil}

That Nichols \& BAYER (1930) did not find an increased drawbar pull with decreasing moisture content, which is possible under certain conditions discussed in 1.2, also suggested by BAvER in 'Soil Physics', is caused by the fact that he drove a chisel through loosely packed aggregates. Since dry aggregates will neither adhere to one another nor to the chisel they will only produce a small frictional resistance.

\subsubsection{Shear strength of moist soil}

In 1.1.1 it is stated that the cohesion diminishes with increasing moisture content; consequently also the shear strength should diminish proportionally. This was confirmd to the author by the late FounTaIne and by KUIPERs. The decrease of shear strength with increasing moisture content is however at variance with the experiments of Nighols \& Baver (1930), cited by BAver in 'Soil Physics'. This is caused by the scheme of their experiments, where the bulk shear strength is determined. With this determination the individual aggregates do not shear necessarily and the friction between soil and soil is measured instead. The friction will increase with increasing moisture (up to a maximum) just as the friction with a metal plate. This interpretation tallies with the observation of Nichols (1955) that coarser aggregates did cause a larger bulk shear strength than smaller ones, as the coefficient of friction will increase with the dimensions of the aggregates, the roughness of the shear plane increasing with these dimensions.

1.3.4 Objections against the application of data on remoulded soils to problems of soil tillage

By the remoulding or puddling of soils the bonds between the polyplates and clay crystals have been broken to a large extent, therefore the swelling proceeds unhampered at least during the moulding process (cf. Greacen, 1959) and consequently the energy of the soil water is lowered in the puddled sample with respect to the energy in the unpuddled sample. This has as consequence that Atterberg's liquid limit of soils with a very limited swelling is higher in case the soil has been puddled than with unmoulded samples. The more moisture is bound inside the mass, the less is available at the soil dish interface. Likewise the moisture content at the lower plastic limit, regarded by BoEkEL (1958) as the upper limit of the moisture range where soils can be ploughed, will be higher than the moisture content at which in practice these operations can be done. As in an unpuddled soil the moisture is less strongly bound than in a puddled one at the same moisture content, more water is available puddling and caking together of aggregates is possible at the moisture content of the lower plastic limit (cf. 2.4). 
The yield value and the shear strength determined on remoulded samples will be too low compared with those of the natural aggregates. Partly because the bonds of organic matter or other cementing materials must be broken before the elementary particles can move with respect to one another, partly because the polyplates and clay crystals must be oriented in a direction parallel to the shear plane. The ratio of the shear strength of natural to remoulded units is called 'sensitivity' in the litterature on soil mechanics. According to Hougr 'Basic Soils Engineering' a usual degree of sensitivity is $2-4$ and a high one $4-8$. The sensitivity is illustrated by the experiments of BoDMAN \& RUBIN (1948) who found a sharp rise in torque if more or less compressed soil aggregates were sheared; after having reached a maximum value the torque fell off to a constant level, the friction of the resultant paste.

In short, for agricultural purposes the resistance to puddling, i.e. the work necessary to convert a soil from the granular to the plastic stage, is usually of more direct interest than the properties of the plastic mass.

\section{STABILITY OF THE SOIL STRUCTURE AFTER TILLAGE OPERATIONS}

With our knowledge of the behaviour of the slurry, (cf. summary of I, 2,6), it should be possible to make some predictions as to the stability of the soil structure formed upon working when subjected to the destructive action of excess water. Leaving soils and clays which exhibit an elastic desorption characteristic out of the discussion, (these will not show any stability at low salt concentration regardless of the degree of working) the following factors should be considered.

If the degree of working has been light i.e. a few repititions and small forces applied, then only part of the aggregates present will have been affected even in range $B$, fig. 50. As was pointed out before, the suction of the water in the worked material as a whole will usually be higher than the suction in the original soil (CRONEY \& CoLEMAN, 1954; GREACEN, 1959). Also it will not have reached the value of the dehydrated slurry at the same moisture content. Distinguishing a part that has been puddled and a part of which the structure has not yet been destroyed one should thus expect that the moisture content of the puddled part will be higher than that of the part with the original structure. Since the stability of the puddled part depends strongly on the moisture content an increase of working of the soils will result in an increase of the stability of the fraction puddled. Eventually the entire soil will be puddled which then leads to a constant moisture content of the puddled soil equal to the original moisture content.

The stability of the puddled fraction of a lightly worked soil may be for another reason lower than that of a heavily worked one even if the moisture content of both is the same. It is probable that the original aggregate is divided into coarser particles by the light working in comparison to those resulting from the heavy working. Consequently the distance between the coarser particles will be larger than that be- 
tween the finer, as the amount of water available per unit external surface area, (where the osmotic swelling is less hampered), will be larger. As the resistance must be a function of the distance, the puddled part of the lightly worked soil may have also for this reason less stability than the vigorously worked soil.

As the light work affects only part of the granules, the stability of the rest will remain largely unchanged. The quantity of the unaffected part, which can be determined by the stability analysis, indicates to which degree the treatment has affected the soil. The stability of the affected part will depend on the moisture content of this part after treatment and on the desorption characteristic of the slurry. If the soil belongs to the type with a large range of elasticity, like the potassium soils, the affected part will have zero stability or a very low one. If the soil belongs to the semi-elastic type, the stability of the altered fraction will depend on the degree of elasticity and on the moisture content after working. If both are high the stability of the fraction influenced by the treatment will be low.

Vigorous working will alter the structure to a larger degree and over a larger range. In region A, fig. 50 the soil will be powdered by the treatment, the more so the drier the soil, at least if the pressure is larger than the cohesion. The influence of the larger force will manifest itself by an increase of the moisture range where the stability of the granules has been altered considerably (curve B 2, fig. 50). The moisture content where the highest percentage of the granules is destroyed will have been shifted to a lower value, compared to that of the more gentle treatment. The stability of the puddled part will again be zero with soils with an elastic desorption characteristic over a large range of suctions. With soils with a semi-elastic characteristic the stability of the puddled part will be comparatively increased by the stronger treatment, the moisture content being lower.

With clays which have a semi-elastic desorption characteristic one may observe the feature that with increasing moisture content, the fraction puddled increases but that its stability constant remains nearly the same. This may be caused by an unequal distribution of moisture at the beginning of the working, which will be especially the case if the moisture content is obtained by adding water to a dry soil. Then, with increasing moisture content an increasing percentage of the soil will be brought to field capacity and will have therefore after working the same stability. Even if the moisture is evenly distributed at the beginning, the working may result in a heterogenous paste with two classes of stability. This is so because during the working water is drawn from the granulated part to the puddled one, increasing the resistance of the granulated part. Even if the drier granules are puddled in the course of the working their stability will be nevertheless higher because they will adsorb less water after submersion than the paste formed from granules with a higher moisture content, the colloid being semi-elastic. Only a prolonged working may result in an even distribution of the moisture throughout the paste.

If the soil behaves like an inelastic colloid, the soil puddled at low moisture contents will have nearly the same stability as the original granules. The puddling causes in this case no increased swelling and therefore no decreased stability.

It should be remembered that soils suffering very much from air explosion will 
have zero stability in the air dry region regardless of treatment. The same holds for the stability at high moisture contents, provided the wetting has been quick. In the intermediary ranges the working may increase the stability of these soils as the secondary aggregates or cakes may be denser than the original ones. The pore space which is increased by the swelling of the dry soil, is reduced again by the working, (cf. Vilensky, 1934).

A quantitative relationship between the moisture content during tillage and the resulting stability can not be given, as little is known about the internal cohesion and its relation to suction and as the transfer of the work into the aggregates is not known. It may be assumed however that in range $A$, fig. 50 , the influence of a light treatment on the stability will be negligible.

\section{PRELIMINARY INVESTIGATIONS}

In order to establish the influence of the water content at which a soil is worked on the resistance of the soil against working, the following experiments were carried out, using for the evaluation of the results the technique described with the preliminary investigations in chapter II. With this technique the corrected volume of sediment after shaking is used as a measure of the quantity of aggregates destroyed.

Different amounts of water were added dropwise to 10 gram portions of ovendry granules, which were then kept covered in porcelain crucibles for 5 hours. Thereafter the granules were worked in either one of the following ways:

A. A metal analytical spoon is drawn edgewise 200 times through the mass avoiding any pressure.

B. A metal spoon loaded with a weight of $100 \mathrm{~g}$ is drawn 200 times through the mass. No pressure is exerted on the spoon.

C. The spoon is drawn 200 times through the soil exerting full pressure.

The resulting mass is then brought into graduated cylinders avoiding dispersion as much as possible, if necessary cutting the paste into pieces of 3 to $4 \mathrm{~mm}$. Filling shaking and measurement of the sediment volume proceeded as described in II.

\subsection{Margalite}

The results expressed as percent of the maximum volume of flocculated sediment (i.e. after an infinite number of revolutions) are represented in fig. 51. The graphs for margalite A, B and C, all show clearly the air explosion effect upon immersion. The dry granules are disrupted to such a degree that they flocculate, and the particles are too small to be abraded further. The granules moistened to 20,40 and $60 \%$ have a higher stability, those moistened to 80 and $100 \%$ being less stable again. This is explained as follows; if $40 \%$ of water are added to a soil, a quick, localized swelling is observed there where a granule is hit. After some time, and especially if the granules are subjected to a vigorous treatment, the moisture becomes evenly distributed as is 


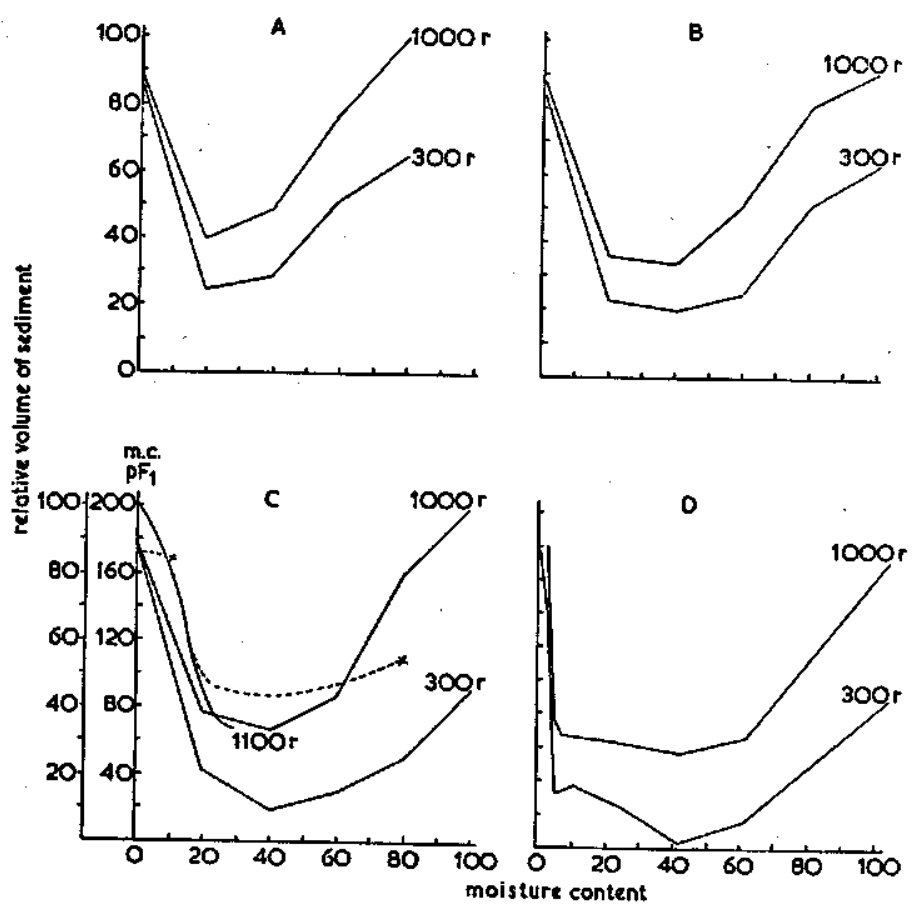

Fro. 51. Influence of moisture content at working and degree of working on the stability of margalite soil (qualitative test)

$300 \mathrm{r}$ and $1000 \mathrm{r}=$ volume of sediment as percent of ultimate volume after 300 and 1000 revolutions

A. slight pressure applied

B. medium pressure applied

C. strong pressure applied

...- moisture content at $\mathrm{pF} I$ after swelling

D. qualitative stability test on drying slurry of margalite

inferred by the uniform black colour. By comparing graphs A, B and C it is seen that the more the soil is worked and compressed after addition of 40 and $60 \%$ of water, the more stable it becomes. Most probably this is caused by the more even distribution of the moisture and the increased area of close contact. If the soil is not worked, some of the soil will remain at high water content and will therefore exhibit little stability.

If more water is added the distance between the polyplates will remain large whatever the degree of working and the stability will remain impaired.

That it will not become zero is explained by the small degree of backswelling at these moisture contents. The degree of dispersion was largest at $100 \%$ moisture, the range in which this maximum was obtained broadening with increasing intensity of working. The maximum volume of sediment is nearly twice as high as at zero moisture. If one compares graph $\mathrm{C}$ with graph $\mathrm{D}$ of the drying slurry, one observes that the stability at $10 \%$ moisture of the drying slurry is larger than that of the mois- 
tened soil. As the rate of increase of the pore volume of a granule which has been prepared by drying a slurry exceeds on moistening the rate of decrease of the pore volume of a drying slurry (cf. HaInes, 1923), the volume of the moistened soil will be higher than that of the dried slurry at identical moisture contents, and, therefore, a larger percentage of the pores will be filled by air. The above observation is in good accordance with the backswelling characteristic of the moistened soil, cf. broken line graph $\mathrm{C}$ fig. 51 .

\subsection{LATOSOL}

The behaviour of the latosol is more simple. It is a soil which slakes very easily but the resulting particles, (of sand and silt dimensions) are far too large to flocculate and are very resistant against dispersion. At low moisture contents the soil is reduced to a powder by treatment $\mathrm{C}$, with smaller dimensions than obtained by slaking. At moisture contents near sticky point the soil is easily puddled, but at higher contents the shearing forces are less well transmitted and a large part of the small granules remains intact. This is demonstrated by the analysis of the treatments $A$ and $C$, curves $A$ and $C$, figure 52. In this figure the suction of the soil moisture before work-

Fro. 52. Influence of suction before working and degree of working on the stability of latosol, (qualitative test) $1000 \mathrm{r}=$ volume of sediment as percentage of ultimate volume after 1000 revolutions

A. slight pressure applied

C. strong pressure applied

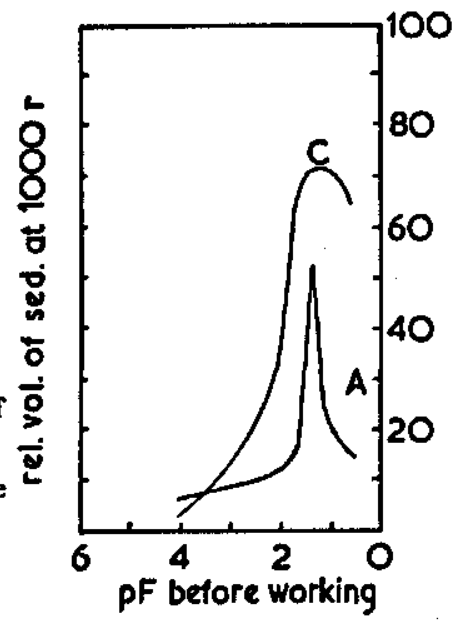

ing is plotted on the abscissa. Curve A shows a distinct peak at pF $1.5(60 \%$ moisture), curve $\mathrm{C}$ shows a broader maximum. The maximum of dispersion coincides for 1000 revolutions with the minimum of stability. At infinite shaking time the sediment volume of the clay worked at $\mathrm{pF} 1.5$ is appreciably higher in case of treatment C than it is with treatment $\mathrm{A}$.

\section{QUANTITATIVE EXPERIMENTS}

The method of analysis was the same as that described chapter II, except that sometimes a sedimentation time of 40 minutes was chosen. This was done because the dry 
granules were converted into a fine powder by treatment $\mathbf{C}$, which failed to settle within two minutes. The equivalent diameter of the particles will have been about 9 micron. With this method the amount of dispersed material is determined as a function of the number of revolutions cf. chapter II, 3.*

As the reproduction of the data of all experiments would make very tedious reading, only some examples will be treated in detail. In figures 53, 54, 55 and 56 the results of all the experiments are summarized and some comments are given in III, 5. For the ease of graphical representation four classes of stability are discerned: $a$, high stability, the constants $\left(\times 10^{3}\right)$ are less than 1 and do not differ much (less than a factor 3 ) from the stability of the unworked soil; $b$, low stability, the constants lie between 1 and $10 ; c$, very low stability, the constants are larger than $10 ; d$, zero stability. The ordinate represents the quantities (\%) of these classes, on the abscissa the $\mathrm{pF}$ of the moisture in the granules at the beginning of the working is given.

The $\mathrm{pF}$ values were found by interpolation of the desorption curves of the granules and slurries. This is not quite correct for the granules, in case the moisture content had been obtained by wetting, as some hysteresis will occur which will tend to lower the suction at the same moisture content.

\subsection{INFLUENGE OF THE APPLICATION OF LARGE PRESSURES (TREATMENT C)}

4.1.1 Soils with slurries behaving like an elastic system over a wide range of suctions As an example of soils with a wide range of elasticity the potassium margalite soil is chosen. The settling time was 40 minutes. The results are presented in table 48 and by graph 4 , fig. 53 .

TABLE 48. Influence of treatment $\mathrm{C}$, at different moisture levels, on the stability of potassium margalite (quantities in $\%$, constant $\times 10^{2}$ )

\begin{tabular}{cllllllll}
\hline \multirow{2}{*}{$\begin{array}{c}\text { moisture } \\
\text { content (\%) }\end{array}$} & \multicolumn{2}{c}{$\mathrm{pF}$} & & & & & & \\
\cline { 2 - 9 } & gran. & slurry & & quant. & const. & quant. & const. & \multicolumn{2}{c}{ quant. const. } \\
\hline 8 & 6 & 6 & 2 & - inf. & 24 & -28 & 63 & -0.081 \\
28 & 3.2 & 3.6 & 42 & - inf. & 17 & -9.5 & 41 & -0.052 \\
48 & 2 & 3 & 80 & - inf. & 4 & -7.7 & 16 & -0.057 \\
68 & 1 & 2.6 & 51 & - inf. & 10 & -7.2 & 39 & -0.052 \\
88 & & 2.2 & 29 & - inf. & 19 & -6.8 & 53 & -0.098 \\
\hline
\end{tabular}

It is seen that a large fraction of the affected part has zero stability, the more so the more effective the puddling had been. Apparently if the distance between the primary particles is only a little increased over the distance at which they stick together, spontaneous swelling follows. The maximum destruction takes place at $\mathrm{pF} 2$, but also at pF 3.2 it is still considerable.

* With the quantitative investigations $2 \mathrm{~g}$ granules were used. Treatment A consisted of 30 strokes no pressure; treatment $\mathbf{C}$ of 100 strokes full pressure. 

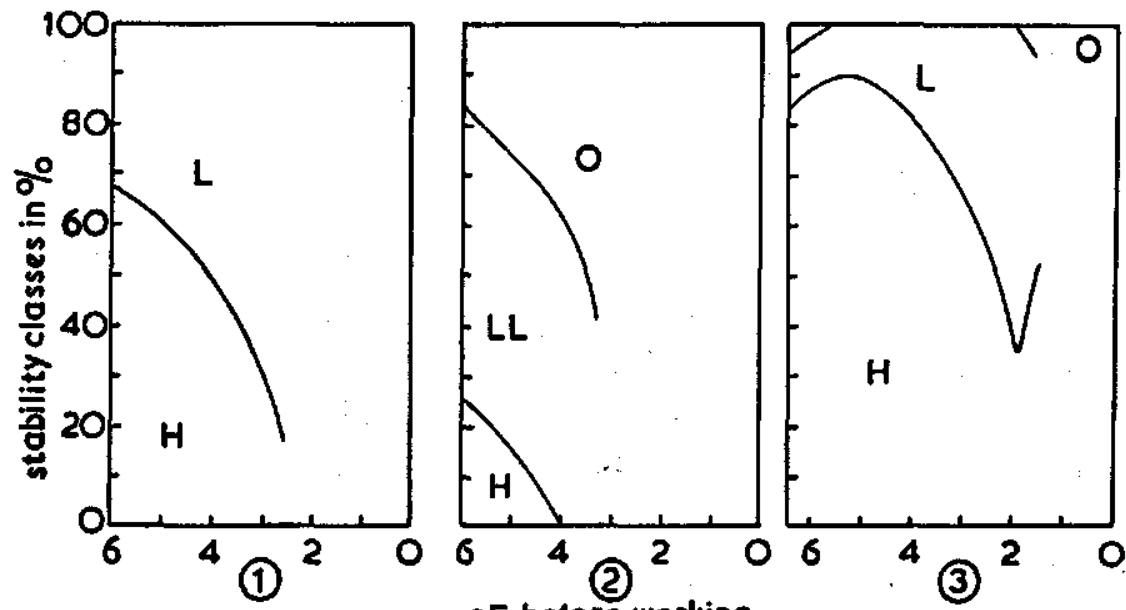

pF before working

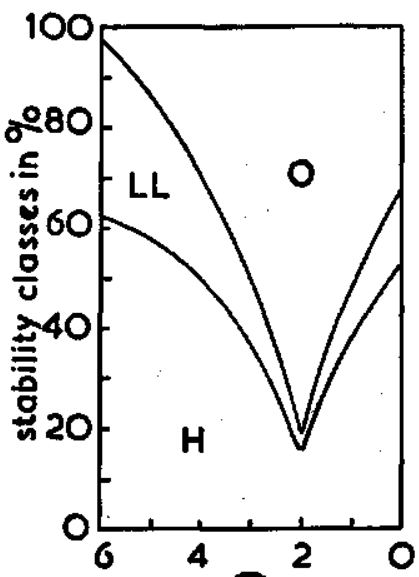

(4)

pF betore working

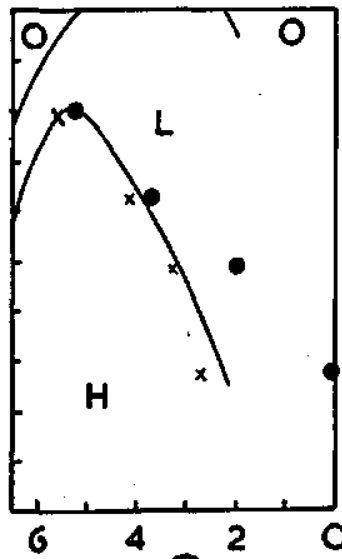

(5)

$x$ pf slurey

- pF gran.

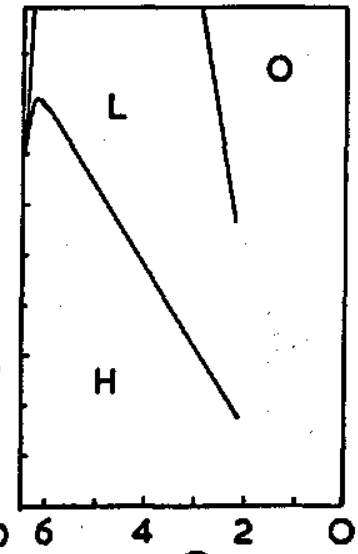

(6)

pF slurry

Frg. 53. Influence of soil moisture suction before tillage (treatment $G$ ) on the stability of bentonite and margalite after tillage

H. high stability

L. low stability

L.L. very low stability

O. zero stability

1 Ca-bentonite; $2 \mathrm{~K}$-margalite colloid; 3 Ca-margalite colloid; $4 \mathrm{~K}$-margalite soil;

5 Camargalite soil; 6 Drying slurry of Ca-margalite soil. 


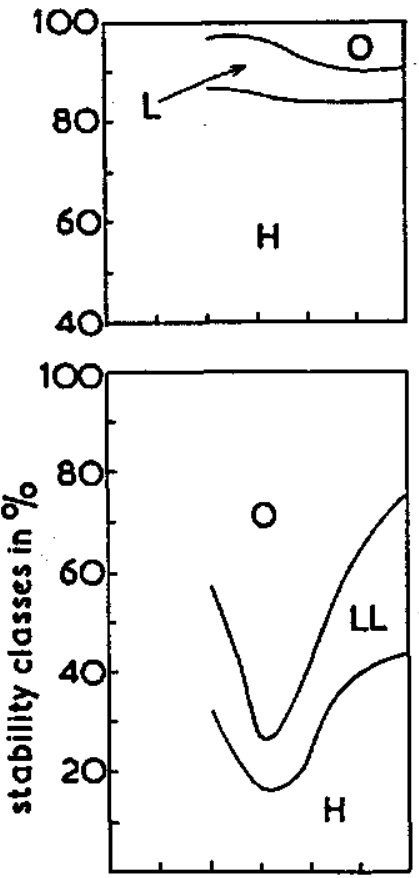

(4)

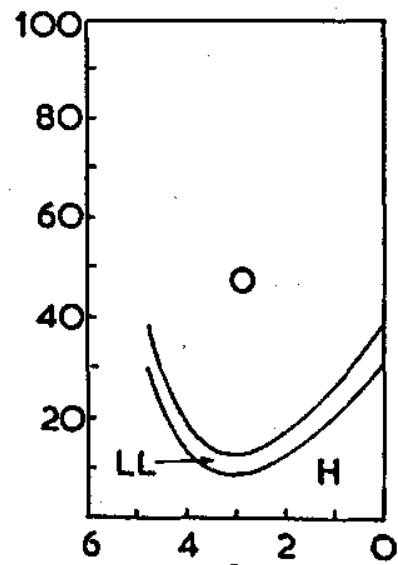

(1)
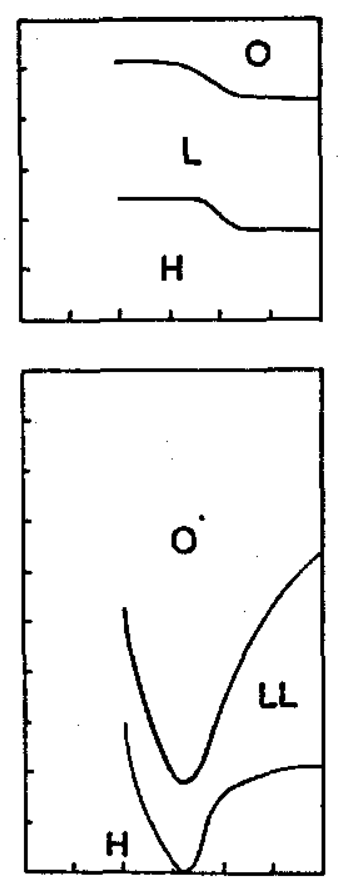

(5)

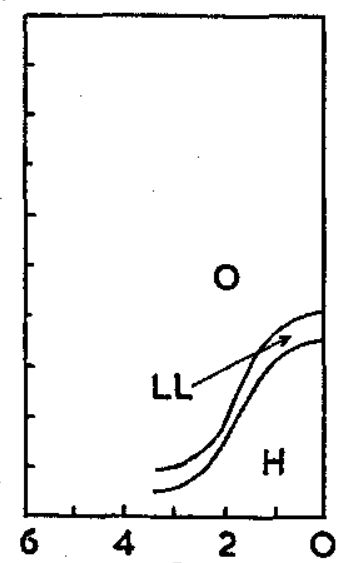

(2)
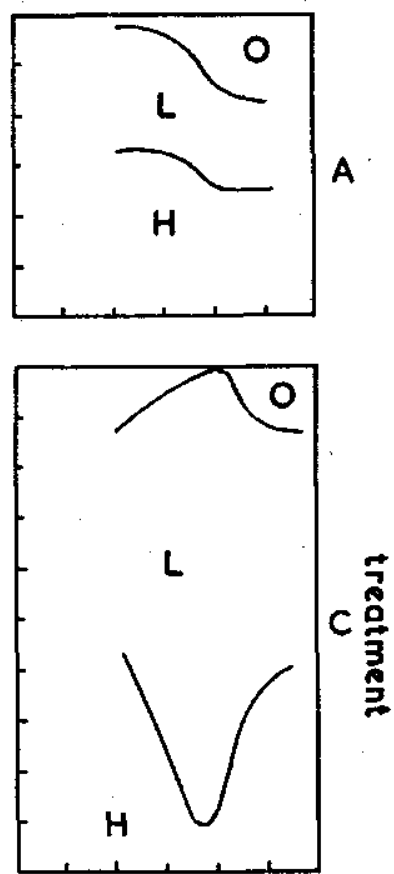

(6)

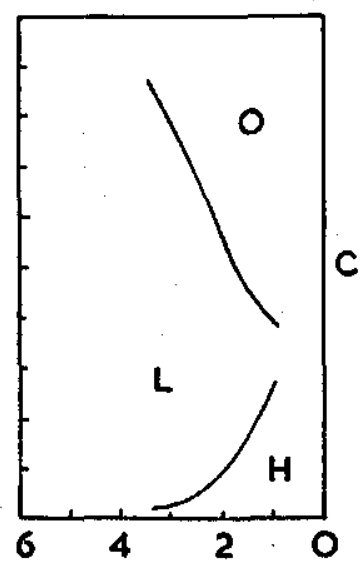

(3)

\section{PF before working}

Fic. 54. Influence of soil moisture tension before tillage of the stability after tillage of basin and Winsum colloids and soils

H. high stability

L. low stability

L.L. very low stability

$1 \mathrm{~K}$-basin colloid; $2 \mathrm{~K}$-Winsum colloid 3 O. zero stability

$6 \mathrm{Mg}$-basin soil 


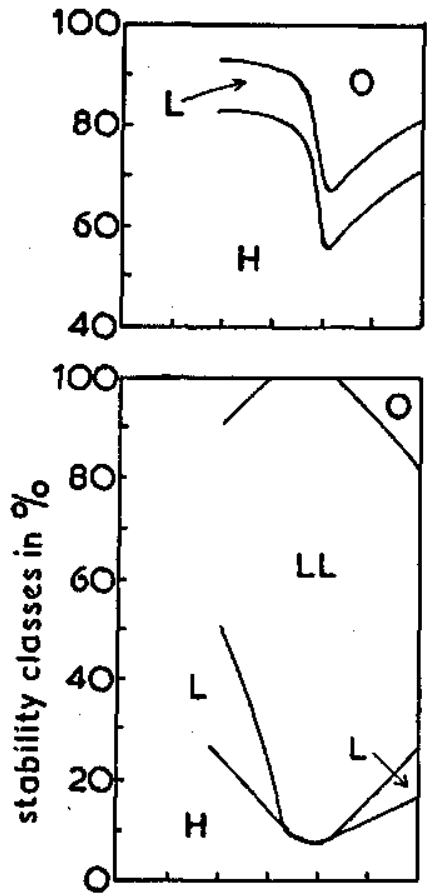

(4)

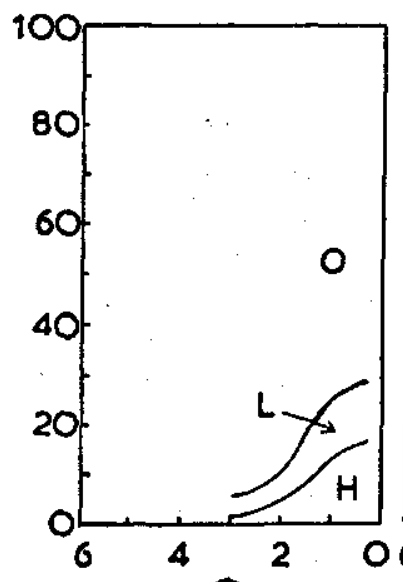

(1)

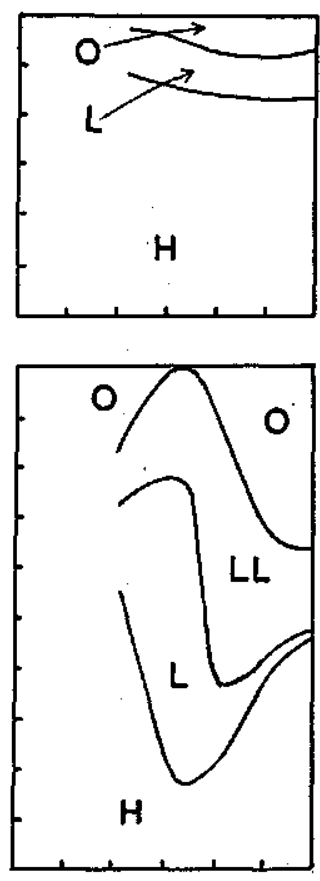

(5)

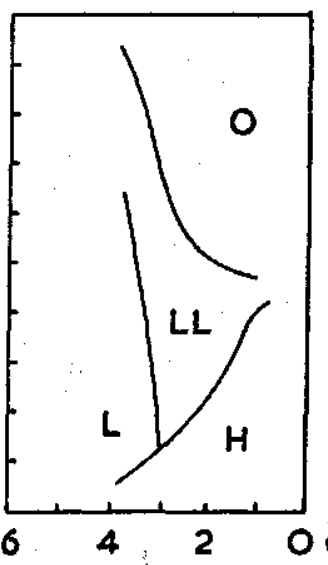

(2)
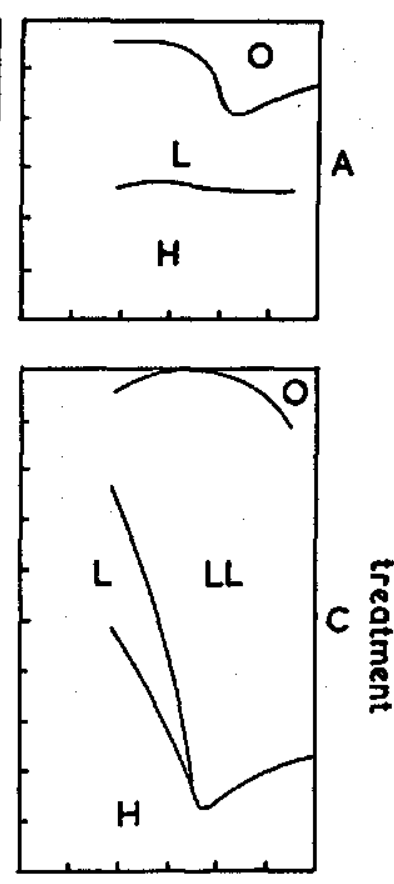

(6)

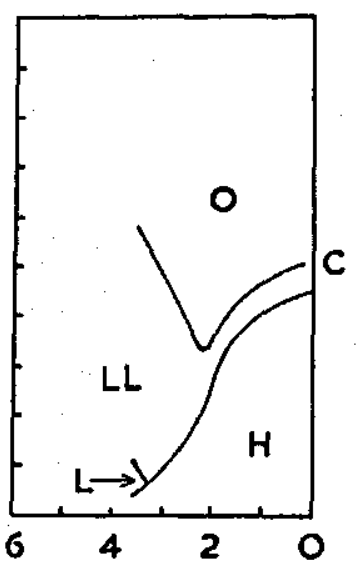

(3)

\section{pF before working}

Ftc. 55. Influence of soil moisture tension before tillage on the stability after tillage of basin and Winsum colloids and soils

H. high stability

L. low stability

L.L. very low stability

$1 \mathrm{Mg}$-Winsum colloid; $2 \mathrm{Ga}$-basin colloid

O. zero stability

5 Ca-basin soil; $6 \mathrm{Ca}$-Winsum soil 

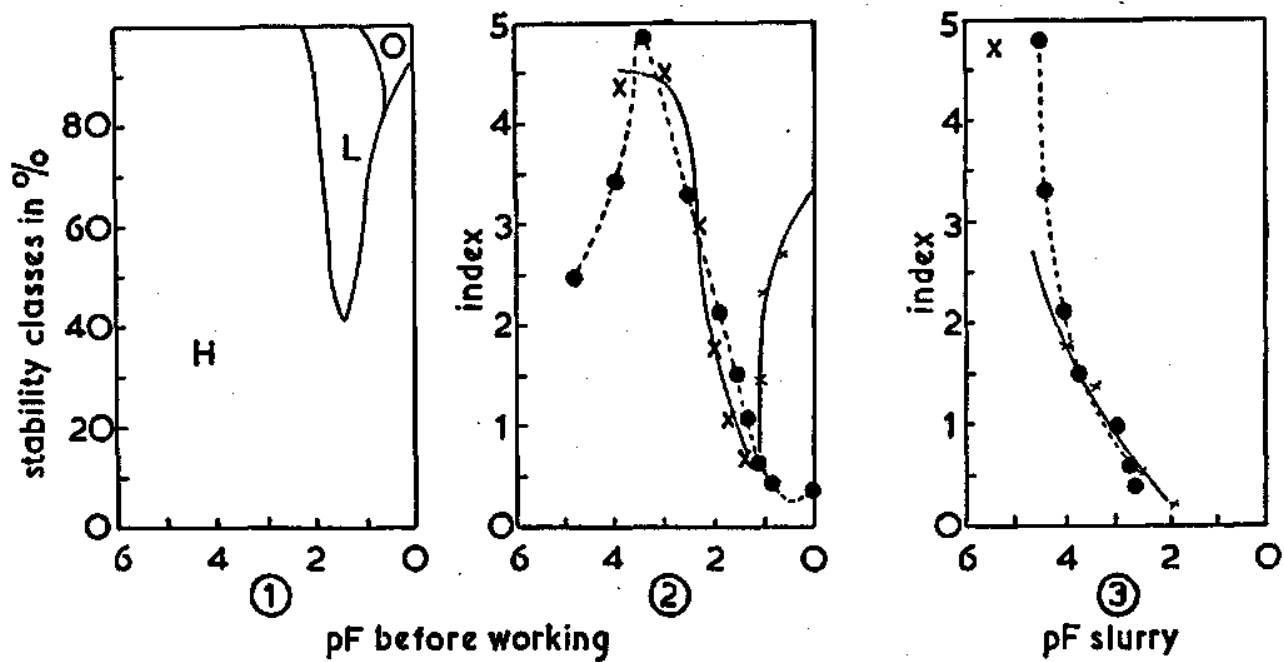

Fic. 56. Influence of soil moisture tension before tillage on the stability after tillage of $\mathrm{Mg}$-latosol.

1. Stability classes after treatment $A$

2. $\times$ x stability indices after light working

- . after 'strong' working

3. $x \times$ Indices of drying slurry

-. indices of worked soil

4.1.2 Soils with slurries behaving like an elastic system over a restricted range of suctions

As example of soils with a intermediate range of elasticity, the calcium basin clay colloid is chosen, although this choice has the disadvantage that only the wet side of the curve had been investigated. During working, treatment $\mathrm{C}$, the following observations were made: $40 \%$ moisture, tough cake below sticky point; $60 \%$, paste a bit above sticky point; $75 \%$, smooth paste; $100 \%$, thin paste; $120 \%$, thin paste with excess liquid.

The results of the stability determinations are given in table 49 , and are presented by graph 2, fig. 55 .

TABLE 49. Influence of treatment $\mathrm{C}$, at different moisture levels, on the stability of calcium basin clay colloid (quantities in $\%$, constants $\times \frac{1}{2}, 10^{3}$ )

\begin{tabular}{|c|c|c|c|c|c|c|c|c|c|c|}
\hline \multirow{2}{*}{$\begin{array}{c}\text { moisture } \\
\text { content } \\
\%\end{array}$} & \multicolumn{2}{|c|}{$\mathrm{pF}$} & \multirow[b]{2}{*}{ quant. } & \multirow[b]{2}{*}{ const. } & \multirow[b]{2}{*}{ auan } & \multirow[b]{2}{*}{ const. } & \multirow[b]{2}{*}{ quant. } & \multirow[b]{2}{*}{ const. } & \multirow[b]{2}{*}{ quant. } & \multirow[b]{2}{*}{ const. } \\
\hline & gran. & slurry & & & & & & & & \\
\hline 40 & 3.7 & 4.2 & 7 & - inf. & 29 & -16 & 58 & -2.0 & 6 & -0.29 \\
\hline 60 & 2.4 & 3.3 & 51 & 一inf. & 19 & -100 & & & 17 & -0.41 \\
\hline 75 & 1.4 & 2.8 & 51 & - inf. & 17 & -100 & & & 32 & -0.28 \\
\hline 100 & 1.1 & 2.2 & 53 & 一 inf. & 5 & -59 & & & 42 & -0.23 \\
\hline 120 & & 1.8 & 53 & - inf. & 5 & -59 & & & 42 & $\rightarrow 0.19$ \\
\hline
\end{tabular}




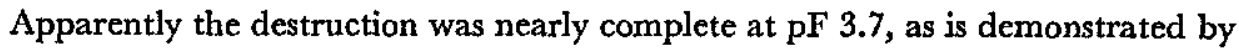
the low quantity with high stability. In contrast with the potassium clays most of the part puddled at this suction has some stability. At lower suctions the puddled part loses its stability quickly. With this type of colloid the maximum of destruction does not coincide with the minimum of total stability. At that moisture content the distance is apparently not so large that spontaneous unlimited swelling follows.

\subsubsection{Soils with slurries behaving like a semi-elastic system}

As examples of soils with a semi-elastic type of backswelling the calcium margalite soil, graphs 5 and 6 , fig. 53 , and the calcium Winsum soil, graph 6 , fig. 55, may serve.

The data for the calcium margalite soil are reproduced in table 50 .The settling time had been forty minutes.

TABLE 50. Influence of treatment $\mathrm{C}$, at different moisture levels, on the stability of calcium margalite soil (quantities in $\%$, constants $\times 10^{3}$ )

\begin{tabular}{|c|c|c|c|c|c|c|c|c|}
\hline \multirow{2}{*}{$\begin{array}{c}\text { moisture } \\
\text { content } \\
\%\end{array}$} & \multicolumn{2}{|c|}{$\mathrm{pF}$} & \multirow[b]{2}{*}{ quant. } & \multirow[b]{2}{*}{ const. } & \multirow[b]{2}{*}{ quant. } & \multirow[b]{2}{*}{ const. } & \multirow[b]{2}{*}{ quant. } & \multirow[b]{2}{*}{ const. } \\
\hline & gran. & $\overline{\text { slurry }}$ & & & & & & \\
\hline 0 & 7 & 7 & 38 & - inf. & 22 & -2.6 & 42 & -0.027 \\
\hline 20 & 5.4 & 5.5 & 3 & - inf. & 16 & -1.4 & 81 & -0.053 \\
\hline 40 & 3.7 & 4.1 & & & 37 & -0.50 & 63 & -0.064 \\
\hline 60 & 2.0 & 3.25 & & & 51 & -0.48 & 49 & -0.052 \\
\hline 80 & 0 & 2.7 & 2 & - inf. & 70 & -1.1 & 28 & -0.024 \\
\hline
\end{tabular}

As the sedimentation time was 40 minutes, the division into stability classes is a bit arbitrary. A further difficulty is that the $\mathrm{pF}$ at the beginning of the working is not known. This is due to the air explosion the soil suffers if wetted suddenly. It changes the dry granules into a slurry the more so the higher the watercontent to which the soil is brought. Therefore the suction will be more like that of the slurry at high water contents and more like that of the granules at lower ones. In consequence hereof the curve in graph 5 , fig. 53 , has been shifted to the $\mathrm{pF}$ of the slurry at high moisture contents.

The most important information is that the soil worked at $\mathrm{pF} 2.7$ has still some stability and that only $2 \%$ disperse spontaneously which is consistent with the semielasticity of the slurry. The maximum of destruction is in this case shifted to very low suctions as the destruction is not wrought by the working but principally by the air explosion.

Graph 6, fig. 53 and table 44 show the relation between stability and $\mathrm{pF}$ for the drying slurry. In this case the $\mathrm{pF}$ of the drying slurry is used as scale on the abscissa. The general features of graph 5 and 6 are the same. But with the drying slurry the air explosion commences at higher suctions, as was already shown by the preliminary experiments reported in 3.1.

During the working of Winsum calcium soil the following observations were made: 
$15 \%$, broken aggregates; $30 \%$, tough secondary aggregates with high shear strength; $40 \%$, paste at sticky point; $50 \%$, homogeneous paste; $75 \%$, soft paste with excess liquid and undestroyed granules. The results of the analysis are presented in table 51 and by graph $6 \mathrm{C}$, fig. 55 .

TABLE 51. Influence of treatment $\mathrm{C}$, at different moisture levels, on the stability of calcium Winsum soil (quantities in $\%$, constants $\times \frac{7}{2} \cdot 10^{3}$ )

\begin{tabular}{crrrrrrrrr}
\hline $\begin{array}{c}\text { moisture } \\
\text { content } \\
\%\end{array}$ & $\frac{\mathrm{pF}}{\text { gran. }}$ & quant. & const. & quant. & const. & quant. const. & quant. const. \\
\hline 15 & 4.2 & 5 & - inf. & 18 & -49 & 27 & -2.5 & 50 & -0.10 \\
30 & 2.4 & 0 & - inf. & 86 & -8.0 & & & 14 & -0.10 \\
40 & 2.0 & 2 & - inf. & 84 & -37 & & & 14 & -0.066 \\
50 & 0.2 & 13 & - inf. & 51 & -96 & & & 23 & -0.070 \\
75 & $<0.0$ & 23 & - inf. & 12 & -46 & & & 41 & -0.070 \\
\hline
\end{tabular}

By the admixture of silt and humus the suction at which maximum destruction is effectuated has been lowered to $\mathrm{pF}$ 2.3. Only at the lowest suctions the fraction with zero stability becomes larger again. The elasticity of this soil is probably intermediate between the calcium basin clay mineral and the calcium margalite soil.

\subsubsection{Soils with slurries behaving like an inelastic system}

As an example of a nearly inelastic colloid serves the magnesium latosol. The following observations were made during the treatment: at 14.5 and $23.5 \%$ of moisture the granules were powdered, at $30 \%$ a very stiff cake resulted sticking to the bottom of the dish, the stiffness of the resulting mass decreased with increasing moisture content and became sticky but it was quite homogeneous up to 74 and $84.5 \%$ where some moisture exuded at the beginning of the treatment; this moisture was subsequently worked into the soil mass, which nevertheless did not become quite homogeneous; at $111 \%$ all the water could not be worked into the soil again and a small fraction of the soil was suspended in this water.

The results of the analysis are presented in table 52 and by graphs 2 and 3 , fig. 56.

The strong treatment results in homogeneous secondary aggregates except in the case of the two highest and the two lowest moisture levels. At the highest moisture content the amount of moisture was apparently too large to allow for the application of a large force and to transmit the applied force from granule to granule. Even at the next lower moisture content, where the index was about the same the paste was not homogeneous, though by the larger friction a larger portion had been affected. At higher suctions the paste becomes homogeneous and the stability increases accordingly as this clay behaves like an inelastic colloid. Due to the absence of backswelling there is no sharp transition between the puddled and the unpuddled soil. Even at $30 \%$, the critical moisture content with this type of working, the soil is still worked 
TABLe 52. Influence of treatment $\mathbf{C}$, at different moisture levels, on the stability of magnesium latosol $\mathrm{pH} 7$ (quantities in $\%$, constants $\times \frac{1}{2} \cdot 10^{3}$ )

\begin{tabular}{|c|c|c|c|c|c|c|c|c|c|}
\hline \multirow{2}{*}{$\begin{array}{c}\text { moisture } \\
\text { content } \\
\%\end{array}$} & \multicolumn{2}{|c|}{$\mathrm{pF}$} & \multirow[b]{2}{*}{ quant. } & \multirow[b]{2}{*}{ const. } & \multirow[b]{2}{*}{ quant. } & \multirow[b]{2}{*}{ const. } & \multirow[b]{2}{*}{ quant. } & \multirow[b]{2}{*}{ const. } & \multirow[b]{2}{*}{ ind. } \\
\hline & gran. & slurry & & & & & & & \\
\hline 14.5 & 4.8 & 5.0 & 18 & 一 inf. & 16 & -0.90 & 66 & -0.095 & 2.45 \\
\hline 23.5 & 4.0 & 4.8 & 5 & -inf. & 11 & -3.6 & 84 & -0.115 & 3.41 \\
\hline 30 & 3.4 & 4.6 & & & & & 100 & -0.12 & 4.86 \\
\hline 39 & 2.5 & 4.4 & & & & & 100 & $一 0.16$ & 3.34 \\
\hline 47 & 1.9 & 4.0 & & & & & 100 & -0.26 & 2.15 \\
\hline 53 & 1.6 & 3.7 & & & & & 100 & -0.36 & 1.52 \\
\hline 62 & 1.3 & 3.3 & & & & & 100 & -0.49 & 1.13 \\
\hline 74 & 1.1 & 2.7 & & & 47 & -1.8 & 53 & -0.42 & 0.63 \\
\hline 84.5 & 0.9 & 2.6 & & & 64 & -2.3 & 36 & -0.30 & 0.43 \\
\hline 111 & $<0$ & 2.1 & 9 & 一 inf. & 31 & -1.7 & 60 & -0.41 & 0.37 \\
\hline
\end{tabular}

into a stiff cake, though with difficulty, but the stability is nearly the same as that of the lightly worked granules. This is the only instance where the observations during the working are not reflected by the stability. The powdering action of the treatment manifests itself by a class with zero stability at the lowest moisture contents.

As the stability had been altered for hundred percent over a wide range it was not possible to use the same way of presentation as for the other clays and soils. The index has been used instead for graphs 2 and 3 , fig. 56 . In graph 3 the $\mathrm{pF}$ of the slurry has been used as unit on the abscissa (which is permitted as the pastes are homogeneous) the constants of the dehydrated slurry have been inserted also. Though the coincidence is not absolute, the agreement between the two curves is fair enough to permit the conclusion that the structure of the paste obtained by dehydration is very similar to that of the paste obtained by working the soil strongly at the same moisture content.

\subsection{INFLUENGE OF THE APPLICATION OF SMALL PRESSURES (TREATMENT A)}

\subsubsection{Comparatively large influence}

As example for a comparatively large influence of the light treatment magnesium latosol has been chosen. The treatment consisted in this case of 50 movements of a spatula hold vertically across the soil. The following results of the treatment were observed; at a moisture content of 25 and $34.5 \%$ no puddling occurred, at $41.5 \%$ only a small part was puddled, at $45 \%$ large secondary aggregates were formed at the end, at $52.8 \%$ a tough paste was the result, at $62.5 \%$ the paste was less tough, at 72.5 and $80 \%$ a sticking mass resulted which was not completely puddled, and at 90 and $110 \%$ some water exuded in which a small part of the soil was suspended, while a very small part sticked to the side of the spatula.

The results of the stability analysis are presented in graphs 1 and 2, fig. 56 and by table 53. 
TABLE 53. Influence of treatment $A$, at different moisture levels, on the stability of magnesium latosol (quantities in $\%$, constants $\times \frac{1}{2} \cdot 10^{3}$ )

\begin{tabular}{|c|c|c|c|c|c|c|c|c|c|}
\hline \multirow{2}{*}{$\begin{array}{c}\text { moisture } \\
\text { content } \\
\%\end{array}$} & \multicolumn{2}{|c|}{$\mathrm{pF}$} & \multirow[b]{2}{*}{ quant. } & \multirow[b]{2}{*}{ const. } & \multirow[b]{2}{*}{ quant. } & \multirow[b]{2}{*}{ const. } & \multirow[b]{2}{*}{ quant. } & \multirow[b]{2}{*}{ const. } & \multirow[b]{2}{*}{ ind. } \\
\hline & gran. & slurry & & & & & & & \\
\hline 25 & 3.9 & 4.7 & & & & & 100 & -0.12 & 4.39 \\
\hline 34.5 & 3.0 & 4.6 & & & & & 100 & -0.11 & 4.51 \\
\hline 41.5 & 2.3 & 4.4 & & & & & 100 & -0.18 & 3.01 \\
\hline 45 & 2.0 & 4.2 & & & & & 90 & -0.27 & 1.73 \\
\hline 52.8 & 1.6 & 3.7 & & & 55 & -0.89 & 45 & -0.28 & 1.07 \\
\hline 62.5 & 1.3 & 3.3 & & & 55 & -1.75 & 45 & -0.245 & 0.736 \\
\hline 72.5 & 1.1 & 3.0 & & & $4 I$ & -4.61 & 59 & -0.128 & 1.44 \\
\hline 80 & 1.0 & 2.8 & & & 35 & -8.9 & 65 & -0.20 & 2.33 \\
\hline 95 & 0.6 & 2.5 & 15 & 一 inf. & & & 85 & -0.14 & 2.72 \\
\hline 110 & $<0$ & 2.1 & 7 & - inf. & & & 93 & -0.14 & 3.33 \\
\hline
\end{tabular}

At high suctions down to $\mathrm{pF} 2.3$, the stability will have been nearly the same as that of the untreated soil. Below pF 2 the stability decreased sharply and two stability classes were observed (at $\mathrm{pF} 2$ the least stable class amounted only to $10 \%$ and was therefore undeterminable).

At $\mathrm{pF} 1$ working had little effect, due to the presence of free or nearly free water. A part of the soil was brought into suspension by the treatment and the stability of the remnant was little affected. With this type of working $\mathrm{pF} 2.3$. will be the critical moisture content for dry agriculture.

That this soil, which is known for its stability is affected to a high degree by the light treatment is caused by the fact, that the artificial aggregates used had been strongly disrupted by the air explosion during saturation. The interaggregate friction per unit of cross section was therefore considerable at the critical moisture contents and the transfer of energy into the aggregates and the degree of puddling consequently high. If the aggregates were kept intact by slow wetting the working had less result. The saturation was necessary because an even distribution of the water at low moisture contents could be best obtained by slow evaporation of excess water. The quick saturation was chosen because it is natural for tropical soils.

Comparison of fig. 57 with 52 (to accomplish this, one of the graphs has to be turned $180^{\circ}$ with the abscissa as axis) shows that the agreement between the qualitative and the quantitative experiments is good, considering that for the qualitative experiment natural granules had been used. The increase of destruction at the dry side of the curve observed with the quantitative experiment, treatment $\mathrm{C}$ (cf. graph 2, fig. 56) was, however, not observed with the qualitative experiment. As the sediment volume increases only if the particles are reduced to such dimensions that they flocculate, one may conclude that indeed the decrease of stability at the dry side is caused by the powdering action of the treatment which reduces the granules to dimensions smaller than the critical one. Thus the qualitative method furnishes in this case a better analysis of the influence of the treatment on the changes within the granules than the quantitative method. 


\subsubsection{Comparatively small influence of the treatment}

As example of a small influence of treatment A (30 movements) the analysis of the worked potassium Winsum soil has been reproduced in table 54 and graph $5 \mathrm{~A}$ fig. 54 .

TABLE 54. Infiuence of treatment $A$, at different moisture levels, on the stability of potassium Winsum soil (quantities in $\%$, constants $\times \frac{1}{2} \cdot 10^{9}$ )

\begin{tabular}{|c|c|c|c|c|c|c|c|}
\hline $\begin{array}{c}\text { moisture } \\
\text { contents } \\
\%\end{array}$ & $\frac{\mathrm{pF}}{\text { gran. }}$ & quant. & const. & quant. & const. & quant. & const. \\
\hline $\begin{array}{c}15 \\
30 \\
40 \\
50 \\
75 \\
\text { unworked }\end{array}$ & $\begin{array}{c}4.0 \\
2.4 \\
2.0 \\
0 \\
<0\end{array}$ & $\begin{array}{r}8 \\
10 \\
14 \\
16 \\
12\end{array}$ & $\begin{array}{l}\text { - inf. } \\
\text { - inf. } \\
\text { - inf. } \\
\text { - inf. } \\
\text { - inf. }\end{array}$ & $\begin{array}{l}28 \\
26 \\
26 \\
26 \\
25 \\
37\end{array}$ & $\begin{array}{l}-3.0 \\
-3.2 \\
-4.3 \\
-3.0 \\
-4.25 \\
-3.4\end{array}$ & $\begin{array}{l}64 \\
64 \\
60 \\
58 \\
63 \\
63\end{array}$ & $\begin{array}{l}-0.23 \\
-0.21 \\
-0.19 \\
-0.17 \\
-0.20 \\
-0.21\end{array}$ \\
\hline
\end{tabular}

The structure has been most impaired at a moisture content above sticky point, which lies at $40 \%$. With the small force applied, the lowering of the cohesion seems to be the dominant factor. As the soil is saturated near $50 \%$, the cohesion has obtained its minimum value, by further addition of water the soil gets oversaturated and the friction with the dish, which determines the force applied, is lowered and therefore the destructive effect of the treatment.

The quantities and constants of the untreated soil are in accordance with the worked one.

\subsection{INFLUENGE OF THE SALT CONGENTRATION ON THE STABILITY AFTER WORKING}

This influence has only been studied with calcium bentonite (II, 4.1.3) and potassium margalite. As the influence is more pronounced with the latter it is given as example here.

The working (treatment $\mathrm{C}$ ) was done at $60 \%$ moisture. The solutions of potassiumchloride were added to two gram portions of the dry granules. The working resulted in a uniform paste, except in case of the one molar solution which was fissurated. Perhaps this was due to a raising of the lower plastic limit by higher internal friction.

After introduction into the corresponding solution, the units of the pastes worked with water and the $0.001 \mathrm{M}$ solution lost their identity and a diffuse layer of dispersed clay was formed. The units of the paste in $0.01 \mathrm{M}$ salt, did swell strongly, but kept their identity and form, no dispersion was observed. In $0.1 \mathrm{M}$ solution the swelling was small and in $1 \mathrm{M}$ solution no swelling was visible. The settling time was two minutes. The results are reproduced in table 55 and by curve b, fig. 40 . 
TABLE 55. Influence of salt concentration on the stability of puddled potassium margalite (quantities in $\%$, constants $\left.\times 10^{3}\right)$

\begin{tabular}{lrrrrrrr}
\hline $\begin{array}{l}\text { concentra- } \\
\text { tion } M\end{array}$ & quant. & const. & quant. & const. & quant. & const. & ind. \\
\hline 1 & & & 24 & -6.4 & 76 & -1.0 & 0.342 \\
0.1 & & & 100 & -4.8 & & & 0.114 \\
0.01 & & & 93 & -24 & 7 & -3.0 & 0.0123 \\
0.001 & 79 & - inf. & 12 & -32 & 9 & -3.0 & 0 \\
$\mathrm{H}_{\mathbf{2}} \mathrm{O}$ & 76 & - inf. & 7 & -39 & 17 & -4.5 & 0 \\
\hline
\end{tabular}

The results of the stability analysis are quite in accordance with the observations. They demonstrate that by raising the concentration a colloid with a large range of elasticity of the desorption characteristic can be transformed into one with a semielastic character. Just as was the case with the calcium bentonite slurry (cf. I, 2.5.1.3. and fig. 11)

\section{GENERAL REMARKS}

\subsection{Sugtion value AT Which the Maximum OF DESTRUction occurs}

The suction at which a soil is most affected by working is often dependent upon the type of cation present. This is demonstrated by the behaviour of the margalite colloid, treatment C., fig. 53, graphs 2 en 3 . With the potassium clay this maximum lies at $\mathrm{pF}$ 3 and with the calcium clay at $\mathrm{pF} 2$. This shift is not observed, however, with the illitic clays. There the maxima for potassium and calcium clay lie both at a tension of $\mathrm{pF}$ 3.5. The practical implication is that the heavy illitic clays, poor in organic matter, must be worked at a higher suction than the corresponding smectite clays, provided that both are chiefly calcium saturated.

The maximum of destruction of the soils is shifted to lower suction values compared to that of the pure clays, e.g. for illitic soils (cf. fig. 54 and 55) from pF 3.5 to $\mathrm{pF}$ 2.5. This is probably due to the higher internal friction in the granules resulting from the presence of silt, sand and organic matter. The difference between the heavy soil high in organic matter (basin clay soil) and the slightly lighter soil low in humus (Winsum clay soil) is negligible.

If the working is less intensive (treatment $A$ ) the differences become larger. The basin clay is affected little with a maximum below $\mathrm{pF} 1$; the Winsum clay is more susceptible to destruction, especially the magnesium soil, with a maximum at $\mathrm{pF}$ 1.8. With the light working the maximum destruction lies above sticky point, with the heavier it occurs below this point confirming the postulation in the introduction.

With the latosol the strong working does in one case not lead to a reduced stability of the resulting paste. The original structure has been changed over a wide range up to $\mathrm{pF} 3.4$ and its stability increases with decreasing moisture content. The destruction obtained with the light working had a maximum near $\mathrm{pF} 2$. 


\subsection{Stability of the SOIL AFfected by Tillage}

The stability of the part affected by the vigorous treatment reflects the bakswelling characteristics of the clays and soils. The backswelling characteristics of the slurries of potassium saturated clays and that of the illitic clays saturated with divalent cations, shows that they are elastic over a wide range, (cf. see summary I, 2.) this range being larger with the former than with the latter.

For potassium clays and soils nearly the entire fraction of the granules affected by working has zero stability. That a small part still has a certain stability is not readily explained. The destroyed granules of the magnesium and calcium saturated illitic soil colloids have a low stability, which becomes zero at higher moisture contents, with the exception of magnesium Winsum the affected part of which has zero stability. The stability of the affected part of granules of illitic soils is larger than that of the corresponding colloids. The differences between magnesium and calcium saturated soils are not consistent; with the basin soil saturation with magnesium gives the highest stability, with the Winsum soil it imparts the lowest. The lower stability of the Winsum soil compared to that of the basin soil (cf. II, 4.63) is also shown by the higher degree of destruction it suffered by the light treatment $A$.

The clays which behave like a semi-elastic colloid, like calcium bentonite and margalite, show only a small fraction with zero stability if worked at very low suctions. This is especially so for the margalite soil.

The stability of the calcium bentonite puddled at $100 \%$ water is however not quite in accordance with the backswelling characteristic of the slurry (fig. 11 and 12). From the latter the conclusion can be drawn that the slurry has to be desorbed to $\mathrm{pF}$ 4 before any stability can be observed; the $\mathrm{pF}$ of the puddled clay is however only 2.8 . Therefore the stability of the pastes obtained by puddling is in this case larger than that of the paste obtained by desorption.

The latosol which behaves like an inelastic colloid, has only a fraction with zero stability if worked at a suction below $\mathrm{pF} \mathbf{0}$. The vigorous working at higher suctions results in homogeneous pastes with a stability increasing with decreasing moisture content, very similar to the stabilities of the desorbed slurry.

The lesser degree of working has a relatively small influence on the granules with the exception of Winsum soil and the latosol. The stability of the affected fraction is however zero or very low, because the moisture content of the puddled part will be higher than the mean moisture content, as explained in the introduction. This phenomenon is observed with all soils.

\section{SUMMARY}

It was possible to determine by the analysis of the stability the degree to which the structure of soils had been affected by a model tillage operation. In accordance with the general principles (cf. 1.1) it was found that this degree depended on the moisture 
content at working, on the magnitude of the applied force, and if a small force was used also on the dimensions of the aggregates. The suction at which the operation had its maximum destructive effect depended with the margalite colloid on the saturating cation. For illitic soils this suction was lower than for the clay isolated from it.

The stability of the part of the soil which had been affected by the operation could be largely explained on basis of the backswelling characteristic of the slurries of these materials. Thus soils which have identical stability when granulated may have widely different stabilities after working at a wrong moisture content. If the climatic conditions are such that one may expect that the soils will be puddled by tillage or harvest operations, then the backswelling characteristic of the slurries and the stability of the puddled soil will provide a better characterization than the $\mathrm{pF}$ curve and the stability measurement of the granulated soil. 


\section{APPLICATIONS OF THE RESULTS TO AGRICULTURE}

\section{LIMITATIONS OF THE RESULTS}

The extension of experimental results found in a laboratory to practical agriculture is a hazardous job, especially with soil physics. Some of the causes are:

\subsection{Ghanges of Samples during dRying}

It has been observed at this laboratory that fresh soil samples, which had very little resistance in the saturated state, acquired considerable resistance if stored for some time. These changes proceeded slowly, even in the air dry state. They may be due to a slowly proceeding dehydration of inorganic or organic gels; microbiological activity may also play a role as suggested by DE LEENHEER \& DE BOODT (1958a). The influence of ovendrying on the moisture affinity of soils and clays has been neglected, though in the case of bentonite no serious influence had been found. The properties of a subsoil will be more changed by drying thang those of a topsoil which dries out periodically anyhow.

\subsection{EQUILIBRIUM WTTH LOW SUCTIONS}

In chapter II suction moisture equilibria have been studied of homoionic clays and soils at low salt concentration in a more or less homogeneous state of aggregation. The degree of backswelling of suspensions after application of a certain suction has been investigated in particular. The extension of these results is difficult, because true equilibrium will seldom be reached in soils for the reason that the mass of soil is so large that before equilibrium is established, the climatic conditions which govern this equilibrium will have changed again. This will be especially the case with wetting; only a small part of the soil will ever be in equilibrium with water at zero suction, perhaps only the surface layer and the walls of large pores and fissures and only as long as rainfall and drainage proceed. Deeper layers of the soil will be compressed by the weight of the ones above, this will prohibit maximum swelling though the tension might be zero or positive, (CRONEY, 1953). As for the salt concentration, it will remain much higher inside a clod than on the outside and it is obvious that the rain water which has percolated some distance will pick up a certain amount of salts. Therefore the equilibria determined at low suctions with very low concentrations are only relevant for surface layers and some pore surfaces. This is however not a very serious handicap since the physical state of this layer is very important as it may limit the air diffusion, the infiltration rate etc.

\subsection{Homoronic GLAYS AND SOILS}

The second objection is that homoionic clays are never found in nature; usually the divalent cations are predominant with a small percentage of hydrogen, potassium and sodium. It is of importance to know at which percentage of sodium or potassium 
saturation, the soil starts to show the unlimited swelling at low concentration, characteristic for most of the sodium soils and some of the potassium soils.

This has been investigated by QuIRK \& SchofIELD (1955) for a silty loam (19.5\% clay, $2 \%$ carbon, the clay fraction being composed of $40 \%$ illite, $40 \%$ kaolinite and $20 \%$ vermiculite). From their data it is seen that if this soil contains $10 \%$ exchangeable sodium the soil equivalent solution has to contain a minimum of $4 \mathrm{me}$. per 1 for a reasonable percolation velocity. At this laboratory it was found that the permeability of distilled water in calcium bentonite is impaired if the percentage exchangeable sodium is higher than $5 \%$. The tolerance for sodium may be increased by a higher content of organic matter as found by ZuUR e.a. (1953), he also stated that generally a $5 \%$ sodium is harmful.

The degree of harmfulness of exchangeable sodium also depends of course on the type of climate. If irrigation water is the only one supplied, then it should be possible to keep the soil granulated even if a high percentage of exchangeable sodium is present. This can be achieved by addition of a suitable quantity of salts to the irrigation water, when drainage is provided for and sufficient water can be supplied to prevent harmful concentration of salts by evapotranspiration.

\subsection{State of aggregation of the solls}

The investigations had to be limited to well defined states of aggregation or dispersion. The finest dispersion was obtained by saturation with sodium, removing the excess salts and suspending in distilled water. Saturation with other cations was carried out without drying the suspension. It has not yet been proved that this finest suspension will ever occur with clays only partly saturated with sodium. The data on the influence of partial saturation with sodium are derived from permeability measurements and the permeability even of a coarse suspension will not differ much from a very fine one, both being zero. It is therefore not certain whether the studies of the finest suspensions have any practical meaning.

The coarse dispersions or slurries on the contrary may be regarded as the finest dispersions occurring in nature, since they have been made by working the soil through a range of increasing water contents and shaking it in excess water.

In dry agriculture the occurrence of this degree of dispersion is purely accidental and certainly not the aim of any practice. This dispersion of a small fraction of the soil layer may however occur during heavy rainfall on unprotected soil and to a higher degree if a soil has been worked at too high a moisture content. Although the percentage of the whole topsoil brought into suspension might be very low, its unfavourable physical properties might well dominate over the more favourable properties of the whole surface layer. For example, the suspension might flocculate during percolation and clog the larger soil pores. The investigation of coarse suspensions seems worth while from this point of view. Moreover fresh sediments or subsoils of older sediments which never did dry out completely, will have similar properties to those of coarse suspensions in a varying state of desorption.

The artificial granules which have been studied were considered as a model of a 
clay soil which had become air dry. Although the density of a natural soil unit will be somewhat lower and therefore its stability, the density will become comparable if the units taken are small enough to exclude larger pores and fissures. Moreover Holmes (1955) has shown that there exists remarkable agreement, between the moisture characteristics of moulded soil blocks and natural aggregates.

\subsection{The stability analysis}

In chapter III, the stability of granules formed by drying or desorption of suspensions with low salt concentrations has been investigated. The end over end shaking method has been chosen for sake of higher accuracy in preference to the raindrop method of VILENSKY (l.c.). From the investigations of EMERSON \& GRUNDY (1954) it is apparent that the method of desintegration under the influence of raindrops is comparable to the action of end over end shaking. Whereas VILENsky's method can be interpreted directly, with the method used a relative scale of stability can be established and calibrated by analyzing soils of known stability. The influence of the salt concentration on stability has been investigated in detail; it will be of particular interest for conditions where the concentration can be controlled.

As the end over end shaking method of stability analysis lasts for 48 hours or more, the swelling should be completed before the start of the analysis, since swelling during the analysis must be avoided so as not to change the stability. This method therefore is only applicable in climates where the rain falls during a long enough period to enable part of the soil to swell completely. The destructive force chosen was such that on the long run very stable soil granules were also dispersed. The stability of a soil may, however, be sufficient to withstand the impact of common raindrops and those soils should be regarded as absolutely resistant.

\subsubsection{Influence of cation concentration on the formation of soil structure}

How the formation of the granules is influenced by the salt concentration has not been investigated except in the case of sodium montmorillonite. This subject has been treated to some extent by HAUSER \& LE BEAU (1939) who found that no waterstable films could be prepared in the cases of films formed from calcium bentonite suspensions where coagulation was incipient (minimum of viscosity). After the flocculation had become visible only individual water resistant flakes were obtainable. In consequence J. B. Peterson (1946) states that 'the best waterstable binding materials or cements in soil granules are formed by the drying of dispersed rather than flocculated clay systems". This is quite probable because flocculation may impede the sliding of the clay polyplates into parallel alignment, causing a larger pore space and a consequently reduced stability.

This factor is very important since the pore space geometry of the dry soil will be governed by it. It is common knowledge that sodium soils form upon drying large and massive clods, probably by the low friction of the clay particles sliding over each other. Except for the pore space which is influenced directly by this behaviour the permeability also is impaired, with the result that under irrigation these soils are not 
wetted quick enough e.g. the slick spots in Idaho, quoted by Lewis, JoRdan \& FosBERG (1959), which remained too dry.

\subsubsection{Air explosion}

Another phenomenon studied to some extent in chapter II is the air explosion. If a dry lump of soil is suddenly wetted the air in it is compressed giving rise to localized pressures often strong enough to overcome the cohesion of the lump, and the latter falls apart into larger or smaller fragments depending upon a large number of factors.

The air remaining in the soil pores tries to assume a spherical shape thus enlarging the diameter of the pore, with as a consequense extra swelling pressure and a reduced resistance against mechanical forces. Whether the air explosion effect should be included or not in aggregate stability determinations depends on the frequency at which this phenomenon occurs in the field.

EMErson (1955) concludes that the rain intensity of $0.2 \mathrm{~cm} /$ hour is too small to cause slaking because crumbs wetted at this rate had the same stability as vacuum wetted ones. He overlooks, however, the fact that rain is not a continuous stream of water but falls in drops. Assuming that the diameter of a drop of a shower is $4 \mathrm{~mm}$, the weight of the drop will be aproximately $33 \mathrm{mg}$. If the apparent density of the crumb is 1.8 and the amount of moisture necessary to saturate a crumb completely is some $60 \%$, then $30.6 \mathrm{~mm}^{3}$ of soil might be saturated, at once, by a raindrop or a cube of $3.1 \mathrm{~mm}$. It is therefore probable that the air explosion effect will be in the first instance correlated with the weight of the raindrops and to that of the soil aggregates; next to the intensity of the rainfall, although the latter and the dimensions of the drops will be often correlated.

\subsection{Deformability of GRANULES}

The most serious objection against the stability measurements is that these tests, carried out in the saturated state, are not a sufficient criterion to ascertain the stability in agricultural practice. Although it should give a reasonable estimate of the resistance of granules to the impact of raindrops, it does not estimate directly the deformability of the granules in the saturated stage. There may be some correlation between the two properties, however. This deformability is a very important soil property as will be explained in the following.

In a large column of loosely packed granules of a clay soil which is wetted, the granules will try to expand and are obstructed herein by their neighbours. The forces which obstruct expansion in the vertical direction are equal to the weight of the overlying soil column and increase therefore with depth. These pressures exerted by the expansion are not equally distributed but are largest at the points of contact. The pressure will result in a flattening of the contact points, until the supporting surface is large enough to carry the burden of the overlying soil. The pore diameter will be reduced accordingly and this reduction will be the more obnoxious the smaller the granules are to begin with. If the pressure is larger than the yield value of the whole soil units, the subsoils will be compressed until are left only some difficultly 
compressible circular pores like worm and root holes. No pore space filled with air at low suctions will be present in the subsoil of clay soils unless their yield value is high. The more and the quicker a soil swells the more work must be done by the subsoil to lift the overlying burden, this results in an extra pressure on the aggregates besides the pressure exerted by the burden. Therefore with swelling soils the probability is small that air filled pores are present in the subsoil. Moreover with strongly swelling and shrinking soils there is a possibility that cracks formed during a dry season will fill with surface rubble, thus increasing the density.

Not only can the deeper layers suffer from compaction, but also the very surface layers may be compressed by water hanging between the granules. This effect will vary inversely with the dimensions of the aggregates since the height of the moisture column held between them is inversely related to the radius of the aggregates and the resistance of the aggregates to compression is proportional to their diameter (KIRKham, De Boodt \& DE LeENheER (1958)). Assuming granules of $2 \mathrm{~mm}$, effective radius of the pores of $0.1 \mathrm{~mm}$, pore space of $50 \%$ and a contact area of one tenth of the diameter of the granules, then the pressure exerted by the capillary water can be roughly calculated. The maximum height of the water column held by pores with radius of $0.01 \mathrm{~mm}$ is $15 \mathrm{~cm}$. A pore space of $50 \%$ means that an equal volume of water is supported by an equal volume of soil; as the supporting surface is only $10 \%$ the pressure will be $150 \mathrm{~g} / \mathrm{cm}^{2}$. This pressure is not negligible as the soil is near its minimum resistance at this suction, and moreover this compaction can not be avoided unless a complete saturation is maintained. The lateral compressive force will be of the same order.

If the compressive force is larger than the yield value of the individual granules the topsoil will be compressed with a resulting decrease in air volume; since the contact points between the granules will have been changed into contact zones, the mass of granules will exhibit a cohesion upon drying proportional to the compression suffered, which must be overcome if the soil has to be restored to its original structure. This compression due to capillary forces is one of the causes of crust formation, it operates independantly of the other factors as slaking and destruction by rainfall.

That this yield value or resistance is not the same as the stability is proved by the stability measurements of sodium bentonite, which were fluid gels at a salt concentration of $0.1 \mathrm{M}$ and lower, but needed some shaking before they were dispersed completely.

\subsection{Model tillage tests}

In chapter III, the influence of tillage operations at various degrees of moisture on the resulting stability has been investigated. Obviously even more restrictions should be applied to the results of these investigations. The moisture content of the soil will not be homogeneous, and only part of the soil will be influenced by these operations. The treatment of soils and clays has been more intensive than with normal tillage operations and the magnitude and direction of the force employed may not be encountered with agricultural implements, although both compression and shear have 
been applied which are used in various proportions by the different tillage instruments. Moreover the stability has been tested before the moisture content of the worked clay sample had decreased, which will not often occur in practice. An advantage is however that with these experiments the deformability is included to some extent. This factor influences the friction between the granules and the friction commands the force applied, which in turn influences the degree of destruction.

\section{NORMAL AGRICULTURE}

\subsection{Necessity of AgGREgation}

In agriculture soil is the main source of ${ }_{3}$ water, oxygen, and nutrients in a more restricted sense for crop roots. The first two functions are more or less incompatible as a maximum supply of moisture excludes the provision of oxygen, the inverse being true also. Depending on the climatic conditions more importance will be given to the ability of the soil to hold moisture or to its ability to supply roots with oxygen. The soil can comply with these demands if large as well as small voids are present in the system, the large ones being drained at low tensions provide the air, the smaller ones (elastic or not), being emptied only at higher suctions, provide the water.

Some soils especially aeolian deposits like loess and volcanic ash soils have a very favourable air and moisture supply due to their textural composition, which commands the minimum pore diameters. Pores large enough to contain air at moderate suctions can only exist in clay soils if the primary particles are united into larger units, since the pores as governed by the texture are so small that they are only emptied at suctions which are higher than those exerted by plantroots. It is obvious that the resistance of the soil granules to destructive forces must be an important feature in agriculture, since with instable granules the air filled pores can not subsist. The conclusion is that clay soils must exhibit a certain swelling to be able to provide plants with water, but that this swelling must be limited since limitless swelling soils will have no mechanical stability at low suctions.

\subsection{ApPLication of BackSWELLING CHARACTERISTICS}

In chapter II the soils have been grouped into elastic soils, which convert automatically into a suspension as soon as the suction becomes zero; soils, the suspensions of which are elastic over a certain range and become semi elastic as soon as this range is passed; semi-elastic soils, the suspensions of which exhibit a limited swelling in excess water even if the desorption has been small, and inelastic soils, the suspension of which do not adsorb water to any extent unless the desorption has proceeded very far.

Applying this classification to the requirements stated above it is easily understood that all soils, the suspension of which behave at low salt concentrations like an 
elastic colloid will be extremely difficult to manage, also the soils, the suspension of which behave like an elastic colloid up to high suctions will be just as difficult as long as they do not dry below the critical moisture range.

The spontaneous dispersion of these clays and soils may however be stopped by raising the salt concentration. Whether this will be feasable depends on the concentration necessary to keep them in a granulated state; these salt concentrations will be found in the summaries I, 2 and II, 7.

In the following paragraphs most attention has been paid to soils with an elastic backswelling characteristic over a certain range and to those with a high degree of elasticity which are the most difficult to manage.

\subsubsection{Regranulation}

Whether a soil will easily revert from the puddled state or a partially dehydrated suspension into the granulated state, may also be an important question as mismanagement of soils can not always be prevented. For instance the harvesting of sugarbeets in the autumn, which is usually a wet season in Holland, leaves the clay soils in a rather puddled state. The regeneration of a puddled soil is only achieved by drying, evapotranspiration, freezing or suction (drainage). The regranulation of a soil will be the easier the less the spontaneous backswelling of a drying slurry is, as the desorption is little or not interrupted at all by adsorption of rain water during this process. The inelastic systems are much preferred from this point of view (cf. summary I, 2.).

The absolute amount of water which must be removed before maximum regranulation is achieved is of course of importance especially where the drying capacity is small. As the capillary conductivity also plays a role, since it may retard the drying of the topsoil, it can not be predicted whether the amount of water to be removed from the topsoil will be decesive. The quicker drying of low lying heavy soils compared with the higher lighter soils may result in a week advance of the tillage operations, as observed by SonNeveld (1959).

\subsubsection{Aggregation of fresh sea deposits}

Except for accidentally puddled soils, the backswelling is of importance for the reclamation of fresh sea deposits and other soils which have never dried before.

Domingo (1951) found that the maximum water capacity A, expressed in percent of dry matter, for fresh sea deposits was related to the clay content by the function $\mathrm{A}=2.35 \times \%$ clay +23 , while for normal agricultural soil flooded by seawater, the relation was approximately $\mathrm{A}=0.5 \times \%$ clay +17.5 . The explanation is that the fresh seawater deposits were necessarily in a flocculated state, the same as the older soils had at the moment of their deposition. During reclamation, the loose flock structure collapses and relatively dense aggregates are formed, which do not swell back when flooded with seawater (the swelling which will occur after dilution of the seawater is not discussed here). This collapse of the flock structure has been extensively studied by SMrrs from whose unpublished reports he kindly authorized me to quote the following data. The correlation of the moisture content at saturation with the 
percentage of clay and the percentage of humus $(\mathrm{H})$ is: $\mathrm{A}=20+n$ (clay $+3 \mathrm{H}$ ), the factor $n$ is 2.2 for permanently submerged fresh deposits. (It is remarkable that this factor changes very little with depth, apparently the pressure and the permeability are too small to squeeze the water from the lowest layers). This factor $n$ changes after reclamation by evaporation, transpiration (reeds) and drainage within $1 \frac{1}{2}$ year from 2.2 to 1 and becomes 0.5 in the course of 11 years. This moisture loss causes considerable vertical as well as horizontal shrinkage. The horizontal shrinkage gives rise to deep cracks and fissures. As computed from graph 3 of Domingo's publication, the vertical shrinkage for the whole layer of $66 \mathrm{~cm}$ amounts to $23 \%$, while the horizontal shrinkage (air filled pores caused by permanent water loss) amounts to $18.7 \%$ for the whole layer and to $37 \%$ for the topsoil of $23 \mathrm{~cm}$. As the adsorbed sodium has usually been exchanged by calcium during the desalinization process (due to the formation of gypsum, by oxydation of iron sulfides reacting with calcium carbonate) the waterloss is to a large extent irreversible and the cracks will not close when the soil is wetted again by excess rainfall. These permanent cracks improve the internal drainage to a large extent, so that clay soils first quite impervious become more permeable than fine sandy soils. The definite drain distance is according to SreBeN (1951) 18-24 $\mathrm{m}$ for silty clay soils and $8 \mathrm{~m}$ for sandy soils.

If the situation is such that it is impossible to lay out drainage experiments, one might use the backswelling characteristic of the fresh deposits in order to make a prediction of the drainage distances. From the backswelling of the dried soil one can calculate its volume at saturation after reclamation. Substraction of this volume from that of the original sediment furnishes the pore volume not closed upon resaturation, i.e. the amount of irreversible shrinkage. Since the proportion between horizontal and vertical shrinkage is known from field experiments one can calculate the horizontal shrinkage. As the influence of this value on the drainage distance has already been established, the estimation of the drainage distance with the aid of the backswelling should be possible. The difficulty that might arise in this case is the evaluation of the change in the adsorption complex on desalinization.

\subsubsection{Subsoils}

Although no data is available it is plausible that the backswelling characteristic exerts an influence on the permeability of normal subsoils. Especially subsoils which are elastic up to a certain suction will be difficult to manage until this suction has been passed since above this suction no irreversible shrinkage is possible. But even in case there is no question of irreversible shrinkage the elasticity of soils willimpededrainage. The cracks in the soil which conduct the drainage water are formed by shrinkage caused by waterloss. They!will be closed if the water is replenished, whether the soil is elastic or not. In the case of normal, slightly elastic, soils this closing will however be a slow process as the outside of the blocks will swell only slightly as it gets saturated and this swelling will slowly continue until the whole blocks are saturated. Furthermore there exists a considerable hysteresis in the swelling, probably due to internal friction, Holmes (1955), which will only be eliminated at low suctions. That this 
slowness of swelling may be of practical importance has been observed by EMERson (1955), who found that the drain performance of a wheat cropped field was consistently better throughout the following winter, than that of an adjoining fallow field. He attributed this fact to the higher water content of the fallow field, which stayed swollen during the summer, whereas the subsoil of the cropped field dried out considerably.

In the case of the elastic soils the outside layer of the blocks will swell unlimited as soon as rainwater starts to percolate and the cracks will be clogged before the whole mass of soil has swollen.

Though the equilibrium situation will be in both cases the same i.e. all large cracks closed by swelling, the rate at which this swelling proceeds may differ and this difference may be so large that it can be of importance to agriculture.

\subsubsection{Filling in of drainage ditches}

This is a subject closely related to the preceeding one. But in this case it is possible for the excavated mass of soils, which behave over a large range like an elastic colloid, to dry out until their elasticity is lost. If this soil is filled in, the big pore spaces between the clods will probably be preserved to a large extent and therefore the permeability of the soil above the drainage tilewill belarge. In most theoretical considerations little thought is given to the permeability of the filled in ditch, but this must be of some importance since the water falling in excess of the infiltration rate and seeping horizontally through the more permeable topsoil can be removed. The permeability of the filled in soil will be of importance, the more the land slopes towards the ditch. This is often the case where open ditches have been converted to tile drains.

The question whether the soil should be filled in dry, or moist after it has been dried, is open to some discussion. If it is filled in dry, it will swell to some extent and the pores will become smaller. If it is filled in moist the swelling will be less, but on the other hand part of the soil might get puddled during this operation and thereby lose its semi-elastic property acquired by drying.

Of course the permeability of subsoils which behave like a semi-elastic or inelastic colloid if they have never dried before will also benefit from this drying procedure.

\subsubsection{Frost action}

Whether the action of frost will be beneficial depends to some extent also the backswelling characteristic of a soil. If the soil behaves like an inelastic or semi-elastic colloid the action will be beneficial, if it behaves like an elastic colloid up to high suctions the effect will depend upon the degree of dehydration.

If a puddled soil is frozen slowly the mass will be divided by vertical plates of ice, cf. De Leenheer, 1958; Czeratski, 1955; Jongerius, 1957 (type B6). This may be roughly explained as follows. The water in the finest pores is subject to considerable undercooling before it freezes, and therefore the freezing will start in a relatively large pore. At first pure water freezes raising the concentration of the solution in the neighbourhood or compressing the double layer. By the osmotic gradient thus created, water will be attracted and frozen. The growth of the ice crystal is retarded 
as the hydraulic conductivity of the paste surrounding it is lowered by the decrease in moisture. The next crystal will only form at some distance due to the decrease in the dimensions of the pores and the increase of the concentration in the vicinity of the first crystal. The vertical growth of the crystal might be influenced by the higher heat conductivity differing with regard to the direction, and its lower specific heat compared to water. Also the expansion of the water during freezing may lead to the creation of fissures. The growth of the crystals before the whole mass of soil freezes determines the degree of dehydration and the dimensions of the 'units' between the ice wedges. This growth is slow, being determined by the flow of water through fine pores.

The following predictions can therefore be made: The larger the cooling gradient and the higher the moisture content the smaller the aggregates. In accordance with this prediction one finds that the surfaces of large clods of winterfurrow are divided into very fine blocks and that the dimensions of these blocks increase rapidly with depth. With natural aggregates freezing will start first in the fissures and pores. As water will migrate to the icecrystals and freeze there, the fissures will be enlarged and the large clods will be broken up into smaller ones.

Although the principal action of freezing in regenerating a puddled soil is a dehydration, it has also the advantage of dividing the puddled mass into smaller units, while only large clods are formed by drying.

If the soil behaves like a semi-elastic colloid water will not be taken up on thawing, with colloids elastic up to a certain suction, water may be taken up again if thissuction has not been surpassed.

With sandy soils the action of frost will seldom be beneficial as the water in the large pores will freeze in every pore at the same time rupturing the bonds of organic matter which hold the units together.

\subsection{AiR EXPLOSION}

The air explosion takes place if the small pores have been emptied and the soil is suddenly wetted. This is beneficial for some soils but harmful for others as the degree to which the aggregates are broken up differs considerably. It usually helps to break up large clods; if the slaking is very strong the units into which the soil is broken will form a crust on drying. As the effect is most pronounced with soils saturated with divalent cations and the effects of salt concentration are negligible the only way to prevent the air explosion is to keep the soil moist by mulching or irrigation.

\subsection{Stability tests}

In chapter III the resistance of clay and soil granules to abrasive forces has been studied. Though it might be inferred from the backswelling of suspensions whether a soil has any stability in the saturated state, the magnitude of this stability has to be found by direct measurements as there exists no simple relation with the moisture content. Provided that the sampling and storage problems have been mastered, the end over end shaking method should give useful indications on the resistance to the destructive 
action of raindrops. By varying the concentration of the salt solution in which the experiment is conducted, the influence of the former can be determined.

This method might be useful in particular to obtain some information as to the stability of soils which have not yet been used for agricultural purposes, such as unreclaimed sea beds, and for the evaluation of the change in stability which is to be expected from such measures as the application of gypsum etc.

From the experiments with calcium saturated clay and soil granules, at very low salt concentrations, the following deductions can be made. Pure montmorillonites have a higher resistance than coarse kaolinites while illite has none. This order may change completely if instead of the pure and well crystallized clay minerals the clays isolated from soils are investigated. The smaller the clay crystals become, the higher the resistance. Also the admixture of small quantities of organic matter may have a large influence on the stability of illite. As the content of ultra clay of a given soil can not be increased, the stability of the soils containing coarse illite and kaolinite will depend on the amount and nature of humus and on the salt concentration. The influence of the humus has been stressed by Trutin (1933): 'It is impossible to get rid of the noxious action of such rough dispersions by liming. In places where they abound one should raise the quantity of highly dispersed colloids in soil, especially those organic'. The influence of the salt concentration has been observed by BOEKEL (1958) who found that the beneficial effect of liming depended on the increase of the salt concentration caused by the liming material.

As the low stability of the pure kaolinite is also increased by raising the concentration, the stability of the soils containing this clay mineral will be also increased by a raise in salt concentration and of organic matter content. The latosol studied had a far higher resistance than the clay mineral, probably because the crystals had much smaller dimensions. The stability of the latosol decreased by raising the salt concentration and the $\mathrm{pH}$. If this is a common feature of latosols heavy applications of fertilizers especially those which raise the $\mathrm{pH}$ will be harmful.

The influence of magnesium saturation has not been investigated extensively, but it seems probable that the illite containing magnesium soils are slightly less stable than the calcium ones.

With potassium saturation the bentonite has no stability at low salt concentration, that of the margalite clay mineral is low, pure illite has none, but the illitic clay mineral from soils is very stable. The potassium margalite soil has about the same stability as the calcium margalite soil. The stability of the illite containing soils is scarcely impaired by saturation with potassium, though part of the potassium saturated humus is soluble in water.

The only soil which remains stable at low concentrations in the sodium form, is the latosol. If the $\mathrm{pH}$ is raised above 9 this soil also becomes unstable.

The stability of the sodium saturated soils depends therefore on the electrolyte content of the solution. Grouping the clay. minerals in a decreasing order of salt concentration necessary to keep the stability we find for clay minerals bentonite, margalite, kaolinite, and illite, and for soils margalite, illite, and latosol. 


\subsection{LABORATORY EXPERIMENTS ON TILLAGE}

The investigations reported in chapter IV have shown that the moisture content at which a soil is worked has a strong influence on the stability of the structure of clay.

\subsubsection{Suction at moisture content of maximum destruction}

In accordance with the observations of ALLMAN \& KoHNKE (1947) it was found that the $\mathrm{pF}$ at which maximum puddling occurred shifted towards higher values with increasing clay content. If small forces were applied the soil could be worked at lower suctions than if large forces were used.

The implications of these results are obvious, with increasing force the moisture content for tillage should be lower. This is in accordance with the observations made on the slow working digging machine operable at moisture contents where ploughing becomes impracticable. The heavy soils should be ploughed at equilibrium with a higher tension of water than the light soils. This is an adverse factor if the climate is so moist that the desired equilibrium is seldom obtained, and it may explain some of the difficulties in management with heavy clay soils.

\subsubsection{Influence of backswelling characteristic on results of tillage}

It appeared that soils elastic over a large range are easily reconverted into soils which swell spontaneously by tillage at too high a moisture content. All of the potassium clays and soils investigated as well as and some of the calcium and magnesium illite clays belong to this type. The organic matter does not alter this characteristic of the potassium clays, but the calcium and magnesium illite soils behaved more like elastic systems than the clays. By raising the electrolyte concentration the puddled potassium soils were made to behave like a semi-elastic gel and their stability was raised. The limiting value was a salt concentration $0.01 \mathrm{M}$ for potassium margalite. It is probable that the soils partly saturated with sodium and calcium will behave like the potassium clays if the sodium percentage is too low to cause spontaneous peptisation of the granules. If these soils are worked they may swell spontaneously; the experience in the Netherlands is, that tillage of soils inundated by seawater may be very harmful, ZuUR e.a. (1953). The danger of reconverting a semi-elastic soil system into an elastic one, is of course only present if climatic conditions are such that the soils will not dry to any extent before they are saturated by rainfall. If puddled soils dry, then their aggregates are often denser and more resistant to rainfall than the original ones, cf. VILENSKY (1934). In the Netherlands where ploughing is often done in the autumn, drying by evaporation will seldom take place. Even soils belonging to the semi-elastic systems may be easily dispersed due to rainfall, if they have been worked at too low a suction, as this working reduces considerably the stability. This phenomenon has been observed by JoNKer \& Vervelde (1953).

The stability analysis of the worked soil could be used in the case of the model tillage tests to determine the degree to which working had affected the soil. It is doubt- 
ful whether this method would give the same results if applied to practice. The dishomogeneity of the field samples might well mask the influence of the tillage operation.

\subsection{NON SCOURING OF SOILS ON IMPLEMENTS}

The backswelling characteristic of a soil may explain to some extent its sticking to the plough. FounTAINE (1959) might have followed the same reasoning writing 'Das legte die Vermutung nahe, dass der auf einem Werkzeug bewegte Boden eine höhere Reibung verursacht als ungestörter Boden'.

If a soil sticks to an implement which is moved through it, this means that the soil particles stick better to the implement than to the other soil particles. This may have two causes; the first is that the soil units are deformed by the sliding over the implement surface so that the contact with the implement is better than with the other soil units; the second factor is that the friction is proportional to the soil moisture tension as investigated by FouNTAINE (1954) and that a certain degree of puddling may occur during the sliding which raises the moisture tension (change from the desorption curve of the granules to that of the drying slurry). On the metal surface this tension will be largest; it will be lower further away, because the puddling will be most intensive near the surface and because no water can flow from the metal to decrease the tension, but must be drawn from the surrounding soil. By the larger tension at the metal-soil interface, the soil will stick to the metal surface.

\section{RIGE GROWING}

The examples and discussions in this paragraph are limited to the rice growing in Indonesia. They should be applicable to all regions where similar conditions as to soil, climate and labour prevail.

\subsection{DesiRability OF A THIN MUD}

In contrast to other crops rice is grown if possible in a near liquid mud, covered by some inches of water. That this mud closely resembles a mechanical suspension which has settled out is corroborated by the statement of VAN DE Goor (1950a), that the mud of a well prepared paddy field contains considerably more moisture than the fully saturated dry soil, which tallies perfectly with the experiments (cf. I, 2.5.8.4).

The necessity of the covering with water is explained by the beneficial influence it has on the suppression of weeds (VAN DE GooR, 1950b), and the low expenditure in work versus the furrow irrigation (TERRA, 1959). The necessity of converting the soil into a mud has usually been founded on the decrease of water losses it induces.

There exist however low lying regions with very heavy soils (margalite) where drainage is naturally low, but where also the soil is converted into a mud. As much labour is required for the preparation of a paddy field, 13 man days and 24 cattle days in Java for rice against 5 man days and 7 cattle days in the Netherlands for rye 
(TERRA, 1959), it is interesting to know whether the mud is a better environment for rice than a finely granulated soil, for instance latośol.

Although numerous authors have stated that a well prepared mud is favourable for the development of rice, i.a. VAN DER ELST (1925) stresses the better water permeability of a mud compared with a paste, real experiments to establish the difference quantitatively are scarce.

\subsubsection{Granules versus mud}

An example is given by VAN DE GOOR (1950b) who studied the influence of mud making on the yield of rice on a mature reddish brown lateritic soil (latosol), derived from andestic tuf near Bogor, Java. The data reproduced in table 56 have been taken from his table 5 .

TABLR 56. Influence of soil structure on yield of rice (VAN DE GOOR)

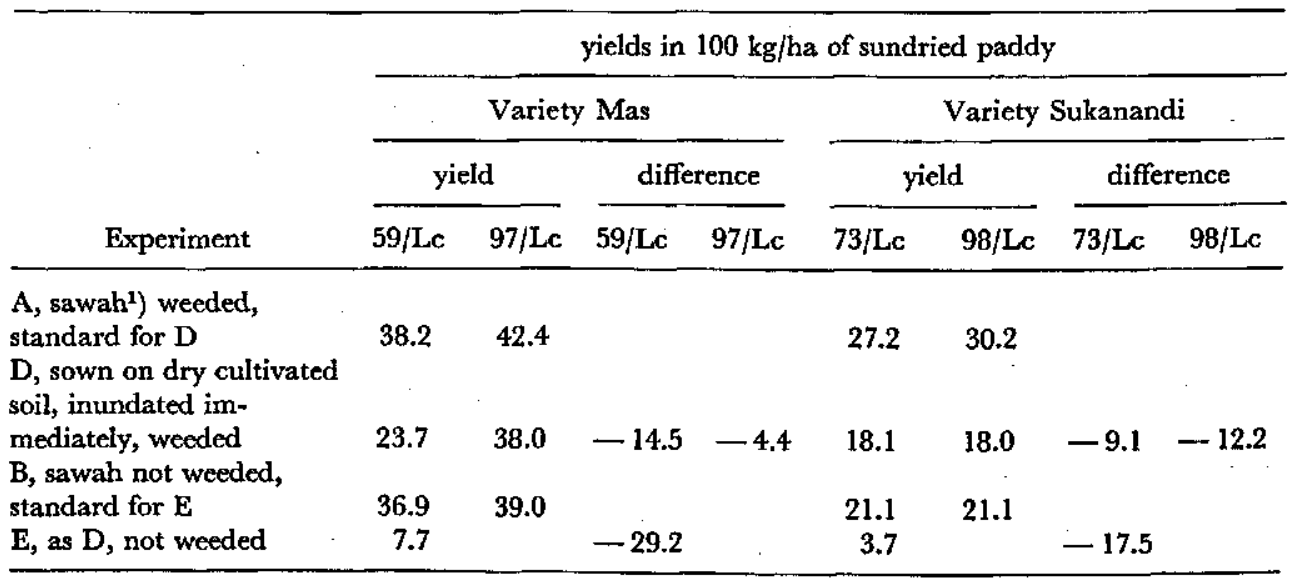

Almost significant differences for 59/Lc $1.6 ; 97 / \mathrm{Lc} 5.2 ; 73 / \mathrm{Lc} 2.7 ; 98 / \mathrm{Lc} 7.4$.

1) A sawah is a wet tilled paddy field.

It is clearly seen that the yields of the dry cultivated soils are appreciably lower than those of the sawah soils, the difference being largest for the unweeded fields. This decrease in depression by weeding, may be explained by the way weeding is usually carried out. The weeds are turned upside down with the toes and trod into the mud, an operation which converts part of the aggregates into mud. The beneficial influence of the mud or flock structure, compared with the small granules may be explained in the following way.

As the Muara latosol if moistened suddenly falls apart into small sandlike granules it is improbable that root growth is impaired by mechanical obstruction, nor is the uptake of water restricted. It is more probable that the exchange of ions between clay surface and soil solution is hampered by the steric factors (close packing) caused by the granulation, so that only the outside surface is available for the exchange reactions, the roothairs being unable to penetrate into the granules. In the mud the distance 
between the clay particles is large compared to that of the granulated soil so that the exchange reactions from the clay surface with the roothairs and the solution are less impeded. As the nutrient status of the mature latosols is usually low, the reduction of the available surface by granulation might be the cause of the lower yield of the dry tilled soil, compared to that of the wet tilled. Where soils are poor, fertilizers expensive and labour cheap, the wet tillage of the paddy fields seems rational not calculating the lower waterloss.

The postulation that the availability of plant nutrients is a function of the direct contact area soil-water, is in accordance with the results obtained by HuFFMAN, Cate \& Deming (1960), who studied the initial solution rates of an iron phosphate with different surface areas and the uptake by cornplants. They found that both the solution rate and the uptake were proportional to the surface area of the fertilizer.

That the better availability of the nutrients is a factor, was indicated by the result of a preliminary pot experiment where the growth of rice in a slurry of latosol was compared with that of the inundated soil. The growth was better in the slurry but stagnated after some time, liquid fertilizer was then injected into the rootzone. The response to the fertilizer was quicker and stronger with the granulated soil, which was ascribed to the quicker adsorption and consequently lower activity of the fertilizer in the slurry.

\subsubsection{Paste versus mud}

That the mud should be nearly liquid is proved by another experiment of VAN DE Goor (1950a) in which he compared ploughing at field capacity with that of tillage after inundation. The soil was the same as in the previous experiment. The data are represented in table 57.

TABLE 57. The influence of moisture content at tillage on the yield of rice (VAN DE GoOR)

\begin{tabular}{lcc}
\hline \multicolumn{1}{c}{ tillage } & yield in $100 \mathrm{~kg} / \mathrm{ha}$ dry kernels \\
\hline \multicolumn{1}{c}{ Mas } & 26.9 & Gendjahratji \\
\hline $\begin{array}{l}\text { with excess of water } \\
\text { at field capacity } \\
\text { difference }\end{array}$ & -6.2 & 25.0 \\
\hline
\end{tabular}

It is seen that the ploughing at the lower moisture content has reduced the yield in one case by nearly half.

By ploughing at field capacity the granulated soil will have been transformed into a more or less homogeneous paste. As this soil has an inelastic moisture characteristic no water is adsorbed by the paste after inundation. By harrowing after inundation the paste will have been only partly dispersed, the slippery rounded surfaces of the large clods offering little grip to the tines of the harrow.

The following factors might have hampered the growth of the rice, if it had to grow in lumps of paste instead of in a liquid mud.

a. More energy is required to withdraw water from the paste than from the mud. 
The mud is comparable with a suspension which has settled out from excess water, the paste with a partly desorbed suspension. This can explain the observed moisture deficiency symptoms.

$b$. The diffusion of nutrients through the lumps will have been slower than through the mud. This may explain the observed nitrogen deficiency, even though green manure had been applied.

$c$. The growth of the roots may be hampered mechanically by the higher resistance of the lumps to penetration.

A pot experiment with margalite from experiment station Ngale, Java, showed that the growth of rice (cv. Manipsuri Dumai 2041) in a thick (66\% water) paste was retarded in comparison with the growth in liquid mud, (180\% water). (cf. photograph 8)

At the end of the experiment it became apparent that the roots had penetrated the cake of stiff paste in the dishes and grew under it. They had lifted the paste, and were able to adsorb free water consequently. The differences in yield may have been reduced by this reason. As the roots will not have this opportunity in the field, in practice the difference in yield might be larger. The yield in ovendry unhusked grain was 5.66 gram per plant for the rice grown in the mud and 4.54 gram for the rice grown in the paste, the difference being 1.12 and the mean error of the difference 0.82. The growth curve is given as total length of leaves per plant, during the vegetative state in fig. 57. The flowering of the plants grown in the mud started about a week earlier than that of the plants in the paste.

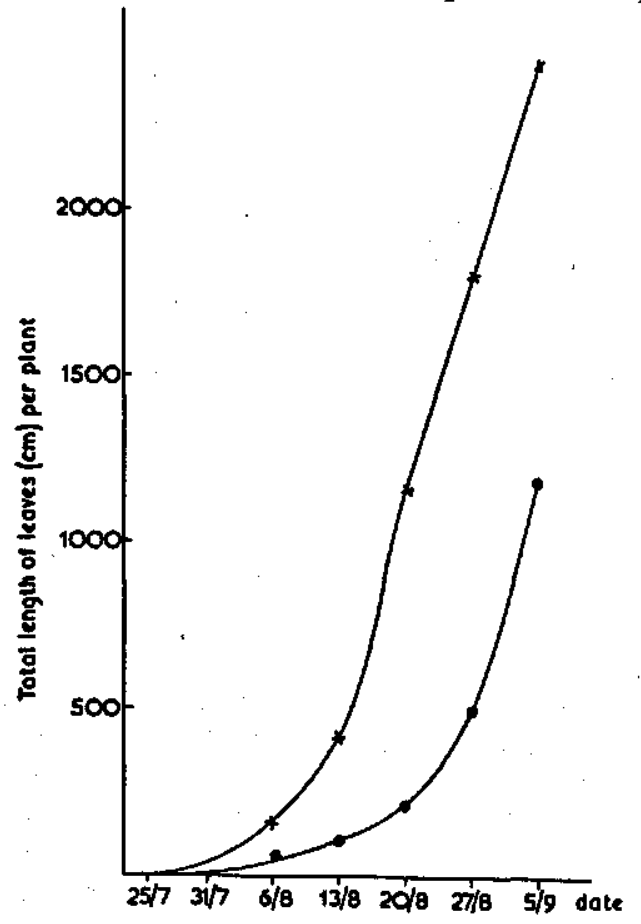

Fic. 57. Growth curve of rice Total length of leaves per plant $\times \times$ mud with $180 \%$ moisture - paste with $66 \%$ moisture 
The causes of the slower growth and lower yield of rice grown on the paste in comparison with that grown on the mud of margalite will be the same as with the latosol.

The differences in availability of water are illustrated in fig. 58. The energy necessary to withdraw a $20 \%$ of water per gram of dry matter will be in the case of

FIG. 58. Desorption curve of margalite soil $\%$ moisture against suction

A. slurry with $180 \%$ moisture

B. soil worked at $66 \%$ moisture

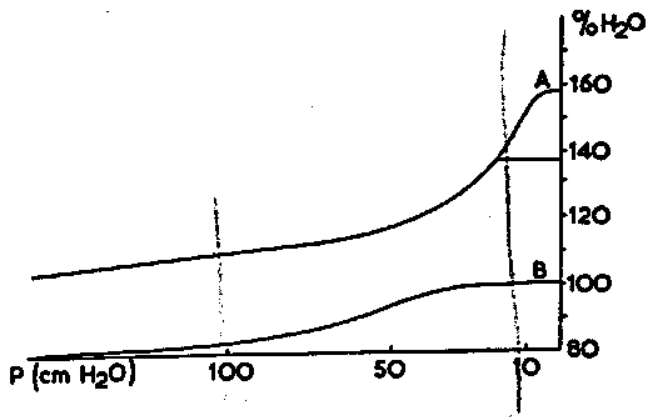

the mud with $180 \%$ moisture, $2500 \mathrm{erg}$ and in the case with the soil worked at $66 \%$ 11000 erg. After withdrawal of this quantity the suction will be $20 \mathrm{~g} / \mathrm{cm}^{2}$ in the first case and $110 \mathrm{~g} / \mathrm{cm}^{2}$ in the last case. It must be born in mind, however, that the energy to withdraw water does not necessarily increase according to the suction moisture content curve; moisture losses may be replenished from the water standing on the field, if the structure of the mud is able to withstand the pressure gradient caused by the suction of the roots. In the field no example of the drying of the mud covered with water has been found, but in pot experiments with vigorously growing rice the mud in the centre of the pot ( $10 \mathrm{l})$ was concentrated into a tough paste. As the permeability of the paste is much lower the probability that waterlosses will be replenished is also lower.

Figure 58 shows the desorption curve of the paste after swelling in excess of water. This may be a favourable representation as it is not certain that in practice the paste will swell to the same extent as its lumps will have larger dimensions, and certainly not if the paste has been made by partial dehydration of a mud caused by failing watersupply.

Summarizing the possible advantages of liquid mud over granulated clay soil or a paste we get the following picture, summarized in table 64 .

TABLE 58. Qualification of soil structures as to their suitability for rice growing

\begin{tabular}{llll}
\hline & mud & paste & granulated \\
\hline waterlosses & low & low & high \\
availability of nutrients & high & low & low \\
availability of added nutrients, no leaching & low & low & high \\
availability of moisture & high & low & high \\
\hline
\end{tabular}

(It is supposed that the roots will grow inside the paste and mud but outside the granulen) 
With these experiments it has been shown that liquid mud is in most cases the best medium of growth for rice and a tough paste the worst.

\subsection{TEChnique OF MUd Making}

As the subject may be unfamiliar it is perhaps appropriate to dwell a bit longer on the tillage operations involved with mud making and some other problems involved with rice growing.

\subsubsection{Necessity of over saturation}

The more or less granulated soil is converted into a mud by ploughing the land after it has been inundated completely. As the soil is super saturated the cohesion of the granules has obtained its minimum value, but as the friction between the soil units is low (Nrahols's lubricant phase) the force that can be expended on the soil per unit of treatment is also low. This means that the drawbarpull is much lower than at field capacity and that the operation will have to be repeated if a high degree of dispersion is desired. This lower amount of energy per unit of treatment is very important as the maximum draw in rice farming is often limited to one pair of buffaloes; but as the time factor is of less importance there is little objection against the repetition of an operation. Moreover if the soil has been worked at field capacity into a paste, this paste has often to be converted into a mud by further operations as the pastes of calcium margalite and latosol do not take up water spontaneously. This is particularly the case with latosol. The granules which are destroyed in excess of water are at once converted into a suspension as has been demonstrated by the tillage experiments. The total amount of labour will be considerably higher in the case the mud making is started at field capacity than in the case tillage is started with a super saturated soil. Only in the case of illitic soil the difference will be less as pastes of these soils have very little stability.

Having explained why the tillage operations should be carried out with some water standing on the land, the question arises at which moisture content should the soil be inundated.

\subsubsection{Influence of state of soil at irrigation}

After harvest the soil is usually in the state of a tough paste divided by fissures into large hexagonal blocks. As the latosols and margalites take up little water and at a slow rate, tillage will be difficult at this stage. The soil being in a worse state than after ploughing at field capacity. A high cohesion, a high uniformity and a slippery surface make it difficult to disperse the soil paste.

The more the soil dries out (between sticky point and shrinkage limit) the more it will be divided into smaller units by shrinkage fissures and the more it will break up by swelling if moistened (cf. photograph 7). This phenomenon is of great importance with the smectite containing clays and is very helpful in the preparation of soils for dry land crops (DAmEs, 1951). With illitic clay and latosols it will not manifest itself to any useful extent. 
If a soil dries out below its shrinkage limit the influence of entrapped air will enhance the slaking, giving rise in the case of the margalites to a very increased swelling and a high degree of dispersion. The latosols being more stable are not dispersed but slake into fine granules with the dimensions of fine sand or silt, while the degree of slaking of the illitic soils depends on the amount of organic matter and ultra clay ranging from no effect to complete dispersion.

Though the stability in the saturated stage of a piece of latosol paste is lower than that of the granules, the amount of work required to disperse a field being in the latter condition will be smaller, as the paste will be present as big lumps and the granules as loosely packed sand. The reasons are the following:

$a$. The friction will be lower. The squeeze of water from the interstices between the granules, by the compressive action of the plough has a lubricating effect. As little free water is present in the paste this lubrication will be nearly absent. With the granules the contact with the implement will be not as good as with the paste and there is not need for cutting loose the plough beam.

$b$. More soil will be brought into suspension per unit of action. The formation of a slurry can take place only at the interface granule water, as the destruction caused by the rolling of soil units over soil units during the upward and forward movement induced by the plough. In a granulated soil this interface is large and free water is present between the granules which will all be displaced with regard to one another. In the paste units are large and there is a possibility that the soil will only suffer plastic deformation with consequent little water mixing.

The importance of the state of the soil before inundation has been made plausible and it is seen that full advantage has to be drawn from the changes that take place spontaneously when a dry soil is flooded to ensure a succesful mud making. The forces at the disposal of the indigenous rice farmer are small compared with the forces which act on a dry soil if it is submerged.

Whether the conditions for mud making, i.e. excess of water on a dry soil are met depends on:

a. The quantity of water available. If the supply is insufficient or intermittent, the swelling of the margalites is interrupted and relatively stable granules are formed. Accordingly SMrTs (1926) has found that the time necessary for the first ploughing of one ha margalite clay soil may vary from 15 to 89 hours depending only on the watersupply (mean value 54.5 ).

b. On the rainfall during the dry season. It can be so high that the mud does only dry into a paste difficult to convert into a mud. VAN DER ELST (1916) mentions that irrigation on a dry soil gives an easier tillage than irrigation on a soil wetted by rains.

The degree of drying necessary to cause air explosion is higher for the margalite, approximately $\mathrm{pF} 6$ for a drying slurry (50\% rel. humidity) than for the latosol, approximately pF 5 (rel. humidity $93 \%$ ).

The coarser has been the slurry the lower will be the $\mathrm{pF}$ at which the pores will be filled with air and air explosion starts. Moreover, drying of the latosol will be 
easier as its backswelling characteristic is inelastic, superficial drainage is easier and the capillary conductivity of the latosol profile will be less than that of the margalite as the ploughpan of the latosol causes a sharp discontinuity (KoENIGs, 1951). Therefore difficulties in drying are only encountered with the margalite.

c. On the continuity of the rainfall during the wet monsoon. If the rainfall is interrupted by a long spell of dry weather the mud will dry into a paste. This mainly occurs where the irrigation system is insufficient or where the water supply depends entirely on the rainfall. This factor has been discussed by Joosten (1934) who, estimating the improvements caused by technical irrigation of a margalite area writes: 'Susceptibility to root rot is stimulated when an early beginning of the rainy season, - is followed by a stagnation of the rainfall. This results in a retardation of the soil treatment and the drying up of the fields. The soil then obtains an unfavourable structure, which can not be improved again to an important extent'.

\subsection{Flocculation}

A desirable property of the mud not yet mentioned is that it should be flocculated. If this is not the case the soil will ultimately be carried from the paddy field into the sea, and severe losses of topsoil occur even on flocculating soils if the outlet of a field is opened during and shortly after the tillage and weeding operations. After the clays has settled out its surface is soon protected by a mat of algae. If the water remains turbid the algae can not develop, and if rice is not transplanted but sown, the seedlings will be suffocated (DE WIT, 1960). Flocculation moreover is necessary to give the mud some rigidity, so that the riceplant will find some support.

\subsection{DisGuSSION OF THE INVESTIGATED GLAYS AND SOILS AS TO THEIR SUITABILITY FOR RICE GROWING}

Having established that for various reasons a well flocculated suspension is the most suitable structure for rice, which has much less exacting demands than the dry crops, we may now group the investigated soils and clays as to their physical suitability for rice growing, bearing in mind that the flocculation value and the stability of granules and pastes should be low but the destructive effect of sudden wetting high.

Table 59

\begin{tabular}{|c|c|c|c|}
\hline Flocculation value & Stability of granules & Stability of paste & Destr. effect of sudden wetting \\
\hline & ( $\mathrm{Ca}$ and $\mathrm{Mg}$ ) & ( $\mathrm{Ca}$ and $\mathrm{Mg}$ ) & ( $\mathrm{Ca}$ and $\mathrm{Mg}$ ) \\
\hline $\begin{array}{l}\text { prohibitive: } \\
\text { all } \mathrm{Na} \text { - and } \mathrm{K} \text {-soils } \\
\text { latosol excepted }\end{array}$ & $\begin{array}{l}\text { low } \\
\text { kaolinite, illite } \\
\text { intermediate } \\
\text { bentonite, margalite soil, } \\
\text { illitic soils } \\
\text { high } \\
\text { latosol, illitic soils } \\
\text { rich in organic matter }\end{array}$ & $\begin{array}{l}\text { low } \\
\text { illite, illitic soils } \\
\text { kaolinite, bentonite } \\
\text { high } \\
\text { margalite soil, } \\
\text { latosol } \\
\quad\end{array}$ & $\begin{array}{l}\text { high } \\
\text { margalite soil, illite } \\
\text { intermediate } \\
\text { bentonite, kaolinite, illitic soils, } \\
\text { latosol } \\
\text { low } \\
\text { illitic soils, rich in organic } \\
\text { matter }\end{array}$ \\
\hline
\end{tabular}




\section{THEORETICAL CONSIDERATIONS}

\section{LIMITATION OF THE SWELLING}

By the experiments described in I,2 it has been proved that many clays have a limited swelling in distilled water and consequently a certain resistance to mechanical dispersion.

In order to explain this phenomenon it seems worth wile to consider the behaviour of calcium bentonite more thoroughly. This material has been investigated by numerous authors: Hoffman \& Bilke (1936), Mooney, KeEnAN \& Wood (1952a), NorRisH (1954). It exhibits a limited swelling in distilled water, the maximum distance of separation observed is $11.6 \AA$, corresponding to four layers of water. Therefore any explanation of this behaviour should apply to a certain degree to the observed limited swelling of soil granules. As the relative vapour pressure at which this initial swelling of bentonite saturated with different cations occurs is inversely related to the hydration energy of the cation present, it is assumed that this first swelling is caused by the hydration energy of the cations.

\subsection{DisPersion FORGES}

To explain this limitation of the swelling one could resort to the LONDON-VAN DER WAALs' forces, which play an important role in the older concepts of soil structure based on flocculation and in the theory on colloids with a constant surface potential. In this approach this force was or is the only attractive force opposing the osmotic force separating the particles.

Until some years ago however no experimental proof had been furnished with regard to the magnitude of the constant necessary for the calculation of the attraction.

In 1954 it was determined by Derjaguin e.a. and in 1960 these experiments were confirmed by BLAGK, DE Jongh, OVERBEeK and SparnaAy.

By these measurements only the constants of the retarted van der Waals' force were determined. As the experimental values for this constant agree fairly well with the theoretical value, it may by assumed that also the theoretical value for the constant A of non retarted LONDON-VAN DER WAALs' force, i.e. $10^{-12} \mathrm{erg}$, is correc.

As also the theory on the swelling pressure of colloids with a constant charge has been worked out $(c f, 1,2)$ a calculation can be made an order to see whether the LONDON-VAN DER WAAL' force is strong enough to prevent separation beyond four layers of water.

\subsubsection{Calculation of attractive potential due to LONDON-VAN DER WAALS}

The calculation of the attractive potential due to LONDON-VAN DER WAALs' forces has been made using the complete formula (No. 48) given by Verwey \& OverbeEK (1948) and using as constant (A) $10^{-12} \mathrm{erg}$. 
This is not quite correct as a correction for $A$ should be applied as soon as the medium is water and not vacuum as used in DerJaguin's experiments. The new constant should be calculated according to: $A=A_{11}+A_{22}-2 A_{12}$, where $A_{11}$ refers to the interaction between the atoms of the plates, $A_{22}$ to the interaction between the watermolecules and $A_{12}$ to that between the clay surface and the water molecules. Since the attraction of clay for water is very strong, $A_{12}$ will exceed $A_{22}$, so obviously $A$ will be smaller than $A_{11}$. Accordingly the use of $A_{11}$ will lead to an overestimation of the attractive potential.

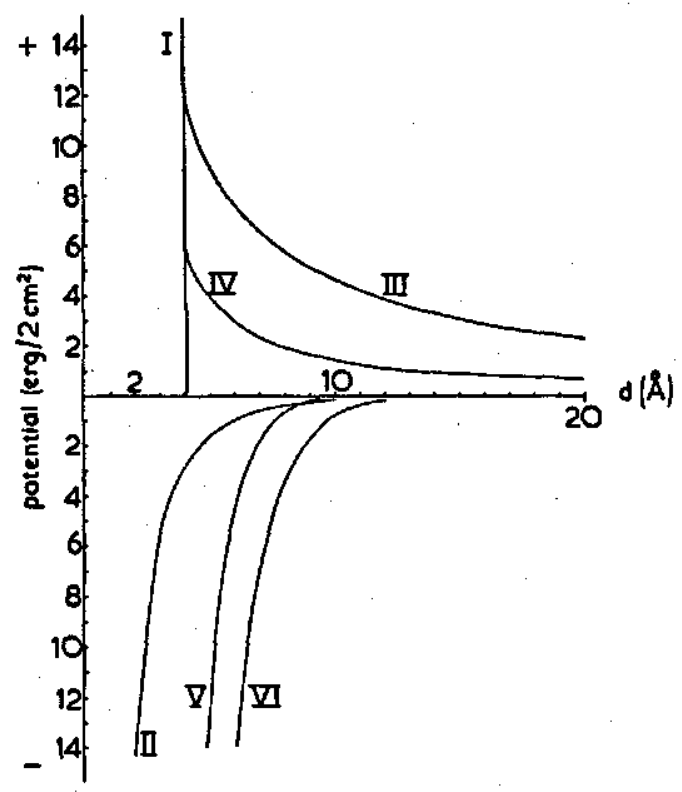

Fic. 59. Energies between plates of montmorillonite at zero electrolyte concentration

I. hydration energy of the cations

II. attractive potential due to LONDON-VAN DER WAALs forces

III. repulsive energy due to swelling pressure of monovalent cations

IV. repulsive energy due to swelling pressure of divalent cations

V. electrostatic contractive potential due to monovalent cations

VI. and to divalent cations, according to MACEwAN

This uncorrected potential is represented by curve II in fig. 59. Curve I illustrates the hydration energy of the cations, which is very high but falls of steeply with increasing distance.

\subsection{Calculation of the Repulsive potential}

The maximum value of the repulsive potential occurs in salt free systems. In that case the potential is easily calculated by means of integration over the swelling pressure- 
distance curve of the system. One finds for the swelling pressure at zero concentration (SchorIELd, 1946)

$$
\begin{aligned}
& \mathrm{P}_{\mathrm{s}}=\frac{\mathrm{R} \cdot \mathrm{T} \cdot \pi^{2}}{\mathrm{z}^{2} \cdot \beta \cdot \mathrm{D}^{2}} \\
& \text { in which } R=8.21 \times 1.01 \times 10^{8} \text { dyne } \\
& z=\text { valency of the counterion } \\
& \beta=1.06 \times 10^{16} \mathrm{~cm} / \text { millimol } \\
& \mathrm{D}=\mathrm{d}+\delta-4, \delta=4 / \mathrm{z} \text { for montmorillonite } \\
& \mathrm{d}=\text { halfdistance in } \mathrm{A} \text { (cf. } \mathbf{1}, 2.4 .2 .2 \text {.) }
\end{aligned}
$$

The repulsive potential $\left(E_{R}\right)$ per $\mathrm{cm}^{2}$ opposing surface is then equal to

$$
\left.E_{R}=2 \int_{D}^{\infty} P \cdot d D=\frac{2 R \cdot T \cdot \pi^{2}}{z^{2} \cdot \beta} \int_{D}^{\infty} \frac{d D}{D^{2}}=\frac{-2 R \cdot T \cdot \pi^{2}}{z^{2} \cdot \beta \cdot D}\right]_{D}^{\infty}
$$

This relation between the repulsive potential and distance is represented by curve III (fig. 59) for monovalent ions and by curve IV for divalent ones.

\subsection{Comparison of ATtractive AND REPUlsive POTENTIAL}

Though the attractive potential has been calculated using a constant which is probably too large, it is evidently not large enough to explain the presence of an energy barrier at about $5 \AA$ half distance, as is necessary to account for the observed limitation of the swelling to this distance. So some other attractive force must be present.

\subsection{Plate gontraction caused by counter ions in the midway posttion}

A suggestion was made by MACEWAN in 1948, followed by a quantitative formulation in 1954, that this contraction may be due to the presence of all the cations in the midway position and that it is based on the resulting electrostatic attraction between the cations and the opposite negative charges.

In order to explain how the cations, which are the cause of the repulsion at one distance can effect a contraction at another distance the following reasoning is adopted chiefly based upon MAcEwAN's work:

\subsubsection{Limitation of the Gouy-Chapman theory}

When the interaction is considered between clay plates at very short distances, i.e. distances comparable to those between the individual charges on the clay plates, the standard treatment based on the GouY-CHAPMAN theory is obviously not satisfactory.

Thus the latter theory departs from the assumption that both the colloid charge and the diffuse countercharge are homogeneously distributed in lateral directions. This then leads to a zero value of the electrical potential gradient in the plane of 
symmetry between the interacting plates, which implies the absence of MAXwELL's stresses in that plane.

For this case the interaction between double layers of adjacent plates leads to a 'swelling pressure' of the system equal to the hydrostatic pressure in the plane of symmetry, which in turn may be found from the ionic concentration in this plane. Consequently any attractive force, if present, must be derived from interactions different from the electrostatic interaction between the diffuse double layers, as e.g. the LoNDon dispersion forces.

The situation becomes entirely different in case the distance between the ions and the plate is such that the individual fields of the ions and the plate charges emerge clearly, cf. fig. 60 . In this case the electric field strength will usually not be zero in the

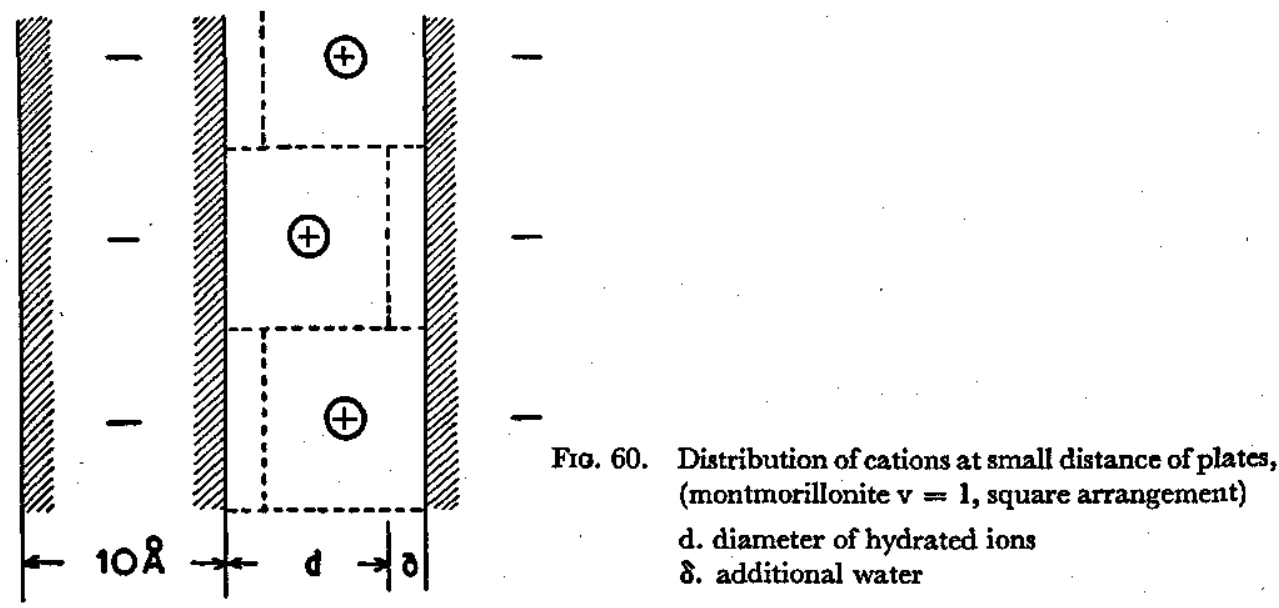

plane of symmetry and the conditions for the application of the GouY-CHAPMAN theory, based on lateral homogeneous fields are not longer met. In consequence the GouY-Chapman type of calculation should be replaced by a Madelung type, in which the interaction of each individual cation with the surrounding negative and positive charges should be calculated.

\subsubsection{MacEwan's calculation of the Madelung potential}

As a first approximation MAcEwAN attempted in 1954 to calculate the attractive potential assuming that the ions were placed in a square. The curves V and VI of fig. 59 signifying the electrostatic attraction of systems containing mono- and divalent ions, resp., have been taken from his fig. 1 (curves 1 and 2). It is seen that these forces are of the right order of magnitude, though they are so large that they will prohibit a swelling beyond $5 \AA$ half distance in the case of monovalant ions.

From the data of NoRRISH it follows that the contractive and repulsive forces are near equilibrium in $0.3 \mathrm{~N}$ sodium chloride solutions, as at that concentration separations of 9 and $30 \AA$ occurred simultaneously. Consequently the attractive 
potential should be even less as the repulsive potential is lowered by the rise in salt concentration. On the other hand one might argue that the repulsive potential as calculated here may be too small as for the calculation of the swelling pressure all of the water between the plates has been taken into account, not correcting for the hydration water of the ions and the clay surfaces. If the hydration water is substracted from the total amount of water the swelling pressure will increase considerably at small separations.

Also it is very dubious whether VAN 'T HofF's law can be applied at all. Thus VAN 'T HOFF's law is based upon ideal (homogeneous) solutions. As the ions will occupy fixed positions at $5 \AA$ half distance, any increase in plate separation should involve a considerable gain in entropy of the system, thus favouring the swelling.

As all these corrections are difficult to apply, the author will limit himself to the suggestion that these electrostatic mozaic forces may, in view of the obvious deficiency of the LONDON-VAN DER WAALS forces to explain the observed plate condensation of calcium montmorillonite, very well prove to be the cause of this phenomenon.

\subsubsection{Energy of activation of the swelling process}

Another difficulty with this kind of calculations is that it is not certain whether the electrostatic attraction and the repulsion act to the same degree over the entire surface. Due to diffusion difficulties the osmotic swelling can only develop fully there where the system is in contact with free water, i.e. initially only on the contour. So at first the repulsive force must be also able to bent the plates apart at the circumference or to overcome the contractive force over the entire surface if water is to be adsorbed. In fact this means that initially a considerable energy of activation must be overcome in order to initiate swelling. Some proof for this hypothesis may be found in the marked hysteresis of the swelling and desorption of clays during equilibrium with water vapour, established by MOONEY, KEENAN \& WOOD (1952 b). If this hypothesis is true, then the primary swelling should also depend on the dimensions of the crystals. This was found by WALKER (1958) who observed that particles of Macon vermiculite smaller than 1 micron expanded within some minutes from 4.4 to $6.3 \AA$ separation, that particles of 40 microns did so within some hours, but that particles of $1 \mathrm{~mm}$ wide and $0.1 \mathrm{~mm}$ thick failed to expand after some weeks.

\subsubsection{Qualitative discussion of the electrostatic attraction}

Though the quantitative approach is difficult, the following qualitative aspects of the electrostatic attraction are evident:

$a$. The electrostatic attraction will diminish quickly, once the clay crystals become separated over a distance larger than the diameter of the hydrated ions.

Most of the ions will not keep their midway position in this case, but segregate to one of the walls (the minimum distance remaining the radius of the hydrated ion). As the contractive force exerted depends on the attraction between the cation and the furthest wall, the contractive potential will decrease rapidly upon separation of 
the plates. This is enhanced by the fact that the dielectric constant of the additional water will be much higher, than that of the first layers of water. Furthermore the repulsive potential will add a vector perpendicular to the crystal plane as soon as all the cations are no longer in a midway position.

$b$. The contraction caused by divalent cations will be larger and persist over a larger separation.

Though the electrostatic attraction remains the same (twice the potential per ion half the quantity of ions), the hydrostatic pressure due to the difference in concentration of the liquid between the surfaces and the outside solution, will amount to about half of the pressure caused by the monovalent ions.

\subsubsection{Difference between sodium and potassium saturated systems}

Though the difference in swelling between monovalent and divalent ions is easily understood this way, the difference in behaviour between sodium and potassium saturated clays must depend on other factors.

The potassium ion has a smaller hydration mantle than the sodium ion. Consequently the distance between the potassium ion in the midway position and the centre of negative charge will be relatively small and the Madelung attraction strong, for this reason, and because at this separation the dielectric constant is low as all the water is still strongly oriented by both the ions and the walls

\section{APPLICATION OF THE CONCEPT OF MADELUNG ATTRAGTION}

\subsection{The cohesion of granules}

In case the electrostatic attractive forces prohibit the swelling within the polyplates, they should also be active there where polyplates are in close parallel contact with another. In the regions where the contact is not close, the full or a fraction of the swelling pressure - may exist, depending on the separation in that region. Whether the net contractive force of the areas in close contact or the net swelling pressure in the areas further separated prevails, will depend on the ratio of the respective areas and the values of the forces acting there.

The net swelling pressure reaches its maximum at some distance beyond the critical separation. Therefore the chance that desaggregation will occur is maximum when the distance of separation equals that of the distance where the net swelling pressure is maximum, it will decrease at larger or smaller separations. (This is the reason why there is little hope to verify the MADELung forces experimentally. If by $\mathrm{X}$-ray a separation of $10 \AA$ is measured, the separation at one quart or one third of the surface of the cross section will be $30 \AA$, see fig. 1, a distance where the repulsive forces will be larger than the attractive ones. Therefore the value found for the concentration at which the interlayer distance of sodium bentonite jumps from 10 to $30 \AA$ is no base for theoretical considerations without corrections). 
So an infinite range of combinations, on which the stability of the granules will depend, may occur.

We may thus regard the cohesion of granules as the resultant of Gour separation force and electrostatic attraction, the latter being enforced by edge to surface attraction and confining forces such as bonds caused by the presence of organic, matter. In the case that all these forces nearly balance each other a small decrease of the swelling pressure may result in a relatively large increase in stability.

\subsection{OBSERVATIONS SUPPORTING THIS CONCEPT}

The electrostatic force does only work if the cations are in the midway position between the charged plates. As the dimensions of the hydrated calcium ion are larger than those of the potassium ion, the moisture content at which stability is reached will be higher for calcium than for potassium. This has been demonstrated by the back swelling curves of margalite clay, knip clay and basin clay. That higher pressure will be necessary to obtain this distance in the case of the potassium suspension follows from the higher swelling pressure of clay saturated with monovalent cations, which continues to be active at smaller separations than is the case for clays saturated with divalent cations.

That especially the clays saturated with the small potassium ion have to be compressed to values lower than those at which electrostatic attraction should become dominant may be caused by the irregularity of the arrangement of the clay plates. To bring about a large enough area of contact, a part will have to be compressed beyond the desired distance to bring another part within that distance. With subsequent swelling some rearrangement, bending or fractionation may be the cause that the area of contact is not decreased proportionally to its increase at compression.

An interesting observation is that the backswelling was quickest with pastes desorbed just near the point where the colloid became semi-elastic. Perhaps part of the polyplates were then at a distance where the osmotic force is maximum.

That the types of arrangement and the possibilities to ensure close contact play an important role, is demonstrated by the fact that with slurries allways a higher degree of dehydration is necessary to get a semi elastic behaviour than with suspensions (cf. backswelling curves of calcium bentonite, -margalite, -basin clay, potassium margalite and -basin clay). Secondly with coarser fractions of clay minerals the semi-elasticity becomes less pronounced and is originated at higher pressures (calcium knipclay), the coarse pure calcium illite (Fithian) exhibiting no limited swelling.

By working soils and clays at increasing moisture contents and determining the stability then, it was found that the potassium clays and soils did disperse spontaneously if the original structure had been altered by the kneeding in such a way that the moisture was evenly distributed. The calcium clays mostly stuck together if worked into a homogenous paste, especially the smectites. Moreover the moisture content at which complete alternation of the original structure could be obtained was lower with the potassium clay than with the calcium clays. This is in agreement with the predicted influence of the dimensions of the hydrated cation and its valency. 


\section{OBSERVATIONS NOT EXPLAINED COMPLETELY BY THE CONCEPT OF MADELUNG ATTRACTION}

According to the theory presented considerable work must be done to overcome Gouy repulsion between parallel plates, before the distance is lowered to the range where the MadELUNG forces become active. Nevertheless the following observations seem to prove the contrary.

\section{1 'Flogculation' phenomena}

\subsection{1 'Flocculation' at low salt concentration}

From the change in colour from the transparent yellow to opaque white, observed if a sodium bentonite suspension is passed through a calcium resin column, it might be inferred that the crystals are bound into larger units. At the same time a strong Schlieren effect is observed which means that the larger units are elongated in the direction of the $a$ and $b$ axis (cf. LE CHATELIER, 1910). Although this schlieren effect is not observed with sodium bentonite at low salt concentrations, a weak effect can be seen if the concentration of sodium chloride is increased (between $10^{-3}$ and $10^{-1}$ ). That it does not depend on the thickness of the crystals follows from the observation that the ultraclay of the soil illites does not show the Schlieren effect although the crystals are at least twice as thick as those of the sodium bentonite since the specific surface area of the soil illites is half of that of the bentonite. The suspensions of the coarse fractions of these illites show the Schlieren effect strongly, irrespective of the saturating cation.

That this association is accompanied by a condensation has been proved by BLACKMORE \& MiLler (1961) who observed that a $10 \AA$ separation was detectable after the exchange had been completed and that this separation was still observed in the ultra clay separated by a supercentrifuge. They proved also that the units increased in thickness with increasing suction.

From these observations it can be concluded that the energy necessary for this type of condensation may be provided by the kinetic energy of the platelets themselves and that this association takes only place over a small part of the surface as otherwise no Schlieren effect could be observed.

In order to explain this type of flocculation one might think of the influence that the strength of the positive field of the edges (cf. Schofinld \& Samson, 1953) has on the place where the collision between the plates will take place. The relative strength of the positive field depends on the salt concentration. If the negative field is very extended (monovalent ions, low salt concentration), then the positive field is overlapped by the negative one. With decreasing thickness of the negative field (divalent ions or higher salt concentration), the positive field will emerge gradually (cf. FRISSEL, 1961).

It is thought that in the first case the negative field is so strong that no collision will take place. If the negative field is however weakened slightly, then the fields from 
the edges are nearly neutral or weakly positive. The interaction of the negative fields would be strong enough to prevent a penetration of an edge to the negative surface in the middle of the plate. Nearer to the edge there is however a region where the negative field will be weaker and a collision may have place there. The most probable collision will be a frontal one. All other collisions will be deflected by the interaction of the negative fields. Till the plates come quite near to one another no interaction will take place. If the plates are not moving in the same plane, the collision will be elastic and no bond will be the result. If they are moving in nearly the same plane, then at very short distances the positive edges will interact deflecting the plates slightly from their course. Once the edges of the plates have passed each other, both will be attracted to the surface of the other plate (linear type of attraction). From the kind of the collision the possibility is given that the plates slide over each other during a short moment over a short distance, giving the electrostatic attraction a chance to become operative. Whether this collision will result in a permanent bond will depend on the relation of the attractive forces between edge and surface with the combination of MADELUNG and osmotic forces in the area overlapped and on the surface of this area.

As this type of flocculation is only possible with a very special type of collision, it must be necessarily slow. This 'Chain' type of units formed is illustrated by figure 61 .
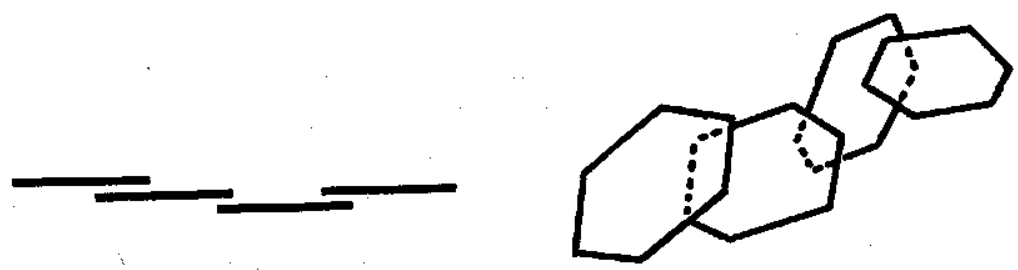

Frg. 61. Chain type flocculation of calcium bentonite at low salt concentration

\subsubsection{Flocculation at high salt concentration}

At high concentrations where the negative field is more suppressed and the positive field emerges clearly, the mentioned type of flocculation is not expected as the positive fields will repulse each other. An edge to surface flocculation as suggested by VAN OLPHEN (1951) is more probable, the plates moving in crossing planes. As at this concentration nearly every collision will result in a permanent union of the particles the flocculation will be quick. These units should be isotropic and consequently no Schlieren effect is observed if flocculated suspensions are stirred.

This type is the common or card house type of flocculation, illustrated by fig. 62 .

The direction of the collisions makes it more probable that the plates will remain at angles unless forced by external pressure into a parallel orientation. This type of flocculation will be reversible. The electrostatic attractive forces are small, only a point type of contact, and consequently they will be overcome if the negative fields expand again on lowering of the salt concentration. The parallel type of flocculation will be more resistant as the attraction between edge and surface takes not place at 


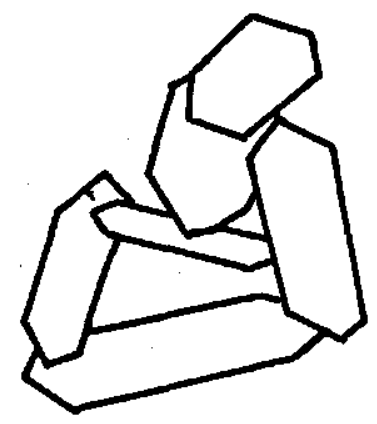

Fro. 62. Common or cardhouse type of flocculation at high salt concentration

some points only, but over a longer linear distance. It will depend on the surface covered, where with decreasing concentration repulsive forces might prevail, in proportion to the line where attraction will dominate whether the bonds will be severed. The chain type of flocculation will permit a $10 \AA$ separation to be observed in the case of calcium bentonite, as this distance will prevail in the overlapped area. With the card house type of flocculation this separation will not be observed as no parallel orientation will occur. As BLACKMORE exchanged in a $0.001 \mathrm{M}$ solution, it is probable that he got the chain type of flocculations. As the chains will not be very long, (Brownian movement, breakage by collisions) they may flocculate edge to surface at higher concentrations. On the other hand formation of sheet like associations or a two dimensional network should be possible.

\subsection{Semi-ELASticity}

\subsubsection{Semi-elasticity of suspensions}

The phenomenon that slightly compressed suspensions of calcium bentonite do not redisperse spontaneously needs some explanation.

As the desorption curve of calcium bentonite suspensions is not reversible, and as at low pressures the moisture contents are higher than predicted, not only Goux repulsion but a gradual collapse of some structure must play a role. The only structure which might contain water in excess of the theoretical value is that of the flocks of the edge to surface type. It is probable that in the deflocculated state some degree of orientation will exist between the plates as the charges are not equally distributed, the edges being near neutral and the planar surfaces negatively charged. The most probable orientation will then be one with the plates perpendicular to one another. That this orientation is probable, has been demonstrated by WARKentin, BoLT \& MrLler (1957) who found that even the compression curve of sodium bentonite $\left(10^{-4} \mathrm{M} \mathrm{NaCl}\right)$ was above the predicted value, but decompression and recompression curves just on it. So if water is removed from the calcium system the plates will be forced into contact with one another and the energy barrier which prevented flocculation will be pierced. The pressure is not born by the whole surface of the clay but only at some points of contact where it will be considerably larger.

Further withdrawal of moisture will necessitate an ever increasing degree of 
structural rearrangement and because the points of contact become more and more numerous the friction will increase. As the plates or small chains bend easily, they may be forced into close contact over a certain area and in this zone the same forces will act as between the plates at chain formation (linear edge surface and electrostatic attraction).

The reason why the pastes formed by dehydration do not disperse if brought into contact with excess water may be the following:

$a$. The energy barrier due to the edge-surface flocculation (only of importance at very low pressures).

b. The energy barrier due to the linear edge-surface attraction plus the Madelung forces of the bent area in close contact.

c. The denser structure of the desorbed suspension, compared with that of a suspension made by salting out, resulting in more points of contact per unit of cross section.

A certain amount of backswelling is easily explained by a certain degree of unbending and by the osmotic pressure in the interstices. With increasing desorption, the contact area where attractive forces prevail eventually reaches its maximum. As this area will never be more than $75 \%$ of the total, the swelling of the granules will always be larger than calculated by the observed intercrystal separation.

It is possible that in certain cases the edge to surface type of structure is water stable and the plane to plane type not. This is observed with the swelling of sodium bentonite where in a salt concentration of 0.4 normal the granules change into dense flocks. The linear edge surface attraction is changed into a point surface attraction by the osmotic pressure in the overlapped area. The attractive force between pointsurface is apparently still strong enough to overcome the interaction of the double layers.

\subsubsection{Semi-elasticity of slurries}

Assuming that the afore mentioned concept of the semi-elasticity of suspensions is right, this leaves one with some difficulty to explain why the same factors are not operating to the same degree with the slurries and suspensions of multilayer crystals.

Factor $a$, the energy barrier of flocculation, should be the same for both.

If the polyplates are thought to be much thicker than the chained monocrystals, then they would be much stiffer and bent less easily. This would prevent the close contact of part of the polyplates.

If also the dimensions with regard to the $\mathbf{a}$ and $\mathbf{b}$ axis would be much larger (which is probable) than the number of contact points per unit of cross section would be smaller and the structure therefore less stable. With decreasing distance the roughness of the surface will come into play as exposed in the discussion on the consequences of MADELUNG attraction.

\section{CONCLUSION}

It may be said that the electrostatic attraction is nowhere in contrast with the floccu- 
lation concept, but that they contribute to each other. In combination with the Gour theory most phenomena can be understood fairly well on a qualitative basis.

The old picture that the flocculation by addition of salts is a conditio sine qua non for a stable structure must however be abandoned as waterstable granules can also be prepared from deflocculated suspensions and slurries depending on the saturating cation.

Moreover with waterstable granules saturated by divalent cations, no sharp increase of the resistance to abrasive forces was found when the salt concentration of the liquid was raised above the flocculation value.

Therefore one might better define the causes of aggregation as 'close distance t' instead of 'flocculation +'.

\section{THE EXGEPTIONAL BEHAVIOUR OF LATOSOLS}

The behaviour of the latosol is in contrast with the above theory as its stability decreases with increasing concentration, whereas the kaolinite behaved normally.

The main difference between the latosol and the kaolinite, is probably the presence of a large amount of iron as oxide or hydroxide, in addition to the difference in dimensions of the crystals. The latter obviously does not offer any perspectives as to the explanation of the observed decrease in stability with increasing electrolyte concentration. With regard to the presence of the iron compounds the following hypothesis may be forwarded.

As the iron oxides act as cementing agent between adjacent clay crystals (cf. Hoffman e.a., 1941; Fripiat \& Gastuche, 1952, Beutelspacher, 1955), a loss in stability could be caused by a decrease of the bonding strength between iron oxide and clay surface. The question thus arises in what manner an increase in salt level could influence this bonding strength. The iron oxides and hydroxides (at least the amorphous and poorly crystallized forms) are presumably nearly uncharged or even weakly positive at $\mathrm{pH}$ values near neutral. If now the anions of the electrolyte present are chemically adsorbed by the iron oxide surface, a reversal of charge would occur at a certain minimum level of electrolyte concentration, the magnitude of the negative charge rising with increasing concentration. This then would weaken the bonds between oxide and clay, thus decreasing stability.

Obviously this hypothesis implies that the anion of the salt present may serve as a potential determining ion of the oxide. In fact the destruction of the bonds between clay and iron oxide will be a matter of competition between the bond strength oxideclay and that between oxide-anion. Naturally both $\mathrm{OH}-$ and $\mathrm{F}$ ions are strongly adsorbed by iron and also aluminum oxides, and thus will influence the stability of these soils to a considerable extent. Thus it was found (cf. I,2.5.8.1 and I, 2.5.8.3) that sodium, potassium and ammonium latosols did only behave like an elastic colloid above $\mathrm{pH} 9$, while only above the same $\mathrm{pH}$ the suspensions did not flocculate. It seems less probable, however, that anions like chloride could affect the stability in 
the same manner. In this respect it is of interest to note that THOMAs (1960) observed that only ferruginous salt free soils (saturated with calcium) exhibited a salt retention when percolated with $0.005 \mathrm{~N}$ potassium chloride, implying that probably the chloride ion was chemically adsorbed, the potassium ion being subsequently retained as counter ion. Also MatTson's observation (1931) that the iso-electric point of Nipe colloid was influenced by the anionic species present in the system, indicates that chemical adsorption of the anion was taking place.

\section{SUMMARY}

\subsection{The SWELLING OF BENTONITE POLYPLATES}

Water will be adsorbed between the crystals of a polyplate if the energy of hydration of the cations plus that of the walls of the crystals is larger than the LONDON-VAN DER WAALs' forces plus the electrostatic forces holding them together. By the hydration of the cations the crystals will be separated roughly to a distance equal to the diameter of the hydrated cations, which will be in a midway position.

Whether the plates will swell further will depend on the balance of the osmotic pressure in the separated area and the electrostatic attraction between the ions in the midway position and the negative plates. Exact calculation of both forces is impossible for lack of information on the osmotic activity of the cations and the dielectric constant in the space between the plates.

It appears that with divalent cations the separation is not increased beyond the equilibrium midway position. With monovalent ions ( $\mathrm{Li}$ and $\mathrm{Na}$ ) the distance is increased over the distance where the ions are held in the midway position by their hydration hull. The electrostatic attraction diminishes then rapidly due to the segregation of the cations to the walls and the Gouy repulsion separates the plates further. With the potassium ion the distance is usually not increased beyond the midway position as its energy of hydration is low.

By raising the electrolyte concentration, the difference in osmotic pressure between the solution within the polyplate and the outside solution decreases and consequently the swelling pressure. Therefore if the concentration is raised far enough even sodium clays have a limited swelling. The same result is achieved by raising the dielectric constant, using ethanol-water mixtures instead of pure water.

\subsection{IMPLIGATIONS FOR THE SWELLING OF GRANULES}

By the introduction of the electrostatic attraction at close distance the limited swelling of pure clay granules in distilled water can be explained and also the behaviour after working the clay at different moisture contents. The failure of some clays to become semi-elastic is thought to be caused by their roughness of surface, preventing close contact over a large enough area. 


\subsection{SeMt-ELASTICTTY At LoW SUGtions}

For the semi-elasticity at low suctions, observed with suspensions of some clays saturated with divalent cations, the edge to surface attraction is held responsible. The edge to surface attraction can be differentiated into a point type of contact giving little stability and a linear type of contact. The last one is more stable as the edge to surface attraction is reinforced by the electrostatic attraction. The plates are then parallel and in close contact over part of their surface. By the introduction of these forces all phenomena observed could be explained fairly well.

\subsection{LatosoL}

With regard to the observed decrease of stability with increasing electrolyte concentration observed with latosol, some indication is found that the attractive forces of the cementing agents, like iron and alumina oxides and hydroxides, are shielded by the higher salt concentration, causing reversal of the charge of the oxides.

The coincidence of deflocculation and degranulation at the same $\mathrm{pH}$ makes it probable that the flocculation forces play an important role with the stability of the latosol granules. 


\section{SAMENVATTING}

Volgens de colloidchemische theorie over aggregatie wordt de overgang van klei uit de gesuspendeerde naar de geaggregeerde 'vaste' toestand ingeleid door een uitvlokking van de klei. Men stelt zich voor dat de in de natuur voorkomende eenheden van de grond opgebouwd zijn uit deze vlokken. De uitvlokking is een functie van de zoutconcentratie (vlokwaarde). De vlokwaarde is vele malen groter bij eenwaardige dan bij tweewaardige kationen. De krachten die de aggregaten bijeenhouden zijn volgens deze opvatting dezelfde als die welke de vlokking veroorzaken. De concentratie waarbij een suspensie uitvlokt, moet volgens deze theorie dan ook als minimum concentratie aanwezig blijven om redispersie te voorkomen. Daar de vlokken vooral wat hun dichtheid betreft sterk afwijken van de natuurlijke eenheden, wordt in deze verhandeling onderscheid gemaakt tussen de gevlokte toestand en de gegranuleerde toestand, in het vervolg aangeduid met vlokken en korrels.

Het blijkt, dat korrels voornamelijk als zij met tweewaardige ionen bezet zijn, wel een beperkte zwelling vertonen maar niet spontaan in gedestilleerd water dispergeren, in tegenstelling tot vlokken. De colloidchemische theorie van de aggregatie en de bezwaren hiertegen zijn in I, 1.2 en I, 1.3 besproken.

In het experimentele deel wordt de overgang van suspensie naar waterstabiele korrel behandeld. Als maat wordt hiervoor de hoeveelheid water gebruikt die door de klei bij een lage onderdruk vastgehouden wordt. De klei kan immers in gesuspendeerde toestand oneindig veel water bevatten en in gegranuleerde toestand, ook bij verzadiging, slechts een beperkte hoeveelheid, mits de korrels waterstabiel zijn. (Daar de bepaling van het vochtgehalte bij volledige verzadiging niet mogelijk is, wordt in plaats daarvan als maat het vochtgehalte bij een lage onderdruk ( $\mathrm{pF}$ 1) gekozen).

Uit de literatuur, besproken in I, 1.3, blijkt dat uitdroging een voorwaarde is voor de korrelvorming en dat de ionenbezetting een zeer belangrijke invloed uitoefent op het al dan niet waterstabiel zijn van de korrels.

Om na te gaan of uitvlokking een voorwaarde voor de korrelvorming is, werden suspensies van homoione kleien met zoutgehaltes lager dan hun vlokwaarde in evenwicht met toenemende zuigspanningen gebracht. Van de zo verkregen pasta's werd, na zwellen in overmaat water, het vochtgehalte bij $\mathrm{pF} 1$ bepaald.

Het verband tussen het weer opzwellen en de mate van voorafgaande desorptie wordt 'herbevochtigingskarakteristiek' genoemd. De proeven werden zowel met de kleimineralen montmorilloniet, illiet en kaoliniet, als met de corresponderende gronden margaliet, knipklei en komklei en laterietgrond uitgevoerd. Van de margaliet en de komklei werd bovendien de kleifractie geisoleerd en onderzocht. De materialen worden beschreven in I, 2.2.1. De bepalingsmethode wordt in I, 2.3 beschreven.

De theoretische desorptie curves (volgens de Gouy-Chapman-theoric) zijn op transparanten gedrukt om vergelijking met de experimentele waarden mogelijk te maken. Er werden voor de berekening van de curves correcties toegepast voor de straal van het gehydrateerde ion en voor het residuaire poriënvolume, I, 2.4.2.

Uit de experimenten bleek dat de kleien en gronden aan de hand van hun herbevochtigingskarakteristiek in vier groepen te verdelen zijn: 
a. Een groep waarvan de suspensie zich gedraagt als een elastisch systeem. De zwelling is ook na complete uitdroging onbeperkt.

$b$. Een groep, waarvan de suspensie zich als een elastisch systeem gedraagt, totdat een zekere mate van indroging bereikt is. Daarna gedraagt deze groep zich als die van groep $c$. De zwelling van geheel gedroogde korrels is beperkt.

c. Een groep, waarvan de suspensie zich gedraagt als een semi-elastisch systeem. Het vochtgehalte tot welk de pasta's bij toenemende desorptie zwellen vermindert naarmate de desorptie voortschrijdt, totdat het minimum vochtgehalte na zwelling gelijk is aan dat wat de droge grond bereikt.

d. Een groep, waarvan de suspensie zich gedraagt als een inelastisch systeem. Na een geringe desorptie worden geen noemenswaardige hoeveelheden water meer opgenomen. Pas na een zeer sterke desorptie vertonen deze gronden enige zwelling.

Tot welke groep de kleien behoren hangt van de volgende factoren af:

1. De aard van het tegenion: waardigheid, straal. Alle Na-kleien behoren bij groep $a$, behalve de lateriet grond.

2. De grofheid van het materiaal. Hoe grover het materiaal is (grote kristallen of geringere graad van dispersie), des te elastischer de herbevochtigingskarakteristiek wordt.

3. De aard van het kleimineraal. K-bentoniet behoort tot groep $a$, de andere K-kleien en $\mathrm{K}$-gronden tot $b$.

4. De pH. Met eenwaardige ionen bezette lateriet grond behoort boven $\mathrm{pH} 9$ tot groep $a$, beneden $\mathrm{pH} 9$ tot groep $c$.

Door verhoging van het zoutgehalte kunnen suspensies van groep $b$ naar groep $c$ overgaan. Door deze verhoging kan ook de zwelling van korrels, behorende tot groep $a$ beperkt worden. (Een verlaging van de diëlektriciteitsconstante heeft hetzelfde resultaat). De zoutconcentratie waarbij de oorspronkelijke vorm van de korrels verloren gaat werd geacht de kritische concentratie te zijn. De resultaten van al deze proeven zijn samengevat in I.2.6.

Nadat vastgesteld was of kleien en gronden water stabiele korrels vormen, werd hiervan de stabiliteit bepaald.

De methode en resultaten zijn beschreven in hoofdstuk II. In II,2 wordt eerst een kwalitatieve methode beschreven. Een bepaalde hoeveelheid korrels werd in een maatcylinder gebracht. $\mathrm{Na}$ vulling met water of een zoutoplossing werd over de kop geschud, waardoor de aggregaten langzaam aan werden vernietigd. De losgeschudde kleideeltjes vlokken uit en, daar het bezinkingsvolume van de vlokken vele malen groter is dan dat van de korrels, kan men aan de hand van de toename van het bezinkingsvolume van de vlokken nagaan in hoeverre de aggregaten vernietigd zijn. De resultaten zijn beschreven in II,2.2.

Het bleek dat het vlokvolume per gram afnam met toenemende hoeveelheid gedesintegreerde klei, zodat er geen kwantitatieve analyse op deze methode is tebaseren.

Bij de kwantitatieve methode werd de hoeveelheid materiaal die door schudden gedispergeerd was (als grens werd $40 \mu$ genomen), afgezogen, ingedampt en gewogen. Uitgaande van de veronderstelling dat de per omwenteling gedispergeerde hoeveel- 
heid klei recht evenredig is met de aanwezige hoeveelheid dispergeerbaar materiaal, kon de volgende relatie opgesteld worden:

$$
\ln (\mathrm{A}-\mathrm{X})=-\mathrm{K} \cdot \mathrm{R}+\ln \mathrm{A} \text {. }
$$

Hierin is $\mathrm{A}$ de oorspronkelijke hoeveelheid materiaal, $\mathrm{K}$ een stabiliteitsconstante, $X$ de hoeveelheid gedispergeerd materiaal $(<40 \mu)$ en $R$ het toerental. $A$ wordt gevonden als som van $X$ na oneindig toerental en $X$ wordt uitgedrukt als percentage van $\mathrm{A}$. Het verband tussen $\log (\mathrm{A}-\mathrm{X})$ bleek vaak niet rechtlijnig te zijn. Het is vooral aan het begin sterk gekromd en eindigt in een recht stuk. Dit kan het gevolg zijn van hef feit dat verschillende typen korrels, met verschillende stabiliteit en in verschillende hoeveelheden, tegelijkertijd door de mechanische actie afgebroken worden. De gevonden curve is dan de som van een stel rechte lijnen die elk de stabiliteit en de hoeveelheid van een bepaalde klasse aggregaten weergeven. Een analyse van de curve maakt het mogelijk een aantal stabiliteitsklassen, elk met een stabiliteitsconstante te onderscheiden. Voor de vergelijking van het gedrag van verschillende gronden werd ook nog een stabiliteitsindex ingevoerd. Zoals te verwachten was is de stabiliteit van de Na-kleien sterk afhankelijk van de zoutconcentratie. De stabiliteit van de K-kleien hangt sterk samen met het kleimineraal; bij bentoniet is de afhankelijkheid van de zoutconcentratie groot, bij margaliet kleiner, bij de zuivere illiet weer groot, bij de illiet uit grond geisoleerd en bij de lateriet grond gering.

De stabiliteit van de Ca- en Mg-kleien is over het algemeen weinig af hankelijk van de zoutconcentratie (zuivere illiet uitgezonderd), Een duidelijke verandering bij het passeren van de vlokwaarde werd niet geconstateerd. Neemtbijde besproken kleien de stabiliteit toe met toenemend zoutgehalte, bij de laterietgrond is dit juist andersom, hoe hoger het zoutgehalte hoe lager de overigens hoge stabiliteit. De afhankelijkheid is echter gering. Slechts boven $\mathrm{pH} 9$ neemt de stabiliteit van Na-lateriet grond toe met toenemend zoutgehalte.

Dit onderdeel van het onderzoek werd behandeld in II, 4. Vervolgens werden de stabiliteits indices uitgezet tegen het zoutgehalte en tegen het vochtgehalte bij $\mathrm{pF} 1$, zie II,5. Over het algemeen is er een nauwere correlatie tussen de stabiliteitsindex en het vochtgehalte dan tussen deze en het zoutgehalte.

Ofschoon er een nauwe correlatie zal bestaan tussen de stabiliteit van de verzadigde grond en de weerstand tegen regenval, is dit echter niet de enige factor die een redispersie teweegbrengt.

Ook een onoordeelkundige bodembehandeling kan de oorzaak zijn. Zo is het te verwachten dat de gronden, waarvan de suspensies zich gedragen als een systeem dat over een groot traject elastisch is (groep b), na een versmerende grondbewerking geen stabiliteit bij verzadiging zullen vertonen. Daar de al dan niet funeste invloed van een bodembehandeling in hoge mate afhankelijk is van het vochtgehalte, werd eerst een beschouwing gegeven over deze relatie, zie III,1.

Drie factoren blijken het resultaat van een grondbewerking te beinvloeden nl.:

1. de samenhang in de aggregaten, die sterk afneemt bij toenemend vochtgehalte;

2. de samenhang tussen de aggregaten, deze is bij laag vochtgehalte gering en gaat bij toenemend vochtgehalte door een maximum; 3 . de energieoverdracht van het 
werktuig op de aggregaten; deze is een functie van de samenhang tussen de aggregaten.

Deze relaties werden met modelproeven onderzocht. Het bleek dat men door een stabiliteitsanalyse van de bewerkte gronden en kleien na kan gaan in hoeverre de interne structuur door deze bewerking veranderd wordt. Verder bleek dat de zuigspanning waarbij het grootste percentage van een grond door een bewerking veranderd wordt, hoger ligt voor zuivere kleien dan voor de overeenkomstige gronden. Naarmate grotere krachten bij de bewerking toegepast werden, verschoof de maximale verandering naar de hogere zuigspanningen. De stabiliteit van de resulterende pasta's blijkt nauw gecorreleerd te zijn met de herbevochtigingskarakteristieken van de kleien en gronden. De resultaten zijn in grafieken samengevat, waarbij vier klassen van stabiliteit onderscheiden zijn. De bewerking van de laterietgrond heeft zeer homogene pasta's ten gevolge, de stabiliteiten van deze pasta's blijken samen te vallen met die van gedehydrateerde suspensies.

Uit de resultaten (zie II,4) blijkt dat gronden waarvan de droge aggregaten een gelijke stabiliteit vertonen, na een bewerking een totaal verschillende stabiliteit kunnen bezitten.

Men zal dus voor geval dat versmering van de grond geregeld optreedt, ook de stabiliteit van het versmeerde monster moeten bepalen.

In hoofdstuk IV worden voorbeelden uit de landbouwpraktijk besproken. In de eerste paragraaf worden de beperkingen waaraan de toepassingen van een laboratoriumonderzoek onderworpen zijn, belicht. In de tweede paragraaf worden de toepassingen voor de gewone landbouw besproken, o.a. de rijping van jonge gronden, de werking van de vorst en het kleven van grond aan landbouwwerktuigen. In de derde paragraaf wordt de natte rijstbouw behandeld, waarbij naar voren komt dat de traditionele methode van grondbewerking rationeel genoemd mag worden.

In hoofdstuk $\mathrm{V}$ wordt met Ca-bentoniet als model nagegaan, welke krachten de beperking van de zwelling zouden kunnen veroorzaken. Aangenomen werd dat de zwelling wordt ingeleid door de hydratatie van de geadsorbeerde kationen. Het bleek dan dat de LONDON-VAN DER WAALS krachten te klein zijn om de osmotische zwelling te voorkomen. Daarentegen was de elektrostatische aantrekking, veroorzaakt door de laterale inhomogeniteit van het elektrische veld op korte afstand, (MADELUNG krachten), zoals berekend door MAcEwAN, van de goede orde van grootte. Vele verschijnselen lieten zich door de MADELUNa krachten verklaren. De semi-elasticiteit zal echter ook gedeeltelijk op de aantrekking tussen de positieve randen en de negatieve vlakken van de kleiplaatjes berusten. Om de waargenomen spontane associatie van calciumbentoniet bij lage zoutconcentraties te kunnen verklaren, werd een hypothese opgesteld, waarbij een vlokking van het kettingtype gesteld werd tegenover het kaartenhuistype, dat bij hoge zoutconcentratie optreedt. Voor het abnormale gedrag van de laterietgrond waarbij de stabiliteit afnam bij toenemende zoutconcentratie, werd aangenomen dat door anionenadsorptie aan de ijzeroxyden de kittende werking van de oxyden vermindert. .

Men kan de resultaten van de onderzoekingen in een zin samenvatten: Stabiliteit is korte afstand plus'. 


\section{SUMMARY}

From the investigations as outlined in the preface the following conclusions may be drawn.

Suspensions of soils and clays may be grouped into four categories according to their backswelling characteristics at low salt concentration:

$a$. Elastic systems, exhibiting unlimited backswelling.

$b$. Systems exhibiting complete elasticity over a certain range of suctions.

c. Semi-elastic systems, exhibiting limited backswelling.

d. Inelastic systems exhibiting no backswelling.

Whether clays belong to any of the above categories depends upon the following factors:

1. The saturating cation. All sodium clays and soils, with the ecxeption of the latosol, belong to group $a$.

2. The size of the particles in suspension. The coarser the material (big crystals or low degree of dispersion), the more complete its backswelling.

3 . The type of clay mineral. Potassium bentonite belongs to group $a$. all other potassium clays belong to group $b$.

4. The $\mathrm{pH}$. Latosols saturated with monovalent cations belong to group a. above pH 9, and to group $c$. below pH 9.

Suspensions of group $b$. may be shifted to group $c$. by an increase of the salt concentration. Conversely the swelling of granules of clays belonging to group $a$. may be limited above a certain critical salt concentration, the same could be achieved by lowering the dielectric constant.

The stability of the granules was determined by weighing the amount dispersed by agitation in an end over end shaker. The treatment of the data was based on the assumption that the rate of destruction during agitation is proportional to the amount of destructible material present. This leads to a linear relationship between the log of the amount of destructible material present and the number of revolutions of the shaker. In case non linear relations were found, the curves were split into a number of composing straight lines each line indicating the quantity and the stability of a certain class of aggregates.

From these experiments it became evident that the stability of the clays and soils belonging to group $a$ is strongly dependent on the salt concentration. The stability of the calcium and magnesium systems was influenced comparatively little by the of the calcium and magnesium systems was influe flocculation value was never ob-
salt concentration and a sudden change near the
served. The backswelling characteristic was not reflected by the stability of the waterstable granules. The sequence of the stabilities of the investigated soils was in accordance with practical observations. Latosol exhibited an abnormal behaviour as below $\mathrm{pH} 9$ its stability decreased with increasing salt concentration. A consideration of the influences of moisture content (at $\mathrm{pF} \mathrm{1)} \mathrm{and} \mathrm{the} \mathrm{salt} \mathrm{con} \mathrm{with} \mathrm{the} \mathrm{me}$ stability of granules indicates that the stability is closer connected with content than with the salt concentration. 
Analysis of the stability of soil and clay granules subjected to model tillage tests at different moisture contents showed that it was possible to determine the degree to which the structure of the soil had been affected. The stability of the affected part was closely related with the backswelling characteristic.

Various soil properties as encountered in agricultural practice were elucidated by the results of the experiments.

When explaining the observed limited swelling of certain clays, the LondonVAN DER WAALS forces proved too small to be of consequence. The electrostatic attraction arising from the presence of the ions in the midway position between plates at close distance as calculated by MACEwAN was of the right order of magnitude. The phenomena observed could be explained in a satisfactory manner by the presence of this type of attraction in combination with edge to plate attraction.

The decrease of the stability of latosol with increasing salt concentration is explained by the adsorption of anions at the surface of iron oxides thus decreasing theeffectivenes of this cementing agent.

The results of the investigations can be summarized in the following statement: Stability is close distance plus'. 


\section{LITERATURE}

Agricultural Handbook No. 601953 U.S. Dep. Agriculture. Diagnosis and improvement of saline and alkaline soils. Washington, D.C.

Atrman, M. S. and H. KohnKe 1948 The pF of soil moisture at the wet limit of the plowing range.

Ayzmore, L. A. G. and J. P. QUIRK

BAVEL, C. H. M. VAN

BAVER, L. D.

- and H. WINTERKORN

Beutelspacher, $\mathbf{H}$.

BrACK, W., J. G. V. DE JONG

J. Th. G. OvereeEk and

M J. Sparnaay

BLAGKMORE, A. V. and

R. D. Mruler

- Bodman, G. B. and J. Rubin

BOEKEL, P.

BoLt, G. H.

- and R. D. MitLER

— and M. Peech

and B. P. WARKENTIN

Bower, C. A. and

J. O. Gogrtzen

BRADPTELD, $\mathbf{R}$.

Cerrnuda, G. F., R. M. S S and J. V. Ghandier

Chatelier, H. K. te

Currustensen, 0 .

CRONEx, D.

and J. D. Coleman
Soil Sci. Soc. Amer. Proc., 12, 22-23.

1959 Swelling of clay-water systems. Nature 183, 1752-1753.

1949 The meanweight diameter of soil aggregates as a statistical index of aggregation. Soil Sci. Soc. Amer. Proc., 14, 20-23.

1956 Soil Physics IIIrd ed. John Wiley and Sons, New York.

1935 Sorption of liquids by soil colloids. II Surface behaviour in the hydration of clays. Soil Sci. 40, 403-419.

1955 Wechselwirkung zwischen anorganischen und organischen Kolioiden des Bodens. Zeitschrift für Pflanzenemährung. NF 69, 108-115.

1960 Measurements of retarted van der Waals' forces. Trans. Faraday Society, 56, 1597-1608.

1961 Tactoid size and osmotic swelling in calcium montmorillonite. In press.

1948 Soil puddling. Soil Sci. Soc. Amer. Proc., 13, 27-36.

1958 Betekenis van de geadsorbeerde en oplosbare kationen voor de

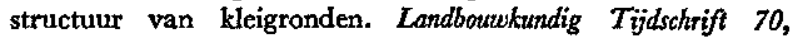
775-789.

1952 The significance of the measurement of the Zeta Potential and the Membrane Potential in soil and clay suspensions. Thesis Master of Science, Cornell.

1954 Physico-chemical properties of the electric double layer on planar surfaces. $\mathrm{Ph}$. D. Thesis, Cornell Univ.

1956 Physico-chemical analysis of the compressibility of pure clays. Grotechnique 86-93.

1955 Compression studies of illite suspensions. Soil Sci. Soc. Amer. Proc., $19,285-288$.

1953 The application of the Gouy Theory to soil water systems. Soil Sci. Soc. Amer. Proc., 17, 210-213.

1956 Influence of the method of sample preparation on the negative adsorption of anions in montmorillonite suspensions. Proceedings VIth Int. Cong. Soil Sci., Vol. B, 33-40.

1959 Surface area of soils and clays by an equilibrium ethylene glycol method. Soil Sci. 87, 289-293.

1950 Soil structure. Proceedings IVth Int. Cong. Soil Sci., Vol. II, 9-19. X

1936 The value and limitations of calcium in soil structure. Amer. Soil Survey Assn. Bull. XVII, 31-32.

1954 Influence of initial soil moisture condition on resistance of macro-aggregates to slaking and to waterdrop impact. Soil Sci. $\varnothing$ $77,19-27$.

1910 La plasticité de l'argile. Gedenkboek J. M. van Bemmelen, Helder. 167-173.

1929 An index of friability of soils. Soil Sci. 29, 119-135.

1953 Soil moisture suction properties and their bearing on the moisture distribution in soils. Proc. third Int. Conf. on Soil Mechanics D and Foundation Engineering.'Switzerland., Vol. I, 13-19.

1954 Soil structure in relation to soil suction. Foum. Soil Sci. 5, 75-85. 
Czeratzki, W.

DAMEs, T. W. G.

DAY, P. R. and G. G. HolmGREN

Demolon, A. and E. Bastrsse

Derjagum, B. V., A. S. TitiJevskaia, Y. I. Abricossova and A. D. Malkina

Domngo, W. R.

EDelman, C. H.

Eist, P. VAN DER

ELsT, P. VAN DER

Emerson, W. W. and G. M. F. Grundy

Fountane, E. R. (ob)

Fripiat, J. J. and

M. C. Gastuche

Frissel, M. J.

Gardner, R.

Goor, G. A. W. v. D.

Greacen, E. L.

Hannes, W. B.

Hatlgren, G.

Hardon, H. J.

and J. G. L. FAvejeE.
1955 Die Ackerscholle zwischen Herbst und Frïhjahr. Landbau Forschung 5, 84-86.

1948 Some notes on the soil survey of Java. Proc. First Commonwealth Conference on Tropical and Subtropical soils. Harpenden. 115-120. V

1950 Margalite soils in Indonesia. Trans. IVth Int. Cong. of Soil Sci., Vol. II, 180-182.

1952 Microscopic changes in soil structure during compression. Soil Sci. Soc. Amer. Proc., Vol. 16, 73-77.

1934 Sur la dispersion des colloides argileux. Trans. Ist Com. Int. Soc. Soil Sci., Versailles, 47-64.

1954 Investigations of the forces of interaction of surfaces in different media and the application to the problem of colloid stability. Faraday Soc. Disc., No. 18.

1951 De physische rijping van de jongere Zuiderzee afzettingen in de Noord-Oost Polder. Van Zee tot Land, No. 2.

1950 Soils of the Netherlands. North-Holland publishing company, Amsterdam.

1916 Irrigatie van het rijstgewas voorzover verband houdend met de bodem. Praeadvies Algerneen Nederlandsch Indisch Bodemcongres te Djocja. 137-157.

1925/1926 Over het uiterlijk van padi-planten. Landbouw $I, 357-390$. if

1955 The rate of water uptake of soil crumbs at low suctions. Fourn. Soil Sci. 6, 147-160.

1944 The effect of rate of wetting of water uptake and cohesion of soil crumbs. Fourn. Agr. Sci., 44, 249-253.

Personal communication. Nat. Inst. Agr. Eng., Silsoe Beds.

1954 Investigations into the mechanism of soil adhesion. Fourn. Soily Sci. 5, 251-263.

1959 Wechselwirkungen zwischen Pflug- und Boden. Mitteilungen der Deutschen Landwirtschafisgesellschaft, 13, 368-373.

1952 Etude physico-chimique des surfaces des argiles. Publications de I'Institut national pour l'étude agronomique du Congo-Belge. Série Scientifique, No. 54.

1961 The adsorption of some organic compounds especially herbicides on clay minerals. Versl. Landbouwek. Onderz., 67. 3.

1945 a Some soil properties related to the sodium salt problem in irrigated soils. U.S.D.A. Techn. Bull., No. 902.

$1945 \mathrm{~b}$ Some effects of freezing and thawing on the aggregation and permeability of dispersed soils. Soil Sci. 60, 437-447.

1950 a Bevloeiingsonderzoek bij sawah rijst. Landbouzw 22, 195-222. $\chi$

$1950 \mathrm{~b}$ Onkruidbestrijding met behulp van synthetische groeistoffen. Landbout 22, 141-181.

1959 Swelling forces in straining soils. Nature 184, 1695-1697.

1923 The volume-changes associated with variations of watercontent in soil. Journal Agric. Sci. 13, 296-311.

1944/45 On the physical and chemical effects of saline irrigation waters on soils. Lantbr. Högsk. Ann. 12, 23-48.

1939 Researches on the composition of the clay fraction of the principal soil types of the Duich East Indies. Meded. Alg. Proefst. Landbouw 37.

1939 Qualitative X-ray analyses of the clayfraction of the principal soil types of Java. Meded. Landb. Hogesch., Wageningen. 43, Verh. 6, 55-59. 
Hauser, E. A. and D. S. LE BEAU

Heinonen, $R$.

Hoffmann, U. and W. Bilke

- A. JACOB and

H. LOOFMAN

Holmes, J. W.

Hough, B. K.

Huffmann, E. O., W. E. Gate and M. E. Deming

JANSE, A. R. P.

JenNy, H. and P. F. RIITEMEIER

JOFFE, J. S.

Jongrarus, A.

JONKER, J. J. and

G.J. VERVELDE

Joosten, J. H. L.

\section{KiRKHAM, D.}

, M. DE BOODT and
L. DE LGENKEER
KoENIG, F.F.R.
KUIPERS, H.
LEENHERR, J. DE
: and M. DE BOODT

Lewis, G. G., J. V. JoroAN and M. A. FosBerg

Low, Pr. F. and

D. M. ANDERSON

MacEwan, D. M. C.

Mattson, Sante
1939 Studies in gelation and film formation II. Fourn. Phys. Chem. 43, 1037-1048.

1955 Soil aggregation in relation to texture and organic matter. Agrogelogisia Julkaisuja, No. 64.

1936 Ueber die interkristalline Quellung und das Basenaustauschvermögen des Montmorillonits. Kolloid Zeitschrift 77, 238-251.

1941 Untersuchungen der Tonfraktion der Böden mit dem Elektronen-Mikroskop. Zeitschr. für Bodenk. und Pflanzenernährung. 25, 257-271.

1955 Water sorption and swelling of clay blocks. Fourn. of Soil Sci. 6 , 200-209.

1954 Basic soils engineering. Ronald, New-York.

1960 Rates and mechanismas of dissolution of ionic ferric compounds. Soil Sci. 90, 8-15.

1954 A simple membrane press. Landbouwk. Tijdschrift 66, 40-41.

1935 Ionic exchange in relation to the stability of colloidal systems. Journ. Phys. Chem. 593-604.

1949 Pedology, 2nd ed. New Brunswick, N. Y.

1957 Morfologische onderzoekingen over de bodemstructuur. Versl. Landbouwk. Onderz., 63. 12.

1953 Geleiding van water van bewerkte grond. Landbouwk. Tijdschrift $65,418-420$.

1934/35 Beschouwingen over de te verwachten landbouwkundige verbeteringen voor het irrigatiegebied Notopoero (Residentie Madioen) door bevloeiing uit een reservoir bij de desa Ngasinan. Landboutw, 10, 2-33.

Personal communication. Professor of soils and physics. Ames, Iowa.

1958 Modulus of rupture determination on cyclindrical soil core samples. Proceedings Int. Symp. on Soil Structure, Ghent. 369-377.

1950 A 'sawah' profile near Bogor. Trans. IVth Congr. Int. Soc. Soil Sci., Vol. I, 297-300.

Personal communication. University lecturer on tillage. Wageningen.

1958 La dégradation de la structure des sols en Belgique et ses causes. Proceedings Int. Symp. on Soil Siructure, Ghent. 1-23.

1958a Soil sampling and storage for soil structure research. Proceedings; Int. Symp. on Soil Structure, Ghent. 257-267.

1958b Determination of aggregate stability by the change in mean weight diameter. Proceedings Int. Symp. on Soil Structure, Ghent. 290-300.

1959 Tracing moisture movement in slick spot soils with radiosulfur. Part II. Soil Sci. Soc. Amer. Proc., 23, 202-210.

1958 The partial specific volume of water in bentonite suspensions. Soil Sci. Soc. Amer. Proc. 22, 22-24.

1948 Adsorption by montmorillonite and its relation to surface adsorption. Nature 162, 935-936.

1954 Short range electrical forces between charged colloid particles. Nature 174 39-40.

1929 Laws of soil colloidal behavior II. Cataphoresis, flocculation, and dispersion. Soil Sci. 28, 373-408.

1931 Laws of soil colloidal behavior VI. Amphoteric behavior. Soil Sci. 32, 343-365. 
McGeorge, W. F.

MaKenzer Taylor, E.

Middeton, H. E.

Mohr. E. C.J.

and F. A. van Baren

Mooney, R. W.,

A. G. KEENAN and

L. A. Woon

$\longrightarrow, \longrightarrow$, and $\longrightarrow$

Nichols, M. L. and L. D. BAVER

NORRISH, K.

OAkrs, H. and J. ThorP

Olphen, H. van

Peterson, J. B.

Puri, A. N. And B. A. KeEN

PURI, A. N. and B. RAI

QUIRK, J. P.

- and R. K. Schofmid

Raden Rachmat
HaRDJOsoesastro
Russel, M. B.

- and C. L. Feng

Schofierd, R. K.

and H. P. SAMSON

SchuYLENBORGF, J. VAN

Sirben, W. H.

Stgmond, A. A. J. DE

Surts, H.

Sarrs, M. B.
1937 Studies on soil structure. Some physical characteristics of puddled soils. University of Arizona, Agr. Exp. Sta. Techn. Bull. 67. V.

1956 Control of soil and structure. 6th National Power Farming Conference.

'1930 Properties of soil wich influence soil erosion. U.S.D.A. Techn. Bull. 178.

1911 Ergebnisse mechanischer Analysen tropischer Böden. Bulletin du département de l'agriculture aux Indes Neerlandaises, No. XIVII, ix 17.

1954 Tropical soils. Van Hoeven, The Hague.

1953a Adsorption of water vapor by montmorillonite II. Effect of exchangeable ions and lattice swelling as measured by X-ray diffraction. Journ. Am. Chem. Soc., 74, 1371-1374

1953b Adsorption of water vapor by montmorillonite $\mathrm{X}$. Heat of desorption and application of B.E.T. theory. Fourn. Am. Chem. Soc. 74, 1367-1371.

1955 Soil structure and consistency in implement design. Agr. Eng., $~$ 36, 517-519.

1930 An interpretation of the physical properties of soils affecting til- $\rightarrow$ lage and implement design by means of the Atterberg consistency constants. Proceedings IInd Int. Cong. Soil Sci., Vol. II, 175-189.

1954 The swelling of montmorillonite. Faraday Soc. Disc., No. 18, 120-134.

1950 Dark-clay soils of warm regions, variously called rendzina, black cotton soils, regur, and tirs. Soil Sci. Soc. Amer. Proc. 15, 347-354.

1951 The rheological properties of drilling fluids. Thesis, Delft. $\quad \backslash$

1946 The role of clay minerals in the formation of soil structure. Soil Sci. 61, 247-256.

1925 The dispersion of soil in water under various conditions. Foum. Agr. Sci. 15, 147-162.

1944 Studies in soil dispersion II Ind. Fourn. Agr. Sci. XIV, 210-215.

1950 The measurement of stability of soil micro-aggregates in water Australian Journal Agr. Res. 1, 276-284.

1955 The effect of electrolyte concentrations on soil permeability. Joum. Soil. Sci. 6, 163-179.

1956 Preliminary note on cristoballite in clay fractions of volcanic ashes. Journ. Soil Sci., 7, 185-189.

1941 Pore-size distribution as a measure of soil structure. Soil Sci. Soc. , Amer. Proc., 6, 108-112.

1947 Characterization of the stability of soil aggregates. Soil Sci. 63 299-304.

1946 Ionic forces in thick films of liquid between charged surfaces. Trans. Faraday Society, 42B, 219-225.

1953 Deflocculation of kaolinite. Clay Minerals Bull., 2, 45-52.

1947 A study on soil structure. Thesis Wageningen.

1951 De ontwatering van de zavelgronden in de Noord-Oost Polder. Van Zee tot Land, 3.

1938 The principles of soil science. London. Personal communication. Directie van de Noord-Oost Polderwerken, Kampen, Netherlands.

1926 Arbeidsaanwending in den natten rijstbouw op Java. Landbouw $I$, i 255-299. 
SONNEveld, F.

Terra, G.J. A.

Thomas, G, W.

Trunis, A.

VAGELER, P. and F. AlteN

Vernenbos, J. S. and J. VAN SchUYLENBORGH

VERWEY AND OVERBEEK

VILENSKY, D. S.

WALKer, G. F.

WARKRNTt, B. P., G. H. Bolt and R. D. MuLcer

WeEnig, C. F.

Westerhor, J. G.

WIEGNER, G.

WIKLANDER, L. and

G. HALLGREN

Wrr, TH. P. M. DE

YODER, R. E.

ZuUR, A.J. e.a.
1959 Bodemkartering van het Land van Heusden en Altena. Versl. Landbouwk. Onderz., 64. 4.

1959 Agriculture in economically underdeveloped countries, especial- $x$ ly in equatorial and subtropical regions. Neth. Journ. Agr. Sci. 7, 216.

1960 Effects of electrolyte imbibition upon cation exchange behavior of soils. Soil Sci. Soc. Amer. Proc, 24, 329-332.

1933 Certain considerations on the genesis of soil structure and on methods for its determination. Trans. Lst. Comm. Int. Soc. Soil Sci. Moscow, A. 1, 111-132.

1931 Böden des Nil und Gash. Zeitschr. Pflanzenemahrrung 22 A, 21-51.

1951 Het knip- of knikverschijnsel van kleigronden. Boor en Spade IV, 24-39.

1948 Theory of the stability of lyophobic colloids. Elsevier, Amsterdam.

1934 Influence de l'humidité du sol sur sa structure. Trans. first Comm. Int. Soc. of Soil Science, Versailles. 97-113.

1958 Reactions of expanding lattice clay minerals with glycerol and ethylene glycol. Clay Min. Bull., 3, 302-313.

1960 Macroscopic swelling of vermiculite crystals in water, Nature 187, 312-313.

1957 Swelling pressure of montmorillonite. Soil Sci. Soc. Amer. Proc., $21,495-497$.

1951. Kristallijne ijzeroxyden en -hydroxyden in de bodem. Boor en Spade IV, 54-67.

1956 Bodemstructuur en gips. T.N.O. Nietzes 11, 12-20.

1931 Boden und Bodenbildung in Kolloidchemischer Betrachtung, Steinkopff, Dresden und Leipzig.

1944/'45 Ueber die Dispersion der Bodenkolloide. Lantbrug Hogsk. Ann. $12,230-250$.

1960 The Wageningen rice project in Surinam. Thesis Wageningen.

1936 A direct method of aggregate analysis of soils. Joum. Am. Soc. of Agron. 28, 337.

1953 Reclaiming land flooded with salt water. Neth. F. Agr. Sci. $1,153-163$ and 225-244. 

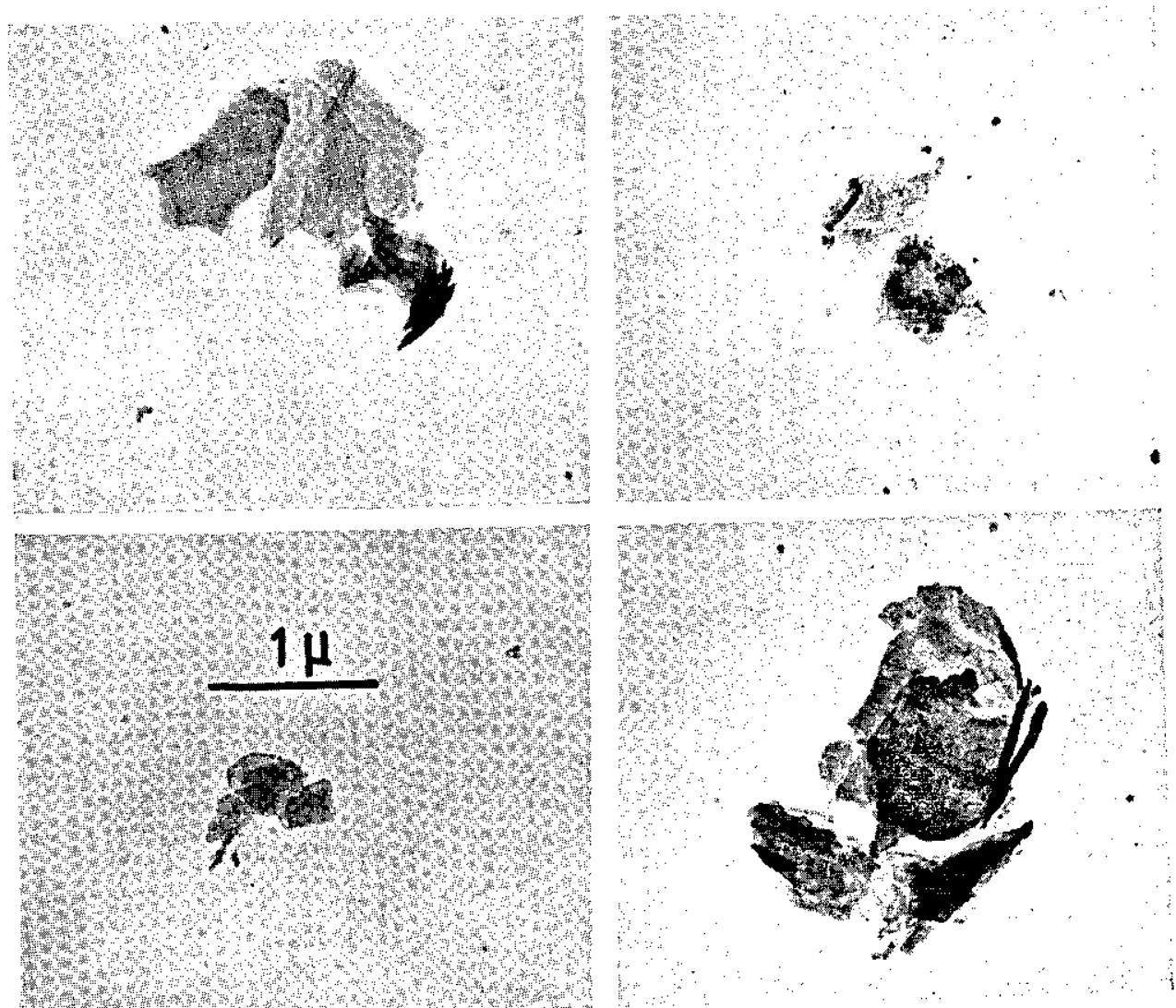

Foтo 1. Na-margalite colloid

(By courtesy of Miss Dra C. van der Scheer; Physico-Technical Service of Agriculture, Wageningen) 


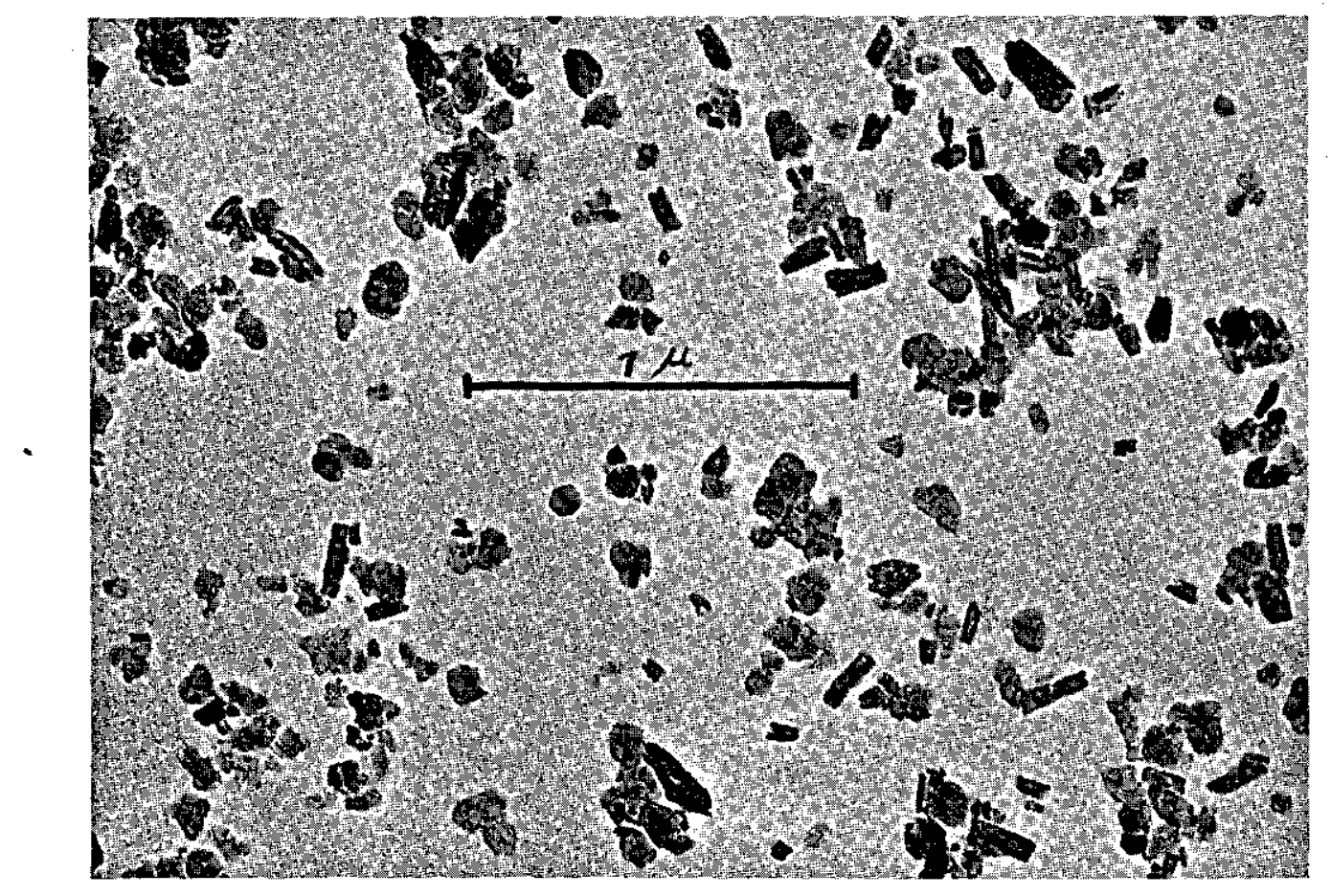

Foto 2. Na-latosol

(By courtesy of Miss Dra C. van der Scheer; Physico-Technical Service of Agriculture, Wageningen) 


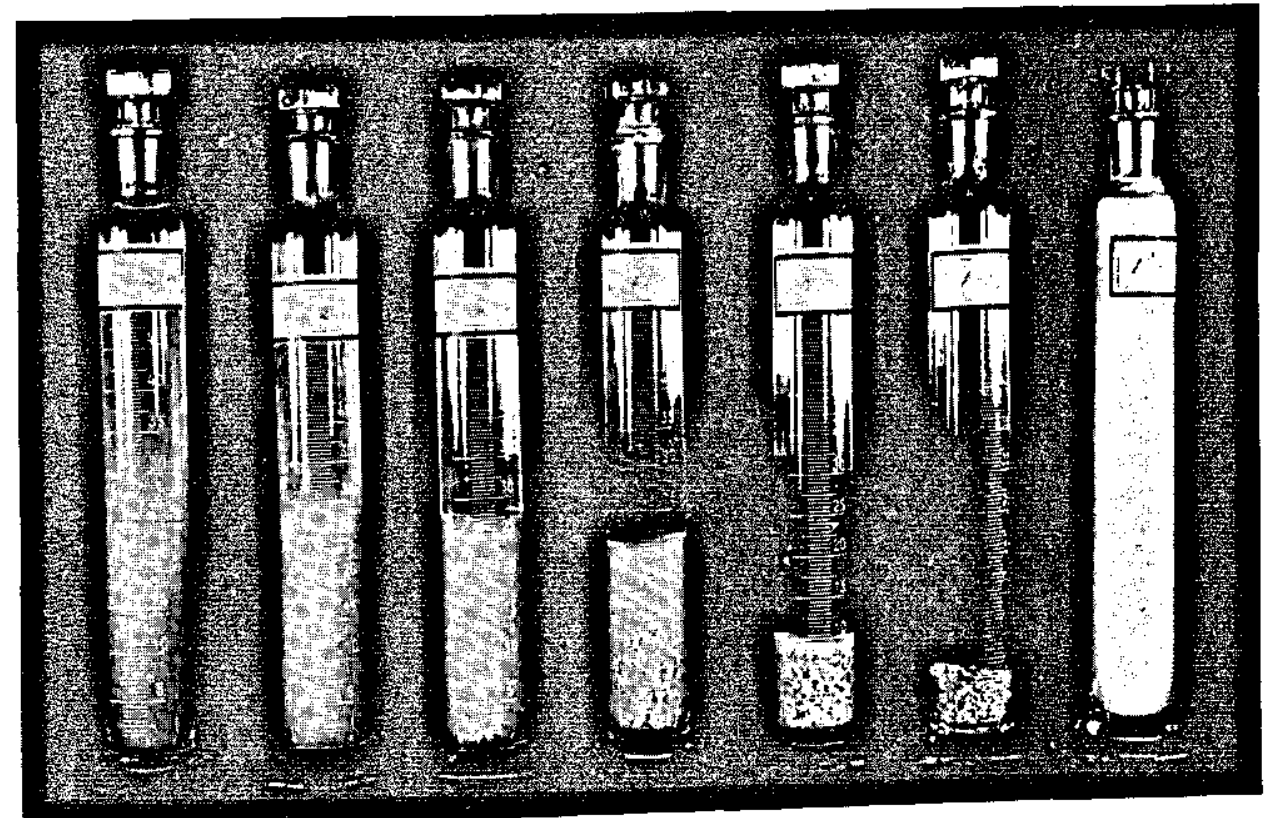
Foro 3. The swelling of Na-bentonite in dependence of salt concentration. $1 \mathrm{~g}$ granules in, from left to
right $0.002 \mathrm{~N}, 0.02 \mathrm{~N}, 0.2 \mathrm{~N}, 0.4 \mathrm{~N}, 0.6 \mathrm{~N}, 1 \mathrm{~N}$, and $1 \mathrm{~N}$ swollen in distilled water, salt added afterwards.

Fото 4. The swelling of $\mathrm{Na}$-bentonite in dependence of salt concentration. $1 \mathrm{~g}$ granules in, from left to right $0.4 \mathrm{~N}, 0.6 \mathrm{~N}$ and $1 \mathrm{~N}$ solution

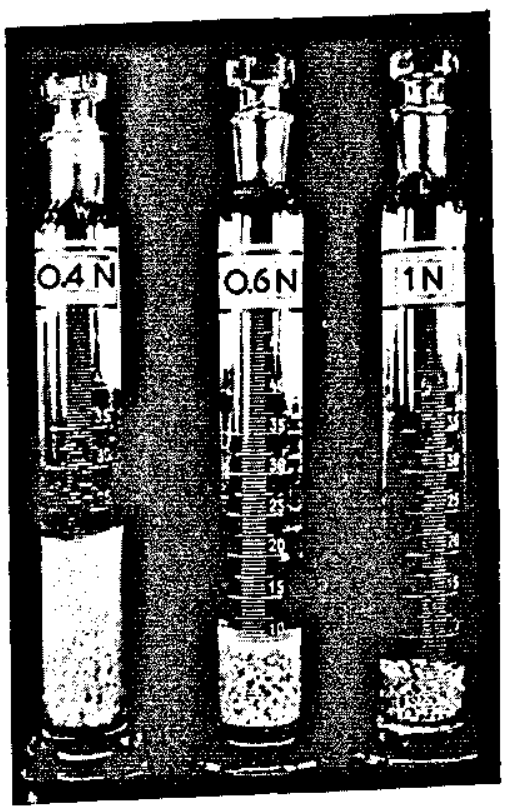




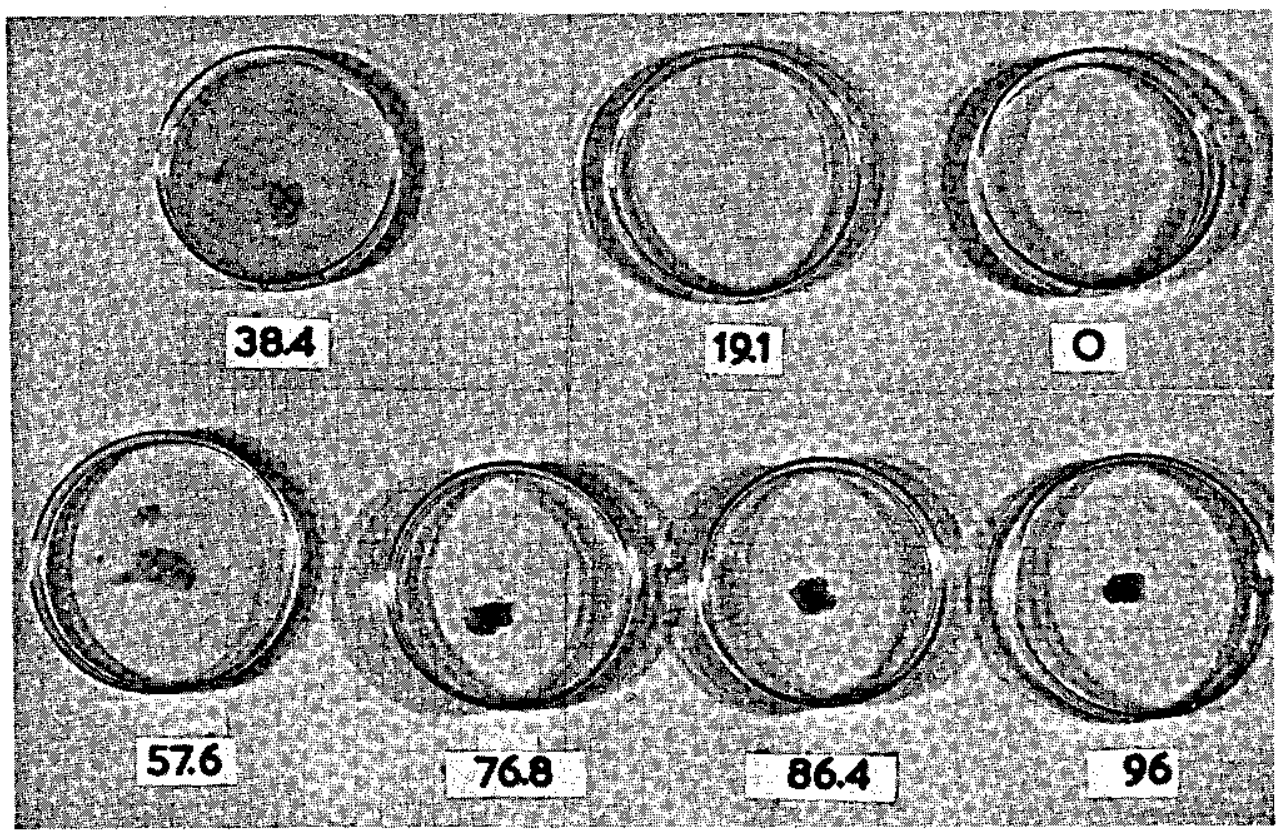

Fото 5. The swelling of $\mathrm{Na}$-bentonite in dependence of ethanol concentration 
Fото 6. The air explosion of Ca-margalite soil

$a=$ original granule

$\mathrm{b}=5$ minutes after immersion
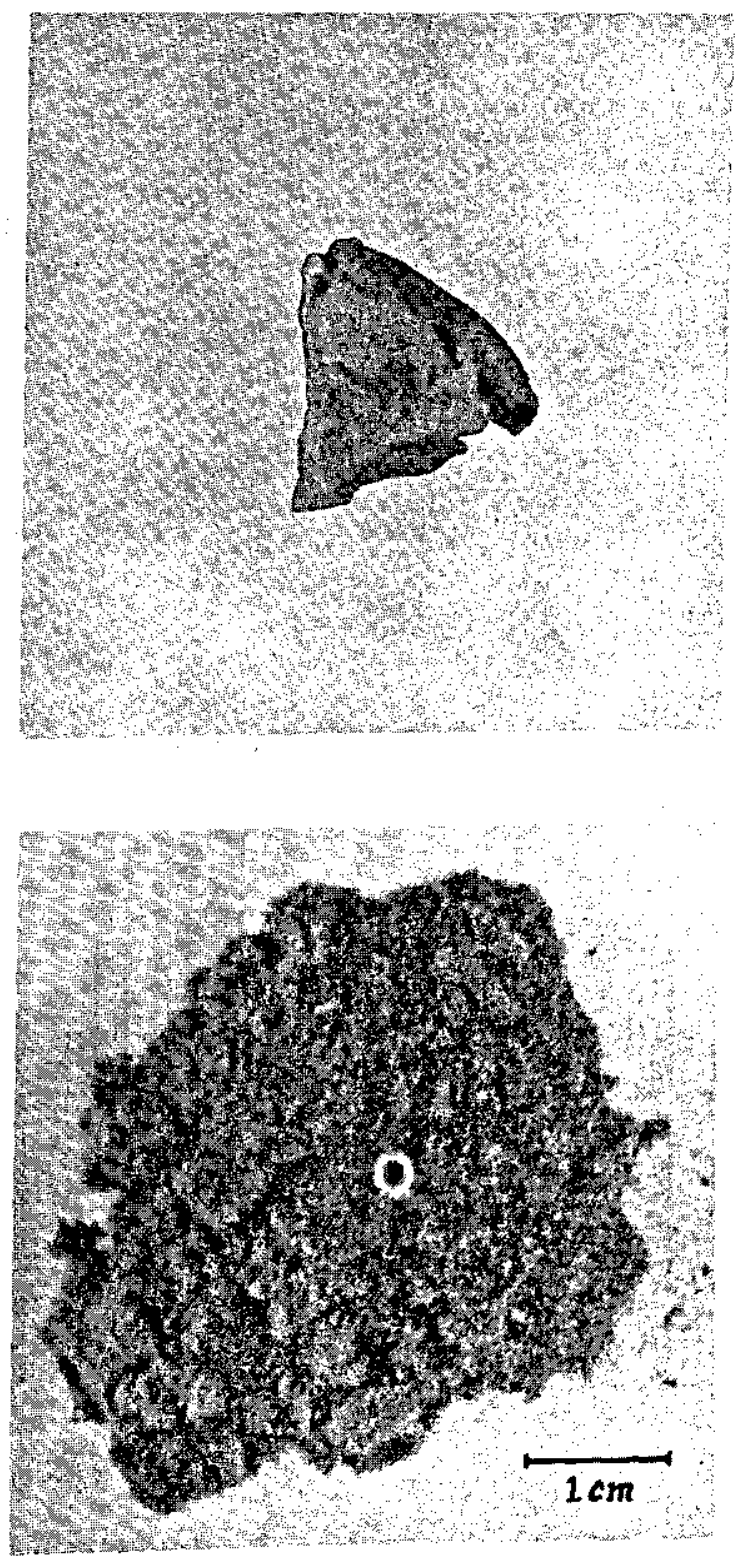

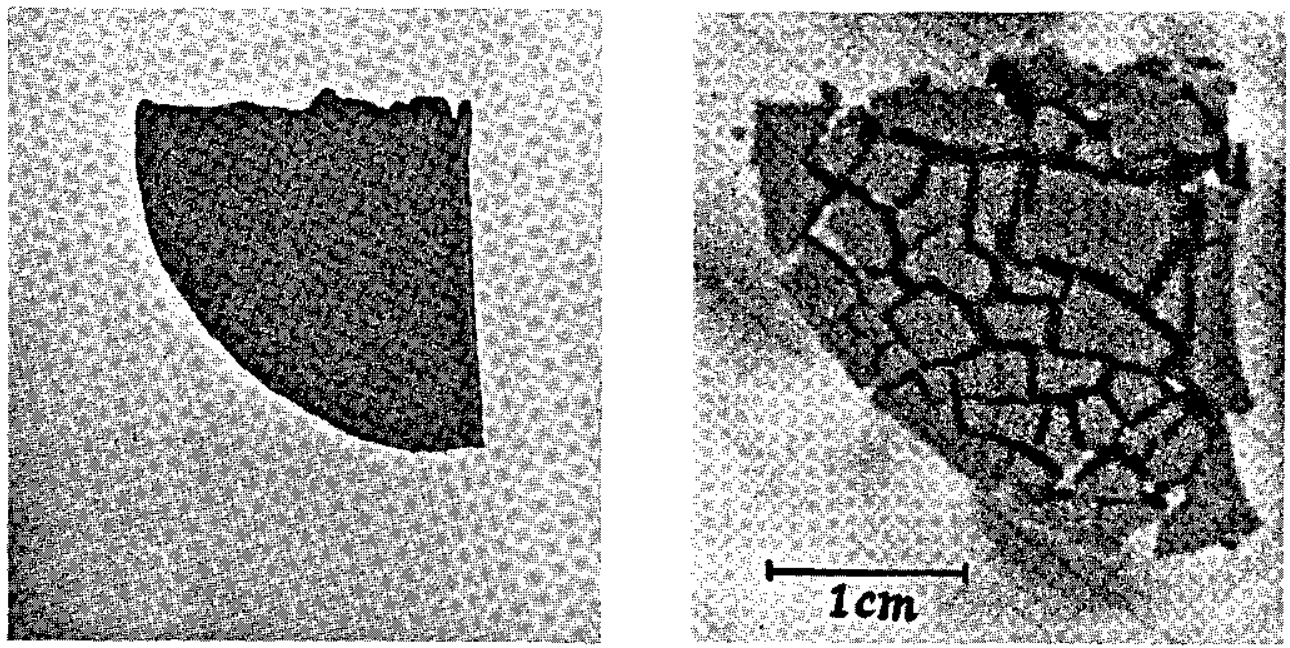

Foто 7. The swelling of a granule of Ca-margalite soil, dried to just above the shrinkage limit; left $=$ original granule; right $=12$ hours after immersion.

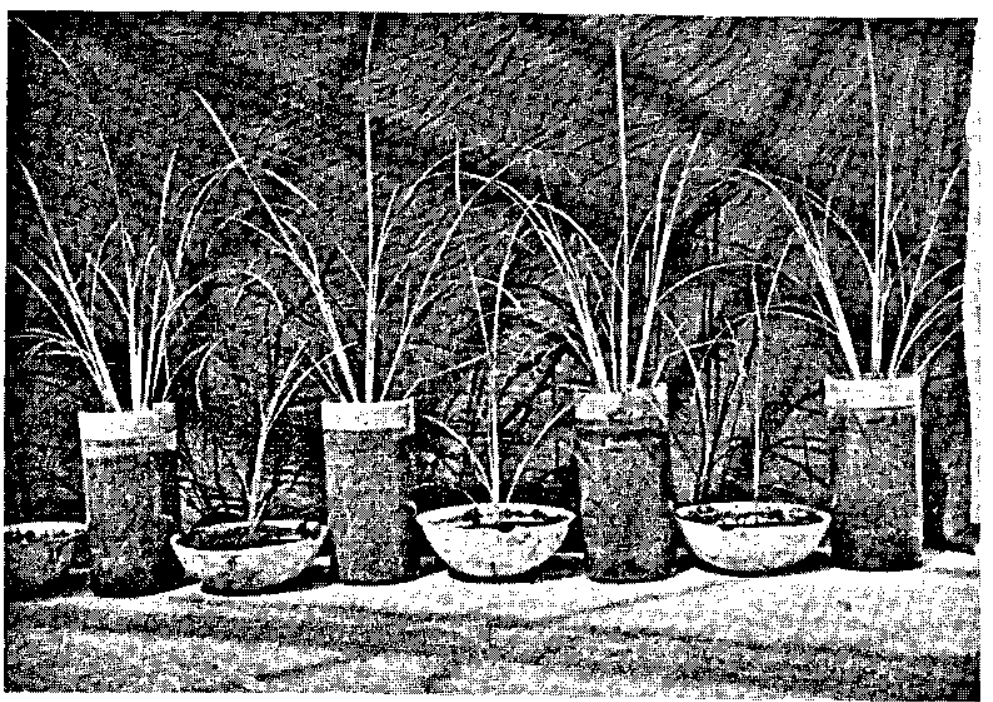

Foтo 8. Growth of rice as influenced by the original moisture content of the mud. Upper row, $180 \%$ moisture; lower row, $66 \%$ moisture. 


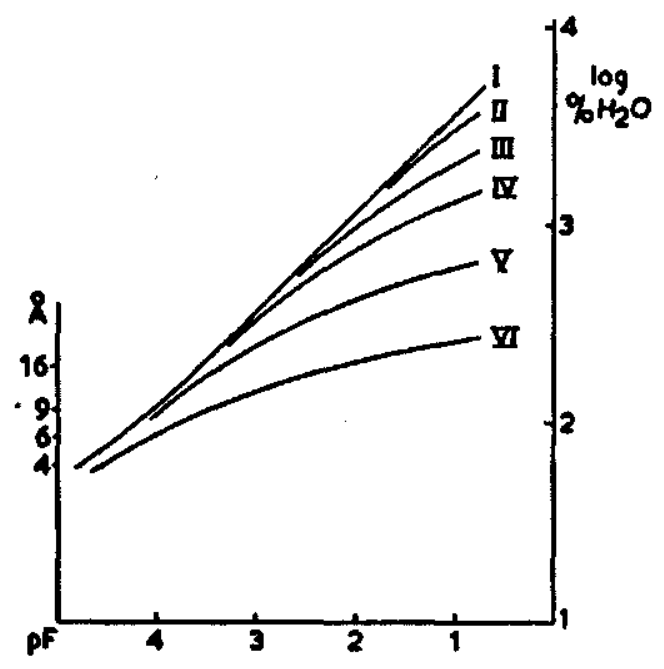

Fio. 32. (Overlay). Theoretical desorption curver for montmorillonite. $v=1$; Surface are $=730 \mathrm{~m}^{2} / \mathrm{s}$; pore space $-1 / 3$. $(e-1 / 2)$

I, co $=10^{-\infty}$

II, $c_{1}=10^{-4}$

III, $c_{0}=10^{-4}$

$I V, c_{0}=5.10^{-0}$

$V, c_{0}=5.10^{-1}$

VI, $c=5.10^{-1} \mathrm{M}$

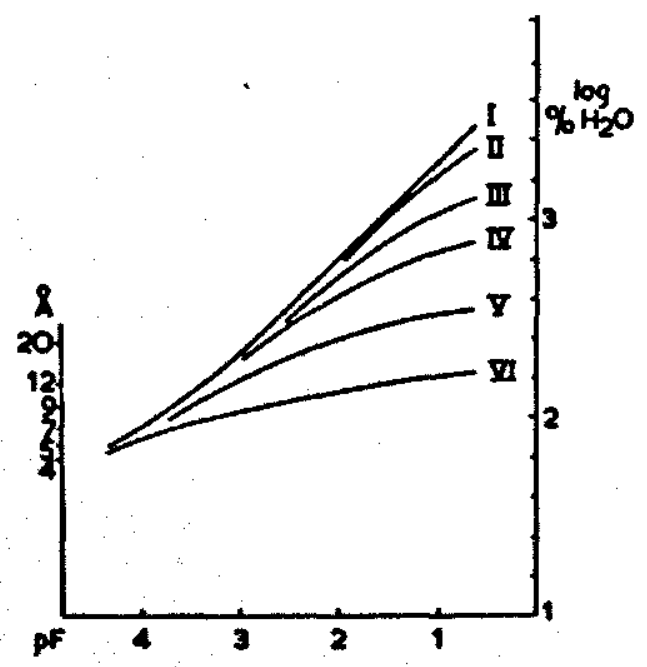

Fro. 4h. (Overlay). Theoretical desorption curves for montrotillonite $\gamma=2$; surface erea $=730 \mathrm{~m}^{*} / \mathrm{g}$; pore space $-1 / 3 .(e-1 / 2)$

$1, c_{0}=10^{-\infty}$

$11, c_{0}=10-$

III, $c_{0}=10^{-9}$

IV, $c_{0}=5.10-$

$V, c_{0}=5.10^{-2}$

$V I, c_{0}=5.10^{-1} \mathrm{M}$ 

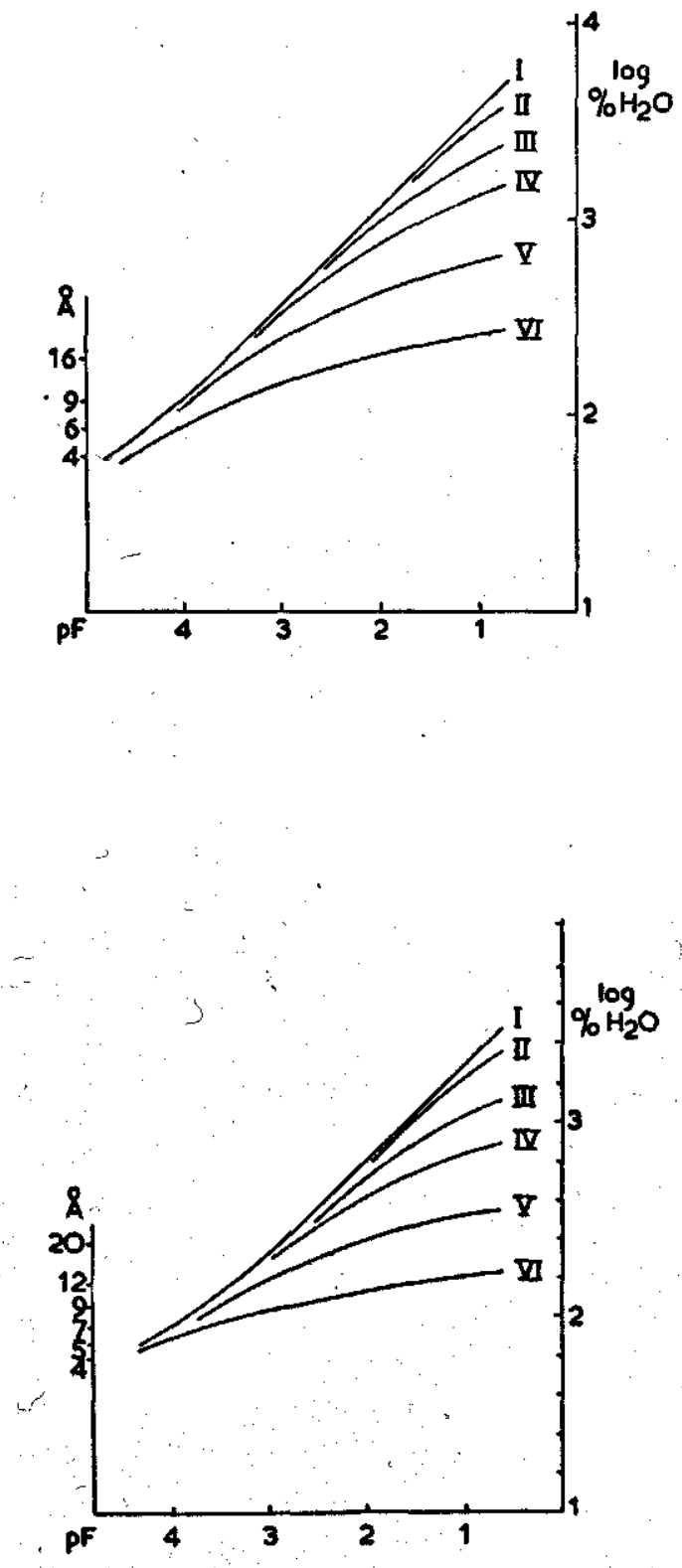

Fio. 3a. (Overlay). Theoretical desorption curves for montmorillonite. $\mathrm{v}=1$; Surface area $=730 \mathrm{~m}^{2} / \mathrm{g}$; pore space $=1 / 3 .(c=1 / 2)$

I, $c_{*}=10^{-\infty}$

II, $\mathrm{c}_{0}=10^{-4}$

III, $c_{0}=10^{-8}$

IV, $c_{0}=5.10^{-8}$

$\mathrm{V}, \mathrm{c}_{0}=5.10^{-\mathrm{*}}$

VI, $c_{0}=5.10^{-1} \mathrm{M}$

Fro. 4a. (Overlay). Theoretical desorption curves for montmotillonite. $\mathrm{v}=2$; surface area $=730 \mathrm{~m}^{2} / \mathrm{g}$; pore space $=1 / 3 .(c=1 / 2)$

I, $c_{0}=10^{-\infty}$

II, $c_{0}=10^{-1}$

III, $c_{0}=10^{-2}$

IV, $c_{0}=5.10^{-9}$

$\mathrm{V}, \mathrm{c}_{*}=5.10^{-2}$

$\mathrm{VI}, \mathrm{c}_{0}=5.10^{-1} \mathrm{M}$ 